\title{
The Economics of Tobacco Use in Jordan
}

\author{
BY \\ NADIA JALIL SWEIS \\ B.S. University of Jordan, 1996 \\ M.A. University of Jordan, 1999 \\ M.A. University of Illinois at Chicago, Chicago, 2004
}

\section{THESIS}

Submitted as partial fulfillment of the requirements for the degree of Doctor of Philosophy in Economics in the Graduate College of the University of Illinois at Chicago, 2012

\author{
Chicago, Illinois
}

Defense Committee:

Frank Chaloupka, Chair

Robert Kaestner

Richard Peck

John Tauras

Timothy Johnson, Public Administartion 
This thesis is dedicated to the soul of my father Jalil Sweis. 


\section{AKNOWLEDGMENTS}

I would like to thank my thesis committee--(Drs. Robert Kaestner, John Tauras, Richard Peck, and Timothy Johnson)--for their valuable comments and suggestions on several issues in my dissertation. I am indebted to my chair, Dr. Frank J. Chaloupka for his unwavering support and assistance. He provided guidance in all areas that helped me accomplish my research goals and enjoy myself in the process.

My thanks also extended to all the faculty members, staff, and friends at the Department of Economics.

My thanks to AlBalqa Applied University in Jordan, who sponsored my study in the united States.

I would also like to acknowledge the Ministry of Health in Jordan namely Dr. Malek Al-Habashneh for their support during the data collection process.

My deep thanks to all the students who helped me in collecting the data, without them I could not have finished the data collection in a very short period.

My deep thanks extended to my beloved family who supported me during this period, my Mother, my brothers, my sisters especially Nadera, my husband; Alaa' and my son; Amir whom they always encouraged me and was a source of inspiration.

Thank you all.

Nadia 


\section{TABLE OF CONTENTS}

CHAPTER

BACKGROUND AND RATIONALE

1.1 Rationale 1

1.2 Prevalence of Tobacco Use in Jordan ......................................................................................

1.2.1. Tobacco Use Among Adolescents ................................................................ 4

1.2.2. Possible Explanation of High Prevalence of Tobacco Use ..................................... 4

1.3 Tobacco-Related Costs ......................................................................................................... 5

1.4. Variables that Impact Tobacco Use ...............................................................................

1.5. Brief Overview of Tobacco Economics in Jordan ...............................................................

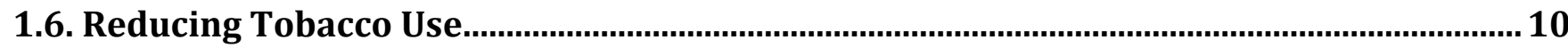

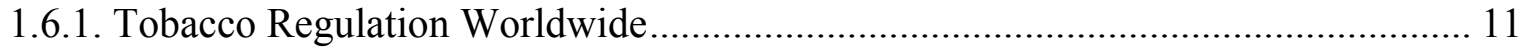

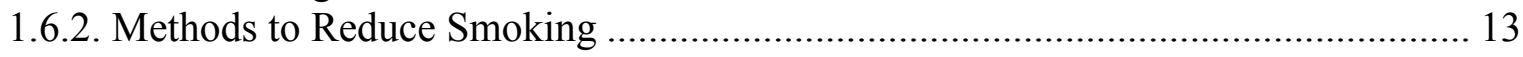

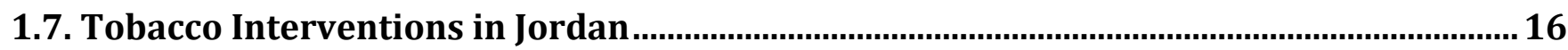

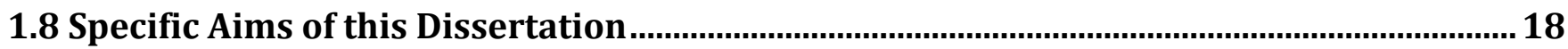

1.9.

LITERATURE REVIEW .......................................................................................................... 21

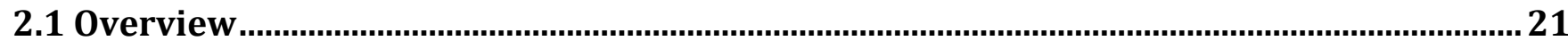

2.1 Health Consequences of Tobacco Use .................................................................................... 26

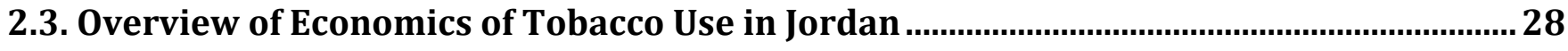

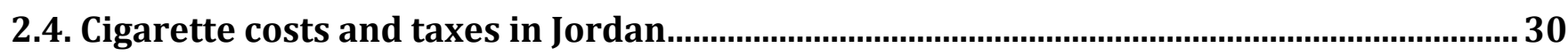

2.5

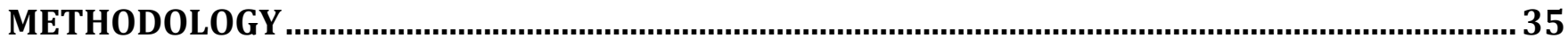

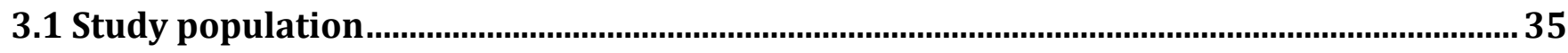

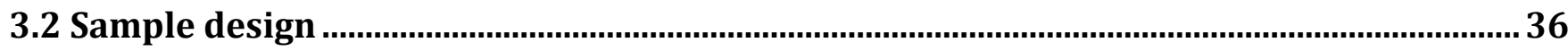

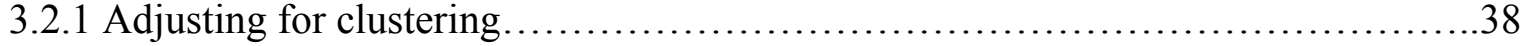

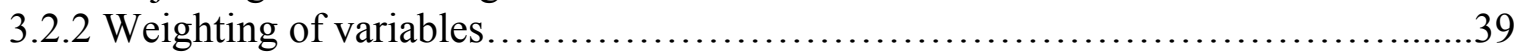

3.2.3 Assessment of interviewers differences in measurement........................40

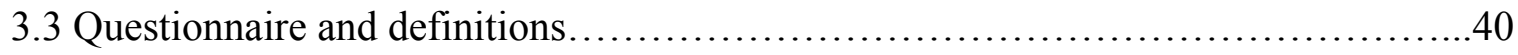

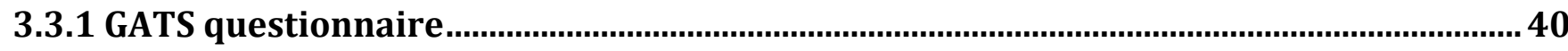

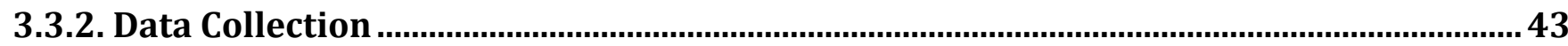

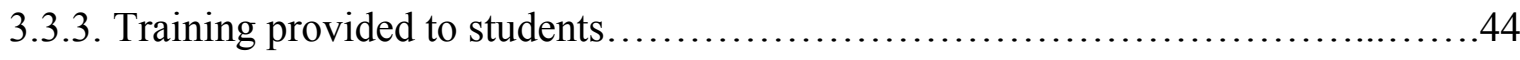




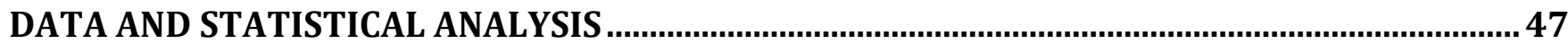

4.1 About the Survey ....................................................................................... 47

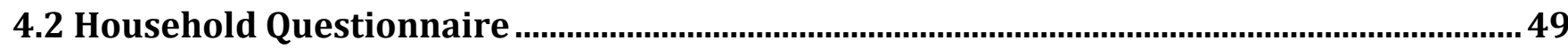

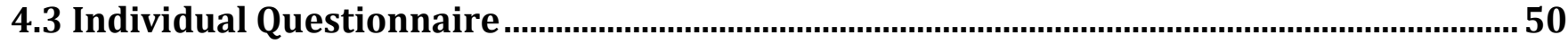

4.3.1.Tobacco use by frequency, type, education, work status, and gender ..............................50

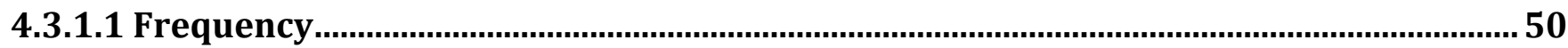

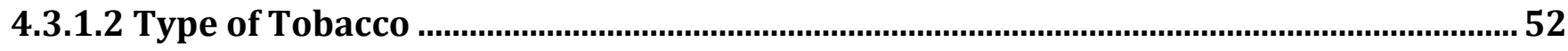

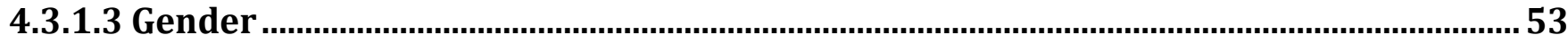

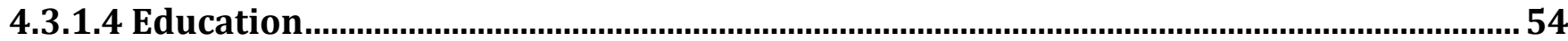

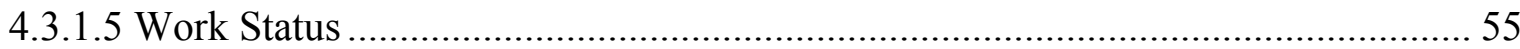

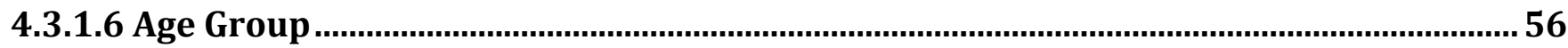

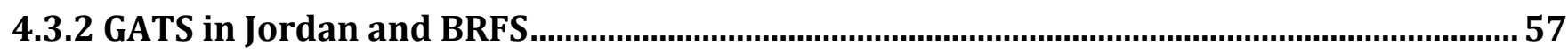

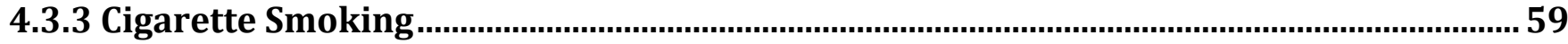

4.3.3.1 Cigarettes price quantity and expenditure stratified by age group, education, work

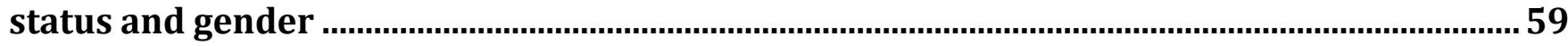

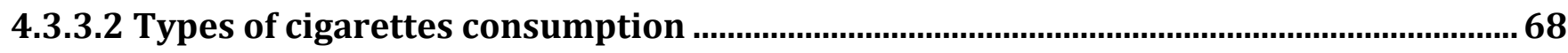

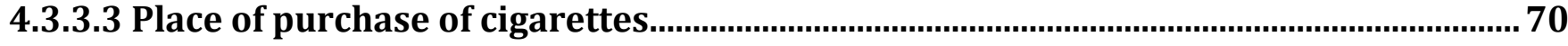

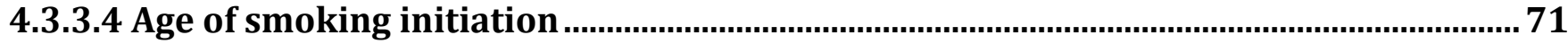

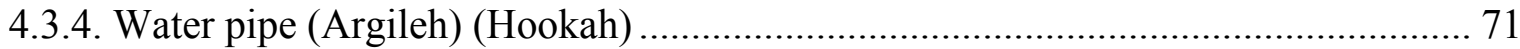

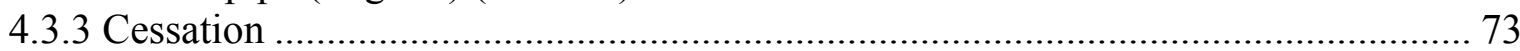

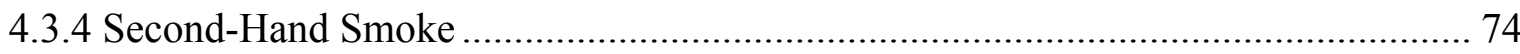

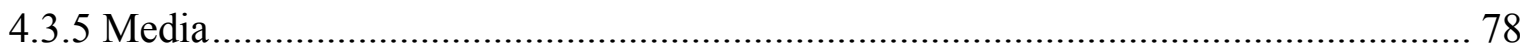

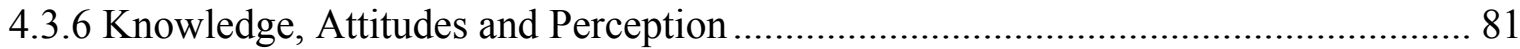

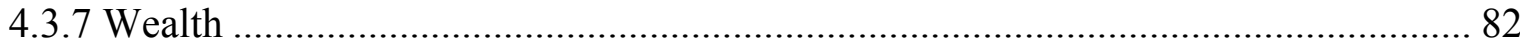

4.3.8 Demand Analysis ................................................................................ 83

4.3.8.1 Outcome Variable: Propensity and Intensity of Cigarettes Consumption ............ 83

4.3.8.1.2 The Intensity to smoke variable

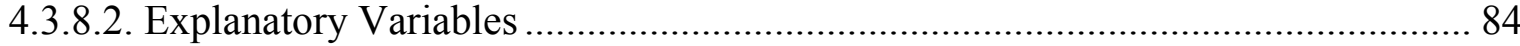

4.3.8.3 Price Elasticity of Cigarette Demand in Jordan ............................................ 87

4.3.8.3.1 Part One Model: Propensity to Smoke .......................................................... 87

4.3.8.3.2 Part two model: Amount smoked by smokers............................................ 89

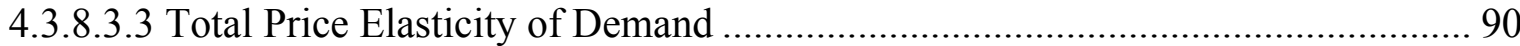

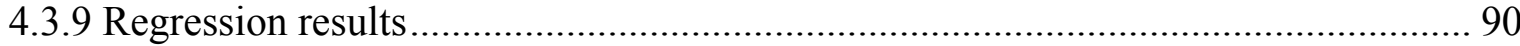

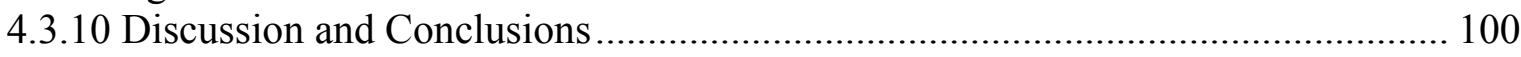

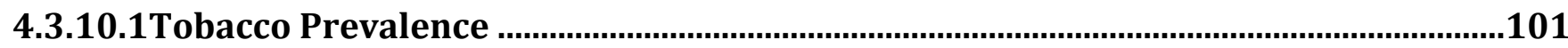

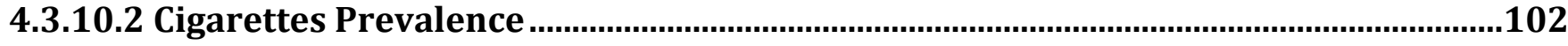

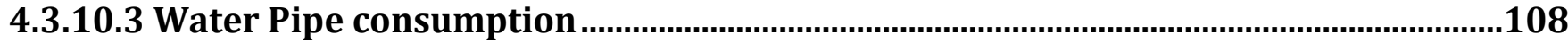




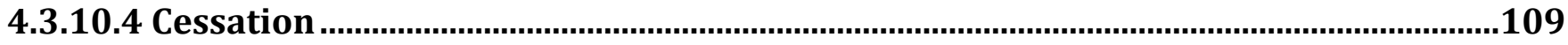

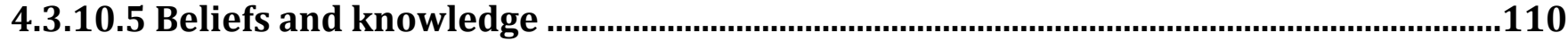

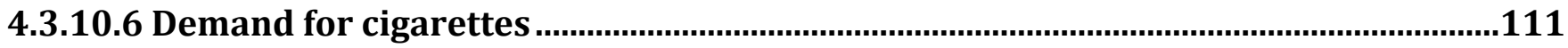

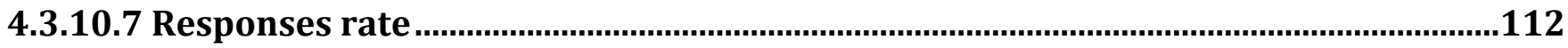

4.3.10.8 Study Limitations

4.3.10.9 Policy Implication of the results ........................................................................114

4.3.10.9.1 Local Level .................................................................................................................114

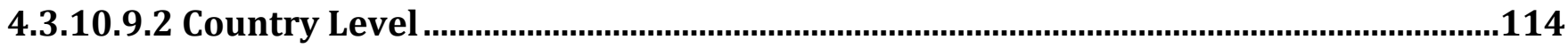

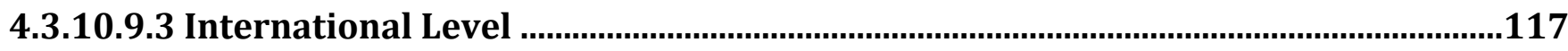

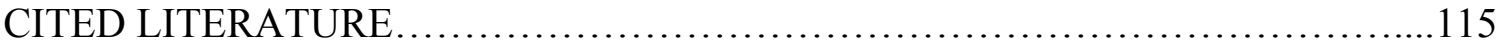

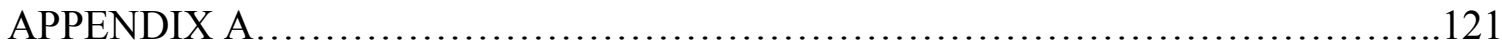

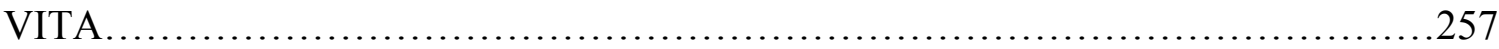




\section{LIST OF TABLES}

TABLE

PAGE

I. LOG LINEAR REGRESSION RESULTS OF THE QUANTITY OF

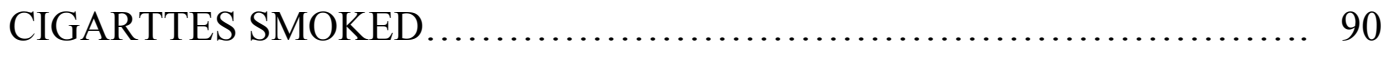

II. LOGISTIC REGRESSION RESULTS OF THE DECISION TO SMOKE

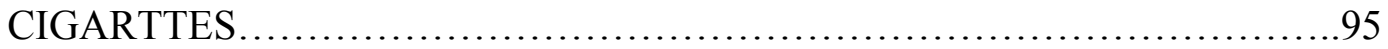




\section{LIST OF FIGURES}

FIGURE

PAGE

1. Tobacco and manufactured tobacco substitutes imports value in Jordanian Dinar

2. Tobacco and manufactured tobacco substitutes exports value in Jordainan Dinar .30

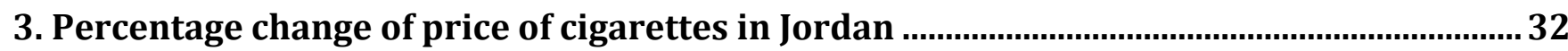

4. The response rate by governorate and country level

5. Average number of individuals living at home,individuals aged a5 and above, and males aged 15 and above living at hoem by governorate.

6. The prevalence of tobacco use among governorates and by gender 51

7. Prevalence of tobacco smoking by type of tobacco 52

8. Prevalence of tobacco use by type 53

9. Smoking prevalence by education................................................................................... 54

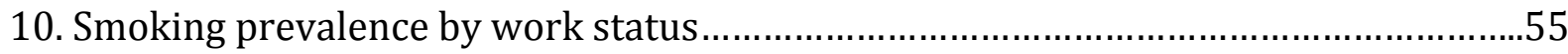

11. Prevalence of tobacco use by age group...................................................................

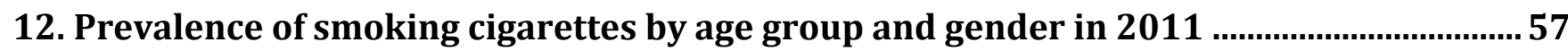

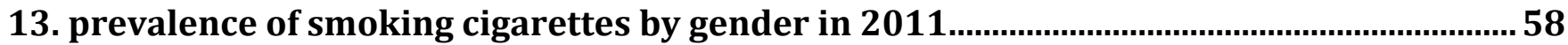

14. Average price per pack of cigarettes by age group ….......................................................... 59

15. Quantity of cigarettes smoked every week in packs by age group .......................................60

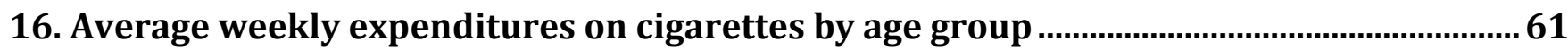




\section{LIST OF FIGURES (Continued)}

FIGURE

PAGE

17. Average price per pack of cigarettes, average quantity in packs and average weekly expenditures on cigarettes by gender

18. Average price per pack of cigarettes by work status

63

19. Quantity of cigarettes smoked every week in packs by work status 64

20. Average weekly expenditures on cigarettes by work status 64

21. Average price per pack of cigarettes by education 65

22. Quantity of cigarettes smoked every week in packs by education 66

23. Average weekly expenditures on cigarettes by education. 66

24. Prevalnce of cigarettes smoking for different types of cigarettes by age group.

25. Prevalnce of cigarettes smoking for different types of cigarettes by education 68

26. Prevalnce of cigarettes smoking for different types of cigarettes by work status

27. Age of smoking initiation for cigarettes and water pipe 71

28. Prevalence of advertisement by type of advertisement and gender.

29. Prevalence of cigarettes promotion by type of promotion and gender .80 


\section{SUMMARY}

This dissertation examines the economics of tobacco use in Jordan. The motivation for this study arises from the increase in tobacco epidemic in developing countries. Thus, Jordan as a low -middle income country with a small economy and limited resources is experiencing a wide spread of tobacco use.

To our knowledge the demand for smoking has not been studied in Jordan nor has the price elasticity of cigarettes use been estimated. National and sub-national tobacco use, exposure to second-hand smoke, and quit attempts among those aged (15 and above) has not been studied in Jordan either. Therefore, a gap in our knowledge of tobacco use practices in this country exists. Before effective antitobacco strategies can be implemented in Jordan, we need to have a better understanding of tobacco demand and other factors that influence tobacco use. The overarching aim of this research is to provide the first important insights about economics of tobacco use and the demand analysis in Jordan.

The heart of this analysis is to conduct a global survey called the Global Adult Tobacco Survey (GATS) that can be compared to other countries, from which the prevalence of tobacco use in Jordan, exposure to second hand smoke, quit attempts for those aged 15 and above, Gender differences of tobacco use and elasticity of demand for cigarettes can be estimated. 


\section{SUMMARY (Continued)}

The results from the GATS showed that the overall prevalence of tobacco use for those aged 15 years old and above in 2011 was $42.2 \%$. By Gender men prevalence of smoking is estimated to be $55.9 \%$ and women is $23.7 \%$. By type of tobacco The overall prevalence of cigarettes use is $35.2 \%$, water pipe is $15.2 \%$, and other types like hand rolled ciagreets, pipes and cigars is $1.5 \%$.

With respect to the age of smoking initiation, approximately $42 \%$ of smokers started smoking cigarettes between the ages of 15 and 18 , whereas $29 \%$ of respondents began smoking between the ages of 19-23. The least likely time to begin smoking in Jordan is between the ages of 7-9 and over the age of 60 (2\% and $3 \%$ of respondents, respectively). The average price of a pack of cigarettes is estimated to be 1.4 Jordanian Dinar and an average quantity of approximately 8 packs per week.

With respect to water pipe approximately $29 \%$ of water pipe smokers initiate smoking between the ages of 19-23. Similar to cigarette smoking, people are least likely to begin smoking between the ages of 7-9 and over 60 years.

Our results show that the average time it takes to smoke a water pipe in Jordan is 2.2 hours (range, 30 minutes to 5 hours). On average, 2 people share the same pipe (range, 0 to 6 people). The average number of rocks smoked while participating in the session was 2.1 (range, 1-4 rocks). Of water pipe smokers, $52 \%$ use flavored tobacco while $48 \%$ uses unflavored tobacco. Most water pipe smoking is done at home $(87 \%)$, followed by coffee shops $(12 \%)$, restaurants 


\section{SUMMARY (Continued)}

$(0.9 \%)$, bars and nightclubs (0.1\%). Approximately half of all respondents (48\%) mix something with their tobacco, such as lemon or alcohol According to the GATS survey in Jordan, 2\% of the sample consisted of former smokers. We found that $27.4 \%$ of Jordanian current smokers tried to quit smoking during the past 12 months, whereas $72.6 \%$ did not. Those who tried to stop smoking tried for several days, weeks, and months with no success. We found that smoking is allowed inside the home by $45 \%$ of all respondents. Another $22.6 \%$ of Jordanians allow some smoking in the home with some exceptions.

Only $11.2 \%$ of respondents reported that smoking is never allowed at home. Other than those persons just described, another $8.4 \%$ have no rules about smoking in their homes and $12.8 \%$ don't know if smoking is allowed in their home.

In addition to household smoking, of the people interviewed, $42 \%$ work outside their home and 50\% don't work outside the home, and $8 \%$ did not answer. A little more than one-fourth of respondents $(26.2 \%)$ work indoors, $7.1 \%$ work outdoors, and $9 \%$ work both indoors and outdoors. Smoking is allowed in all areas of the work place for $13.2 \%$ of respondents. Another $16.1 \%$ of interviewees reported that their workplaces allowed smoking only in some indoor areas. Only $6.6 \%$ of respondents stated that smoking is not allowed in any indoor areas, whereas $2.2 \%$ reported that there is no smoking policy at their work. And 64.1\% don't know.

The majority of respondents $(81 \%)$ know that breathing other people's secondhand smoke causes serious illnesses in non-smokers. 


\section{SUMMARY (Continued)}

By gender advertising where sometimes noticed more by female than their male Counterparts. For example females noticed advertisements more than males on television $(17.4 \%$ and $15.6 \%$ respectively), billboards $(12.4 \%$ and 5.8 respectively), cinema ( $10.5 \%$ and $5.9 \%$, respectively) and elsewhere like text messages (5.6\% and $4.8 \%$ respectively). $6 \%$ of females reported getting free samples of cigarettes compared to $2.2 \%$ of males. Females reporting getting cigarettes at sale prices were $7.8 \%$ compared to $5.5 \%$, while females report getting free gifts when buying cigarettes by $6.7 \%$ compared to men $6.4 \%$. Females are also getting clothing with cigarettes brand name or logo $(8.9 \%)$ more than males (7.7\%).

In summary the overall prevalence of smoking in Jordan according to our data from GATS is alarming compared to other Middle Eastern countries like Egypt, where the prevalence of tobacco use was $19.4 \%$ in 2009 . Women prevalence of cigarettes use is increasing compared to 2007, and water pipe smoking is becoming very popular among both men and women.

The elasticity of smoking in Jordan was estimated to be -0.6 . An additional 1\% tax that increases the price of cigarettes would bring about $6 \%$ a reduction in cigarette consumption. It would also help reduce the incidents smoking-related illnesses. Elasticity of smoking for females was estimated to be -0.008 and for males -0.81 . 


\section{SUMMARY (Continued)}

In terms of policy implication, warning, offering cessation programs, reinvesting in men, reeducating women, reinforcing current laws of prohibiting smoking, increasing prices to keep pace of inflation, and revisiting the GATS ever year or so with some modification are of high priority in Jordan. 


\section{BACKGROUND AND RATIONALE}

\subsection{Rationale}

More than one billion people smoke tobacco worldwide. Of these smokers, $80 \%$ live in low-to-middle income countries, according to the World Health Organization (WHO). As such, the majority of tobacco-related deaths, most of which are preventable, occur in lower income countries. It has been estimated that tobacco kills up to half of all people who use it. In 2010, 5.4 million people died due to tobacco-related diseases worldwide (World Health Organization 2009). Of these deaths, 600,000 were attributed to second-hand smoking (World Health Organization 2009). Since the year 2000, when 4.8 million tobacco-related deaths occurred (Jha and Chaloupka 2000), the annual death toll has risen by approximately $12.5 \%$ across the globe over the past 10 years. Without efforts to lessen tobacco use, the WHO estimates that more than 8 million deaths in 2030 will be related to tobacco use, and 6.4 million of these deaths will occur in developing countries (World Health Organization 2009).

Tobacco use is a major risk factor for many chronic diseases, which means that some diseases are more common in tobacco users than in individuals who abstain from tobacco. Smokers are more likely to have diabetes, chronic obstructive pulmonary disease, and asthma than non-smokers (Schroeder and Warner 2010). Furthermore, tobacco is most important risk factor for lung cancer, with cigarette smoking increasing its risk of development by up to 25-fold (Al-Kayed 
Qasem 2006). Smoking water pipes, cigars, and pipes has also been linked to lung cancer.

Due to the well-established mortality and morbidity associated with tobacco use, the economic consequences of tobacco use-mostly related to healthcare costs and loss of productivity—are substantial. Modeling the demand for cigarettes has long been of interest to economists. Historically, many economists viewed cigarette smoking and other addictive behaviors as irrational and unsuitable for conventional economic analysis (Winston GC 1980)(Schelling, 1984). They believed that demand for cigarettes does not follow the basic laws of economics, such as the downward-sloping demand curve. However, this view has changed over time as a result of a large body of economic research demonstrating that cigarette demand clearly responds to changes in prices and other factors.

Worldwide, the WHO estimates that tobacco damages are on the order of hundreds of billions of dollars each year. In United States alone, people spend approximately $\$ 83.6$ billion on cigarettes, $\$ 3.2$ billion on cigars, and $\$ 2.6$ billion on smokeless tobacco each year. Direct medical costs and indirect costs due loss of productivity total $\$ 193$ billion annually. This translates to $\$ 10.47$ for every pack of cigarettes sold (World Health Organization 2009). In Jordan, which has one of the smallest economies in the Middle East (Central Intelligence Agency 2010), an estimated 250 million Jordanian dinars (JOD) or nearly 356 million in US dollars annually on tobacco products (Belbeisi, Al Nsour et al. 2009). Direct and indirect costs of smoking, however, remain to be calculated in this country. The economics of tobacco use in Jordan are the focus of this dissertation. 


\subsection{Prevalence of Tobacco Use in Jordan}

Despite the detrimental health and economic effects of cigarette use, the prevalence of smoking in Jordan is increasing, according to several studies. However, estimates of the prevalence of tobacco use in Jordan vary by different sources and different studies. Findings from a questionnaire distributed to 851 scholars and students at Al-Isra University in 2006 demonstrated that 33\% of participants were smokers; however, only $9 \%$ of all participants were over the age of 25 (Naddaf 2007). In this study, More recently, the United States Centers for Disease Control and Prevention (CDC), the Jordan Ministry of Health, and Jordan University of Science and Technology collaborated on a review of tobacco control of Jordan and estimated that the lifetime prevalence of ever smoking 100 or more cigarettes among women and men in Jordan is $7.8 \%$ and $61.8 \%$, respectively (Belbeisi, Al Nsour et al. 2009). Overall, this amounts to $40 \%$ of adults in Jordan having smoked at least 100 cigarettes previously. The prevalence of current smoking for those aged 15 and above according to the behavioral risk factors survey was reported to be $5.1 \%$ for women and $48.2 \%$ for men (Belbeisi, Al Nsour et al. 2009).

Across all adults, the prevalence of tobacco use has been reported to be $36 \%$, which is higher than every other Eastern Mediterranean country measured by the WHO, including Afghanistan, Egypt, Iraq, and Saudi Arabia, among others (World Health Organization 2009). A different survey by the Jordanian Ministry of Health reported that the prevalence of smoking increased from 27 to $29 \%$ from 2005 through 2007, among Jordan's population of 5 million people (World Health 
Organization 2008). Moreover, Jordan ranks $17^{\text {th }}$ with respect to the prevalence of tobacco use among countries for which data are available. It is tied with Cuba, Estonia, Lithuania, and Turkey for the $17^{\text {th }}$ ranking. In this category, Greece ranks first, with $51 \%$ of the population being smokers (World Health Organization 2009).

\subsubsection{Tobacco Use Among Adolescents}

Adolescent smoking is also prevalent in Jordan, with $22.7 \%$ of boys and $8.7 \%$ of girls aged 13-15 years old admitting to using cigarettes (Belbeisi, Al Nsour et al. 2009). The questionnaire that was administered to university students and scholars, mentioned above, also found that $65 \%$ of smokers admit to initiating their smoking habits before the age of 18 . An additional $23 \%$ of respondents began smoking between the ages of 18-21 (Naddaf 2007). As such, smoking tobacco is prevalent among adolescents and young adults in Jordan, similar to adults.

\subsubsection{Possible Explanation of High Prevalence of Tobacco Use}

One reason for the high prevalence rates of tobacco use in Jordan is that Middle Eastern culture dictates that smoking is an acceptable social behavior at home and in public, especially for men (Belbeisi, 2009) (Merrill, Madanat et al. 2008). Furthermore, Belbeisi and colleagues suggest that estimates of women smokers in Jordan may be low, as women may deny that they smoke and/or underestimate the impact of cigarettes on their health (Belbeisi, Al Nsour et al. 2009). 
Given the rising prevalence of tobacco use in Jordan, the total consumption of cigarettes rose from less than 3.7 billion to almost 4 billion per year throughout the 1990s in this country (US Dept of Agriculture 2010). Consequently, the Jordanian population has suffered from the detrimental effects of cigarettes and other tobacco products. One-third of deaths in Jordan in 2006 were due to heart disease and stroke. Cancers caused $13 \%$ of deaths, with lung cancer causing the majority of these deaths (Belbeisi, Al Nsour et al. 2009). The prevalence of lung cancer in Jordan is 9.9 cases per 100,000 people being reported between 1996 and 2001 (Al-Kayed and Qasem 2006). The health consequences and their cost burden are described in more detail in the next chapter.

\section{$\underline{1.3 \text { Tobacco-Related Costs }}$}

In the United States, direct tobacco-related medical costs and indirect costs due to loss of productivity total $\$ 193$ billion annually (World Health Organization 2009). Of these costs, $\$ 96$ billion are attributed to healthcare expenses and $\$ 97$ billion relate to lost productivity (World Health Organization 2009). Estimates of tobacco-related expenditures have also been conducted in the European Union. Total costs are estimated to be 97.7 billion Euros, with direct costs totaling 49.83 billion Euros and indirect costs totaling 47.87 billion Euros (Smokefree Partnership 2011). Furthermore, in the EU, cardiovascular disease costs 192 billion Euros, and $22 \%$ of all cases of cardiovascular diseases have been attributed to tobacco smoke exposure, suggesting that indirect costs of tobacco use might be underestimated (Smokefree Partnership 2011). The costs of smoking in other countries with smaller economies, including Jordan, are not known. However, a 
relationship between tobacco use and poverty has been suggested, and mounting evidence supports this association.

\subsection{Variables that Impact Tobacco Use}

Many analyses from across the globe, particularly in the United States, have revealed that individuals with incomes that fall below the poverty line are more likely to smoke than individuals with higher incomes. Poverty is the term used to describe family incomes lower than the United States Census Bureau's family income poverty, which depend on the size of the family, but not its geographic location. Data from the National Health Interview Survey revealed that in 2004, nearly $50 \%$ of individuals below poverty line were current smokers. The prevalence of smoking was higher in those below the poverty line than those at or above the poverty line (Fagan, Moolchan et al. 2007).

Tobacco use also varies by factors that may be associated with lower income levels in the United States, such as occupation, education level, race, and ethnicity. Smoking initiation has been predicted by socio-economic status in many prospective studies conducted since the 1980s (Conrad, Flay et al. 1992). In particular, those with lower socioeconomic statuses are more likely to initiate cigarette smoking, and it has been demonstrated that children living in lowincome areas more likely to smoke than age-matched counterparts (Fagan, Moolchan et al. 2007). In lower income areas, exposure to second-hand smoke also is high. Of note, an exception to this rule is that some mechanisms of tobacco use might be less prevalent in lower socioeconomic classes. For instance, Azab and colleagues recently investigated the frequency of water pipe tobacco smoking 
in Jordan. The investigators had interviewers randomly select students from four different universities to answer a questionnaire about their sociodemographics, personal data, and water pipe tobacco use. Findings from the 548 participants suggest that water pipe tobacco smoking is highly prevalent and is associated with male gender and upper middle income levels (Azab, Khabour et al. 2010).

Similar to socioeconomic status, a relationship between tobacco use and education level has also been established. Across geographical locations and racial/ethnic groups, more education corresponds to better health outcomes and lower mortality rates due to cardiovascular disease and cancer. Moreover, a growing discrepancy in mortality rates between individuals with higher and lower levels of completed education exists. However, smoking rates are decreasing among children in low-income households, even though some studies suggest that such children are more likely to try cigarettes and other tobacco products (Steenland, Henley et al. 2002; Fagan, Moolchan et al. 2007).

With respect to occupation, more individuals with blue-collar jobs smoke cigarettes than those with white-collar jobs (Fagan, Moolchan et al. 2007). For example, only $1 \%$ of physicians smoke whereas more than $30 \%$ of individuals in some blue collar populations are smokers (Schroeder and Warner 2010). Furthermore, individuals in the service industry, as well as blue-collar workers, are less likely to successfully quit smoking than individuals with white-collar jobs (Fagan, Moolchan et al. 2007). 
Although some racial and ethnic groups have higher poverty rates than others, the prevalence of current smokers does not necessarily correlate with the groups' poverty statuses. Black and/or African American individuals have the highest poverty rates, at $24.7 \%$, compared other groups, including Latinos/Hispanics (21.9\%), Native Hawaiian/Pacific Islanders (13.2\%), whites (10.4\%), and Asian Americans (9.8\%). However, rates of current smoking in the same groups are 20.2\%, 15.0\%, 22.2\%, and 11.3\% (Fagan, Moolchan et al. 2007). Interestingly, despite their high poverty rates, black individuals have lower smoking initiation rates, a delayed onset of smoking (ie, over the age of 18, usually), and declining rates of smoking, compared to white individuals. By contrast, white individuals have high smoking rates, usually with initiation occurring during adolescence (Fagan, Moolchan et al. 2007). Despite the lower smoking prevalence among black individuals, this racial/ethnic group has the highest incidence of cancer, including lung cancer, as well as the highest death rate due to cancer among all groups. This finding was reported in the 2005 Annual Report to the Nation on the Status of Cancer, a yearly report published as collaboration between the American Cancer Society, the CDC, the National Cancer Institute, and the North American Association of Central Cancer Registries. According to this report, other cancers that have been linked to tobacco use, including stomach and esophageal/oral cavity also cause $200 \%$ and $75 \%$ more deaths in black/African Americans than in whites (Edwards, Brown et al. 2005).

In addition to cancer, living in poverty and using tobacco have been linked to other adverse health problems as well (Fagan, Moolchan et al. 2007). In addition, 
people who suffer from chronic mental illnesses or have a history of substance abuse are more likely to smoke tobacco, consume more cigarettes than other smokers, and have more difficultly quitting (Schroeder and Warner 2010).

In addition to poverty affecting the prevalence of tobacco use and tobacco-related illnesses, it may also influence the ability of people to quit smoking. Fewer people below poverty quit smoking than those above poverty ( $22.6 \%$ vs $49.9 \%$ in 2000 ). This discrepancy may reflect better access to cessation programs at higher income levels, but more studies are needed to fully understand this (Jha and Chaloupka 2000; Centers for Disease Control and Prevention 2002).

Another consideration related to tobacco use and poverty is the affect of increasing the price of tobacco through taxes. Critics of increasing cigarette taxes cite a disproportionate burden on poor individuals undertaken when prices increase. Cigarette affordability, which refers to the ability of an individual to buy cigarettes, would obviously differ among individuals with different income levels. As such, the affordability would be lower for people with less dispensable income (Blecher and van Walbeek 2004). Accordingly, increasing the price of cigarettes and other tobacco products via taxation, is one of the most effective means used to curb tobacco use. This point will be described in great detail at the end of this chapter.

\subsection{Brief Overview of Tobacco Economics in Jordan}

In the Middle East, Jordan has one of the smallest economies, with a gross domestic product (GDP) of $\$ 34.53$ billion in US dollars. Its reliance on foreign 
assistance stems from it lacking an adequate water supply and natural resources, such as oil. Jordan suffers from high unemployment rates, inflation, a large budget deficit, and chronic high rates of poverty, with $14.2 \%$ of the population being below the poverty line (Central Intelligence Agency 2010). Although some measures taken to improve the economy over the past decade, the dismal global economy has stunted Jordan's growth. Per capita GDP is $\$ 5,300$ in US dollars (Central Intelligence Agency 2010).

Despite the small economy and high rates of poverty, there remains a high demand for cigarettes in Jordan. As mentioned above, a recent survey conducted by the Jordan Ministry of Health found that smoking prevalence was 29\% between in 2007 (World Health Organization 2008). Therefore, spending on tobacco and cigarettes is also high. People who smoke in Jordan spend an estimated 250 million Jordanian dinars (JOD) or nearly 356 million US dollars annually on tobacco products (Belbeisi, Al Nsour et al. 2009). In all of Jordan, the total consumption of cigarettes rose from less than 3.7 billion to almost 4 billion per year throughout the 1990s (US Dept of Agriculture,2010). Since cigarette production and consumption in Jordan is increasing (Naddaf, 2007), it is likely the spending is increasing as well.

\subsection{Reducing Tobacco Use}

The extents to which smoking behaviors and tobacco spending habits affect the Jordan economy remain largely unknown. Given the high economic impact of smoking-related morbidity and mortality, reducing the consumption of cigarettes in Jordan may positively affect its economy. Strong evidence from across the 
globe has proven that there are several ways to successfully decrease smoking rates. For example, prohibiting indoor smoking, counter-marketing cigarettes, and banning cigarette advertisements have all been used globally to persuade tobacco users to quit. In addition to these methods, increasing the taxes levied on cigarette consumers has also successfully reduced smoking (Schroeder, 2010). One study from the United States found that increasing the price of cigarettes by $10 \%$ results in a $4 \%$ decrease in cigarette consumption (The Task Force on Community Preventive Services 2005). In the United States, cigarette taxes increased to up to $\$ 4.35$ per pack in 2009 in some states. Taxes in Europe are higher, reaching more than $\$ 11$ per pack in some countries (Schroeder, 2010).

\subsubsection{Tobacco Regulation Worldwide}

In 1998, the WHO created a Tobacco Free Initiative in 1998 to try to draw attention to the worldwide tobacco epidemic. In doing so, they also wanted to begin to try to regulate tobacco consumption to decrease morbidity and mortality associated with tobacco use. As part of this initiative, the WHO Framework Convention on Tobacco Control (FCTC) was created, which strives to strengthen tobacco control and prevent tobacco-related deaths across the globe (Belbeisi, Al Nsour et al. 2009; World Health Organization 2011). According to the WHO, the FCTC is the first evidence-based, public health treaty that affords every person the right to have the best health possible

The FCTC is WHO's first international, legally binding treaty that requires countries to implement tobacco control programs developed by and with help 
from the WHO. Currently, $87 \%$ of the world's population in 172 countries (as of June 2011) is covered by the treaty. When countries become part of the treaty, they make a commitment to do the following (Belbeisi, Al Nsour et al. 2009; World Health Organization 2011):

- Reduce the demand for tobacco using price and tax measures

- Take non-price measures to reduce tobacco demand including: protecting people from tobacco smoke exposure, regulating the contents of tobacco products, regulating tobacco product disclosures, using packaging and labeling to reduce demand, providing education, communication, training and awareness of the campaign, regulating tobacco advertising, and demanding reduction measures concerning tobacco addiction and quitting

- Provide economically viable alternative activities to using tobacco

- Prohibit sales to and by minors

- Strive to prevent illicit tobacco trading

In addition to the FCTC, the WHO has also developed the MPOWER platform, which supports the FCTC in monitoring tobacco use, warning about the dangers of tobacco use, protecting individuals from exposure to smoke, helping smokers quit, enforcing bans on tobacco marketing, and raising taxes on tobacco products. Notably, banning smoking in public places, a component of the WHO FCTC and MPOWER strategies has been successful at protecting persons from tobacco smoke. Such bans coincide with an assertion by the U.S. Surgeon General that no safe level of tobacco smoke exposure exists. Despite arguments from those who 
oppose such smoking bans due to the potential financial consequences of business owners, studies have demonstrated that making smoking illegal does not affect business. With this knowledge, smoke-free policies have garnered attention across the globe. According to the WHO, 485 million people are now protected from the damage tobacco smoke can do, as they are covered by smoke-free policies in bars and restaurants (Centers for Disease Control and Prevention 2011; World Health Organization 2011).

\subsubsection{Methods to Reduce Smoking}

Several different interventions have been used to successfully decrease the prevalence of smoking throughout the world (Jha, Chaloupka et al. 2006). Most of the methods used to reduce the use of tobacco are aimed at children and young adults, in order to prevent them from ever starting to use tobacco products. Currently, the majority of adult tobacco users began their habit during adolescence and developed a dependency on nicotine soon after. Delaying or altogether preventing tobacco initiation could potentially be more effective than attempting to persuade adults who are addicted to nicotine to quit (The Task Force on Community Preventive Services 2005).

As mentioned above, banning indoor smoking is one of the interventions used to protect all individuals from unsafe exposure to tobacco smoke. It is estimated that smoking bans and restrictions in certain geographical areas have reduced the exposure to second-hand/environmental smoke by approximately $72 \%$ (The Task Force on Community Preventive Services 2005). Making smoking illegal in 
public places also may help change the perception of smoking from it being an acceptable habit to it being an undesirable one (Smith, Siebel et al. 2008). As previously indicated, all of these positive effects came at no expense to business owners, and they have not affected tourism (Eriksen and Chaloupka 2007).

Counter-marketing cigarettes and other tobacco products through mass media educational campaigns also have been shown to effectively reduce their consumption (Terry-McElrath, Wakefield et al. 2007). Mass media campaigns are used to educate the public about the harmful effects of tobacco use. Two types of messaging are used in these campaigns: Demand reduction education and agendasetting messaging. Demand reduction education messages primarily encourage children and adolescents to remain tobacco-free by providing information about the harmful effects of tobacco use. The goal of agenda-setting messaging is to counter-market tobacco by directly opposing the messages that tobacco companies use to market their products. For example, some agenda-setting messages reveal tactics used by tobacco companies to recruit users. Both demand education and agenda-setting messages come in the form of television, radio and print ads, which use recurring messages to motivate children, adolescents, and young adults to remain tobacco-free. When combined with other interventions, such as school-based education and public service announcements, mass media campaigns have been reported to decrease the prevalence of tobacco use by approximately $2.4 \%$ (The Task Force on Community Preventive Services 2005). Increasing the length of time each campaign message is used is accompanied by 
an increase in its effectiveness (The Task Force on Community Preventive Services 2005).

Of the interventions used to reduce tobacco use, the most dramatic effects are obtained upon raising the prices of tobacco (Grossman and Chaloupka 1997; Chaloupka, Cummings et al. 2002; Chaloupka, Straif et al. 2011). Price increases have two forms: Raising the price of the product itself and increasing the taxes levied on the products. For the most part, raising the price of tobacco products involves raising the price of the excise taxes at the city, state, and/or federal levels. Studies from the United States have shown that increasing the price of cigarettes by $10 \%$ reduces consumption by $4 \%$ (The Task Force on Community Preventive Services 2005). Such increases in price may be particularly effective at persuading adolescents and young adults to remain tobacco-free, given the likelihood that younger individuals have a more limited income to spend on expensive tobacco products (Pacula and Chaloupka 2001; Liang and Chaloupka 2002; Ross and Chaloupka 2003). In the United States, the highest price reported per pack of cigarettes in 2010 was $\$ 4.35$. In the European Union, a pack of cigarettes costs as much as \$11 in some areas (Schroeder and Warner 2010). One reason for the particularly high price of cigarettes in the European Union is that the minimum tax charged on all cigarette sales is $57 \%$ of the retail price of the tobacco product. Some countries actually have tax rates as high as $75 \%$ of the price of the cigarettes (Chaloupka and Nair 2000). 


\subsection{Tobacco Interventions in Jordan}

For the past 40 years, the Jordan government has actively tried to decrease smoking prevalence among its population. In 1971, public health law established jail sentences and fines for public smoking. However, these laws were poorly enforced, and no noticeable difference in tobacco consumption occurred. Then, in 2001, Juvenile Monitoring Legislation was passed to discourage young people from using tobacco products. Under this law, fines were imposed on minors buying cigarettes for both the minor and the vendor of the product (Belbeisi, Al Nsour et al. 2009).

In 2003, Jordan was one of the first countries to adopt the WHO's FCTC (Belbeisi, Al Nsour et al. 2009). As described above and expanded up here, the FCTC is the WHO's international treaty that commits members to eliminate tobacco advertising within 5 years, require warning labels that take up a at least $30 \%$ area of cigarette packs (now $50 \%$ of the label is required to contain a picture warning), forbids misleading statements about cigarettes being mild or light, and protect non-smokers (Belbeisi, Al Nsour et al. 2009).

In 2008, the public health law was amended to ban smoking in majority of public venues at the discretion of the Minister of Health. Included in this law are the following: hospitals, schools, libraries, cinemas, museums, public transportation, airports, closed playgrounds, lecture halls, public and nongovernmental buildings, theatres, and shopping malls (Belbeisi, Al Nsour et al. 2009). In addition, five star restaurants are required to have smoking and non-smoking sections now. Even 
restaurants that are poor, such as fast food chains, are now being regulated by smoking restrictions.

Historically, some tobacco-limiting measures have been difficult to enforce in Jordan. However, enforcement is now ensured by reducing wages and benefits for Ministry staff who smoke in these public areas and assigning monitoring areas in some of these buildings, such as airports (Belbeisi, Al Nsour et al. 2009). Despite the attempts by Jordan to adopt and enforce anti-tobacco programs, the effectiveness of these policies has yet to be measured, and only time will tell how successful these interventions are.

Because regulatory measures have not yet significantly influenced cigarette use in Jordan, economic actions have also been taken to curb smoking through the use of high cigarette prices and excise taxes. Cigarette prices per pack (20 cigarettes) in Jordan are US $\$ 0.98$ for domestic brands and US $\$ 1.90$ for imported brands (World Health Organization 2010). As of 2010, specific excise and sales taxes were 0.30 and 0.38 Jordanian dinars (JOD) per pack for domestic and imports. In addition to these specific taxes, a general sales tax of $20 \%$ also applies to all cigarette packs purchased in this country. Also levied are import taxes for the cost, insurance, and freight (CIF) of cigarettes. Import taxes in Jordan amount to $100 \%$ of the cost of cigarette packs (World Health Organization 2010). Combined, all taxes make up more than $60 \%$ of the total cost of a cigarette pack in Jordan (US Dept of Agriculture 2010). Whether price escalations will affect cigarette consumption in Jordan has not been determined. 


\subsection{Specific Aims of this Dissertation}

The overarching aim of this research is to identify potential ways to decrease cigarette consumption in Jordan through taxation. Furthermore, I will make recommendations as to whether cigarette tax policy reforms in Jordan will be beneficial to its economy. The reason that I have chosen this topic for my dissertation is because the demand for smoking has not been studied in Jordan nor has the price elasticity of cigarettes use been estimated. National and sub-national estimates on tobacco use, exposure to second-hand smoke, and quit attempts among adults has not been studied in Jordan either. Therefore, a gap in our knowledge of tobacco use practices in this country exists. Before effective antitobacco strategies can be implemented in Jordan, we need to have a better understanding of tobacco demand and other factors that influence tobacco use.

Studies of the population of other countries suggest that increased cost of cigarettes may affect their demand (Chaloupka and Nair 2000; Jha and Chaloupka 2000; Jha and Chaloupka 2000; Nassar 2003; Tauras JA 2005; The Task Force on Community Preventive Services 2005; vanWalbeek, Lewis-Fuller et al. 2005; Tauras JA 2006; Hu, Mao et al. 2010). Findings from these demand analyses have revealed price of tobacco products and consumer income are the two most relevant economic factors that influence demand. Namely, increasing the price of tobacco products reduces their demand, which explains why taxes on tobacco products have successfully decreased the prevalence of tobacco use across the globe. Economically, this phenomenon can be explained by price elasticity, which describes the relationship between the price of a commodity and its demand. 
More specifically, price elasticity of demand is the percent change in amount demanded in response to a one percent change in price, if all other variables remain fixed.

Analyzing the elasticity of tobacco demand in Jordan will be important for understanding differences in tobacco use habits across socioeconomic categories, as well as between genders and various age groups. Therefore, I undertook my research of demand for tobacco products in Jordan with the following hypotheses: 1) that the quantity of cigarettes consumed is negatively related to their price; 2) the demand for cigarettes in Jordan is inelastic; and 3) that taxation may reduce the quantity of cigarettes consumed and increase government revenue.

\subsection{Dissertation Outline}

To tests the hypotheses listed above, I collected data from Jordanian households to determine the demographics of the smoking population in Jordan. With this information, I was able to analyze the demand for tobacco in Jordan. Surveys are usually a good tool to collect data. These surveys are large-scale efforts by others to study the demographics, health, and/or economics of a particular country. Therefore, I used the Global Adult Tobacco Survey (GATS), developed by the WHO's and CDC's Global Tobacco Surveillance System. This survey has been used worldwide to collect information on tobacco use and was developed as a standard protocol for monitoring global adult tobacco use and measures (Global Tobacco Surveillance System (GTSS) 2010). 
Before discussing my results, I will first provide an overview of the tobacco economics in Jordan based on a thorough literature review of this topic, in the second chapter of my dissertation. The third chapter provides more detailed information about the methodology used to conduct this research, including an overview of the GATS. And finally, the last chapter of my dissertation presents the results from my analyses. Within this chapter, I describe the factors that may help curb smoking in Jordan and provide my recommendations for how to do so. 


\section{LITERATURE REVIEW}

\section{$\underline{2.1 \text { Overview }}$}

Despite the detrimental health and economic effects of cigarette use, the prevalence of smoking in Jordan is increasing, according to several studies. Prevalence estimates of tobacco use in Jordan vary by different sources and different studies. Findings from a questionnaire distributed to 851 scholars and students at Al-Isra University in 2006 demonstrated that 33\% of participants were smokers; however, only $9 \%$ of all participants were over the age of 25 , which makes extrapolation of these findings to a broad population difficult (Naddaf 2007) In a different study, the CDC collaborated with the Jordan Ministry of Health and Jordan University of Science and Technology and estimated that the lifetime prevalence of ever smoking 100 or more cigarettes among women and men in Jordan is $7.8 \%$ and $61.8 \%$, respectively (Belbeisi, Al Nsour et al. 2009). Overall, this amounts to $40 \%$ of adults in Jordan having smoked at least 100 cigarettes previously. The prevalence of current smoking was reported to be $5.1 \%$ for women and 48.2 for men (Belbeisi, Al Nsour et al. 2009).

In the same study above Global Youth Tobacco Survey (GYTS) was conducted in 1999 as well. This survey showed that $22.9 \%$ of students between the ages of 13 and 15 (25\% of male and $14.5 \%$ of female students) are smokers. Also the GSHS Global school based student health survey conducted in 1999, 2004 and in 2006 showed that the prevalence of smoking among youth (13-15) is $18 \%, 19.9 \%$ and $24.9 \%$ respectively 
Across all adults, the prevalence of tobacco use has been reported to be $36 \%$, which is higher than every other Eastern Mediterranean country measured by the WHO, including Afghanistan, Egypt, Iraq, and Saudi Arabia, among others (World Health Organization 2009). A different survey by the Jordanian Ministry of Health reported that the prevalence of smoking increased from 27 to $29 \%$ from 2005 through 2007, among Jordan's population of 5 million people (World Health Organization 2008). Moreover, Jordan ranks $17^{\text {th }}$ with respect to the prevalence of tobacco use among countries for which data are available. It is tied with Cuba, Estonia, Lithuania, and Turkey for the $17^{\text {th }}$ ranking. In this category, Greece ranks first, with $51 \%$ of the population being smokers (World Health Organization 2009).

The smoking prevalence in Jordan has also been studied in sub-populations. Several studies of youth in Jordan indicate that the prevalence of smoking is high in this population, which is an indicator of when people in Jordan initiate smoking. In 2000, the Global Youth Tobacco Survey (GYTS) was used to analyze youth tobacco habits in 13 countries worldwide, with Jordan being one of them. The GYTS is a tool developed by the CDC and the WHO to measure smoking prevalence and attitudes among 13 to 15 year-olds. In this study, $16.6 \%$ of children in Jordan surveyed currently smoked cigarettes and $11.2 \%$ used other tobacco products. In the other countries included in the study, the prevalence of current smoking ranged from 10 to $33 \%$, indicating that Jordan is in the middle of the spectrum, with respect to youth tobacco use. (Warren, Riley et al. 2000). 
Global Youth Tobacco Survey (GYTS) was conducted in 1999 as well. This survey showed that $22.9 \%$ of students between the ages of 13 and $15(25 \%$ of male and $14.5 \%$ of female students) are smokers. Also the GSHS Global school based student health survey conducted in 1999, 2004 and in 2006showed that the prevalence of smoking among youth(13-15) is $18 \%, 19.9 \%$ and $24.9 \%$ respectively The prevalence of smoking in Jordan among adult 18 and above is estimated to be $28 \%$ according to the Behavioral risk Factor Surveillance System in 2007 (BRFS).

The most studied population in Jordan is university students. Madanat and colleagues conducted a pilot study of 296 students at the University of Jordan to examine attitudes and knowledge of smoking policies and hazards. Most participants $(70.3 \%)$ had never smoked but more than one-fourth of respondents were current smokers, suggesting that the prevalence of smoking is still quite high in university students (Madanat, Barnes et al. 2008). These findings confirm those reported in earlier studies of college studies. The first included 650 students at the Jordan University of Science and Technology. The investigators reported the prevalence of smoking to be $28.6 \%$ (50.2\% among males and $6.5 \%$ among females) (Haddad and Malak 2002). The next study, a cross-sectional analysis of 400 students at the same university (the Jordan University of Science and Technology), assessed the perception of lung cancer and smoking among students. The prevalence of smoking in this study was quite a bit lower than that reported in other studies. Of students surveyed, 16.5\% were current smokers. Astoundingly, more than $90 \%$ of respondents were at of cancer risk associated 
with air pollution, but only $57.5 \%$ acknowledged second-hand smoking as a cancer risk (Kofahi and Haddad 2005). The highest rate of smoking was reported by Khader and Alsadi, who surveyed 712 university students in north Jordan. The authors found that $35 \%$ (56.9\% males and $11.4 \%$ females) currently smoke (Khader and Alsadi 2008). Several conclusions were drawn by the authors of these various studies. All authors directly or indirectly suggested that a reduction in smoking among university students is desirable and that policies to limit smoking may benefit these individuals and those exposed to second-hand smoke. In addition, some authors concluded that students with more accurate perceptions of the health consequences of smoking were less likely to smoke than their counterparts. Therefore, education may be a useful tool in reducing the prevalence of smoking among university-aged individuals in Jordan.

Among Jordanian university students, water-pipe (Narghile) smoking is also highly prevalent. A study of 548 students at four different universities in Jordan found that $61.1 \%$ of respondents had smoked tobacco from a water pipe, with $42.7 \%$ using a water pipe at least monthly. In this study, women were approximately 10 times less likely to use the water pipe than men (odds ratio $=$ 0.11, 95\% confidence interval $=0.07-0.17$ ) (Azab, Khabour et al. 2010). The authors of this study concluded that water pipe smoking is prevalent in Jordan and is associated with male gender and upper middle-income levels. A different crosssectional study of water pipe smoking among university students found that $36.8 \%$ of individuals surveyed were current water pipe smokers. Of these smokers, $61.9 \%$ were male and $10.7 \%$ were female. Of note, $42 \%$ of men in the 
study sample stated that cigarettes and the water pipe are both preferred methods of smoking. In contrast, $53 \%$ of women prefer the water pipe only (Dar-Odeh, Bakri et al. 2010).

Studies evaluating tobacco use among women specifically have confirmed the propensity for water pipe smoking among Arab women. In the Arab culture, it is becoming more acceptable for women to use Narghile than cirgarettes, especially in more conservative societies. In a review of 7 studies evaluating Narghile smoking in Arabic states, the prevalence of Narghile use among young females ranged from $0.2 \%$ in Tunisia to $37.8 \%$ in Egypt. The prevalence in Jordan was reported to be 19\% (Dar-Odeh and Abu-Hammad 2011). These high rates of Narghile use potentially reflect a belief that Narghile has fewer health risks than cigarettes. However, Narghile use has been associated with chronic obstructive airway disease, cardiovascular effects (eg, hypertension), esophageal cancer, bladder cancer, and pancreatic cancer.

Despite the established risks of cigarette and Narghile smoking, studies of health care workers indicate that even people well versed in the detrimental effects of tobacco are prone to smoking in Jordan. In a study conducted at King Hussein Medical Center that included 760 healthcare workers, the prevalence of smoking was reported to be $65 \%$. This number is nearly double the prevalence of the overall Jordan population that is reported in most studies. With respect to various physician subgroups, $75 \%$ of family practitioners working in the emergency department smoked, compared to $44 \%$ of internests, $10 \%$ of dermatologists, and 
0\% of pulmonologists (El-Khushman, Sharara et al. 2008). Among nurses, 49\% of men and $17 \%$ of women were current smokers. These results were confirmed in studies of only nurses as well. According to cross-sectional survey of 266 nurses in Amman, Jordan, $42 \%$ of male nurses smoke, compared to $13 \%$ of female nurses. These prevalences are slightly higher than those reported in the overall Jordanian population, listed above. Interestingly, while nurses who participated in this study favored anti-smoking policies, they did not necessarily agree that nurses should council patients about quitting smoking (Merrill, Madanat et al. 2010). Of note, a cross-sectional study of 251 physicians from public and private hospitals suggests that the prevalence of smoking among physicians is actually much lower. In this study by Merrill and colleagues, $22.4 \%$ of male and $9.1 \%$ of female physicians smoke. Strikingly, this study also

questioned participants about smoking in front of patients, with $29.1 \%$ admitting to smoking in front a patient at least once. Overall, physicians seem to be more aware of the health consequences of smoking, but less than 1 in 5 have received formal training about counseling patients to quit smoking (Merrill, Madanat et al. 2006).

\subsection{Health Consequences of Tobacco Use}

The morbidity and mortality associated with tobacco use is well established, though the general public is not always aware of these detrimental effects. In 2010, 5.4 million people died due to tobacco-related diseases worldwide (World Health Organization 2009). Without efforts to lessen tobacco use, the WHO estimates that more than 8 million deaths in 2030 will be related to tobacco use, 
and 6.4 million of these deaths will occur in developing countries (World Health Organization 2009).

Tobacco is a major risk factor for many chronic diseases. Smokers are more likely to have diabetes, chronic obstructive pulmonary disease, and asthma than nonsmokers (Schroeder and Warner 2010). Fertility and birth outcomes also may be impacted by tobacco use, including second-hand use. In a study of 804 adult smokers, 530 of whom were men, semen quality was found to be greatly reduced in smokers versus non-smokers. Sperm concentrations and motility were significantly lower in smokers $(P<0.001$ for both comparisons) (Al-Matubsi, Kanaan et al. 2011). Furthermore, lower birth weights have also been associated with tobacco use. In a study of the association between second-hand smoking and birth weight, Abu-Baker and colleagues found that a correlation exists between exposure to second-hand smoke and the incidence of low birth weight infants (Abu-Baker, Haddad et al. 2010). Tobacco is also the most important risk factor for lung cancer, with cigarette smoking increasing its risk of development by up to 25-fold (Al-Kayed and Qasem 2006). Other cancers that have been linked to tobacco include oral cancer, head and neck cancer, kidney cancer, bladder cancer, and pancreatic cancer.

Smoking water pipes has also been linked to many adverse health outcomes, include the development of cancer. Some research has focused on the impact of Narghile smoking on oral health, although for the most part, these studies are quite scarce. Periodontal bone loss and dry socket have been described in some 
dental studies, as has oral cancer (Dar-Odeh and Abu-Hammad 2009). However, well-controlled studies have yet to rigorously test the suggested relationship between Narghile smoking and health consequences. Therefore, further study of this topic is warranted (Maziak 2008; Chaouachi and Sajid 2010).

\subsection{Overview of Economics of Tobacco Use in Jordan}

Due to the well-established mortality and morbidity associated with tobacco use, the economic consequences of tobacco use-mostly related to healthcare costs and loss of productivity—are substantial.

Jordan has one of the smallest economies in the Middle East (Central Intelligence Agency 2010) and is plagued by poverty, inflation, unemployment, and a large deficit. Although some measures have been taken to improve the economy over the past decade, the dismal global economy has stunted Jordan's growth. Its per capita GDP is US\$5,300. Jordanians spend 250 million JOD or close to US\$356 million on cigarettes and other tobacco products each year (Belbeisi, Al Nsour et al. 2009). Tobacco consumption is on the rise, with the number of cigarettes smoked increasing from fewer than 3.7 billion to nearly 4 billion throughout the 1990s, as illustrated below (US Dept of Agriculture 2010).

In 2009, Jordan imported approximately 50.6 million JOD of tobacco and manufactured tobacco substitutes (US\$35.8 million) and exported around 26 million JOD (US\$18.4 million) of the same product. Imports have risen over time since 1994, whereas exports have risen from 1994 until 2006, when it began to 
decrease. A sharp decrease in exports occurred in 2005 (Department of Statistics, Jordan) as illustrated in figure 1 and 2, Appendix A.

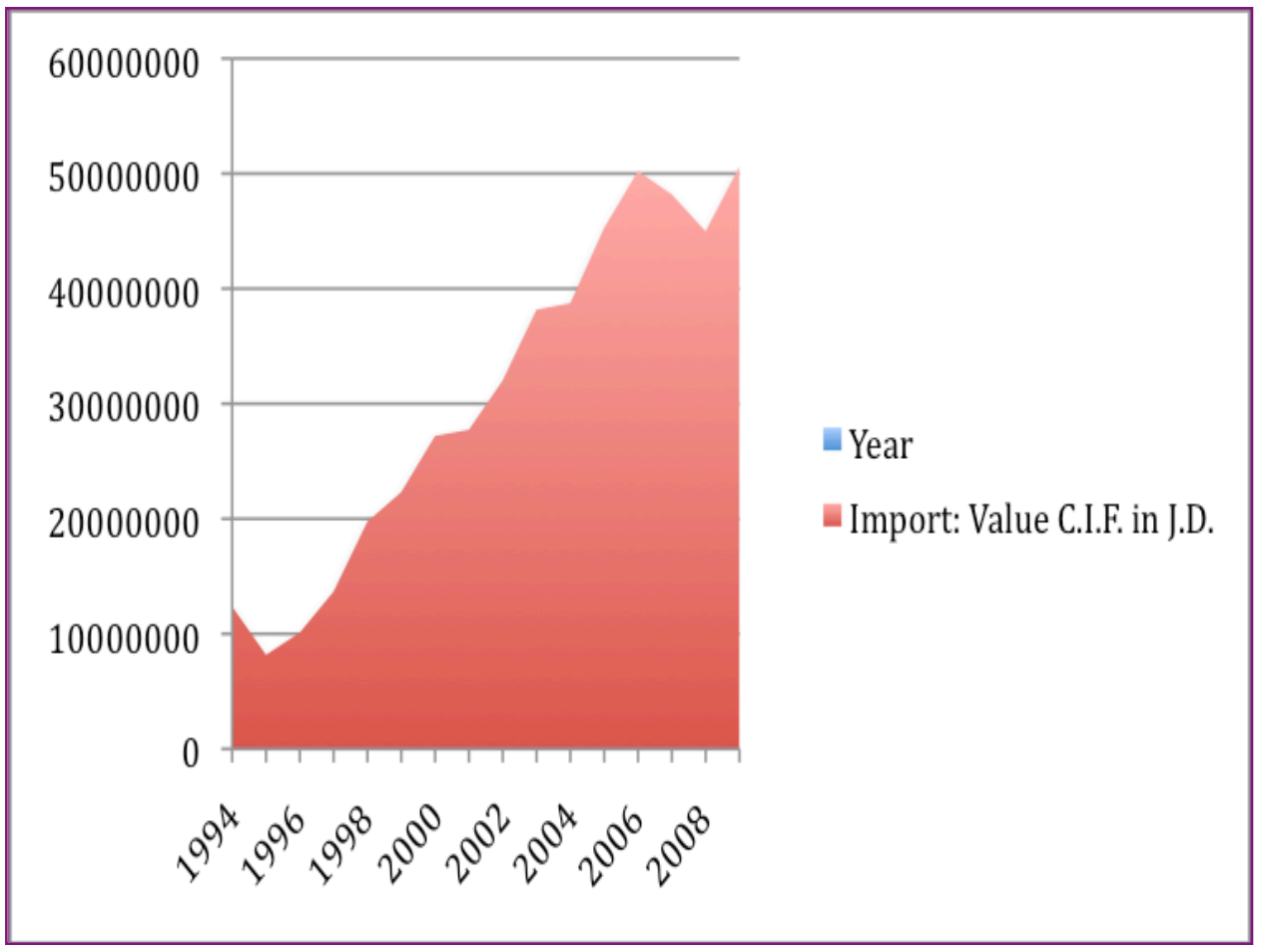

Figure 1. Tobacco and manufactured tobacco substitutes imports value in Jordanian Dinar 


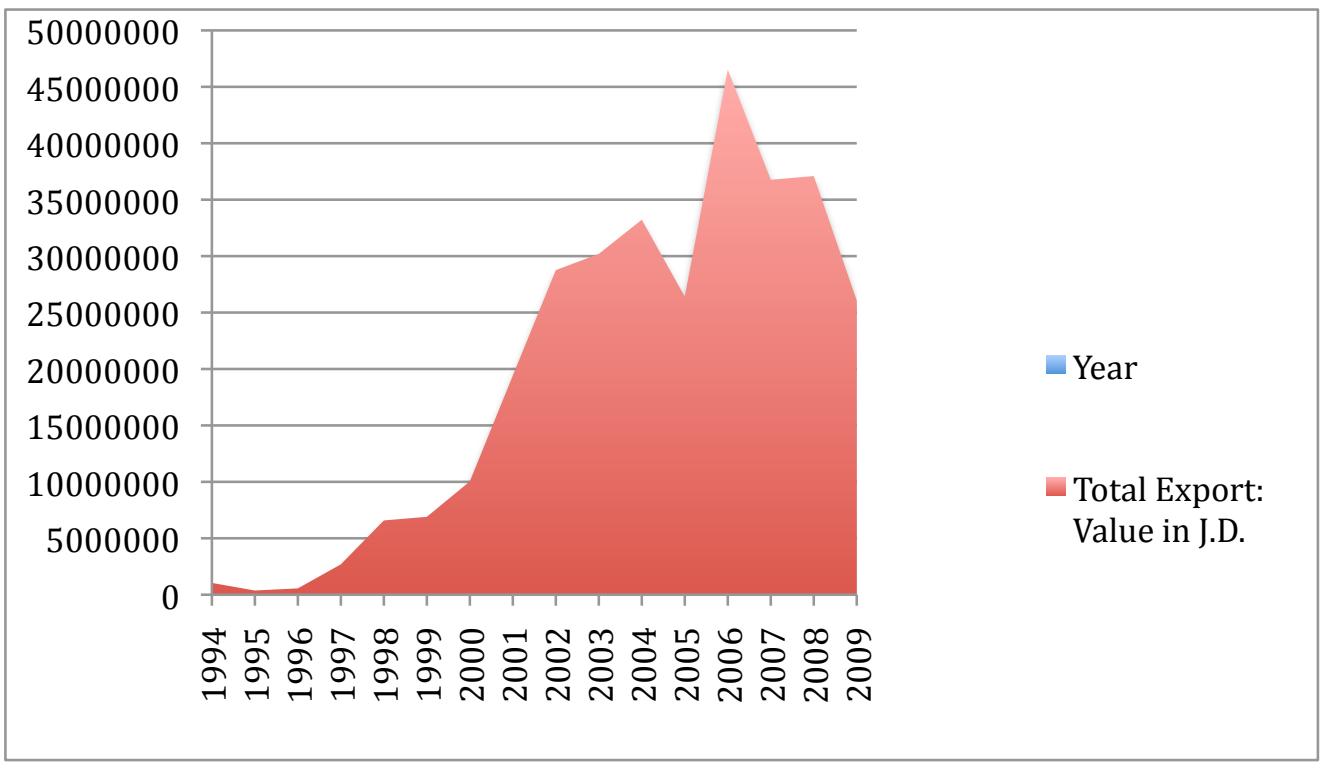

Figure 2. Tobacco and manufactured tobacco substitutes exports value in Jordanian Dinar

\subsection{Cigarette costs and taxes in Jordan}

Microeconomic theory dictates that several factors influence cigarette demand. Importantly, numerous studies have repeatedly shown that increasing cigarette price negatively influences their demand. That being said, the supply and demand of tobacco products are affected by the addictiveness of nicotine in cigarettes (Chaloupka 1999), adding a layer of complexity to my analyses. Current estimates indicate that the price elasticity of demand for cigarettes is around -0.4 for developed countries and between -0.4 and -0.8 for developing countries, like Jordan. Although studies in Jordan have not been performed, it has been 
suggested that younger adults and teenagers may be more sensitive to price increases. Accordingly, price elasticity of demand may be as much double that for adults in younger individuals. These findings suggest that increases in the prices of tobacco products may be particularly effective in preventing smoking initiation in children, adolescents and young adults (Chaloupka 1991; Grossman and Chaloupka 1997).

Related to the price of tobacco products affecting their demand is income level. Those with higher disposable incomes are less likely to be affected by increasing cigarette prices than those with lower incomes. This variable will not be explored in this dissertation.

In addition to the price of tobacco products and income, several other factors also influence demand. For example, prices of related products that can substitute for cigarettes may be used instead of cigarettes if they are cheaper. Also affecting tobacco demand are personal preferences. Specifically, if a person prefers one brand of cigarettes or other tobacco products over another, the demand for that brand will be much higher for that particular person. Although it is worthwhile to note that personal preference can influence demand, this variable is difficult to measure and will not be explored in this dissertation.

Recall from the introduction of this dissertation that a pack of cigarettes in Jordan currently costs approximately US\$0.98 for domestic brands and US\$1.90 for imported brands (World Health Organization 2010). For all imported brands, import taxes amount to $100 \%$ of the price of the pack, effectively doubling the price of these cigarettes, before any other taxes included in the price. Added to this price (for domestic and imported brands) is a general sales tax of $20 \%$, which 
applies to all cigarette packs. Sales and excise taxes, 0.30 and $0.38 \mathrm{JOD}$, are also levied (World Health Organization 2010). In June 2010, the Jordan government announced that they would increase taxes on luxury items in order to address their country's largest ever budget deficit (Obeidet, 2010). With this measure, cigarette packs will each be taxed an additional 50 fills. The percentage change in prices of cigarettes in Jordan is shown below. In 2006, the largest change occurred, with a $15.24 \%$ increased in price noted as shown in figure 3,Appendix A.

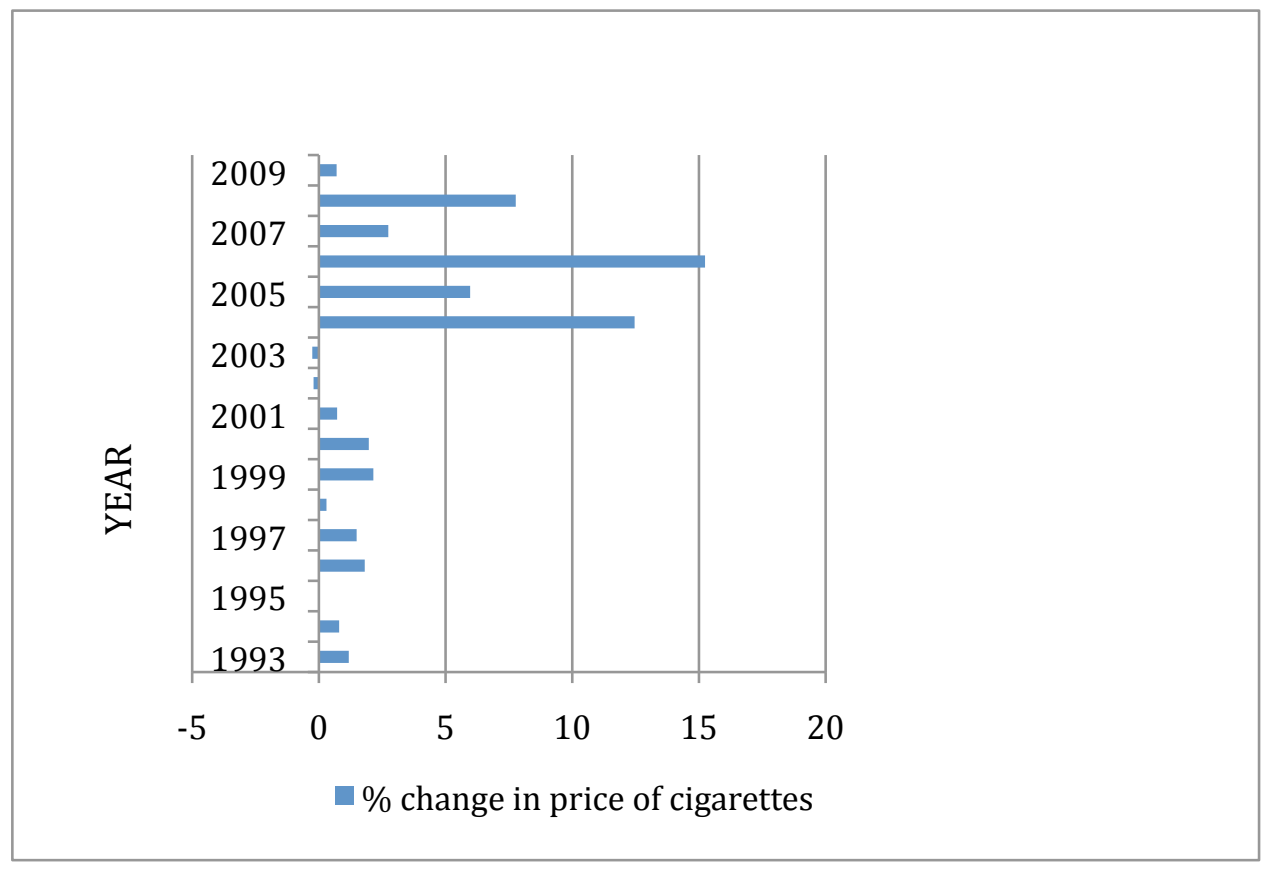

Figure 3. Percentage change of price of cigarettes in Jordan 


\subsection{Cigarette Demand}

As already mentioned, microeconomic theory dictates that cigarette price, income, prices of related products and personal preferences influence the demand of tobacco products. Demand also is influenced by legislative actions. For example, smoking restrictions are in place in many public places in Jordan. Evidence from other countries indicates that restrictions do force people to smoke fewer cigarettes per day. For example, in a survey of Californian residents in 1990, 18\% of smokers were "heavy" smokers. As of 2005, this number has dropped down to $7 \%$ of smokers being "heavy" smokers. One potential explanation for this 2.5 -fold decrease in heavy smoking is that California is now smoke-free. Similar analyses have not yet been performed in Jordan.

Also affecting cigarette demand are market and counter-marketing advertisements for tobacco products. Studies have shown that advertising cigarettes does increase their sales. Therefore, a means to counter this increase is to limit the amount of advertising tobacco companies are allowed to do. In fact, econometric analyses indicate that restricting cigarette advertising may decrease cigarette use by as much as $6 \%$ (Chaloupka 1999). Complementing these counter-marketing campaigns is the Global Task Force on Expanded Access to Cancer Care and Control in Developing Countries and similar organizations. This task force, created at Harvard Medical School, is dedicated to evaluating ways to prevent new cancers, including through tobacco control via education and other methods (Farmer, Frenk et al. 2010). 
More recently, increasing the size of warning labels on cigarette packaging has garnered attention as a possible mechanism to reduce the prevalence of smoking and persuade young individuals to remain tobacco-free. Currently, Jordan requires warning label to cover $50 \%$ of area of the cigarette pack size. The WHO's FCTC only requires that $30 \%$ of the pack be covered, but Jordan's laws are more strict. Furthermore, Jordan legislation also stipulates that the warning must include a picture in addition to words, in order to appeal to any person who may not be able to read and to children (Belbeisi, Al Nsour et al. 2009). Of note, no WHO TCTC compliant warning labels currently exist for water pipes, according to a recent study that evaluated the warning labeling on narghile water pipe tobacco products. Given the high, and potentially growing prevalence of water pipe use in the Arabic culture, particularly among women, adding such warning labels may help educate individuals about the detrimental health effects of narghile, and thus curb smoking (Abu-Baker, Haddad et al. 2010).

Given that multiple interventions are now in place to restrict the use of tobacco products in Jordan, studying the demand and elasticity of tobacco is essential. Not only will such an analysis provide insight into the magnitude of the tobacco epidemic in Jordan, it will also allow the success of current interventions to be measured. It is my hope that interventions currently in place will help reduce the prevalence of tobacco use in my home country and motivate young people to remain tobacco free. 


\section{METHODOLOGY}

The Hashemite Kingdom of Jordan is an upper middle-income country with a population of 6 million and a per-capita GNI of US $\$ 4,350$ (World Bank 2010). As mentioned in previous chapters, I used the Global Adult Tobacco Survey (GATS), developed by the WHO's and CDC's Global Tobacco Surveillance System to conduct my analysis of tobacco and cigarette use in Jordan. This crosssectional household survey aims to produce national-level estimates of indicators of interest by gender, age group, education, work status and region. This survey has been used worldwide to collect information on tobacco and is considered a standardize tool to collect such information (Global Tobacco Surveillance System (GTSS) 2010). By using the GATS protocol, I created a version of the GATS specific to Jordan in both English and Arabic listed in Appendix A.

\subsection{Study population}

The target population for the GATS in Jordan included men and women aged 15 years and above. Sixty-three (63\%) of the total population is over the age of 15 years according to most recent Jordanian census conducted in 2010. The percentage distribution of the total population by sex is $51 \%$ men and $49 \%$ women. A minimum total sample of 4000 households was required by the CDC to represent this target population in Jordan. To fully understand the use of tobacco in both urban and rural communities, 8000 household surveys must be conducted. Due to time and money constraints, my analysis provides an estimate for the 
region, based on a planned minimum of 4000 household surveys, without accounting for urban versus rural differences, to be collected from those residing in all Jordanian governorates. All individuals aged 15 years and over in private households, who considered the household to be their primary place of residence the night before the survey was conducted, were eligible to complete the GATS. Foreigners, military and other institutionalized populations were excluded from the sample.

\subsection{Sample design}

The sample for the GATS was selected by using a multistage, geographically clustered design. In a multistage sampling technique subsamples are selected from previously selected sample until we reach the final sample unit to be selected as described below.

In selecting the sample, we took into account the following as was suggested by the sample design manual by the world health organization ( World Health Organization 2010):

1- To randomize our selection, we took into account that every member of the target population has a non-zero probability of being selected in the sample.

2- The probability of selection for every household is known so it can be used later when adjusting for clustering and calculating the weight and relative weight variable

In conducting the GATS, all 12 governorates in Jordan were included. Taking anticipated non-response and non-eligibility into consideration; the sample size 
was calculated to be 4820 households which would allow us to gather enough information from the GATS to conduct this analysis. This sample size was calculated with guidance from the GATS sample design manual, which states that at least a sample size of 4000 completed respondent questionnaires was required, with 2000 each for men and women (World Health Organization 2010). It also allowed generation of estimates that met the expected precision requirements of GATS. In addition, this relatively large national sample included proportional sample of reasonable sizes for smaller governorates (World Health Organization 2010).

In the first stage of identifying the research sample, a subsample of 12 governorate areas (the primary sampling unit) was selected.

In the second stage, all districts in the 12 governorate were selected, a total of 51 districts. In the third stage, a total of 65 sub-districts were selected randomly from districts. In the fourth stage, a total of 113 zones were selected randomly from sub districts. In the fifth stage, a total of 185 areas were selected randomly from zones. In the sixth stage, a total of 193 blocks were selected randomly from areas. In the final stage, the seventh stags, and final stage we systematically selected households in each block while taking into account the weights of each block to the total number of households in the area and the total sample to be taken from each governorate.

By following the method of probability proportionate to size, 193 blocks were selected randomly from sub-districts, from which to choose households to survey. A map showing the number of households available in each block was used to 
guide surveyors to appropriate households. In the final stage of the sample selection process, a weighted average of households was selected systematically from each area of 193 blocks (secondary sampling unit) to yield a total sample size of 4820 households.

Selected households in all segments were randomly designated as male or female in a ratio that produced equal numbers of male and female respondents. Designating houses as male or female also enabled male or female interviewers to determine which house should they select. In Jordan, honest responses from women and men are more likely to be obtained when the interviewer is of the same sex as the person being interviewed. Once households were chosen, one eligible individual aged 15 years old or older was selected randomly using the KISH table available in the survey. To use this table, use the last number of the questionnaire ID is found in the table that correlates with the number of households in the block with persons over the age of 15 . For example, assuming the questionnaire ID number is 12051 and number of household aged 15 and above is 5 then we check the number that cross with 5 and 1 . According to the table its number 2, then number 2 in the list of individuals aged 15 and above in the household is chosen as the interviewee. If the house is designated as male, only those individuals who are male and aged 15 and above are eligible in the selection process.

\subsubsection{Adjusting for clustering}


Cluster sampling is a technique in which all the entire population of interest is divided into groups, or clusters, and a random sample of these clusters is selected. In cluster sampling, the clusters are the primary sampling unit (PSUs) and the units within the clusters are the secondary sampling units (SSUs). It is important to keep these two levels in mind when calculating standard errors from cluster samples.

Most large national surveys involve both cluster and stratified samples (Johnson, Illiott,L 1998)

Usually standard errors are small when not adjusting for clustering and leads to incorrect inference. We used the STATA software to correct for clustering, as it is related to weighting and subsamples. The Taylor series was used to account for this problem.

\subsubsection{Weighting of variables:}

In order to adjust for clustering two variables were created

1- Cluster variable: which includes a number of the block a household was selected from.

2- Relative weight variable: that is the mean weight for individuals multiplied by the weight for each individual. The weight for each individual is the reciprocal of the probability of selection in strata $i$. The probability of selection in strata $i$ is the number sampled from strata i divided by the total population in strata i.The above calculation was estimated as below: 


$$
\begin{aligned}
& \mathrm{Ni}=\text { total population in strata } \mathrm{i} \\
& \mathrm{ni}=\text { number sampled from strata } \mathrm{i} \\
& \mathrm{fi}=\text { probability of selection in strata } \mathrm{i}=(\mathrm{ni} / \mathrm{Ni}) \\
& \mathrm{wi}=\text { base (expansion) weight in strata } \mathrm{i}=(\mathrm{Ni} / \mathrm{ni})=1 / \mathrm{fi} \\
& \mathrm{w}=\text { mean expansion }(\text { base }) \text { weight }=\left[\sum(\mathrm{wi})(\mathrm{ni})\right] / \mathrm{n} \\
& \mathrm{rwi}=\text { relative weight }=[(\mathrm{wi}) /(\mathrm{w})]
\end{aligned}
$$

\subsubsection{Assessment of interviewer differences in measurements}

Fifty students helped conduct the survey. In an assessment of potential interviewer differences in responses and to see whether or not the interviewer has a personal effect in getting the information, I created a variable called interviewer variable in which a number was assigned for each interviewer and that number was assigned again to the survey conducted by that interviewer.

A test called Itraclass Correlation (ICC) was used to assess the consistency or reproducibility of quantitative measurements made by different observers measuring the same quantity. The two variables used were the interviewer and the decision to smoke which was one of the main variables in our study.

The Rho value is equal to 0.0055 and suggests that there is little interviewerrelated effects.

\subsection{Questionnaire and definitions}

\subsubsection{GATS questionnaire}


The GATS questionnaire consists of two main questionnaires: Household and individual questionnaires. Each questionnaire has a core set of questions, which all participating countries administer. In addition, optional questions can be included, depending on the cultural norms in the country of interest (Global Tobacco Surveillance System (GTSS) 2008).

The Jordan household questionnaire provides information about the household members who considered the selected household as their primary place of residence the night prior to the survey date. It also collects information about the number of household members 15 years of age and older eligible to be interviewed.

For this project, we also used a Jordan individual questionnaire, which included the core GATS questions. These core questions ask about tobacco prevalence and consumption, cessation, exposure to second-hand smoke, media and advertising exposure, economics, and knowledge, attitudes and perception. Due to the prevalence of Argileh use in Jordan, a module for this particular product was also developed. The core questionnaire consists of eight sections (A-H), one of which was not included in this analysis, as described below.

Section A collects information about background and demographic characteristics. Questions ask about gender, age, education, work status, and possession of household items. In the Jordan questionnaire, this section has been modified to account for education level and work status. 
Section B inquires about tobacco use. Questions specifically ask about daily consumption, less than daily consumption, or no consumption at all. It also asks about past tobacco consumption, age of initiation of daily smoking, consumption of different tobacco products (cigarettes, pipes, cigars, or shisha), nicotine dependence, and frequency of quit attempts. Within section B, we added section WP, which questions respondents about shisha smoking. In particular, this section inquires about shisha smoking frequency/session, duration, number of hagar (ras) smoked per session, and the different places where Argileh is smoked.

The GATS has a section $\mathrm{C}$, which is devoted to smokeless tobacco. For the purposes of the Jordan-specific questionnaire, this section has been deleted since smokeless tobacco is not available in Jordan. Also any question that involves smokeless tobacco was eliminated from the questionnaire.

Section D collects information about tobacco cessation. This section includes questions about whether or not healthcare providers have provided advice about how to quit smoking, method used to try to stop smoking, and reasons for attempting to stop smoking.

Section E focuses on second-hand smoke. This section includes questions on smoking rules and exposure to second-hand smoke at home, smoking policies at one's workplace, exposure to second-hand smoke in the workplace over the past 30 days, and second-hand smoke exposure in government buildings/offices, 
health-care facilities, restaurants and public transportation. For the purposes of the Jordan survey, optional questions about exposure at schools, universities, and bars were included.

Section F includes questions about the economics of tobacco use in the country of interest. Questions pertain to the common brands of cigarettes smoked in Jordan and the quantity bought. Also included are questions about the cost of tobacco product(s), type of product(s) purchased, and source(s) of tobacco products.

Section $G$ focuses on tobacco in the media. This section includes questions on exposure to pro- and anti-tobacco media, such as advertisements on television, radio, billboards, public walls, and at sporting events. Exposure to tobaccopromotion activities, including free cigarettes, coupons, mails and e-mails, is also included. Reaction to health-warning labels on cigarette packages and exposure to anti-tobacco advertising and information are also questioned. In addition, the Jordan-specific survey included media questions about shisha.

They final section, section $\mathrm{H}$, focuses on knowledge, attitudes and perceptions of tobacco. This section includes questions about the knowledge of health effects of both smoking cigarettes and shisha among Jordanians. Information about beliefs related to religious anti-smoking rules is also collected.

\subsubsection{Data Collection}


To collect data from Jordanian households, a total of 50 Jordanian students served as surveyors. All surveyors were trained using the University of Illinois collaborative institutional training initiative CITI training on obtaining informed consent and the ethics of research. In addition, each question included in the survey was explained in detail to ensure complete understanding of the survey questions. Subsequently, every surveyor was asked to respond to all the questions on the survey. In doing so, the degree of knowledge of each surveyor and their capability of conducting the survey was assessed.

All surveys were conducted face-to-face using pen and paper.

UIC Institutional Review Board (IRB) approval was obtained and two copies of consent forms were given to respondents - one to keep and one to sign. Consent forms are shown in Appendix A in both languages, English and Arabic.

\subsubsection{Training provided to students}

When obtaining the institutional review board (IRB) approval the principal investigator and the key personnel were required to meet the initial training requirements in human subjects protection before conducting the research.

The investigator and the 50 students selected as surveyors took the online sessions provided by collaborative institutional training initiative CITI. The following courses were the minimal requirement for an IRB approval:

1- The basic course: which covers the ethical principles of research and regulations about human subject protections. It requires three to six hours to complete. 
Acertificate is given upon the completion of the course. Explanations in Arabic were provided to those students who are fair in English.

2- HIPAA training course: since some of the questions in the GATS inquire about visiting a physician in last 12 months, a health insurance portability and accountability act HIPAA privacy rule provides additional protection for protected health information. Thus a HIPAA online course was required to be taken by the Principal investigator and the key personnel as well.

3- Obtaining Effective Informed Consent: This course includes an overview of the historical issues and problems that led to the current regulation to obtain consent form. It explains the way consents should be obtained to enhance the way a research is done and make sure that personal information will be kept private and confidential. This course was taken by the principal investigator and the students and they obtained certificates upon the completion of the course.

All certificates were submitted to the IRB as a major requirement to obtain the final approval.

Participating in this study marked the first time many of the students interviewers were involved in such training. It added a lot to their experience and knowledge.

\subsubsection{Data Entry and statistical softwares used}

The data was entered into an excel sheet by the principal investigator (PI). The data were doubled checked by the PI to make sure the data was entered correctly. Also a $10 \%$ of the surveys were re-selected randomly and rechecked to find out the entry error.

The error was $0.16 \%$ (a total of 153 errors). 
The researcher used three different software to analyze the data: Excel, SPSS, and STATA. 


\section{DATA AND STATISTICAL ANALYSIS}

\subsection{About the Survey}

The Global Adult Tobacco Survey (GATS) was used to gather information about tobacco use in Jordan from July 2011 until September 2011. The GATS was developed as part of the Global Tobacco Surveillance System (GTSS) to provide a standardized method for monitoring global tobacco use. National and subnational estimates of the following variables can be made using the GATS: Tobacco use, exposure to second-hand smoke, and quit attempts. The intention of the GATS is to help countries develop tobacco control and prevention programs and measure their success or failure. The GATS is available on the Center of Disease Control CDC website for public use.

The GATS is a household survey for adults of ages 15 years and older. As mentioned earlier, it uses a standard and consistent core questionnaire to evaluate tobacco use while also gathering demographic information and perceptions about tobacco use. The GATS Core Questionnaire was constructed by tobacco control and survey design experts and has undergone rigorous development and testing (Global Tobacco Surveillance System (GTSS) 2010).

For this research, the GATS was used as a tool to obtain information from Jordanian individuals about tobacco use. To our knowledge, the GATS has never been used in Jordan, and the only Middle Eastern country with GATS results reported is Egypt. 
In designing this research project, we planned to conduct GATS interviews in approximately 4820 households. We planned to interview one individual in each household. The overall response rate to the GATS survey in Jordan 93.9\%. The response rates were $91 \%$ and $96.8 \%$ for males and females, respectively. Relative response rates for the various governates are shown in Figure 4. As illustrated, the highest response rate was obtained in Amman, the capital of Jordan, which is a centrally located governorate. The lowest response rate was $77.6 \%$, which was obtained in Tafelieh, a southern and underserved governorate in Jordan.

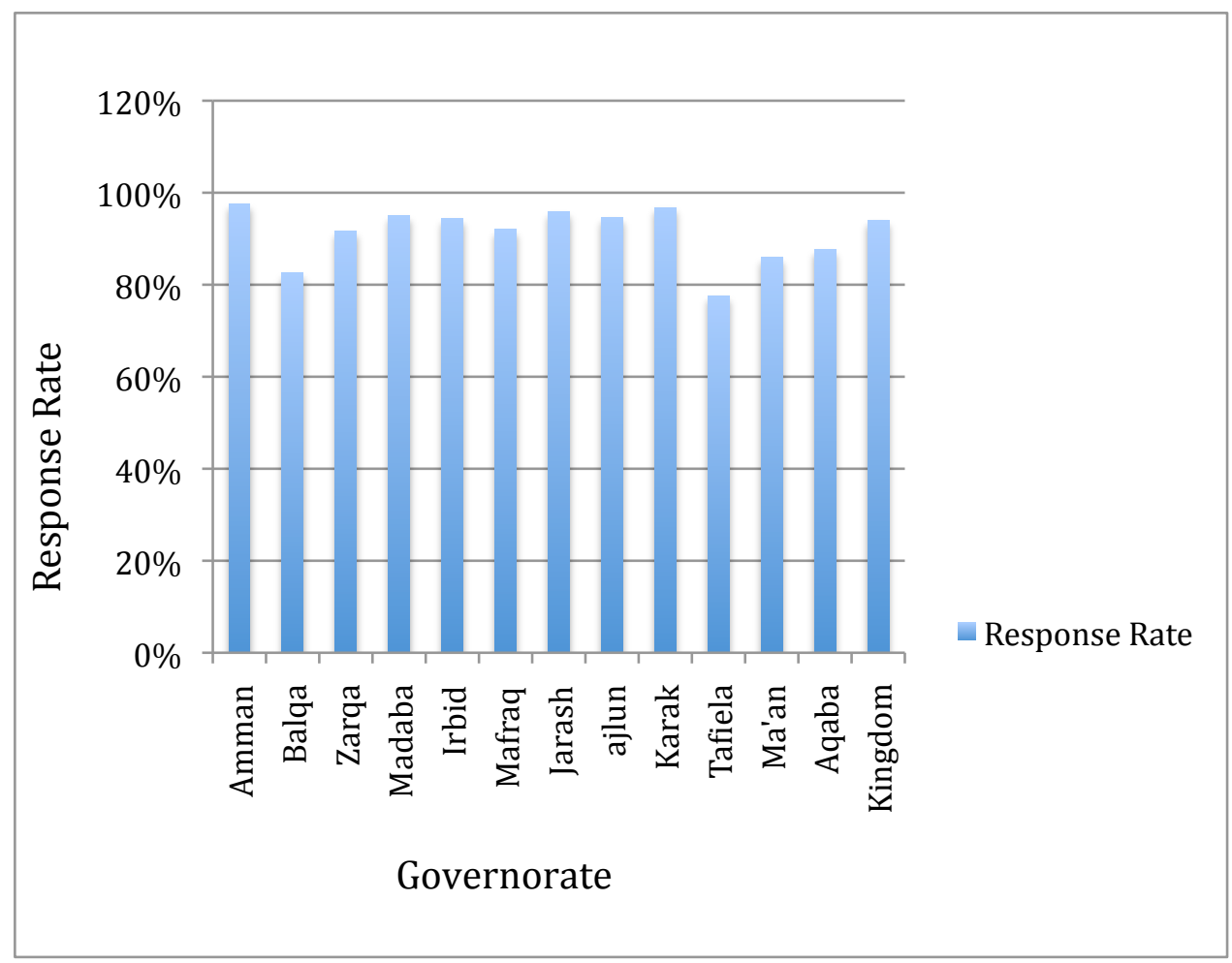

Figure 4 . The response rate by governorates and country level (Kingdom) 


\subsection{Household Questionnaire}

The household questionnaire illustrated in Appendix A obtains demographic information about the persons being interviewed, including information about their households. The average number of individuals living in the houses surveyed was 4.5. An average of 3.1 individuals in each household was 15 years old or older, of which 1.7 individuals were males and 1.4 was females as shown in figure 5.

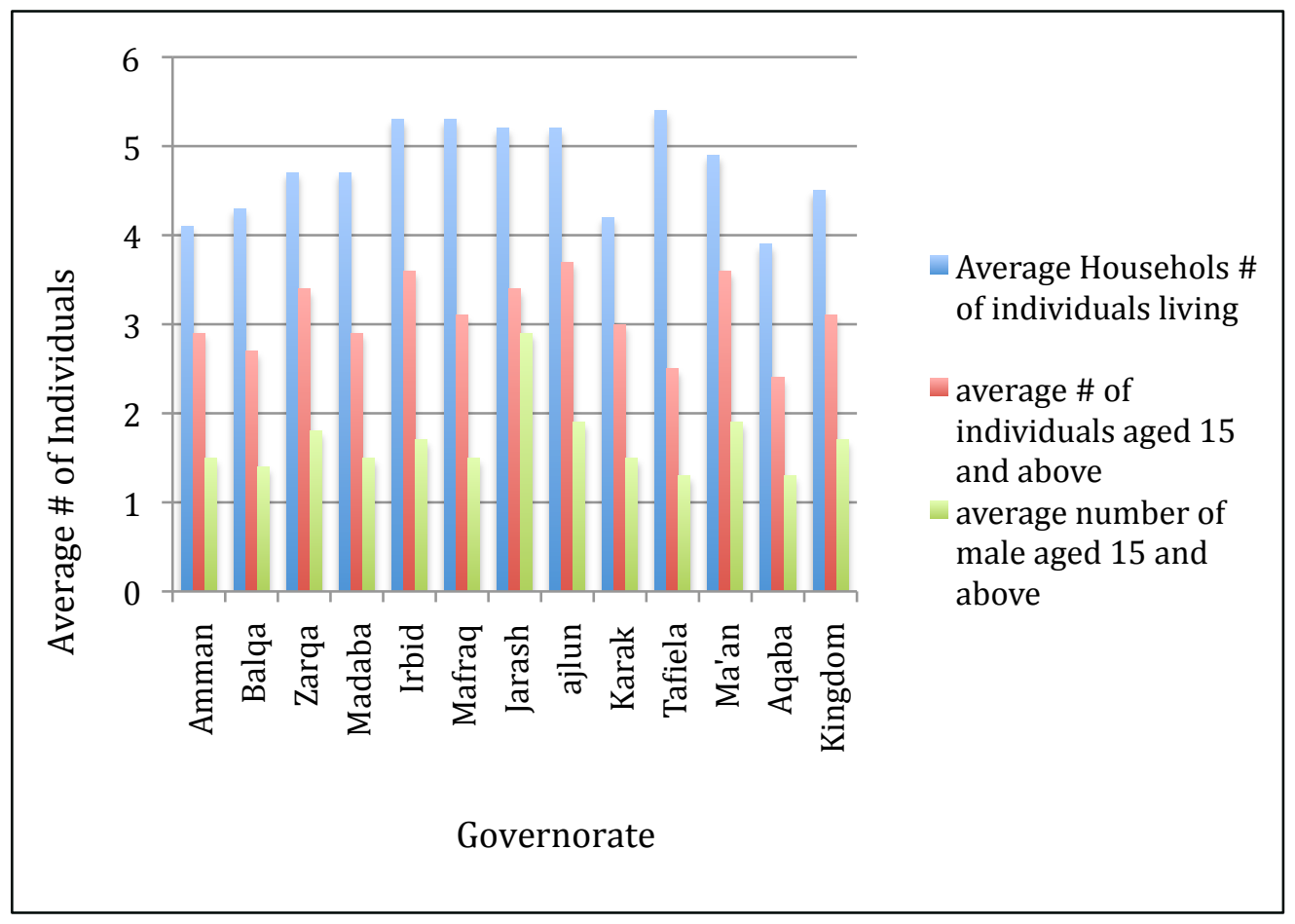

Figure 5. Average number of individuals, and average number of males individuals aged 15 years old and above living at home 
With respect to the actual person interviewed, the average age was 33.2 years. The average age of female and male respondents was 34.8 and 32.2 years, respectively.

\section{$\underline{4.3 \text { Individual Questionnaire }}$}

\subsubsection{Tobacco use by frequency, type, education, work status, and gender}

\subsubsection{Frequency}

The toolkit for Economic Analysis Using the GATS (World Health Organization 2008) was used to analyze the data from individual questionnaire. Several different methods of using tobacco exist in Jordan, including cigarettes, water pipe (Argileh in Jordan; Hooka in the USA), cigars, hand-rolled cigarettes (Hishi), and pipes. Smokeless tobacco is not used in Jordan thus it was not included in this study.

After obtaining demographic information with the Household Questionnaire, the Individual Questionnaire was used to gather tobacco use statistics. We found that $42.2 \%$ of individuals aged 15 and above in Jordan smoked tobacco. This is more than twice as high as the smoking prevalence in Egypt, which was determined to be $19.4 \%$ using a GATS survey in 2009 (World Health Organization 2009). By gender, $55.9 \%$ men and $23.7 \%$ women were found to use tobacco products in our study.

Our results correspond to other published rates of smoking in Jordan, which range from 33\% to 40\% (Naddaf 2007; Belbeisi, Al Nsour et al. 2009). Extrapolating 
the prevalence we found to the entire Jordanian population would suggest that an estimated 1.6 million adults use tobacco in Jordan.

The highest prevalence of smoking was found in the Ajlun governorate, which is in the Northern part of Jordan. In this governorate nearly half $(52.4 \%)$ of all individuals currently use tobacco (Figure 7) further more the prevalence of smoking in Ajlun was $63 \%$ and $26 \%$ in men and women respectively. The lowest prevalence was in Balqa, which is in the middle part of Jordan in which (29\%) admit to using tobacco with $55 \%$ and $10 \%$ in men and women respectively. The prevalence of tobacco use in the different governates, sub-analyzed by gender is illustrates in Figure 6.

In a study performed by the Department of Statistics in Jordan, the highest prevalence of chronic diseases was in Ajlun, a northern government in Jordan, where $41 \%$ of households have at least one individual with a chronic disease (Department of statistics in Jordan 2011). By comparison, in the entire kingdom, $34.4 \%$ of households have at least one individual with a chronic disease. The study related part of this high prevalence of chronic disease in Jordan to smoking behaviors.

Further exploratory analysis was performed in which, we divided the country into three geographical areas: North, South and Central Jordan. In these respective regions, the prevalence of smoking is $42.9 \%, 38.5 \%$, and $42.2 \%$. 


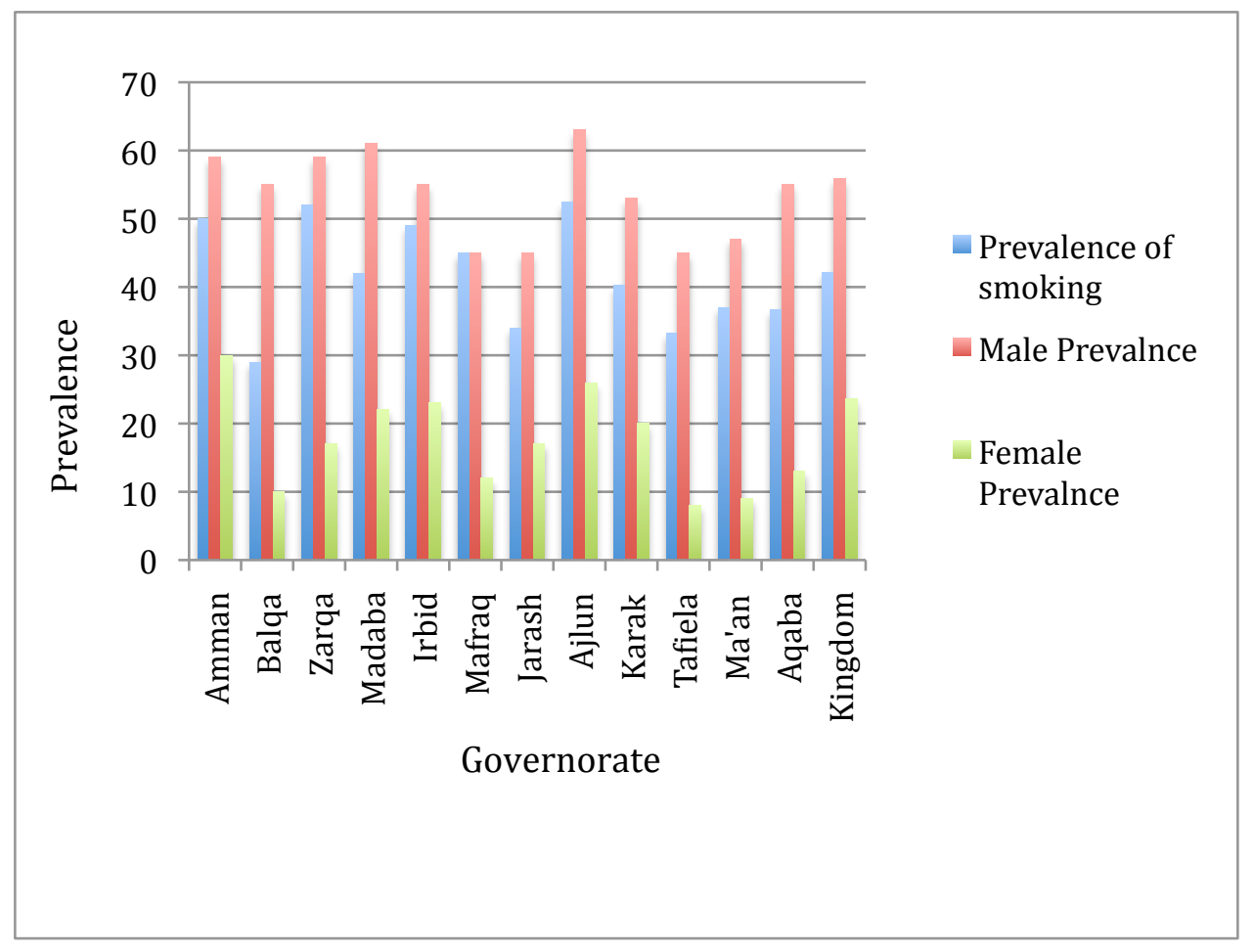

Figure 6. The prevalence of tobacco use by governorates and gender

\subsubsection{Type of Tobacco}

We also measured the frequency of tobacco use in individuals who currently use tobacco. Among those who smoke, $84 \%$ of total smokers were daily smokers and $15 \%$ were less than daily smokers. Among the total population $32.2 \%$ were daily smokers and 6\% were less than daily smokers. Among those who smoke tobacco, $35.2 \%$ smokes cigarettes, $15.2 \%$ smokes water pipe (Argileh), and less than $2 \%$ smoke other types of tobacco such as pipes, cigars and/or hand-rolled cigarettes (Hishi), as shown in figure 7. 


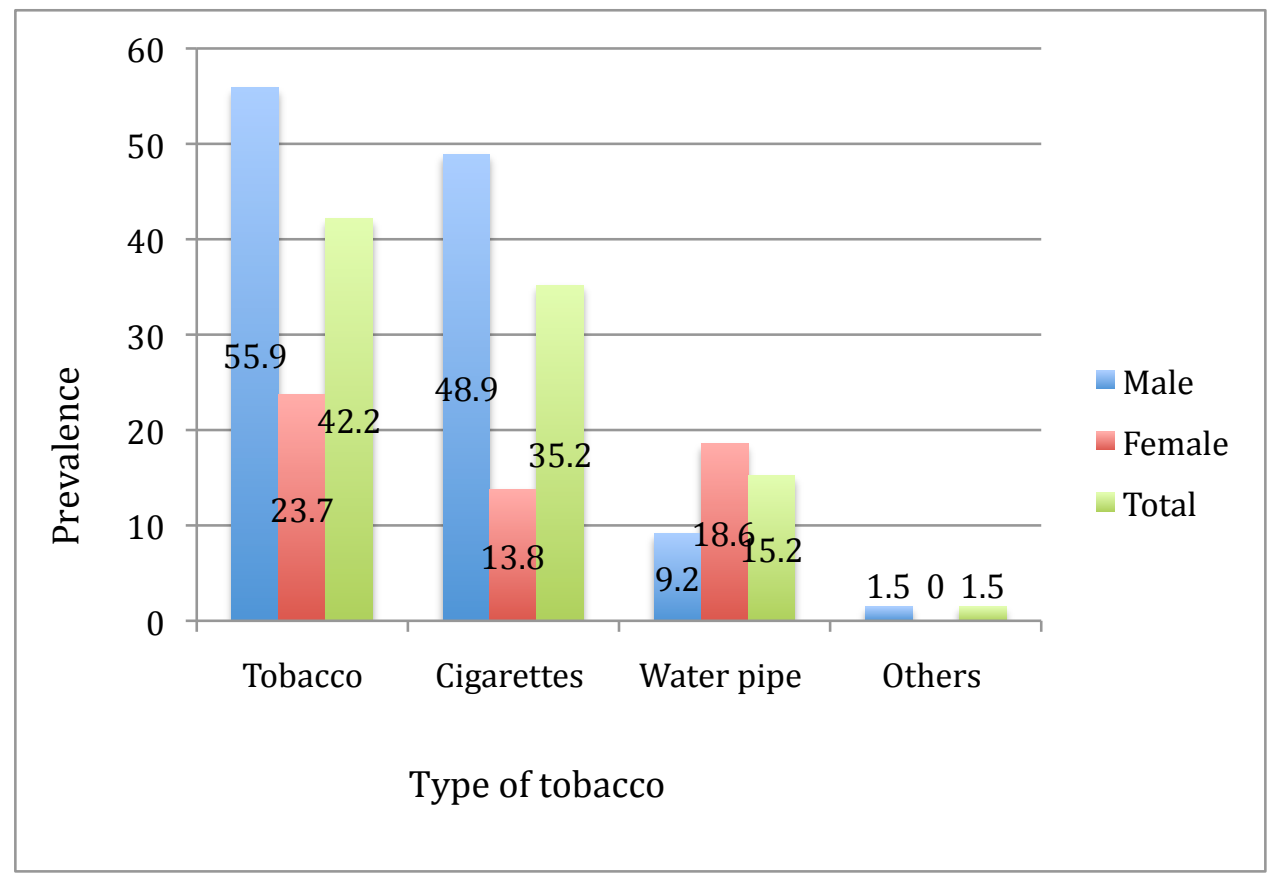

Figure 7. The prevalence of tobacco use by type of tobacco

\subsubsection{Gender}

For men and women the prevalence of tobacco smoking was $55.9 \%$ and $23.7 \%$ respectively. Men smoke more cigarettes than water pipe with a prevalence of $48.9 \%$ and $9.2 \%$ respectively. The prevalence of smoking cigarettes and water pipe in women is $13.8 \%$ and $18.6 \%$ respectively. The overall prevalence of cigarettes use only is $45.2 \%$ and the prevalence of waterpipe use only is $7.2 \%$. Those who uses both water pipe and cigarettes are $5.5 \%$ as shown in figure 8 . 


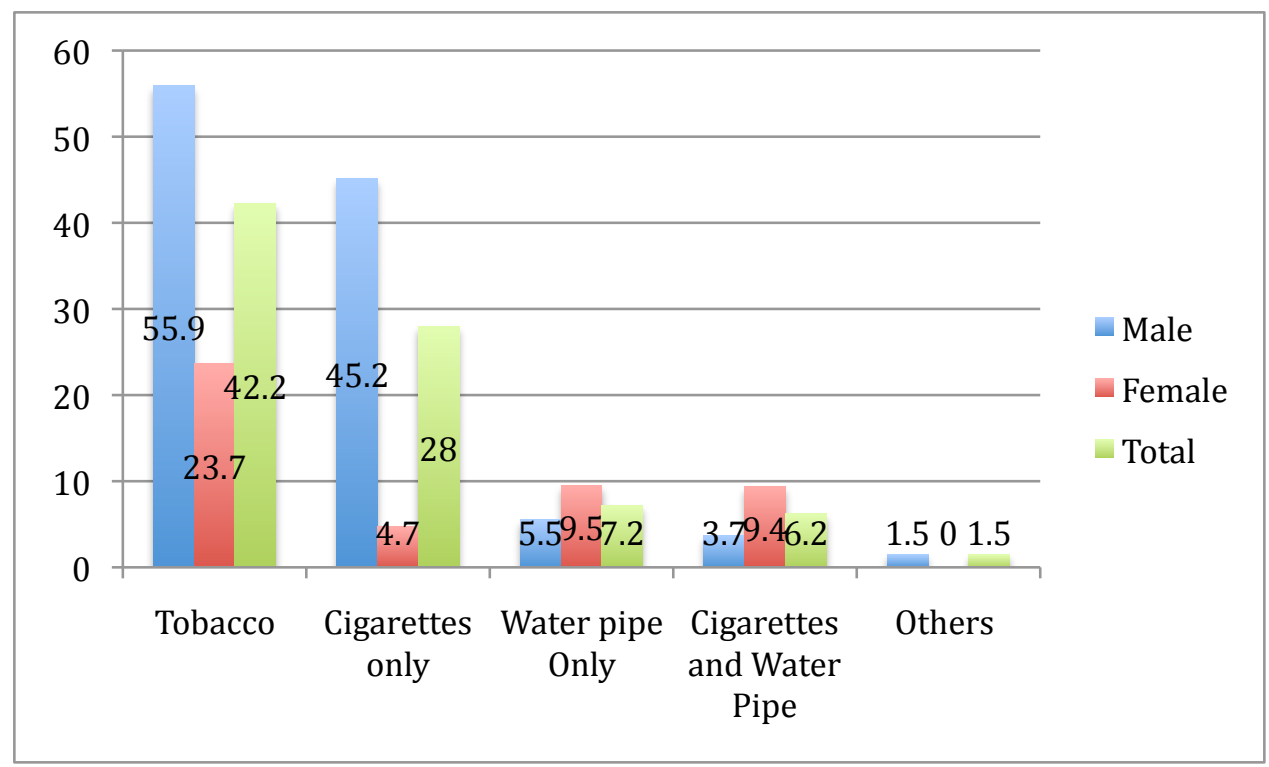

Figure 8 . The prevalence of tobacco use by type of tobacco separated.

\subsubsection{Education}

By education, the highest prevalence of smoking was among individuals with postgraduate completed (49\%) whereas the lowest prevalence rate was among those with only primary school completed (16\%), as shown in figure 9 . 


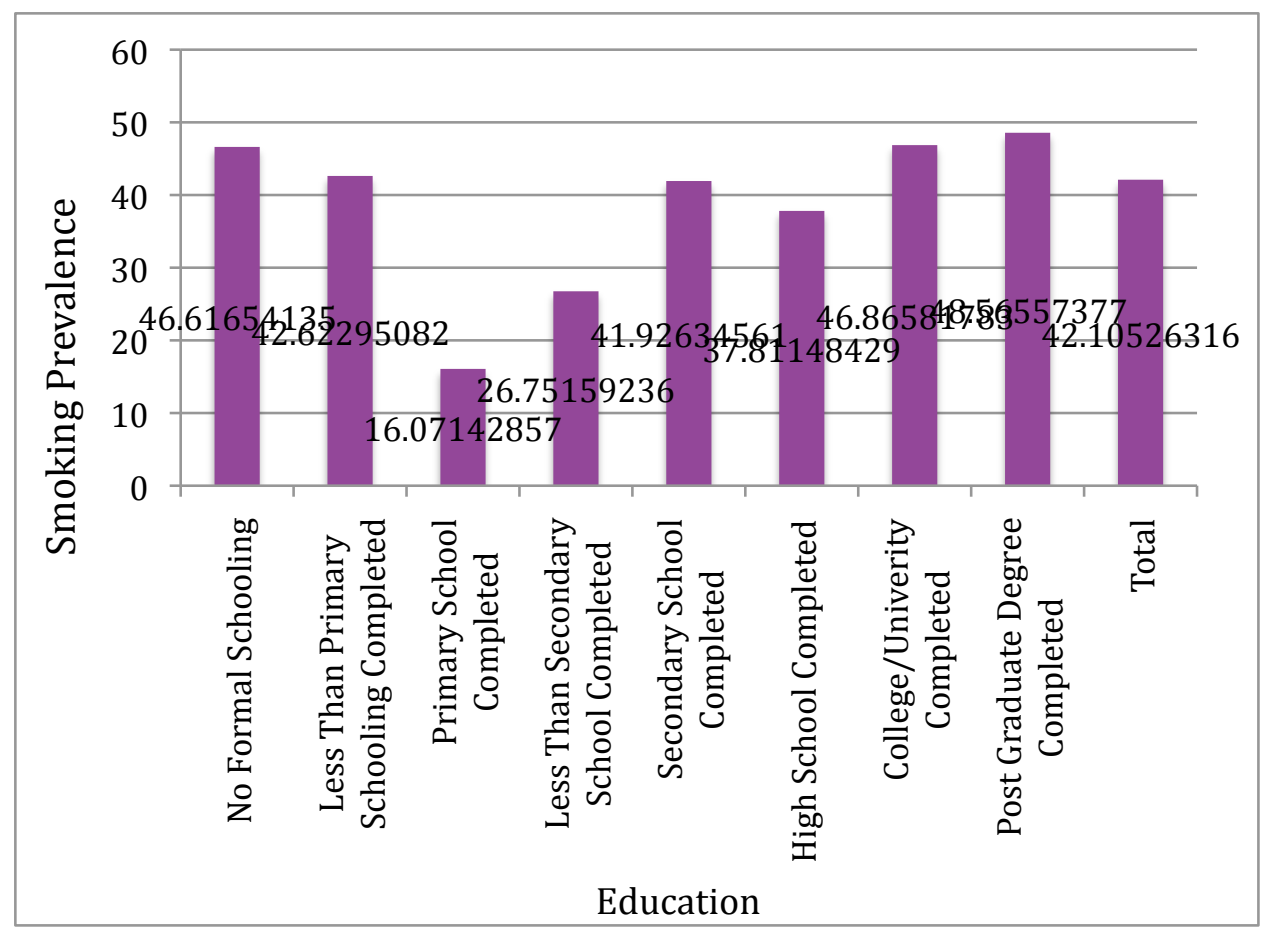

Figure 9. Smoking prevalence by education

\subsubsection{Work Status}

By occupation, $52 \%$ of employed individuals smoke, whereas $19 \%$ of unemployed individuals smoke as indicated in figure 10 . 


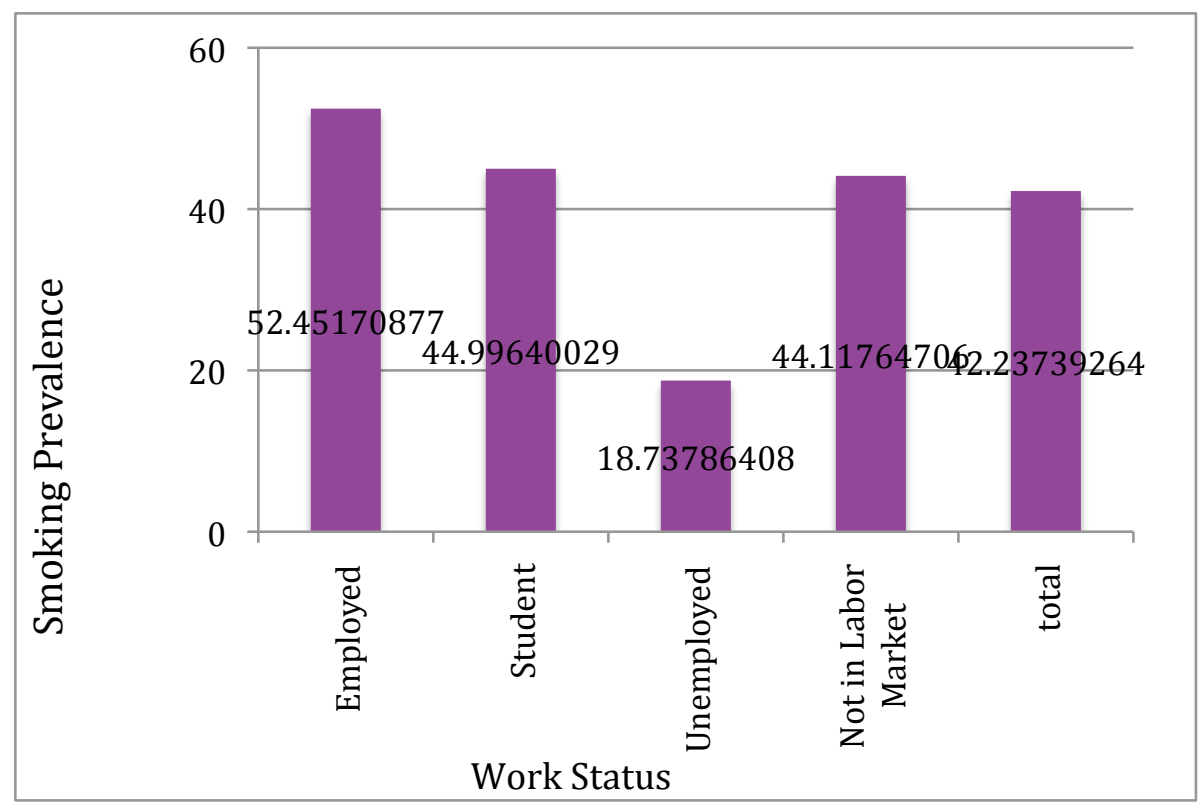

Figure 10. Smoking prevalence by work status

\subsubsection{Age Group}

By age group those who are $31-40$ have a $47 \%$ rate of smoking tobacco. those in age group 15-18 smokes the least with a prevalence of $30 \%$, as shown in figure 11. 


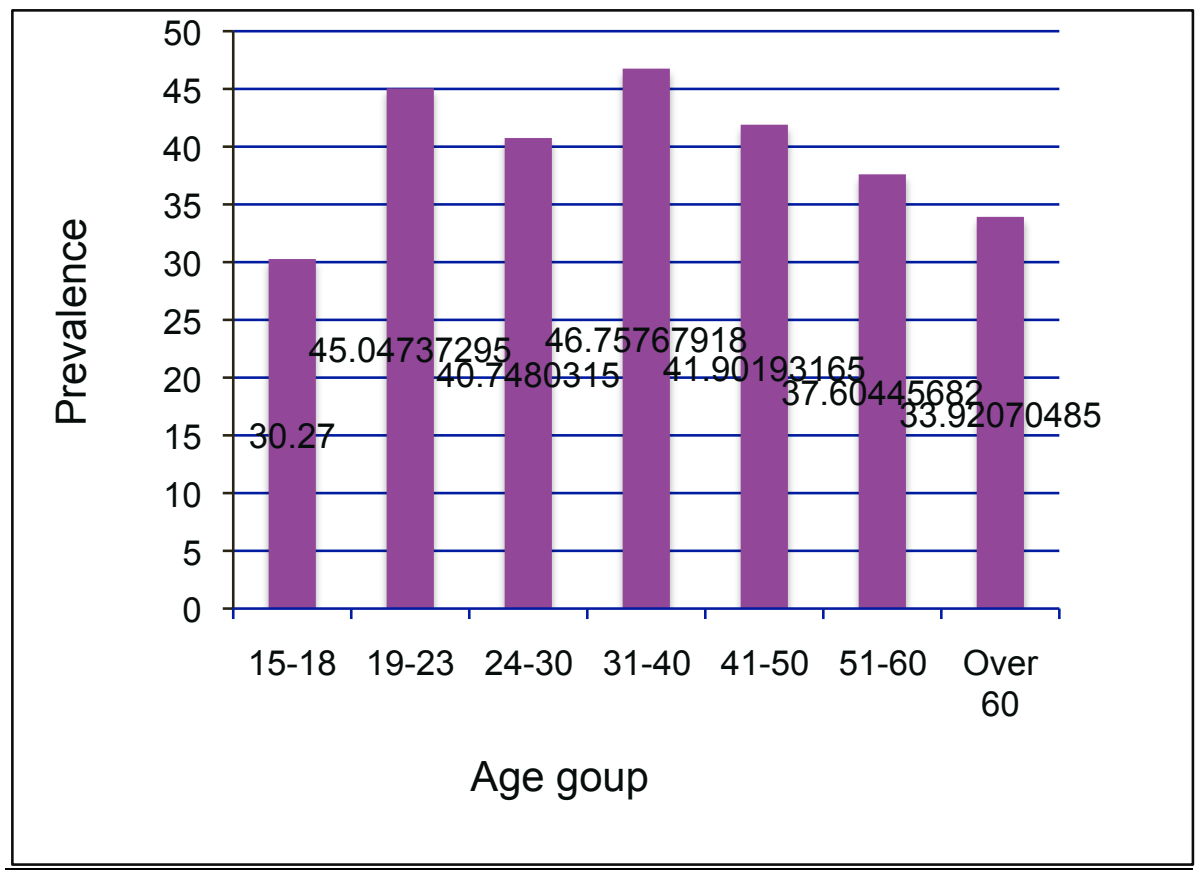

Figure 11. Prevalence of tobacco use by age group

\subsubsection{GATS in Jordan and BRFS}

In chapter 2 we mentioned that the BRFS was conducted in Jordan in 2007. This survey asked individuals about smoking cigarettes for those aged 18 and above. The BRFS survey in Jordan is the one of the published survey that included a large sample size aged 18 and above in Jordan. We performed a sub analysis using the GATS data in Jordan to calculate the prevalence of cigarettes smoking for those aged 18 and above as the GATS includes those 15 and above in an attempt to compare the 2007 BRFS results with the 2011 GATS results. We carefully considered the limitation of such comparison. The BRFS was conducted using a multistage cluster sampling technique, allowing for a comparison of 2007 
and 2011. The analysis was limited to only cigarettes since the BRFS inquires about cigarettes smoking only.

As shown in figure 12 men who are in age 18-24 had the highest prevalence of smoking (62\%), while women who are in age $45-54$ have the highest prevalence of smoking cigarettes among other age groups $(25.6 \%)$.

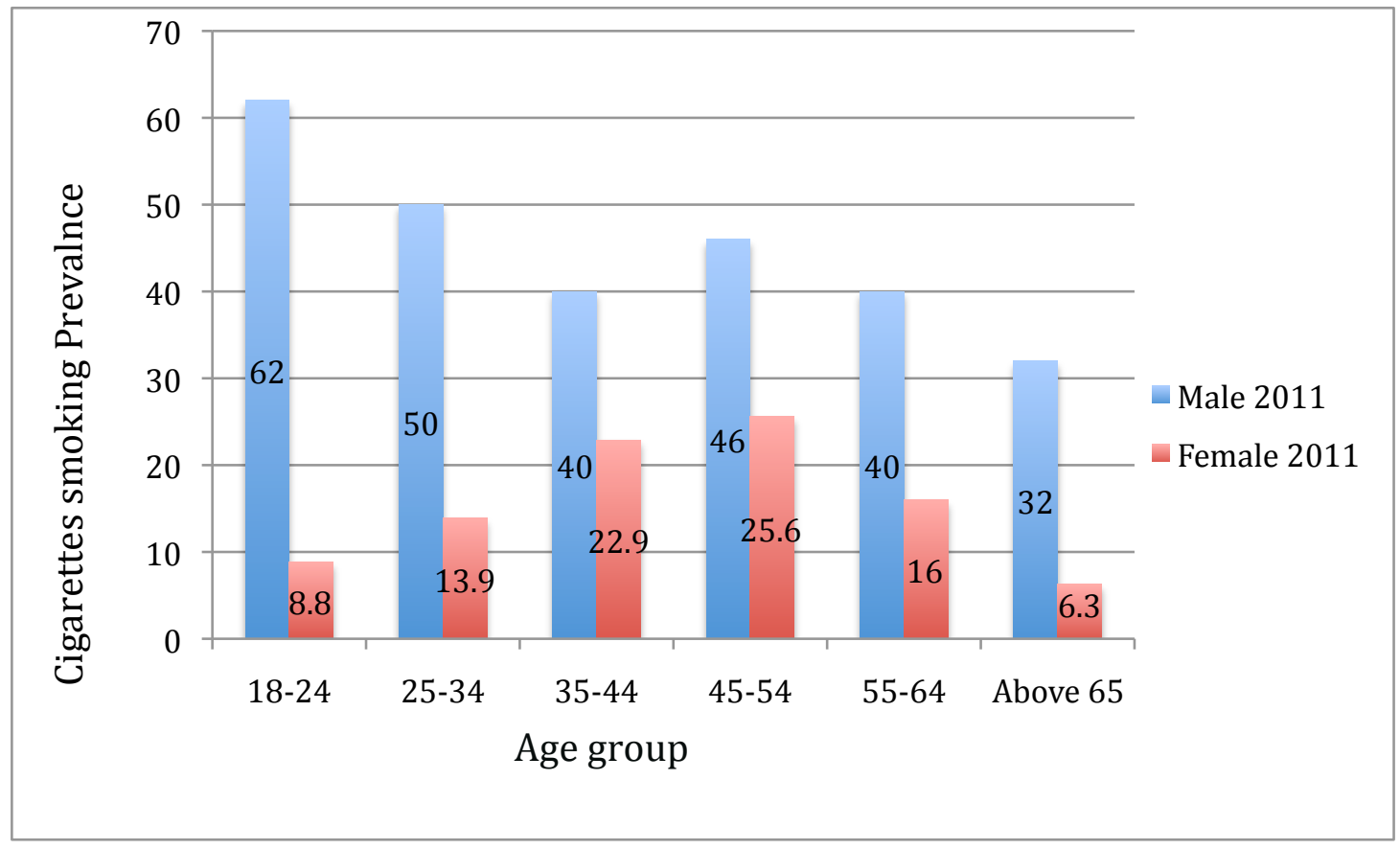

Figure 12. Prevalence of smoking cigarettes by age group and gender in 2011

By gender men age 18 and above smoking cigarettes have a prevalence of $48.9 \%$ while women have a prevalence of $13.8 \%$. A total prevalence of $31.8 \%$ as shown in figure 13 


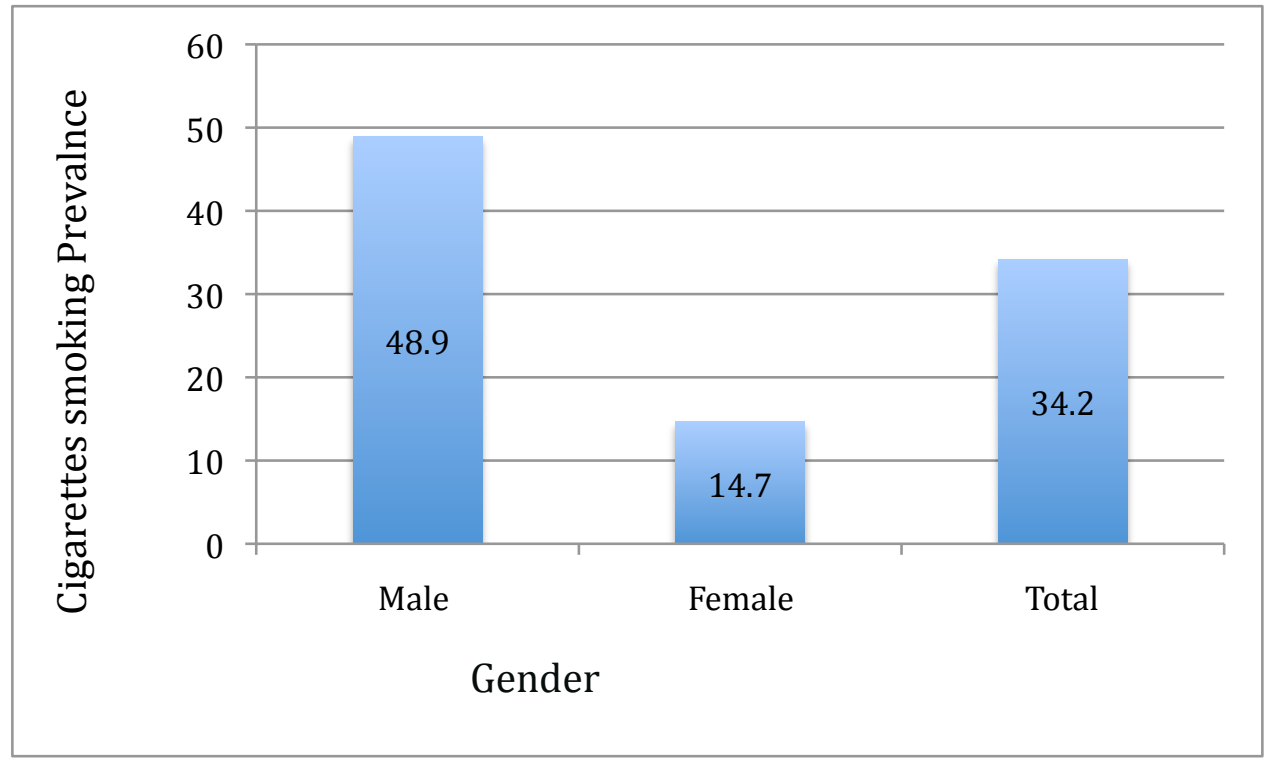

Figure 13. Prevalence of cigarettes use by gender in 2011

\subsubsection{Cigarette Smoking}

As noted in earlier chapters, cigarette price, income, prices of related products, and personal preferences influence the demand of tobacco products. Fortuitously, the GATS contains questions about some of these items, and we used the information gathered while conducting the GATS in Jordan to perform an economic analysis of the demand for tobacco in Jordan. We will briefly describe some of the results in this section.

\subsubsection{Cigarettes price quantity and expenditure stratified by age group, education,} work status and gender

In our analysis, we found that the average price per pack of cigarettes was 1.43 JOD (or appriximately $\$ 2$ ), which was similar to but a bit higher than what has 
been published in the literature, which was approximately JOD 1.36 (World Health Organization 2010).

After sub-dividing cigarette cost among different age groups, we found that respondents aged 41-50 and 51-60 paid the most for cigarettes, at approximately JOD 1.65 per pack on average. Individuals $15-18$ as shown in Figure 14 paid the lowest average price JOD 1.025 .

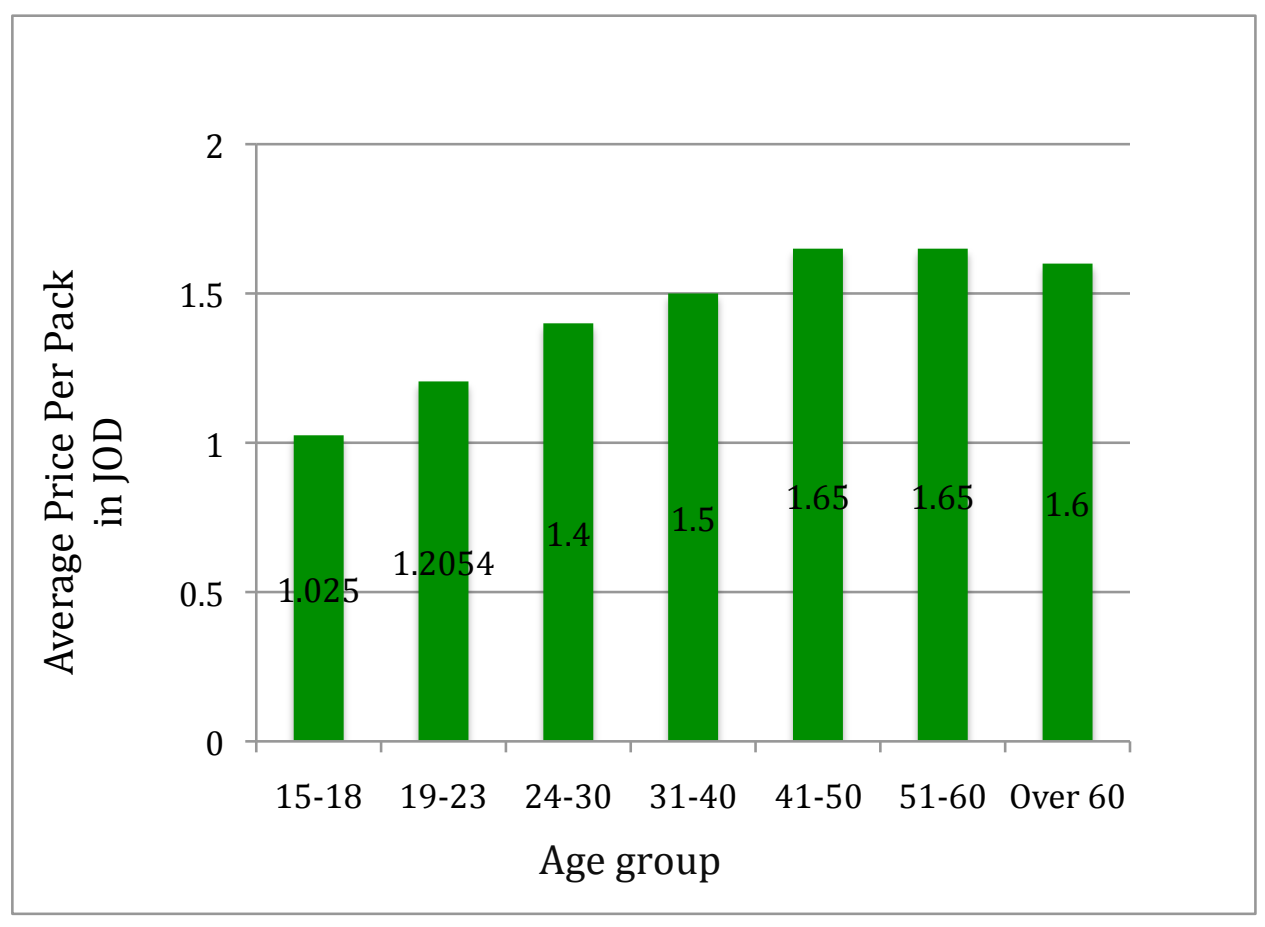

Figure 14. Average price per pack of cigarettes by age group 
The average number of packs of cigarettes smokers used was 7.98 packs per week. Jordanians aged 24-30 years smoke the most, with a reported smoking quantity of 8.3 packs per week. Persons aged 15-18 and 51-60 smoke approximately 7.29 and 7 packs per week, respectively (Figure 15).

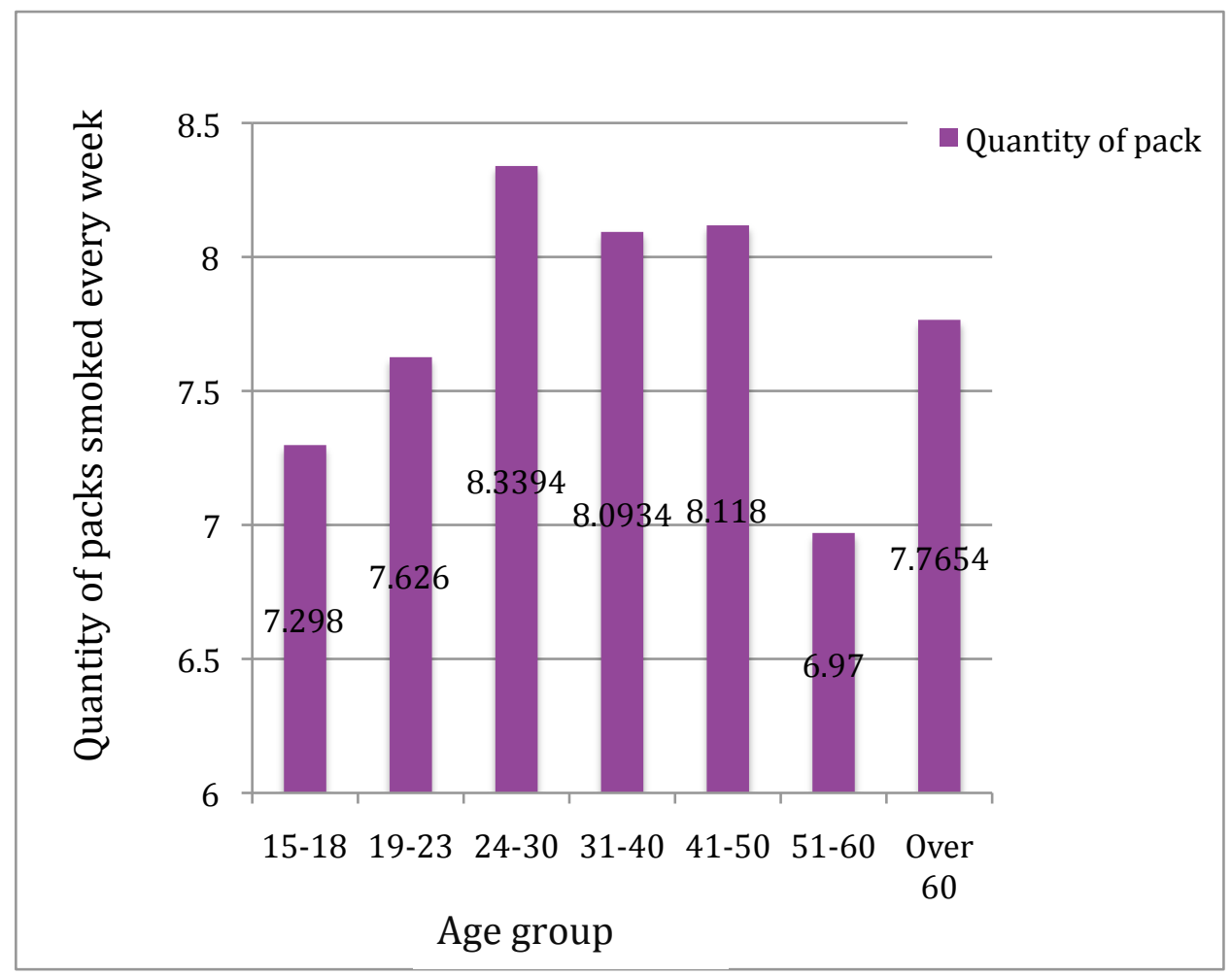

Figure 15. Quantity of packs smoked every week by age group 
Weekly, Jordanians spend an average of approximately JOD 12 on cigarettes. Weekly expenditures are highest for those 24-30 years old, which are estimated to be approximately JOD 13.4 (Figure 15). In contrast, persons aged 15-18 spend the least on cigarettes every week, at approximately JOD 7.5 as shown in figure 16.

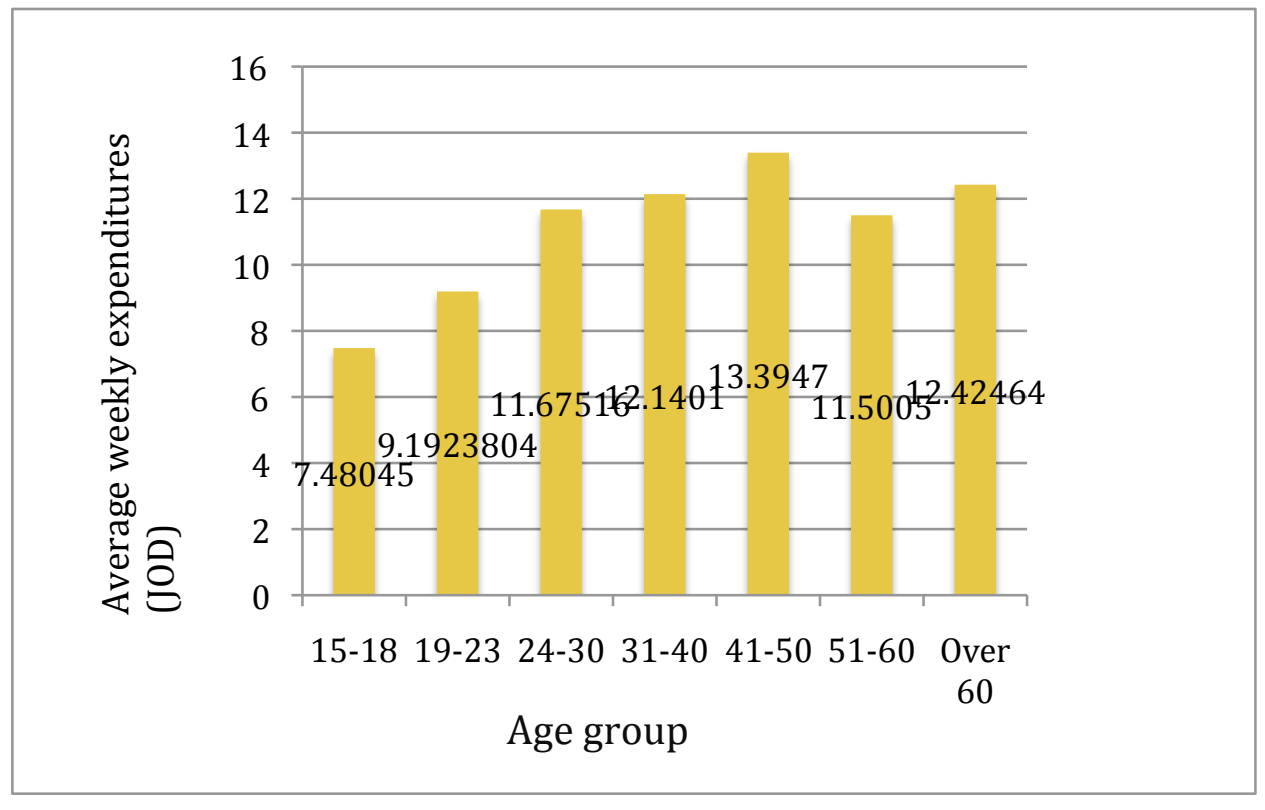

Figure 16. Average weekly expenditures on cigarettes by age groups

Further analyzing the data by gender showed that men smoke more packs of cigarettes per week than women, 8.1 and 6.8 packs per week, respectively. Not surprisingly, expenditures on cigarettes were also higher for men than for women, 
by approximately JOD 14.1 per week as shown Figure 17. In Egypt, monthly cigarette expenditures have been reported, and they are the same for men and women, both 109.8 L,E (World Health Organization 2009).

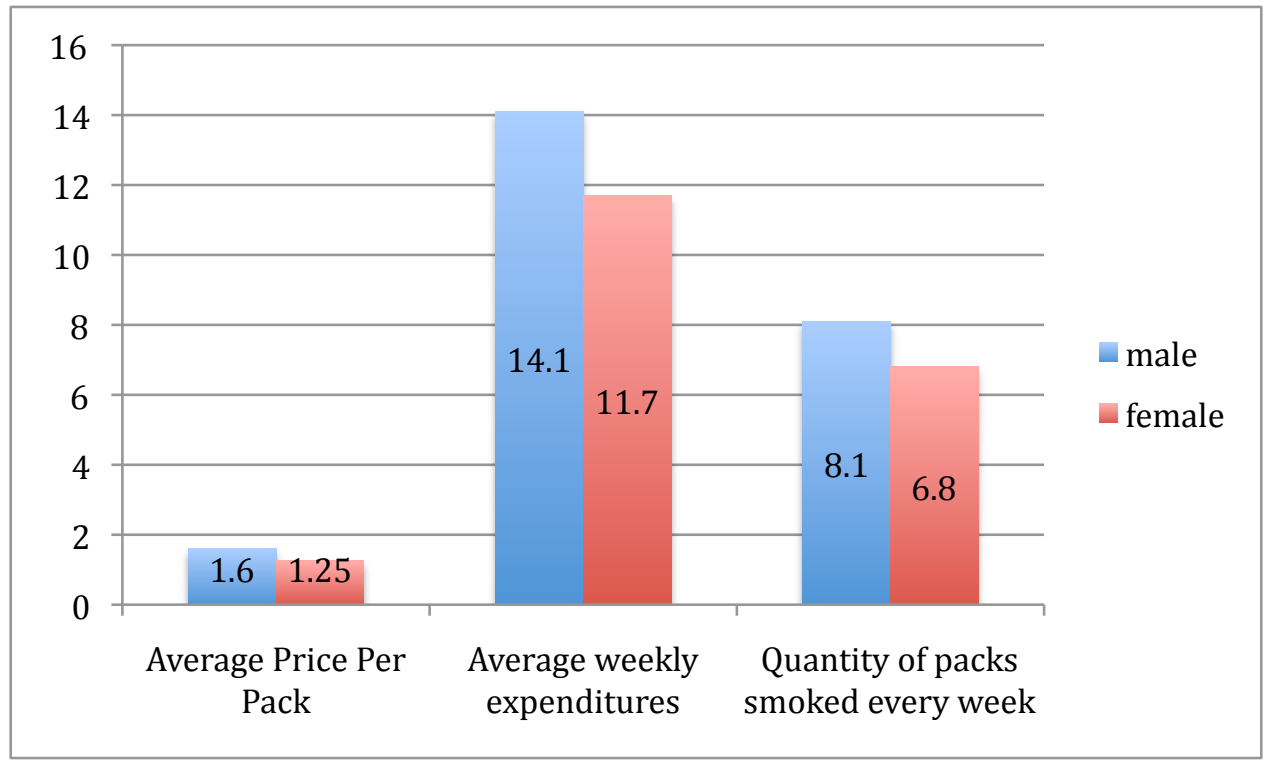

Figure 17. Average prices, quantity and weekly expenditures on cigarettes by gender

By occupation, students tend to smoke the highest quantity of cigarettes per week. On average, students smoke approximately 10.4 packs per week. In contrast, individuals who are not in the labor market tend to smoke 8.3 packs per week (Figure 20). Those who are employed report paying the highest average price per 
pack, and the lowest average price per pack was paid by individuals not in the labor market. Average prices paid per cigarette pack were JOD 1.7, and JOD 1.2 per pack, respectively as shown in Figure 18.

Those who are employed spend more on cigarettes approximately 15.6 JOD per week as shown in figure 19.

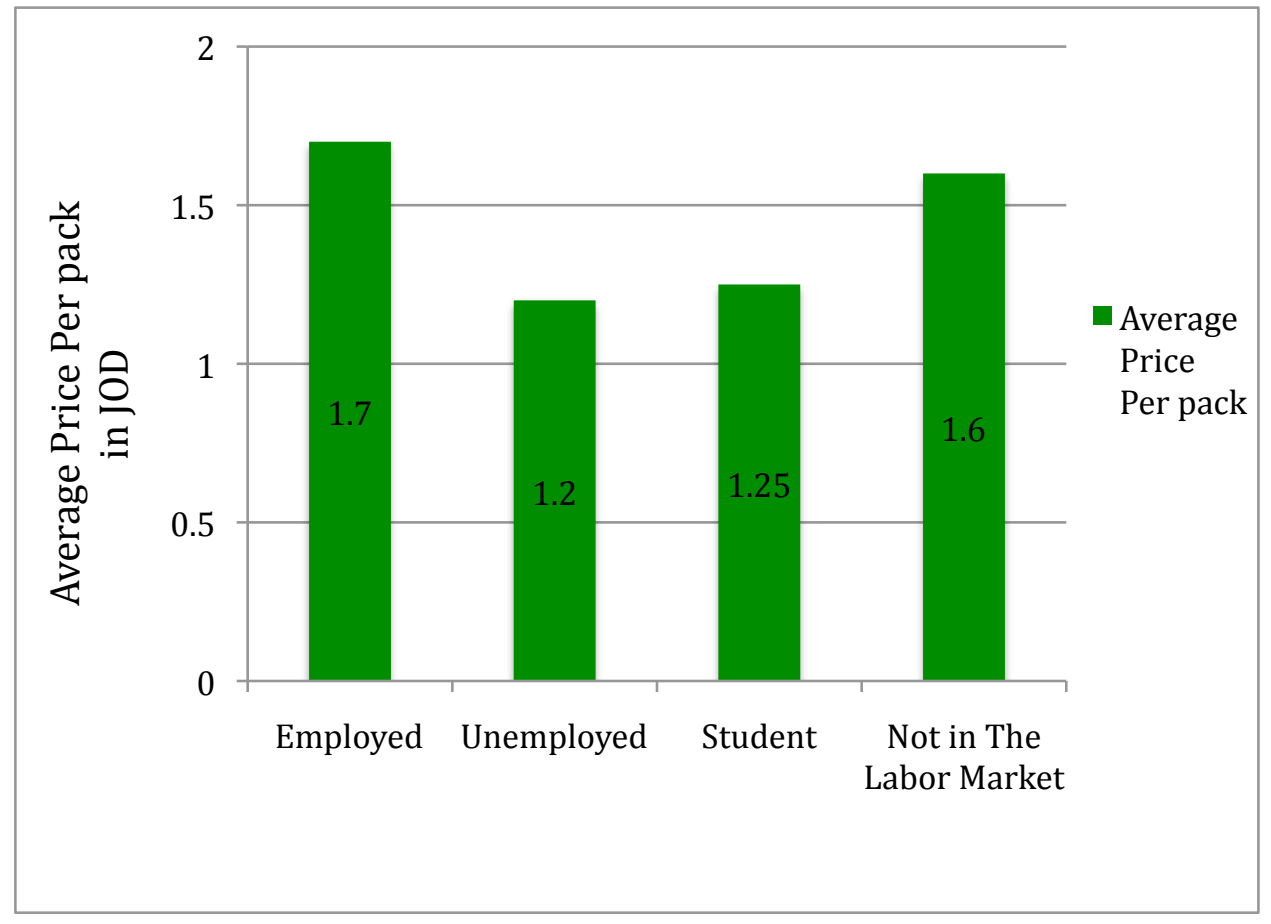

Figure 18. Average price per pack of cigarettes by work status 


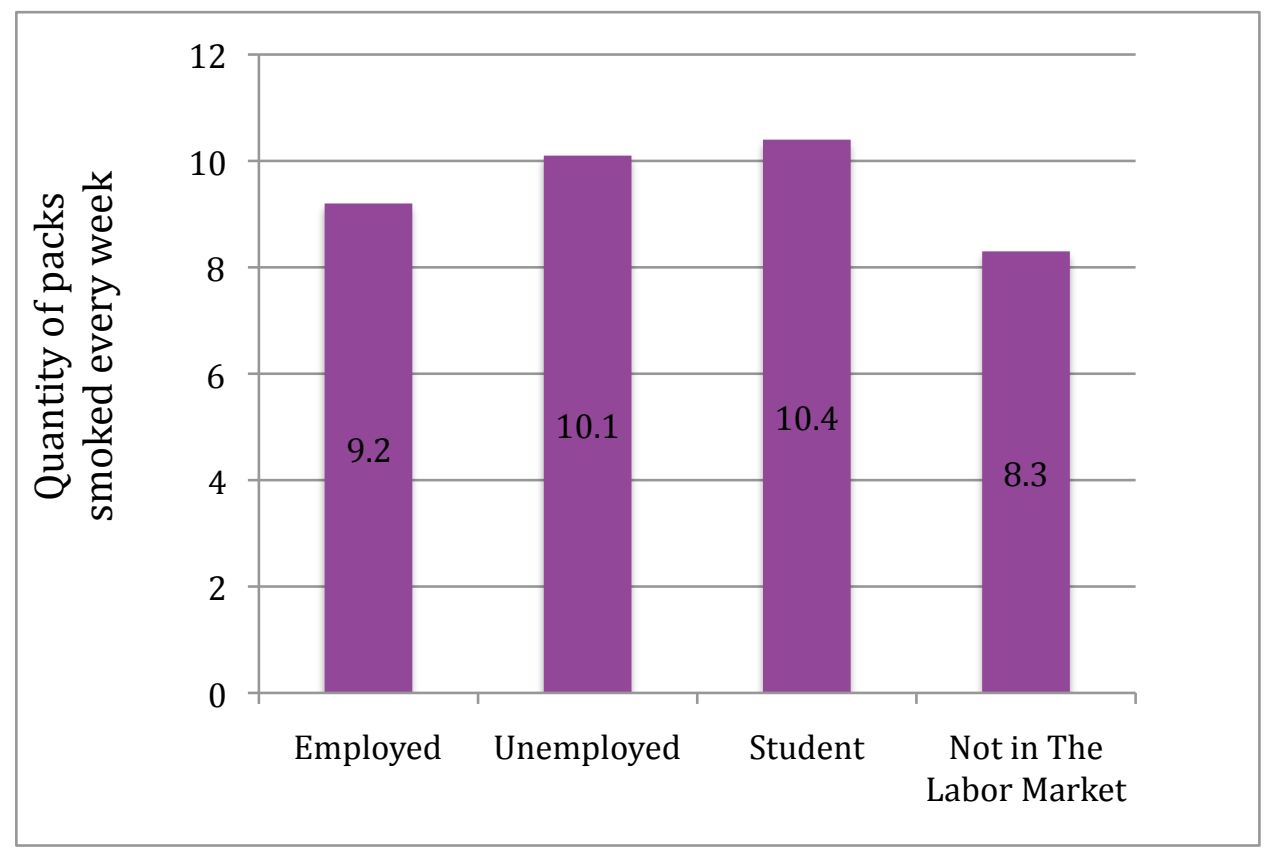

Figure 19. Quantity of packs smoked every week by work status

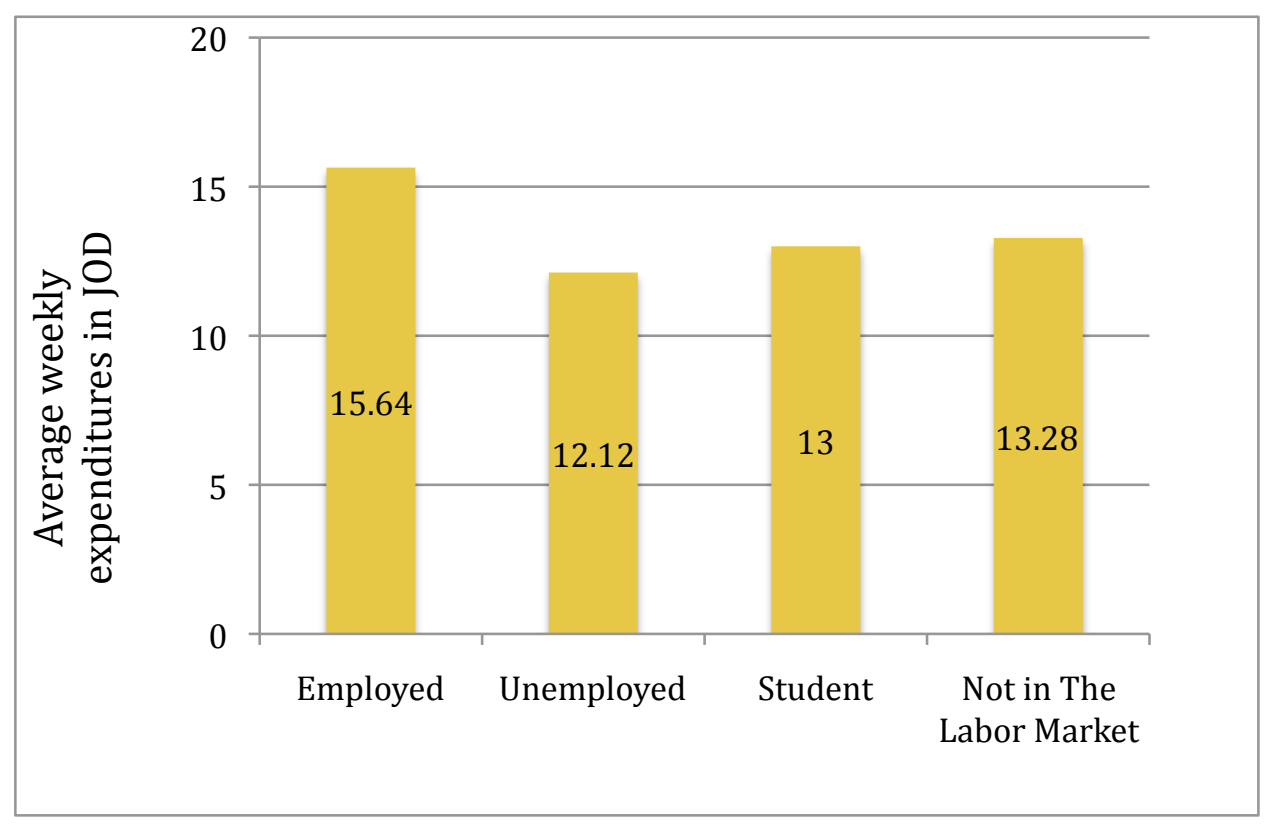

Figure 20. Average weekly expenditures on cigarettes by work status. 
By education level, the people who smoke the most cigarettes per week are those whose highest level of schooling was high school. This group of individuals smokes approximately 9.8 packs per week. Jordanians who completed primary school and had no further education smoked the least amount, at approximately 5.2 packs per week as shown in figures 21 and 22 . The average price per pack was highest among those who completed college/university. The lowest prices paid were among those with no formal schooling. The average prices per pack of cigarettes were JOD 1.5 and 1.23 , respectively.

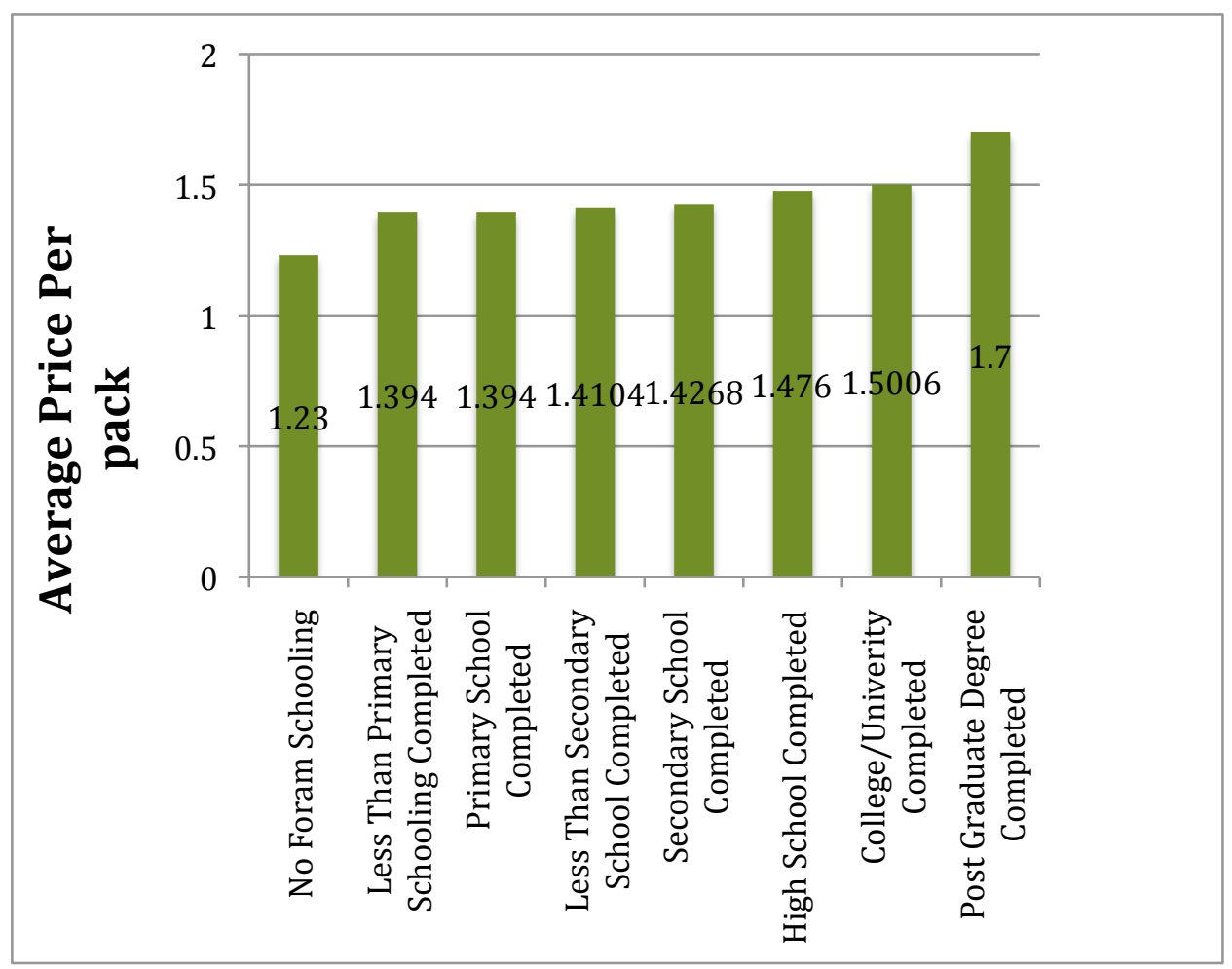

Figure 21. Average price per pack of cigarettes by education 


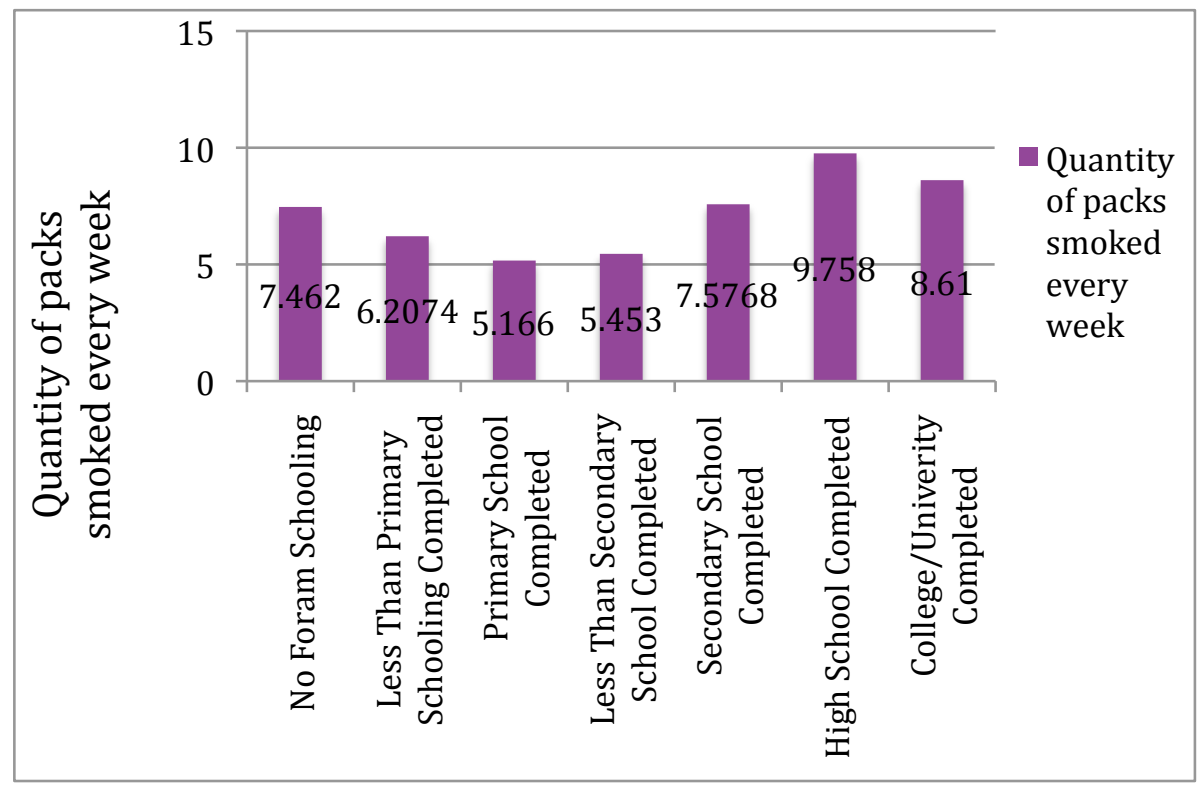

Figure 22. Average quantity of packs smoked every week by education

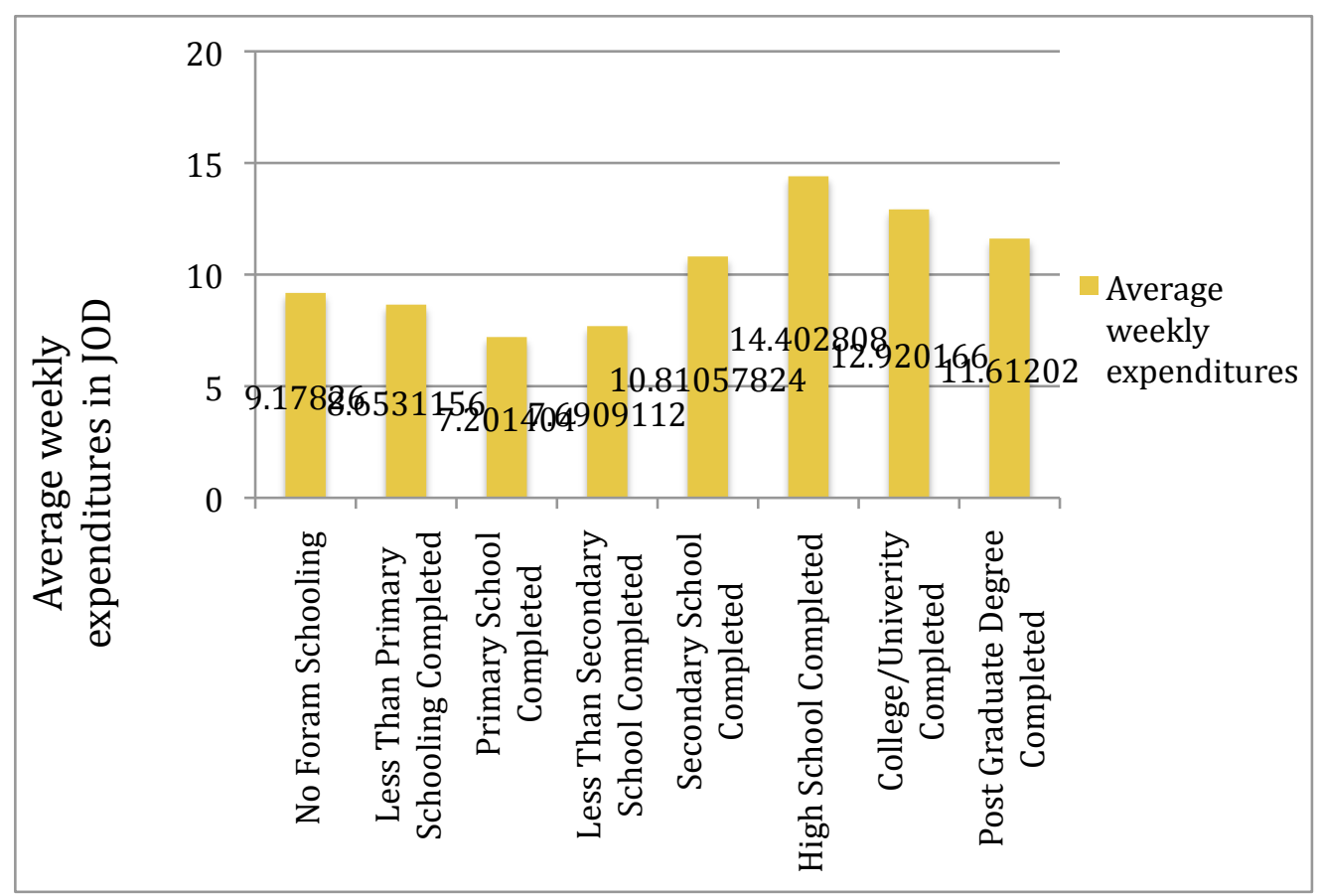

Figure 23. Average weekly expenditures on cigarettes by education 


\subsubsection{Types of cigarettes consumption}

Three main types of cigarettes are smoked in Jordan: Light, Mild, and Low Tar.

The majority of respondents in our survey smoke either light or mild cigarettes.

For example, interviewees aged 41-50 tend to smoke more mild cigarettes than other types of cigarettes (54\%). Respondents aged 51 to 60 tend to smoke more light cigarettes $(52 \%)$ than other types of cigarettes. Although the prevalence of smoking low tar cigarettes was low across all age groups, the age group with the highest frequency of smoking low tar cigarettes was those over age $60(5.6 \%)$ as shown in Figure 24.

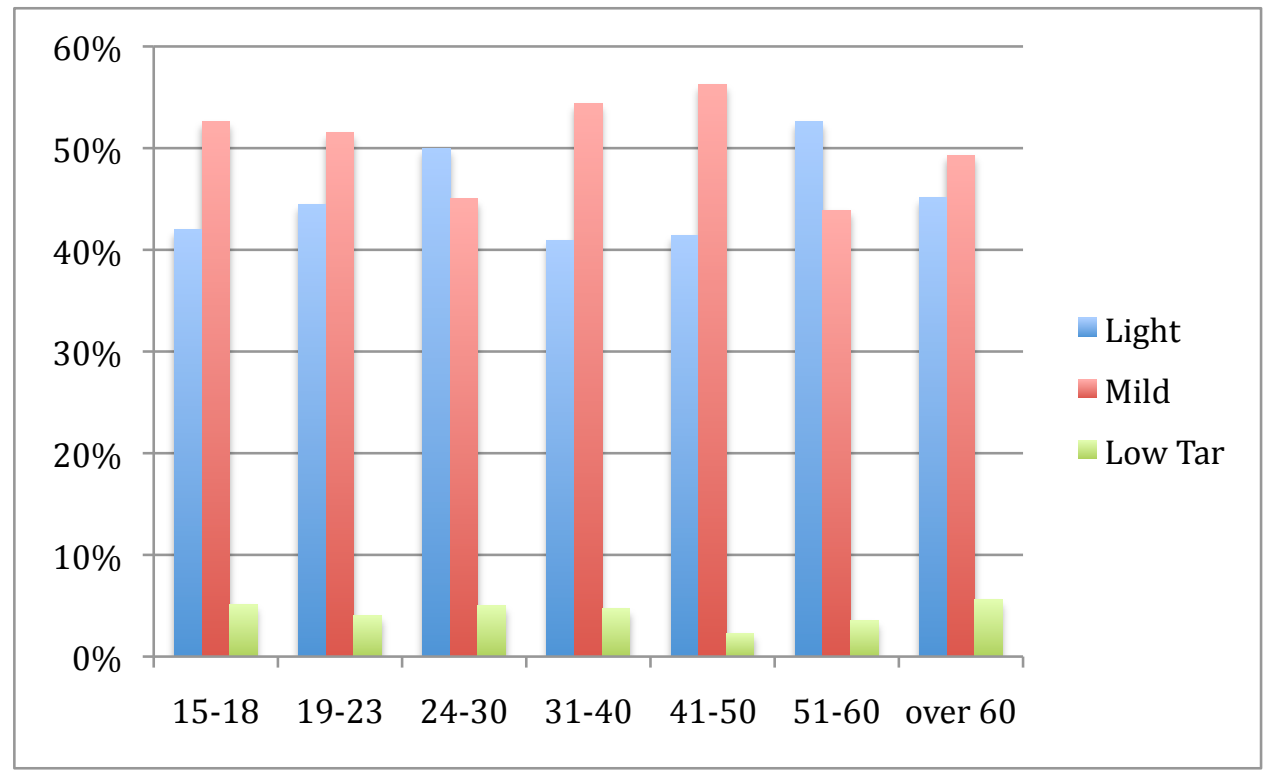

Figure 24. Prevalence of cigarettes smoking for different types of cigarettes by age group 
In contrast to age, education level was associated with the type of cigarette smoked. Individuals with no schooling and those with an education level less than primary schooling smoke more low tar cigarettes than any other types, at approximately $79 \%$. In contrast, $52 \%$ of individuals who completed post-graduate levels of schooling smoke light cigarettes as shown in figure 25 .

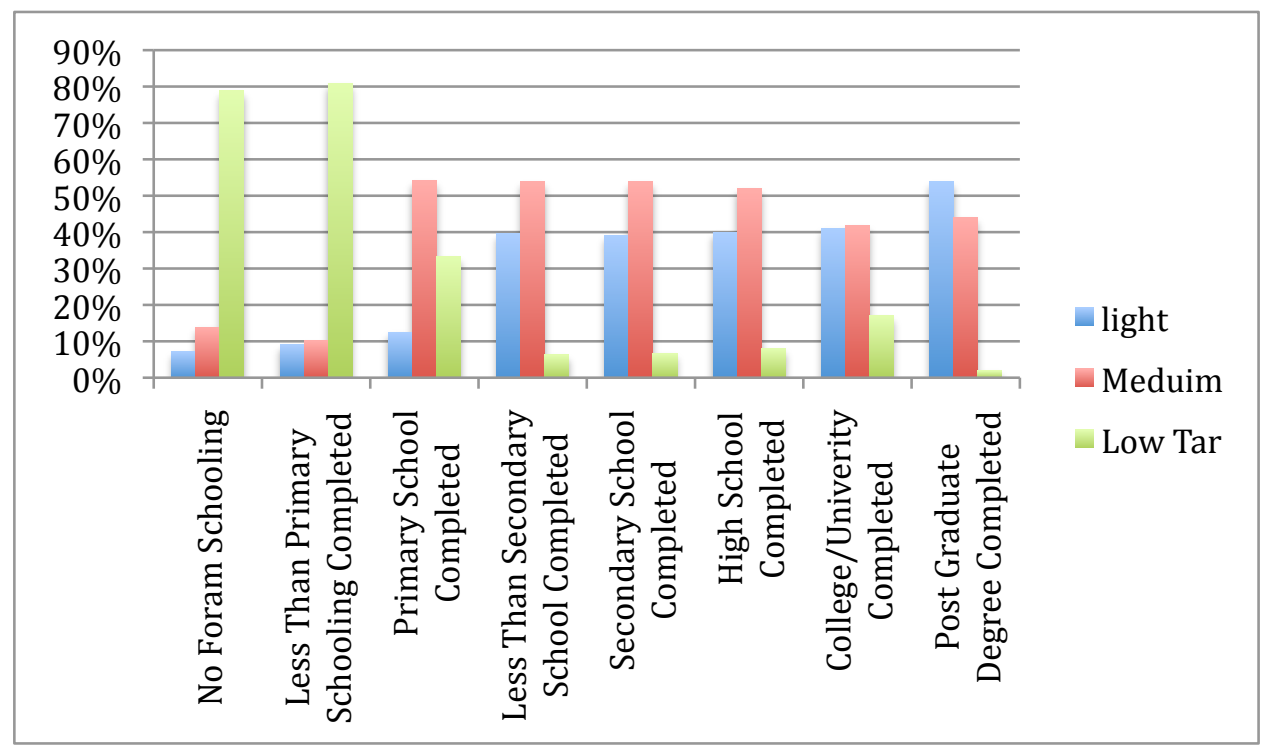

Figure 25. Prevalence of cigarettes smoking for different types of cigarettes by education

Approximately 53\% of individuals who are not in the labor market smoke mild cigarettes, whereas $42 \%$ of employed individuals smoke light cigarettes as shown in figure 26. 


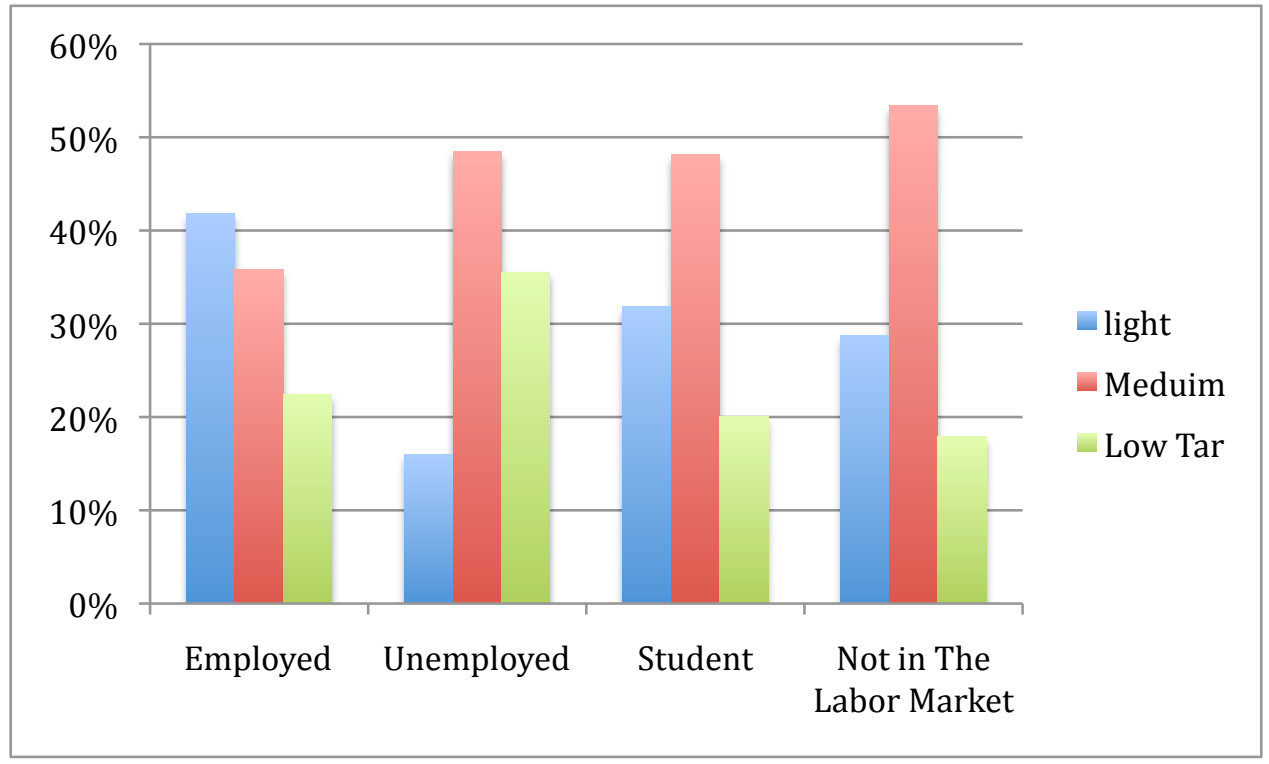

Figure 26. Prevalence of cigarettes smoking for different type of cigarettes by work status

\subsubsection{Place of purchase of cigarettes}

When asked about the place cigarettes were purchased, nearly all (99.9\%) Jordanian smokers bought their cigarettes from a store. A very negligible percentage of smokers bought their cigarettes from duty-free shops and/or outside of Jordan. By comparison, $83.2 \%$ of Egyptians buy tobacco in a store. Other places where tobacco is purchased in Egypt have not been published (World Health Organization 2009). 


\subsubsection{Age of smoking initiation}

With respect to the age at smoking initiation, approximately $42 \%$ of smokers started smoking cigarettes between the ages of 15 and 18. Twenty-nine percent of respondents began smoking between the ages of 19 and 23 . The least likely time to begin smoking in Jordan is between the ages of 7 and 9 and over the age of 60 ( $2 \%$ and $3 \%$ of respondents, respectively). These findings are similar to those reported in Egypt, which has an average age of initiating daily smoking of 16.8 years (World Health Organization, 2009).

\subsubsection{Water pipe (Argileh) (Hookah)}

We found that across Jordan, $18.6 \%$ of Jordanians women smoke water pipes and $9.2 \%$ of men do. Approximately $29 \%$ of water pipe smokers initiate smoking between the ages of 19 and 23. Similar to cigarette smoking, people are least likely to begin smoking between the ages of 7 and over 60 years as shown in figure 27. 


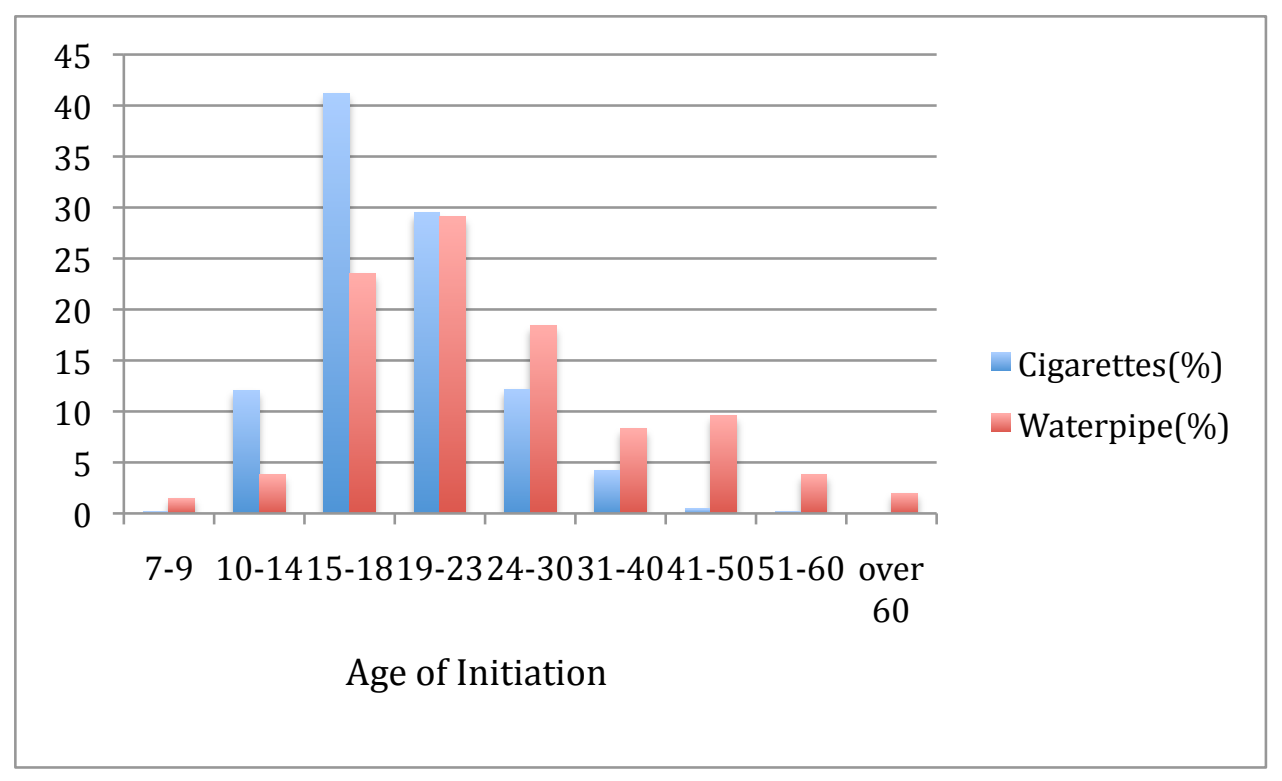

Figure 27. Age of smoking initiation for cigarettes and water pipe

The average time it takes to smoke a water pipe in Jordan is 2.2 hours (range, 30 minutes to 5 hours). Our data indicate on average, 2 people share the same pipe (range, 0 to 6 people). The average number of rocks smoked while participating in the session was 2.1 (range, 1-4 rocks). Of water pipe smokers, $52 \%$ use flavored tobacco while $48 \%$ uses unflavored tobacco. Most water pipe smoking is done at home (87\%), followed by coffee shops (12\%), restaurants $(0.9 \%)$, and bars and nightclubs (0.1\%). Approximately half of all respondents (48\%) mix something with their tobacco, such as lemon or alcohol. In Jordan, a delivery service of water pipes to houses is available now, since preparing the device requires a lot of time. Also, there is now a new version of Argileh available now that has two or three pipes (Barbeesh) in the same Argileh. 


\subsubsection{Cessation}

According to the GATS survey results in Jordan survey, $2 \%$ of the sample consisted of former smokers. We found that $27.4 \%$ of Jordanian current smokers tried to quit smoking during the past 12 months, whereas $72.6 \%$ did not.

Among those who tried to stop smoking for months, $25.7 \%$ tried to stop for one month, $27.5 \%$ for 2 months, $10.2 \%$ for three months, $21 \%$ for four months, $3 \%$ for 8 months and $12.6 \%$ for 12 months.

Among those who tried to stop smoking for weeks 32\% tried to stop for 1 week, $45.8 \%$ for 2 weeks, $18.8 \%$ for 3 weeks, $4.6 \%$ for 5 weeks, $0.8 \%$ for 13 weeks Among those who tried to stop for days, $31.7 \%$ stopped for $1-2$ days, $44.7 \%$ for 3 4 days, $11.8 \%$ for $5-6$ days, $4.5 \%$ for 10 days, $4 \%$ for 15 days, $3.4 \%$ for 32 days. Of the individuals who visited the doctor, $7.6 \%$ visited 1 to 2 times, $4.1 \%$ from 3 to 5 times, $1.1 \%$ visited more than 6 times, and $87.2 \%$ did not answer.

During these visits, only $9 \%$ of individuals were asked whether they smoke, $3 \%$ were not asked whether they smoke, and $88 \%$ did not answer.

Of those who were asked whether they smoke, $7.8 \%$ were advised to quit smoking. This finding is extremely troublesome and may reflect cultural attitudes about tobacco use in Jordan.

Methods used to stop smoking were counseling (3.2\%), nicotine replacement therapy $(2.7 \%)$, alternative medicine $(2.5 \%)$, traditional medicine $(1.4 \%)$, anything else (0.7\%), and (89.5\%) did not answer. 
Approximately 1 in 10 , or $12.8 \%$ of individuals who tried to quit smoking during the last year visited the doctor at some point during that year.

Among those who tried to stop smoking for months, 25.7 tried to stop for one month, $27.5 \%$ for 2 months, $10.2 \%$ for three months, $21 \%$ for four months, $3 \%$ for 8 months and $12.6 \%$ for 12 months.

Among those who tried to stop smoking for weeks 32\% tried to stop for 1 week, $45.8 \%$ for 2 weeks, $18.8 \%$ for 3 weeks, $4.6 \%$ for 5 weeks, $0.8 \%$ for 13 weeks.

The GATS also asks respondents about whether or not they plan to quit smoking in the future. Of the respondents who were smokers, $1.8 \%$ are planning to try to quit within the next month, $2.9 \%$ within the next 12 months, $6.15 \%$ will quit someday but not the next 12 months, $13.9 \%$ are not interested in quitting, and $75.25 \%$ don't know if they will attempt to quit smoking. Again, this finding is troublesome. The same question prompted $42.8 \%$ of smokers in Egypt to share the desire to quit smoking in the next year. As such, the urgency to quit smoking is much less in Jordan compared to other Middle Eastern countries, like Egypt.

\subsubsection{Second-Hand Smoke}

Each year, 600,000 people die from tobacco-related illnesses due to second-hand smoke (World Health Organization 2009). To our knowledge, second-hand smoking has not been measured in Jordan, which is what we attempted to do with 
the GATS. We found that smoking is allowed inside the home by $45 \%$ of all respondents. Another $22.6 \%$ of Jordanians allow some smoking in the home with some exceptions (the exceptions were not specified). Only $11.2 \%$ of respondents reported that smoking is never allowed at home. Other than those persons just described, another $8.4 \%$ have no rules about smoking in their homes and $12.8 \%$ don't know if smoking is allowed in their home. In comparison with Egypt, these findings are actually quite encouraging. Smoking is allowed inside $70.8 \%$ of homes in Egypt, whereas smoking is allowed in less than half of Jordanian homes (World Health Organization 2009).

Within the home, $34.9 \%$ of respondents report that smoking is allowed in every room, whereas $34.7 \%$ report that it is not allowed in any room. Another $30.4 \%$ of interviewees didn't know where smoking was allowed in their house. With respect to the frequency of smoking within the home, $48 \%$ of respondents report smoking every day at their home. Fewer people have smoking in their home only weekly (16.1\%), monthly (3\%), less than monthly (3.4\%), and 29.5\% don't know the frequency of smoking in the home.

In addition to household smoking, we also questioned respondents about smoking while at work. Of the people interviewed, $42 \%$ work outside their home and 50\% don't work outside the home, and $8 \%$ did not answer. A little more than onefourth of respondents $(26.2 \%)$ work indoors, $7.1 \%$ work outdoors, and 9\% work both indoors and outdoors. Smoking is allowed in all areas of the work place for $13.2 \%$ of respondents. Another $16.1 \%$ of interviewees reported that their 
workplaces allowed smoking only in some indoor areas. Only $6.6 \%$ of respondents stated that smoking is not allowed in any indoor areas, whereas $2.2 \%$ reported that there is no smoking policy at their work. And $64.1 \%$ don't know. These findings are also positive in relationship to another Middle Eastern country, Egypt. Approximately $60.7 \%$ of respondents to the Egyptian GATS stated that they were exposed to tobacco smoke in the workplace in the past month (World Health Organization 2009). This finding may suggest that legislation in place by the GTSS and Jordanian government are seemingly effective for reducing the exposure to second-hand smoke in the workplace.

Smoking in government buildings was then assessed. In our cohort, $43.7 \%$ of individuals report visiting government buildings or government offices, whereas $48.8 \%$ do not. Another $7.5 \%$ of respondents don't know if they visit government buildings. Of those who visit government buildings, $32.4 \%$ noticed smoking in the buildings, and $9.4 \%$ did not observe smoking. The rest of the respondents either don't know (1.5\%) or did not answer this question (56\%). In Egypt, $72.8 \%$ of GATS respondents observed smoking in government buildings in 2009. The fact that the prevalence of smoking in government buildings is lower in Jordan is very positive and may indicate that the direction the Jordanian government is moving toward is a second-hand smoke-free one.

Some smoking also has been observed inside health care facilities in Jordan. Of people surveyed, $41 \%$ reported visiting health care facilities, $49.1 \%$ did not visit, $1.7 \%$ didn't know if they visited such facilities, and $7.4 \%$ did not answer the 
question. Of the individuals who visited health care facilities, $19.9 \%$ noticed indoor smoking, $19.9 \%$ did not, and $36.1 \%$ did not know. Despite the surprising findings that smoking may be allowed in some health care facilities in Jordan, the prevalence of it is less than what has been reported for Egypt, which is $49.2 \%$ (World Health Organization 2009).

Smoking in other public areas, such as restaurants, public transportation, schools, was also assessed. The majority of respondents (61.6\%) reported visiting restaurants, $30.6 \%$ did not, $0.6 \%$ didn't know, and $7.2 \%$ did not answer. Just over half $(50.5 \%)$ of interviewees observed smoking inside restaurants (compared to $72.7 \%$ in Egypt), $10.4 \%$ did not, $1.3 \%$ did not know, and $38 \%$ did not answer. Many respondents (54.9\%) use public transportation. Of these respondents, $47.6 \%$ reported noticing smoking inside public transportation vehicles (versus $79.6 \%$ in Egypt), $7.4 \%$ did not, $0.9 \%$ do not know, and $44.1 \%$ did not answer this question. In schools, universities, bars or nightclubs, $19.8 \%, 33.6 \%$, and $12.6 \%$, respectively, of respondents reported seeing smoking. However, these last few questions came at the end of the survey, and the vast majority of respondents did not answer these final questions. The most common place to observe smoking in public was in coffee shops, with $98.4 \%$ of recipients reporting smoking inside these establishments (World Health Organization 2009).

Attitudes toward smoking were also investigated using the GATS. Interestingly, many Jordanians believe that smoking in public places should be allowed: $4.2 \%$ believe that smoking should be allowed in hospitals, $16.8 \%$ work places, $30.3 \%$ in 
restaurants, $43.1 \%$ in bars, $9.3 \%$ in public transportation, $7.9 \%$ in schools, $29.1 \%$ in universities, and $4.4 \%$ in places of worship. That being said, $89.2 \%$ of respondents support the law that prohibits smoking insides hospitals, $71.2 \%$ inside workplaces, $71.2 \%$ inside restaurants, $61.5 \%$ inside bars, $42.7 \%$ inside public transportation vehicles, $82.9 \%$ inside schools, $85.4 \%$ inside universities, and $89.6 \%$ inside places of worship.

The majority of respondents $(81 \%)$ know that breathing other people's secondhand smoke causes serious illnesses in non-smokers. When subdividing these beliefs by diseases that second-hand smoke causes, $74.7 \%$ believe that breathing smoke from another person's cigarette causes heart disease, $75.7 \%$ believe it causes lung illnesses in children, and $75.4 \%$ believe it causes lung cancer in adults. In fact, all of these illnesses have been linked to tobacco-smoke- both direct smoking and second-hand smoke with extensive literature supporting such associations (Steenland, Henley et al. 2002; World Health Organization 2008; World Health Organization 2011). (Edwards, Brown et al. 2005; Al-Kayed and Qasem 2006; Hammoudeh, Al-Tarawneh et al. 2006; Fagan, Moolchan et al. 2007; Jemal, Thun et al. 2008)

\section{$\underline{4.3 .5}$ Media}

Some Jordanians admitted to seeing the hazards of cigarettes published in media outlets. Of survey respondents, $17.4 \%$ noticed information about the dangers of smoking cigarettes or that encourages quitting in newspapers or magazines, $24 \%$ saw ads on television, $13 \%$ heard information on the radio, $12.3 \%$ saw it on 
billboards, and $9.7 \%$ saw it elsewhere, such as on the world-wide web. By comparison, only $79.1 \%$ of respondents to the Egyptian GATS reported seeing anti-smoking counter-marketing in any media source. This percentage is more than four times what is seen in Jordan. Although the hazards of second-hand smoking appear to be better appreciated in Jordan than in Egypt, as per the last section, it seems that even more can be done with counter-marketing campaigns. In Egypt, $51.9 \%$ of respondents noticed counter-advertising on television and $18.9 \%$ heard anti-smoking information on the radio (World Health Organization 2009).

By gender cigarettes advertising where sometimes noticed more by female than male. For example females noticed advertisements more than males on television (17.4\% and $15.6 \%$ respectively), billboards ( $12.4 \%$ and 5.8 respectively), in the cinema $(10.5 \%$ and $5.9 \%$, respectively) and elsewhere such as via text messages (5.6\% and $4.8 \%$ respectively) as shown in Figure 28. 


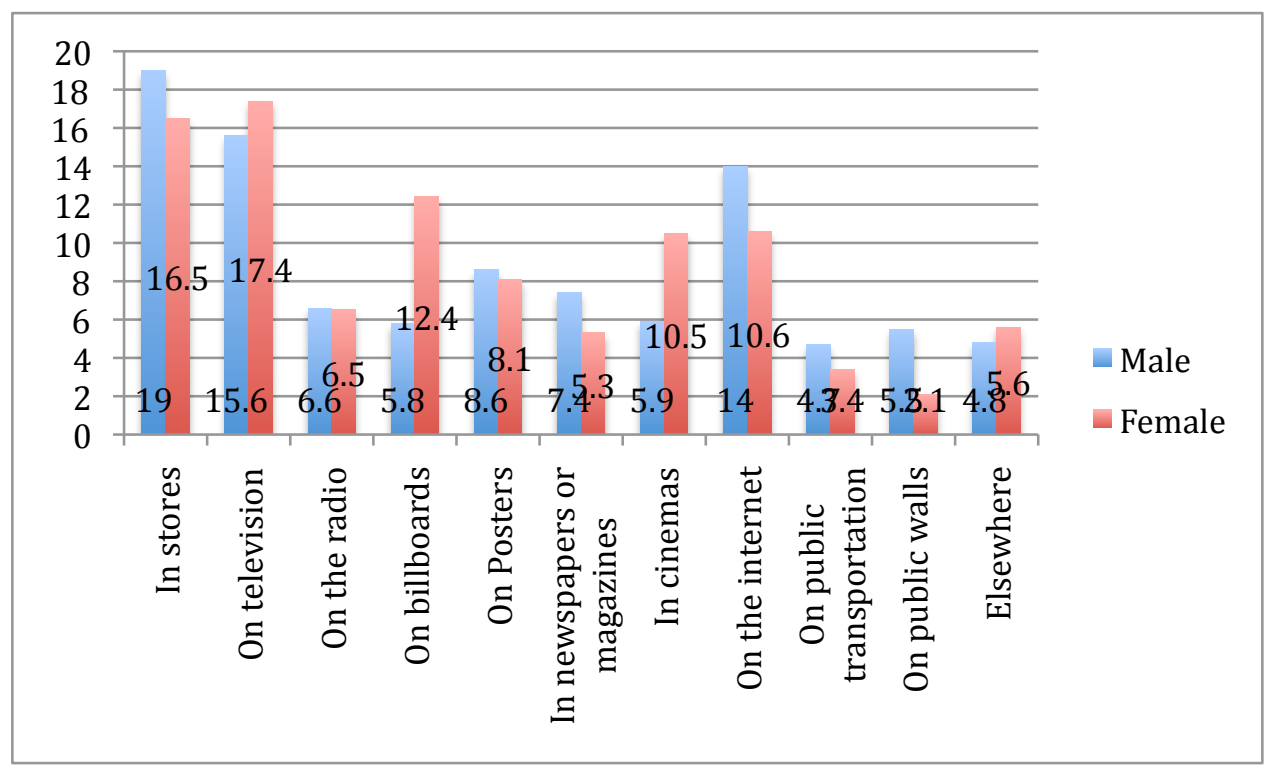

Figure 28. Prevalence of advertisement by type of advertisement and gender

In most of the cases where different types of promotions were noticed, females on generally noticed more of these promotions than males. Advertisement and promotion seems to affect women more than men; $6 \%$ of females reported getting free samples of cigarettes compared to $2.2 \%$ of males. Females reporting getting cigarettes at sale prices were $7.8 \%$ compared to $5.5 \%$, while females report getting free gifts when buying cigarettes by $6.7 \%$ compared to men $6.4 \%$. Females are also getting clothing with cigarettes brand name or logo $(8.9 \%)$ more than males $(7.7 \%)$ as shown in figure 29. 


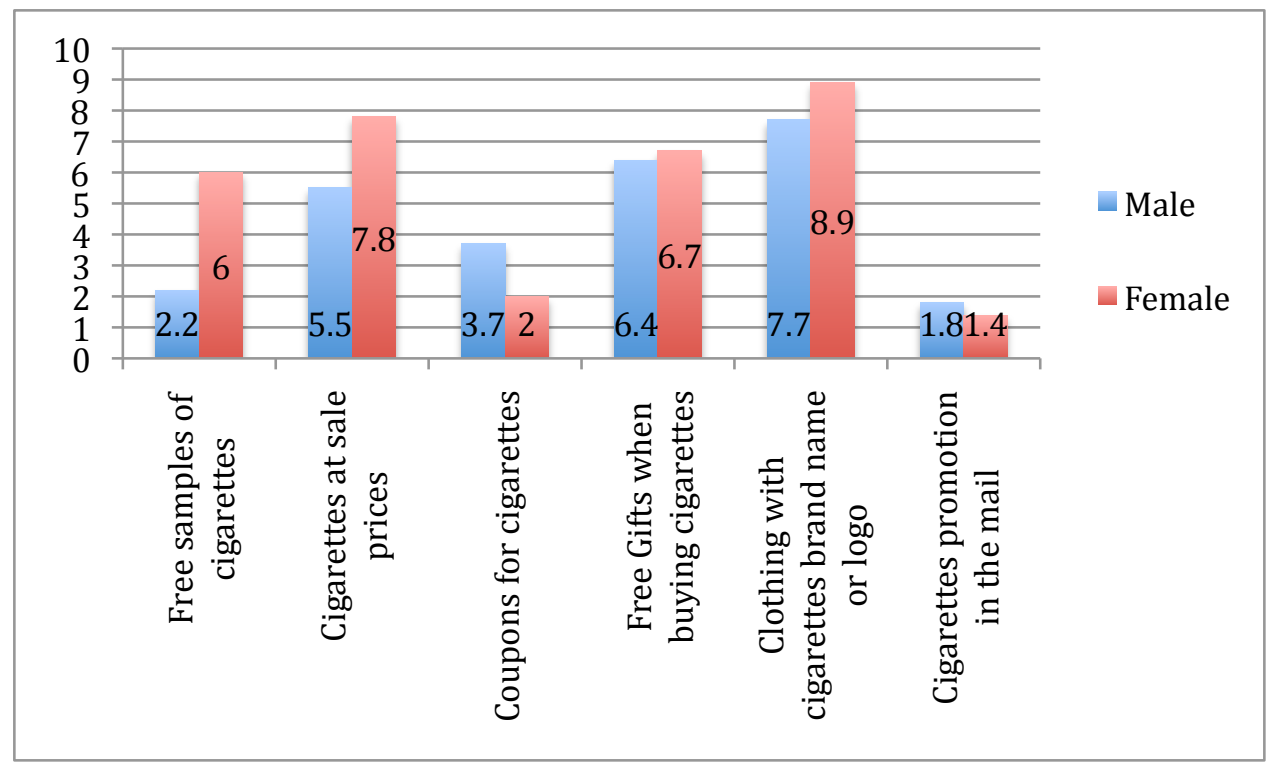

Figure 29. Prevalence of cigarettes promotion by type of promotion and gender

As mentioned earlier, Jordan laws require warnings on cigarette packages. Such warnings must include a picture in addition to words, in order to appeal to any person who may not be able to read and to children (Belbeisi, Al Nsour et al. 2009) The majority of survey respondents (55.4\%) noticed health warnings on cigarettes packages in the last 30 days. Of the people who noticed the warnings, $5.8 \%$ said that the warnings prompted them to think of quitting. However, $30.5 \%$ of those who noticed the warnings said that they were not affected by the warnings at all, and the rest don't know.

\section{$\underline{\text { 4.3.6 Knowledge, Attitudes and Perception }}$}

Attitudes about smoking vary by respondent. Among smokers, $6.2 \%$ think that the current brand they smoke is a little less harmful compared to other cigarettes, 
$12.1 \%$ believes that brand makes no difference, $2.5 \%$ believe their brand of cigarette is a little more harmful than others, $79.2 \%$ did not answer.

Of respondents, $14.9 \%$ believe that cigarettes are addictive but $24.4 \%$ do not, and $60.7 \%$ do not know. Among individuals, $29.2 \%$ reported that the current labeling on cigarettes led them to think of quitting, whereas $72 \%$ did not, and the rest don't know.

Of the interventions used to reduce tobacco use, the most successful is raising the price of tobacco. For the most part, raising the price of tobacco products involves raising the price of the excise taxes at the city, state, and/or federal levels. Studies from the United States have shown that increasing the price of cigarettes by $10 \%$ reduces consumption by $4 \%$ (The Task Force on Community Preventive Services 2005).To prevent smoking in Jordan, $56 \%$ of respondents favor increasing taxes on tobacco products, whereas $26.5 \%$ oppose such measures, and the rest don't know.

\subsubsection{Wealth}

In the GATS some questions about household wealth are used to obtain information about the economics of cigarette use in a particular question. Part A question A6 asks respondents about utilities and other household items, such as electricity, a home phone, and a cell phone. A dichotomous variable was created, coded 0 and 1. A 0 indicated that a household does not have the particular item, 
and 1 means that the household does have the item. Based on this system, a wealth index was constructed.

The wealth index was calculated using the responses from A6 (a-j). The index weights ownership by the inverse of the percentage of population that possesses the particular asset.

Let $\mathrm{i}$ be asset $\mathrm{i}$ from the list of 10 asset categories:

$w_{i}=1 /$ (mean of Asset $\mathrm{i}$ indicator variable)

Household j's wealth index is therefore:

$$
\text { Wealth }=\sum_{i=1}^{10} w_{i} \cdot f_{i j}
$$

Where fij is the indicator variable for asset $\mathrm{j}$ that 1 if household owns that asset $\mathrm{j}$ and 0 otherwise. The highest percentage of quantity purchased by the fourth wealth quintile was 45 , and the lowest $0.39 \%$ by the lowest quintile.

\subsubsection{Demand Analysis}

\subsubsection{Outcome Variable: Propensity and Intensity of Cigarettes} Consumption

Since the survey provided information about cigarette price, I focused on cigarettes since there is no actual measure of prices of other types of tobacco. The dependent variables of interest are two measures of cigarette use in Jordan. The first one is the intensity variable, the amount smoked by a smoker. The second one is the propensity to consume or an individual's decision to smoke. 


\subsection{The propensity to consume variable}

The survey asks individuals about whether they are smoking on a daily basis, less than daily basis, or not at all. For each of these outcomes a number of 1,2 , or 3 was assigned, respectively.

For this variable (propensity to consume), I aggregated the daily and less than daily smokers into one group, smokers, and created a dichotomous variable called "propensity to smoke." For cigarettes, the dichotomous variable, capturing participation, is 1 if an individual is 15 years and above and reports smoking any positive number of cigarettes on a daily basis or less than daily basis. The dichotomous variable is 0 if no smoking is reported. Packs per day was used to measure of cigarette consumption.

\subsection{The Intensity to smoke variable}

In part B of the survey, respondents are asked to report the quantity of cigarettes smoked per day for daily smokers and per week for less than daily smokers. Then, total quantity in packs smoked per day was calculated.

\subsubsection{Explanatory Variables}


1-Price: The main economic variable of interest is price. Respondents were asked to report the quantity of cigarettes purchased at the most recent time cigarettes were bought as well as the price they paid for that purchase. From these findings, an average price per pack was calculated. However, self-reported prices face the problem of endogeneity. One way to correct for this (Ross and Chaloupka 2003) is to create a local or geographically based measure of individual prices. This will also help to solve the problem of missing data. To overcome this problem I have created an average price for each of the 12 governorates and assigned the average price to smokers and non-smokers and missing values in each governorate.

2- Age: I created four categorical Age variables (15-18, 19-23, 23-30, 31-40, 4150, 51-60, 60+). From these seven categories, I assigned a 1 if the respondent's age fell in that particular range and 0 otherwise. The $60+$ category was omitted in the regression model to avoid multicollinearity among these age groups.

3- Gender: $1=$ Male and $2=$ Female in the survey and subsequent raw data. I transformed this into a dichotomous variable with 1 indicating male and 0 indicating female.

4- Education: I created eight categorical Education variables based on the 8 available choices in the survey $(1,2,3,4,5,6,7,8)$. From these eight categories, I assigned a 1 if the respondent's education matched that particular choice and 0 otherwise.

5- Work status: I created eight categorical Work Status variables based on the 8 available choices in the survey $(1,2,3,4,5,6,7,8)$. From these eight categories, I assigned a 1 if the respondent's work status matched that particular choice and 0 otherwise. 
6-Total number of individuals living in household: I created three categorical Household variables based on ranges of total number of people in a household (13, 4-6, 7+). From these three categories, I assigned a 1 if the respondent's total household number fell in that particular range and 0 otherwise. The $7+$ category was omitted in the regression model to avoid multicollinearity among these variables

7-Total number of males $>15$ years old in household: I created three categorical variables here based on ranges of total number of males over the age of 15 in a household $(0-1,2-3,4+)$. From these three categories, I assigned a 1 if the respondent's total household number of males over the age of 15 fell in that particular range and 0 otherwise. The $4+$ category was omitted in the regression model to avoid multicollinearity among these variables.

8- Rules of smoking at home: Question E1 in the second-hand smoke section inquires about smoking inside the home if it's allowed (1), not allowed with exceptions (2), never allowed (3), no rules (4), and don't know (7). I created four dichotomous variables for each group of answers and assigned a 1 if an individual's rule of smoking at home fits into the category and 0 other wise. I merged the "don't know" with no rules category. The never allowed category was deleted to avoid multicollinearity.

9-Rules of smoking at work: Question E7 in the second-hand smoke section inquired about smoking in the workplace. The following numbers were assigned: If allowed (1), allowed in some indoor areas (2), never allowed (3), no policy (4), and don't know (7). I created four dichotomous variables for each group of answer and assign 1 if an individual's rule of smoking at home fits into the 
category and 0 other wise. The never allowed category was deleted to avoid multicollinearity.

10-Wealth: This was calculated as indicated above.

\subsubsection{Price Elasticity of Cigarette Demand in Jordan}

The price elasticity of smoking participation, conditional price elasticity of demand, and total price elasticity were estimated using a two-part model as described by Cragg (1971). The two-part model assumes that households first decide whether or not they will smoke; and then if they decide to smoke, they choose how much to smoke.

\subsection{Part One Model: Propensity to Smoke}

Logit specification (World Health Organization ,2008) was described in the toolkit for GATS analysis as follows:

"The probabilities for a logit model take the form:

$$
\begin{aligned}
& P(Y=1 \mid X)=\Lambda\left(B^{\prime} x\right)=\frac{\exp \left(B^{\prime} x\right)}{1+\exp \left(B^{\prime} x\right)} \\
& P(Y=0 \mid X)=1-\Lambda\left(B^{\prime} x\right)
\end{aligned}
$$

The expected value of the dependent variable takes on the following form:

$$
E(y \mid x)=0 *\left(1-\Lambda\left(B^{\prime} x\right)\right)+1^{*} \Lambda\left(B^{\prime} x\right)=\Lambda\left(B^{\prime} x\right)
$$

Where: $\quad \mathrm{x}=\mathrm{k} \times 1$ vector of explanatory variables 


$$
\mathrm{B}=\mathrm{k} \times 1 \text { vector of coefficients corresponding to the explanatory }
$$

variables

$$
\Lambda=\text { the logistic distribution function }
$$

The marginal effect of a change in one of the explanatory variables on the expected value of the observed dichotomous smoking variable is:

$\frac{\partial E(y \mid x)}{\partial X_{k}}=B_{k} \frac{\exp \left(B^{\prime} x\right)}{\left(1+\exp \left(B^{\prime} x\right)\right)^{2}}=B_{k} \Lambda\left(B^{\prime} x\right)\left(1-\Lambda\left(B^{\prime} x\right)=B_{k} E(y \mid x)(1-E(y \mid x))\right.$

Where $\mathrm{Bk}$ is the coefficient on the kth variable (for example, price).

As can be seen in the equation above, the derivative of $\mathrm{E}(\mathrm{y} \mid \mathrm{x})$ with respect to $\mathrm{xk}$ varies with the level of $x k$ and the other variables in the model. It is standard practice to evaluate the derivatives for an average member of the sample, or in other words, at the mean values of all the $\mathrm{x}$ variables in the sample. The following formula can be used to derive the elasticity of $\mathrm{E}(\mathrm{y} \mid \mathrm{x})$ with respect to the kth variable:

$\frac{\partial E(y \mid x)}{\partial X_{k}} \frac{\bar{x}_{k}}{E(y \mid x)}=B_{k} E(y \mid x)(1-E(y \mid x)) \frac{\overline{x_{k}}}{E(y \mid k)}=B_{k} \bar{x}_{k}(1-E(y \mid x))$

Where: $B_{k} \bar{x}=$ the average value of the explanatory variable (i.e. price)

$\mathrm{E}(\mathrm{y} \mid \mathrm{x})=$ The average value of the dependent variable (i.e. tobacco use)."(World Health Organization 2010) 


\subsection{Part two model: Amount smoked by smokers}

Average smoking is usually measured as the number of cigarettes smoked per day. It is often termed conditional demand because it measures the number of cigarettes smoked on a daily, weekly, or monthly basis conditional on being a smoker (observations for nonsmokers are not included in the second part of the two- part model).

"The ordinary least squares is typically used to estimate a log-linear demand equation. A log-linear demand function can be expressed as:

$\ln \mathrm{Yjl}=\mathrm{a} 0+\mathrm{a} 1 \mathrm{Pl}+\mathrm{a} 3 \mathrm{Xjl}+\mathrm{et}, \mathrm{Y}>0$

where:

$\ln \mathrm{Yjl}=$ natural logarithm of average smoking by the jth individual in the lth locality

$\mathrm{Pl}=$ real average price of cigarettes per pack in the 1 th locality

$\mathrm{Xjl}=\mathrm{a}$ vector of socio-economic and demographic characteristics

et $=$ an error term

Unlike the linear equation, where the marginal effect is constant and can be expressed as:

$$
\frac{d y}{d p}=a_{1}
$$

the marginal effect of the log-linear equation depends on the value of the dependent variable, Y. In particular, the marginal effect of price on average smoking is: 


$$
\frac{d y}{d p}=a_{1} y
$$

Therefore, the price elasticity of demand is:".(World Health Organization 2010)

$$
\frac{d y}{d p} * \frac{p}{y}=a_{1} y * \frac{p}{y}=a_{1} p
$$

\subsection{Total Price Elasticity of Demand}

The total price elasticity of demand measures the percentage change in the number of cigarettes consumed as a results from a one-percent increase in the price of cigarettes. The total price elasticity of demand can be derived by summing the price elasticities of demand from the first and second part of the two-part model (i.e., summing the prevalence price elasticity of demand and the conditional price elasticity of demand).

\subsubsection{Regression results}

Table I represents regression results of Log Quantity smoked 
TABLE I

LOG LINEAR REGRESSION RESULTS OF QUANTITY OF CIGARTTES SMOKED

\section{Linearized}

LNQuantity $\quad$ Coef. Std. Err. $\quad \mathrm{t} \quad \mathrm{P}>|\mathrm{t}| \quad$ [95\% Conf. Interval]

\begin{tabular}{|c|c|c|c|c|c|c|}
\hline Price | & -.2354284 & .0747214 & -3.15 & 0.002 & -.3820004 & -.0888564 \\
\hline Wealth & .012227 & .0037113 & 3.29 & 0.001 & .004947 & .0195069 \\
\hline Gender & .0204045 & .0327627 & 0.62 & 0.534 & -.0438622 & .0846713 \\
\hline Age 15-18 | & -.1271424 & .1651061 & -0.77 & 0.441 & -.4510113 & .1967265 \\
\hline Age 19-23 | & .1006216 & .0826327 & 1.22 & 0.224 & -.061469 & .2627122 \\
\hline Age 24-30 | & .2114409 & .0816203 & 2.59 & 0.010 & .0513363 & .3715456 \\
\hline Age $31-40$ & .1695556 & .0739319 & 2.29 & 0.022 & .0245323 & .314579 \\
\hline Age 41-50 & .1748241 & .0751377 & 2.33 & 0.020 & .0274356 & .3222127 \\
\hline Age 51-60 & .3074708 & .0843934 & 3.64 & 0.000 & .1419263 & .4730153 \\
\hline E1 | & .2522865 & .0996348 & 2.53 & 0.011 & .0568448 & .4477282 \\
\hline E2 & .1340855 & .064227 & 2.09 & 0.037 & .0080992 & .2600719 \\
\hline E3 & .3367951 & .1016309 & 3.31 & 0.001 & .137438 & .5361523 \\
\hline E4 & .4529686 & .0811774 & 5.58 & 0.000 & .2937327 & .6122045 \\
\hline E5 & .0701201 & .0574014 & 1.22 & 0.222 & -.0424773 & .1827174 \\
\hline E6 & .043343 & .0460598 & 0.94 & 0.347 & -.0470069 & .1336929 \\
\hline E7 | & .103294 & .0351748 & 2.94 & 0.003 & .0342958 & .1722923 \\
\hline HH1 | & -.0443723 & .031862 & -1 & 0.16 & -.106872 & $8 \quad .0181282$ \\
\hline
\end{tabular}


TABLE I (continued)

LOG LINEAR REGRESSION RESULTS OF QUANTITY OF CIGARTTES SMOKED

\section{Linearized}

LNQuantity $\mid \quad$ Coef. Std. Err. $\quad \mathrm{t} \quad \mathrm{P}>|\mathrm{t}| \quad$ [95\% Conf. Interval]

\begin{tabular}{llllllll} 
HH2 & -.0247681 & \multicolumn{2}{c}{.0286102} & -0.87 & 0.387 & -.0808893 & .031353 \\
HHM1 & -.082859 & .0451877 & -1.83 & 0.067 & -.1714983 & .0057803 \\
HHM2 & -.0906386 & .0419034 & -2.16 & 0.031 & -.1728354 & -.0084417 \\
Religion $\mid$ & .0153648 & .0376503 & 0.41 & 0.683 & -.0584892 & .0892188 \\
Married $\mid$ & .0035005 & .0214774 & 0.16 & 0.871 & -.0386292 & .0456302 \\
Employed $\mid$ & -.1739797 & .0651001 & -2.67 & 0.008 & -.3016789 & -.0462806 \\
Student $\mid$ & -.2948941 & .0714008 & -4.13 & 0.000 & -.4349526 & -.1548356 \\
Unemployed $\mid$ & -.1258511 & .0775849 & -1.62 & 0.105 & -.2780401 & .0263379 \\
E11 $\mid$ & .0137235 & .0260783 & 0.53 & 0.599 & -.0374312 & .0648782 \\
E12 $\mid$ & -.0061796 & .0335937 & -0.18 & 0.854 & -.0720764 & .0597173 \\
E13 & -.0121698 & .0396392 & -0.31 & 0.759 & -.0899252 & .0655857 \\
E71 & .0050162 & .0296779 & 0.17 & 0.866 & -.0531994 & .0632317 \\
E72 | & .0287751 & .0332269 & 0.87 & 0.387 & -.0364021 & .0939523 \\
E73 & .0021321 & .0666291 & 0.03 & 0.974 & -.1285663 & .1328304 \\
Constant $\mid$ & .4624421 & .1542601 & 3.00 & 0.003 & .1598485 & .7650356
\end{tabular}


Where

E1 is the no formal schooling level of education

E2: Less than primary school completed

E3: Primary school completed

E4: Less than secondary school completed

E5: Secondary school completed

E6: High school completed

E7: College/university completed

HH1: Number of individuals at home from 1-3

HH2: Number of individuals at home from 4-6

HHM1: Number of males at home from 0-1

HHM2: Number of males at home from 2-3

E11: Smoking allowed at home

E12: Smoking not allowed at home

E13: Smoking not allowed with exceptions at home

E71: Smoking allowed anywhere at work

E72: Smoking allowed only in some areas at work

E73: there is no policy for smoking at work

Using the multivariate regression model we found that the price correlated with the quantity smoked. The results were statistically significant. 
Wealth was positively correlated with quantity smoked and the results were statistically significant.

Gender had a positive correlation with the quantity smoked. Males tend to smoke a higher quantity than females however the results were statistically insignificant.

If the individual was aged 15-18 then the individual was less likely to smoke more compared to those who are 60 and above. Those in age groups 19-23, 24-30, 31$40,41-50$ or 51-60 are more likely to smoke more than those who are 60 and above. However the $\mathrm{P}$ value for age group 24-30, 31-40, 41-50 and 51-60 was statistically significant.

Individuals with less than primary school completed, primary school, less than secondary school, secondary school, high school, and College/university School completed are more likely to smoke more than those with postgraduate studies completed.

The only education levels that were significantly associated with smoking were less than primary school, primary school, less than secondary school, secondary school completed and College/university School completed.

If the number of individuals living at home was 1-3 or 4-6 then the individual is less likely to smoke a higher quantity than if the number of individuals living at the home is more than 6 . The results were insignificant.

If the number of males living in the house was $0-1$ or $2-3$, then the individual was less likely to smoke more than if number of males living at home is greater than 
or equal 4. The results were statistically significant for those males living at home from $2-3$.

Being Muslim was associated with a likelihood of smoking more compared to Christians. However the results were insignificant.

Married individuals were more likely to smoke more compared to single individuals, however the results were statistically insignificant.

Employed persons, students and unemployed were less likely to smoke more than those not in the labor market.

However the results were statistically insignificant for unemployed.

When smoking is allowed at home then the individual is more likely to smoke than if smoking was never allowed. The same results were obtained if smoking was not allowed with some exceptions and if smoking has no rules at home. The results were statistically significant.

If smoking was allowed at work or in some areas at work or has no policy then the individual was more likely to smoke more than if smoking was never allowed. The results were statistically insignificant.

The following table summarizes the effect of price and other variables in determining the decision to smoke 


\section{TABLE II}

LOGISTIC REGRESSION RESULTS OF THE DECISION TO SMOKE CIGARTTES

| Linearized

propensity $\mid \quad$ Coef. Std. Err. $\quad t \quad P>|t| \quad$ [95\% Conf. Interval]

\begin{tabular}{|c|c|c|c|c|c|c|}
\hline Price & -.267685 & .260398 & -1.030 & 0.304 & -.7782172 & .2428473 \\
\hline Wealth & -.0600438 & .0124627 & -4.82 & 0.000 & -.084478 & -.0356095 \\
\hline Gender | & 1.46512 & .0926333 & 15.82 & 0.000 & 1.283504 & 1.646735 \\
\hline Age $15-18$ & -1.46595 . & .3571398 & -4.10 & 0.000 & -2.166152 & -.7657471 \\
\hline Age 19-23 & -.2972041 & .2904332 & -1.02 & 0.306 & -.8666227 & .2722145 \\
\hline Age 24-30 & -.3187976 & .2756889 & -1.16 & 0.248 & -.8593088 & .2217135 \\
\hline Age 31-40 & .3130909 & .277908 & 1.13 & 0.260 & -.2317711 & .8579529 \\
\hline Age $41-50$ & .0818555 & .277351 & 0.30 & 0.768 & -.4619144 & .6256255 \\
\hline Age 51-60 & .4496224 & .2849746 & 1.58 & 0.115 & -.1090943 & 1.008339 \\
\hline E1 | & .5428369 & .3066654 & 1.77 & 0.077 & -.0584062 & 1.14408 \\
\hline E2 & 1.8229 & .377549 & 4.83 & 0.000 & 1.082684 & 2.563116 \\
\hline E3 & -.8667884 & 4.2840466 & -3.05 & $5 \quad 0.002$ & -1.423686 & $6-.3098912$ \\
\hline E4 | & -.5797505 & ; 2023994 & -2.86 & 0.004 & -.9765714 & -.1829296 \\
\hline E5 | & .1819908 & .1809642 & 1.01 & 0.315 & -.1728047 & .5367862 \\
\hline E6 & .0428478 & .1492666 & 0.29 & 0.774 & -.2498019 & .3354975 \\
\hline E7 & .1725646 & .1313976 & 1.31 & 0.189 & -.0850514 & .4301806 \\
\hline
\end{tabular}


TABLE II (continued)

LOGISTIC REGRESSION RESULTS OF THE DECISION TO SMOKE CIGARTTES

\begin{tabular}{|c|c|c|c|c|c|c|}
\hline \multirow[b]{2}{*}{ propensity } & \multicolumn{2}{|l|}{ Linearized } & \multirow[b]{2}{*}{$\mathrm{t}$} & \multirow[b]{2}{*}{$\mathrm{P}>|\mathrm{t}|$} & \multirow{2}{*}{\multicolumn{2}{|c|}{ [95\% Conf. Interval] }} \\
\hline & Coef. & Std. Err. & & & & \\
\hline HH1 | & .0213979 & .1085313 & $0.20 \quad 0$ & 0.844 & -.1913868 & .2341827 \\
\hline HH2 | & .1138625 . & .1049237 & 1.090 & 0.278 & -.0918492 & .3195741 \\
\hline HHM1 | & -.0252274 & .1668824 & -0.15 & 0.880 & -.3524145 & .3019596 \\
\hline HHM2 | & .3786607 & .1697441 & 2.23 & 0.026 & .0458631 & .7114583 \\
\hline Religion | & -.0189571 & .1622824 & -0.12 & 0.907 & -.3371253 & .2992111 \\
\hline Married | & .054013 . & .0785261 & 0.690 & 0.492 & -.0999439 & .20797 \\
\hline Employed | & 1.341223 & .2760835 & 4.86 & 0.000 & .7999386 & 1.882508 \\
\hline Student & 1.475803 & .2961982 & 4.98 & 0.000 & .8950813 & 2.056524 \\
\hline Unemployed | & -.0812614 & .289604 & -0.28 & 0.779 & -.6490544 & .4865316 \\
\hline E11 | & -.1306297 & .1033522 & -1.26 & 0.206 & -.3332604 & .0720009 \\
\hline E12 | & -.0313801 & 1.1166132 & -0.27 & $\begin{array}{ll}7 & 0.788\end{array}$ & -.26001 & .1972497 \\
\hline E13 | & .0435751 & .1466898 & 0.30 & 0.766 & -.2440225 & .3311728 \\
\hline E71 | & .1338488 & .1163493 & 1.15 & 0.250 & -.0942637 & .3619614 \\
\hline E72 | & .0534407 & .1035191 & 0.52 & 0.606 & -.1495172 & .2563986 \\
\hline E73 | & -.1411016 & .2567649 & -0.55 & 0.583 & -.6445108 & .3623075 \\
\hline _cons $\mid$ & -1.713209 & .631311 & -2.71 & 0.007 & -2.950947 & -.4754704 \\
\hline
\end{tabular}


Using the logistic regression model we found that the price is negatively correlated with the decision to smoke however the results were not statistically significant.

Wealth was negatively associated with the decision to smoke and the results were statistically significant.

Gender had a positive correlation with the decision to smoke. Males were more likely to smoke than females. The results were statistically significant.

If the individual belongs to the age groups $15-18$ or $19-23$ or $24-30$, then the individual is less likely to smoke than those who are 60 and above. Those in age groups $31-40$ or 41-50 or 51-60 were more likely to smoke than those who are 60 and above. The results were only statistically significant for individuals aged 1518.

Those with no formal schooling, less than primary schooling, secondary school, high school completed, and college/university completed are more likely to smoke than those with a post graduate degree. Less than secondary school, and secondary school completed are less likely to smoke than those with a post graduate completed.

If the number of individuals living at home was 1-3 or 4-6 then the individual is more likely to smoke than if the number of individuals living at the home is more than 6 members. The results were statistically insignificant 
If the number of males living at home from $0-1$ then the individual is less likely to smoke compare to males living at home from 4 and above. If the number of males living at home is from 2-3 then the individual is more likely to smoke than if the number of males is greater then 4 . However the results were statistically insignificant.

Religion was negatively associated with smoking; being a Muslim was associated with less likelihood of smoking compared to Christians. However the results were insignificant.

Married individual were more likely to smoke compared to single individuals in this study.

Employed persons and students persons were more likely to smoke than those not in the labor market. The results were significant. Those unemployed were less likely to smoke than those not in the labor market, however the results were statistically insignificant.

If smoking was allowed at home then the individual is less likely to smoke than if smoking was never allowed. The same results were found if smoking was not allowed with some exceptions. If there were no rules at home then you are more likely to smoke than if smoking was never allowed. The results were not statistically significant.

If smoking was allowed at work or in some areas at work then the individual was more likely to smoke than if smoking was never allowed. If there were no 
policies about smoking at work then the individual was less likely to smoke than if smoking was never allowed. The results were not statistically significant.

It is worth mentioning here that including the rules of smoking at home might be endogenous with smoking. When eliminating the rules of smoking at home from the regression the coefficients did not change by much.

The elasticity of smoking in Jordan was estimated to be (-0.6) with smoking participation elasticity equals to -0.365 and conditional price elasticity equals to ($0.235)$.

Smoking elasticity by age groups was for those ages $15-23(-1.2), 24-30(-1.01)$, $31-40(-1.11), 41-50(-0.75), 51-60(-0.05), 0 v e r 60(-0.059)$.

An additional $10 \%$ increases in the price of cigarettes would bring about a $6 \%$ reduction in cigarette consumption and increased tax revenues.

Elasticity of smoking for females was estimated to be -0.008 and for males -0.81 .

\subsubsection{Discussion and Conclusions}

To our knowledge the GATS survey is the largest survey conducted in Jordan that sheds some light on the Economics of smoking in Jordan a Middle Eastern developing country. In the middle east, the GATS survey was only performed in Egypt in 2009, an effort supported by the CDC and the WHO. Given the increasing number of tobacco related diseases in Jordan and the lack of data on economics of tobacco use in Jordan we sought to investigate an unmet need in 
Jordan and conduct a national survey( GATS) that is comparable to other developing countries.

In this cross-sectional study that included approximately 4820 individuals in Jordan; we concluded the following:

\subsubsection{Tobacco Prevalence}

In Jordan in 2011 the prevalence of tobacco use among those aged 15 and above, was $42.2 \%$. by gender the overall prevalence of tobacco use in men and women was $55.9 \%$ and $23.7 \%$ respectively.

The highest prevalence of smoking was found to be located in the Ajlun governorate in the Northern part of Jordan, in which nearly half (52.4\%) of all individuals currently use tobacco. The lowest prevalence was in Balqa, in the Middle part of Jordan in which (29\%) admit to using tobacco.

Despite this limitation in not accounting for urban and rural areas, our results suggests that a specific attention should be paid to certain regions that have higher smoking prevalence. Future studies to understand the social, health and economic differences between regions in Jordan would be of great interest.

The GATS divided smokers into daily and non-daily or weekly smokers. Among total population $32.2 \%$ were daily smokers and $6 \%$ were less than daily smokers. Although daily smoking is more prevalent than non daily smoking, preventing those who are less than daily smokers from becoming a daily smokers is needed. Special educational programs that are tailored to help those non daily smokers quit and prevent them from becoming a daily smokers is needed at this point. 


\subsubsection{Cigarettes Prevalence}

The overall prevalence of cigarettes use in 2011 is $35.2 \%$ for those aged 15 and above.

Among those who aged 18 and above, $34.2 \%$ smokes cigarettes. Male prevalence of cigarettes smoking is $48.9 \%$ while female prevalence is $13.8 \%$.

In the BRFS conducted in Jordan 2007 using a multistage stratified cluster technique to obtain a national estimates of smoking among adults aged 18 and above, showed the total prevalence of cigarettes use was estimated to be $28 \%$, $48.2 \%$ for men and $5 \%$ for women. Our results show that an increase of cigarettes smoking prevalence by $6.2 \%$ between 2007 and 2011, and this increase is due to increase prevalence of cigarettes consumption among women. It is alarming that the prevalence of cigarettes smoking in women had almost tripled between 2007 and 2011,while the prevalence in men remains the same. This increase among women is critical as smoking is tightly linked to autoimmune disorders, which most commonly affect women in addition to the other health harms of cigarettes smoking. Of note the highest prevalence of smoking cigarettes among women was highest among those aged 45-54 and 35-44.

If we look at real prices to justifying this increase in women prevalence, in 2007 the tobacco price index relative to the overall price index was $98 \%$, as was reported by the department of statistics in Jordan, whereas in 2011 this percentage was $97.5 \%$. Basically real prices of tobacco have decreased by $0.5 \%$. From the smoking participation elasticity for women calculated above in the results chapter 
we noticed that the increase in the prevalence of smoking by is not explained by prices and other factors are driving up this number.

Looking at the indicators driven from the GATS we can find several explanations for the increase in female prevalence of smoking cigarettes in specific and tobacco total prevalence in general.

1- Advertisements: Our results suggest that females noticed advertisements more than males on television (17.4\% and $15.6 \%$ respectively), billboards (12.4\% and 5.8 respectively), cinema ( $10.5 \%$ and $5.9 \%$, respectively) and elsewhere like text messages (5.6\% and $4.8 \%$ respectively). The data also showed that $6 \%$ of females reported getting free samples of cigarettes compared to $2.2 \%$ of males. women reporting getting cigarettes at sale prices were $7.8 \%$ compared to $5.5 \%$, while females report getting free gifts when buying cigarettes by $6.7 \%$ compared to men $6.4 \%$. Females are also getting clothing with cigarettes brand name or logo $(8.9 \%)$ more than males (7.7\%). Although tobacco advertisements are prohibited by law in Jordan, but it seems that laws are not well enforced and tobacco companies are still trying to get to people through different channels to encourage them using tobacco products.

The WHO in its report on global tobacco epidemic, 2008 acknowledged that tobacco use is growing in middle and low income countries due to the increase in population size accompanied by tobacco industry targeting and ensuring that people become tobacco users and addicted each year. Our results provide an insight to the magnitude of tobacco use in Jordan as well as advertisement and promotions for cigarettes. We found that in general women are more exposed to 
tobacco promotions than men, and in some cases women are exposed to tobacco advertisement more than men. In the literature advertisement is known as one of the main factors that affect the demand. This might be the case in explaining why women have a high prevalence of smoking.

2- Exposure to cigarettes smoke: Within the home, $34.9 \%$ of respondents report that smoking is allowed in every room, whereas $34.7 \%$ report that it is not allowed in any room. Another 30.4\% of interviewees didn't know where smoking was allowed in their house. With respect to the frequency of smoking within the home, $48 \%$ of respondents report smoking every day at their home. Fewer people have smoking in their home only weekly (16.1\%), monthly (3\%), less than monthly (3.4\%), and $29.5 \%$ don't know the frequency of smoking in the home.

In addition to household smoking, of the people interviewed, $42 \%$ work outside their home and 50\% don't work outside the home, and $8 \%$ did not answer. A little more than one-fourth of respondents (26.2\%) work indoors, $7.1 \%$ work outdoors, and $9 \%$ work both indoors and outdoors. Smoking is allowed in all areas of the work place for $13.2 \%$ of respondents. Another $16.1 \%$ of interviewees reported that their workplaces allowed smoking only in some indoor areas. Only $6.6 \%$ of respondents stated that smoking is not allowed in any indoor areas, whereas $2.2 \%$ reported that there is no smoking policy at their work. And $64.1 \%$ don't know. This finding reflects that individuals in general and women in specific are exposed to smoking at home, work, and other places 
Smoking in government buildings was then assessed. In our cohort, $43.7 \%$ of individuals report visiting government buildings or government offices, whereas $48.8 \%$ do not. Another $7.5 \%$ of respondents don't know if they visit government buildings. Of those who visit government buildings, $32.4 \%$ noticed smoking in the buildings, and $9.4 \%$ did not observe smoking. The rest of the respondents either don't know (1.5\%) or did not answer this question (56\%).

Some smoking also has been observed inside health care facilities in Jordan. Of people surveyed, $41 \%$ reported visiting health care facilities, $49.1 \%$ did not visit, 1.7 didn't know if they visited such facilities, and $7.4 \%$ did not answer the question. Of the individuals who visited health care facilities, 19.9\% noticed indoor smoking, $19.9 \%$ did not, and $36.1 \%$ did not know. Smoking in other public areas, such as restaurants, public transportation, schools, was also assessed. The majority of respondents (61.6\%) reported visiting restaurants, $30.6 \%$ did not, $0.6 \%$ didn't know, and $7.2 \%$ did not answer. Many respondents (54.9\%) use public transportation. Of these respondents, $47.6 \%$ reported noticing smoking inside public transportation vehicles, $7.4 \%$ did not, $0.9 \%$ do not know, and $44.1 \%$ did not answer this question. In schools, universities, bars or nightclubs, $19.8 \%, 33.6 \%$, and $12.6 \%$, respectively, of respondents reported seeing smoking. However, these last few questions came at the end of the survey, and the vast majority of respondents did not answer these final questions. The most common place to observe smoking in public was in coffee shops, with $98.4 \%$ of recipients 
reporting smoking inside these establishments (World Health Organization 2009).

Being exposed to second hand smoking might be a reason to initiate smoking habits and does not help quitting.

Many additional factors could contribute to this change in smoking behavior among women in Jordan. We list below the author's views and hypothesis regarding this phenomenon however this is not supported by any published data or our own data given the lack of research in this critical area.

Regardless of constitutional guarantees in Jordan and supports for women, women continue to face legal forms of discrimination that pervade every aspects of their life. We hypothesize that the physiological impact of gender discrimination may contribute to adopting unhealthy life style habits like cigarettes smoking. Smoking might be a way for women to show their independence and empowerment. Furthermore cigarettes smoking by women give the women the feeling of equality, confidence, empowerment and attraction.

Smoking among women is now more socially accepted than before as a result we would expect women to report their smoking more than before. From 2003-2007 many effort of a number of Jordanian non government organizations suggested improvements in women's rights in four basic areas : (a) legal; (b) economic; (c) social/ cultural; (d) media. The recommendation was to integrate human rights for women and children and be able to take decisions without the consent of men. Since that time women start gaining power and many social issues have changed to support women's rights and equality with men. Thus smoking might not be an 
accepted habit for women before 2007 and with the new legislations women start gaining enough power to be able to report their smoking habits without an interference from family especially male members.

Furthermore women beliefs about smoking and weight loss might be driving up this prevalence.

The emergence of Internet in a broad manner after 2007 contributed to the change in many social issues especially women's issues through having access to magazines and other media that were not available without the Internet. Information from many different cultures entered the Jordanian society and made some changes in the society. With this movement the barriers between the Jordanian and other cultures have been removed with this technological movement that leads to a social changes in the Jordanian society.

Moreover Jordan as a politically stable country, many others from different Middle Eastern and neighbor countries seek to live in Jordan given the political instability in those countries. For example many Iraqi individuals are living now in Jordan after the war in Iraq, thus we believe a new wave of different social factors have entered the Jordanian society that leads to a change in the social views to many different issues such as smoking habits. Unfortunately the GATS lack such an indicators, but the prevalence of smoking among women in Jordan is an alarming phenomenon that is multifactor and complex to understand. It deserves further well-designed research to reverse this trend given the importance of women in raising children and contributing to the society. 


\subsubsection{Water Pipe consumption}

Our data showed that the prevalence of waterpipe use is $15.2 \%$. By Gender 18.6 $\%$ of women uses water pipes whereas $9.2 \%$ men do. It is a concerning that there seems to be an emergence of epidemic of water pipe smoking in Jordan among men, and women.

Water pipe is becoming more popular in Jordan especially among women. We hypothesize that the emergence of water pipe smoking in Jordan could be related to many reasons; perhaps the belief that water pipe smoking is not hazardas to health.

A study by Eissenberg,T. and Shihadeh, A. in 2009 showed that relative to cigarette smoking, water pipe use is associated with greater $\mathrm{CO}$, same nicotine level, and more smoke exposure. We should take this into account to advising individuals that water pipe tobacco smoking exposes them to some of the same toxicants as cigarette smoking and therefore the two tobacco-smoking methods likely share some of the same health risks.

Again this is alarming in Jordan especially when looking at the average time an individual takes for each session (2.2 hours), and mixing alcohol with water. The long-term consequences of mixing water and alcohol on lung injury are unknown.

Water pipe smoking is a form of social entertainment and perhaps people choose that form of entertainment given the lack of resources for other forms of constructive entertainment. The emergence of coffee shops in Jordan that attract both genders represents a social call and a model for unhealthy behaviors.

A significant percentage of women in Jordan have maids at home that maintains house keeping and even raising kids which allows women who are not working to 
socialize and network with other women and share a cup off coffee with some forms of smoking as a social entertainment.

Further more social parties and social networking initiated by men occurs mostly at homes were tobacco is served with coffee as a cultural norm, thus households members women and children are exposed to unhealthy behaviors.

Educational programs about the hazards of water pipe smoking and its harm should be initiated.

\subsubsection{Cessation}

Many attempt to quit smoking have been done by individuals in Jordan without much success. Individuals may not be knowledgeable about different ways of cessations or might not have this programs available. According to the GATS survey in Jordan survey results, $2 \%$ of the sample consisted of former smokers. We found that $27.4 \%$ of Jordanian current smokers tried to quit smoking during the past 12 months, whereas $72.6 \%$ did not.

Among those who tried to stop smoking for months, 25.7 tried to stop for one month, $27.5 \%$ for 2 months, $10.2 \%$ for three months, $21 \%$ for four months, $3 \%$ for 8 months and $12.6 \%$ for 12 months.

Among those who tried to stop smoking for weeks $32 \%$ tried to stop for 1 week, $45.8 \%$ for 2 weeks, $18.8 \%$ for 3 weeks, $4.6 \%$ for 5 weeks, $0.8 \%$ for 13 weeks Among those who tried to stop for days, $31.7 \%$ stopped for $1-2$ days, $44.7 \%$ for 3 4 days, $11.8 \%$ for 5-6 days, $4.5 \%$ for 10 days, $4 \%$ for 15 days, $3.4 \%$ for 32 days. Of the individuals who visited the doctor, $7.6 \%$ visited 1 to 2 times, $4.1 \%$ from 3 to 5 times, $1.1 \%$ visited more than 6 times, and $87.2 \%$ did not answer. 
During these visits, only $9 \%$ of individuals were asked whether they smoke, $3 \%$ were not asked whether they smoke, and $88 \%$ did not answer.

Of those who were asked whether they smoke, $7.8 \%$ were advised to quit smoking. This finding is extremely troublesome and may reflect cultural attitudes about tobacco use in Jordan. These results should ring a bell as it shows the low intensity and higher failure rate of quitting smoking. Cessation programs and help lines are a priority in Jordan.

\subsubsection{Beliefs and knowledge}

Overall the current label on cigarettes is not effective enough to help smokers quit smoking, moreover individuals believe that smoking is less harmful for some types of cigarettes. And those who believe that smoking is not addictive are more than those who believe its addictive substance.

Among individuals, $29.2 \%$ reported that the current labeling on cigarettes led them to think of quitting, wherase $72 \%$ did not, and the rest don't know.

Among smokers, $6.2 \%$ think that the current brand they smoke is a little less harmful compared to other cigarettes, $12.1 \%$ believes no difference, and $2.5 \%$ believe their brand of cigarette is a little more harmful than others, and the rest did not answer. Of respondents, $14.9 \%$ believe that cigarettes are addictive but $24.4 \%$ do not, and the rest don't know.

Educating individuals about the addictive nature of tobacco and the harms caused by smoking is essential. 
Changing the label to make smoking negative is required and redistributing information about the harm of tobacco in general and cigarettes in specific is needed at this point.

\subsubsection{Demand for cigarettes}

The quantity of cigarettes smoked in Jordan was negatively associated with price. The elasticity of smoking in Jordan was estimated to be -0.6. The elasticity of smoking for females was estimated to be -0.008 and for males -0.81 . Young were more price elastic than old. Smoking elasticity by age groups was for those ages $15-23$ (-1.2), 24-30 (-1.01), 31-40 (-1.11), 41-50 (-0.75), 51-60(-0.05), 0ver 60 ($0.059)$.

An increase in the price by $10 \%$ has shown to induce a decrease in quantity consumed by $6 \%$. Thus keeping increasing the prices of cigarettes is a way to prevent initiation of smoking and reduce current smoking.

When estimating price elasticity according to wealth index, we divided individuals into four groups and the price elasticity was as follows:

Lowest quintile (- 0.73), first quintile (- 0.75), second quintile (-0.85), and highest quintile (-1.7).

As the wealth increases individuals are more sensitive to price changes.

It is also worth mentioning here that as price increases smuggling problems may occur as a result. To shed some lights on this problem we looked at prices in neighbor countries to see whether this is a major problem or not. According to the most recent prices reported by the WHO in 2009

•Iraq: $\$ 0.63$ 
•Jordan $\$ 1.97$

-Syria: $\$ 0.62$

-Saudi Arabia: \$1.6

-Israel: $\$ 5.0$

Taking into account the transportation cost and other costs smuggling from Syria and Iraq is possible given the lower prices of cigarettes compared to Jordan. The average prices of cigarettes in governorates close to the boarders of both Syria and Iraq were estimated. In Irbid the average price of cigarettes was JOD 1.25 (\$1.78) and in Mafraq the average price was JOD 1.35 (\$1.92). The average prices of cigarettes in Amman the capital of Jordan is approximately JOD 1.53 ( \$2.18). This difference in prices between governorates that are close to the Syrian and Iraqi boarders might be due to smuggling. Further research is needed to shed lights on this problem.

\subsubsection{Responses rate}

The over all response rate of conducting the survey was high $93.9 \%$. But in part of the questions the response rate was low. In section $\mathrm{H}$ about knowledge attitude and perceptions question $\mathrm{H} 2 \_1$ and $\mathrm{H} 2 \_2$. In section cessation questions D1, D3 ,D6 and D7 have a very low response rate.

In reviewing these questions for example D3 there is no option to describe quitting on their own, meaning the high non-response rate was due to the insufficient options to answer. For other questions the option "don't know" is not listed as one of their selection, thus the response rate was low. 
Compared to Egypt questions H2_1,H2_2 and H2_3 and 4 were modified to reveal the "don't know " options. For example question H2_1 he questions were restated as follows (World Health Organization 2009):

H2_1 Based on your own smoking experience, do you think that the cigarette brand you smoke is less harmful, is not different from other brands, or is more harmful than other brands?

Somewhat less harmful $\ldots \ldots \ldots \ldots \ldots \ldots . .1$ Go to $\mathrm{H} 2 \_3$

Not different from other brands......... 2

A bit more harmful ................... 3 Go to $\mathrm{H}_{2} \_3$

Don't know........................... 7

Refused............................... 9

Other countries who conducted the GATS have deleted some of those questions in their own surveys.

We would recommend relooking at those questions and modify them to avoid such problems in the future.

\subsubsection{Study Limitations}

We were not able study the differences between urban and rural regions due to limited resources. The lack of some important questions like income and family history of smoking that added a lot to the analysis. Such a national survey lacks these types of questions. The use of the traditional data collection procedure pen and paper might have resulted in a bias. Future electronic data collection is recommended. 
Despite caveats the GATS analysis in Jordan provides the first important insights about economics of tobacco use in Jordan and demand analysis. We believe that this study is important for formulating effective public health policy and smoking cessation programs to combat smoking and its related diseases in a developing country with limited resources.

\subsubsection{Policy Implication of the results}

Jordan has alarmingly high rates of tobacco smoking: $42.2 \%$ of adults aged 15 and above are smoking tobacco. Jordan has also one of the highest male and female smoking rates. A policy action is needed to target this health and social problem. Based on our results from the GATS we suggest the following policies on different levels:

\subsection{Local Level}

Different policies should be tailored to target smoking in different regions in Jordan with different rate of smoking prevalence. Further studies are needed to understand the reasons behind these differences to be able to combat smoking in a correct manner.

\subsection{Country Level}

Warn

GATS conducted in Jordan 2011 have shown that health warnings on cigarette packs are not strong enough to encourage cessation. Those who paid attention to the warning label reported that it did not help them to quit smoking. 
We recommend that effective warning labels be added to all tobacco products are essential.

\section{Offer help}

GATS in Jordan 2011 has shown that many current smokers have an interest in quitting smoking and they tried several times without success.

Providing cessation programs and informing smokers about cessation is a priority. Providing cessation medication to smokers to help them quit is cheaper than treating illnesses caused by smoking.

Ingeminate

By law, cigarette advertisements is prohibited in Jordan, but from the data we noticed that some advertisements still exist and targeting both men and women thus reinforcing the laws of prohibiting advertisements is essential and need further action.

Raising the social awareness of tobacco harm and risks and informing individuals about the tactics of tobacco industry in promoting tobacco use might be an effective way to overcome the effect of advertising on the demand for smoking. Reinforcing laws that prohibit smoking in public and work places is essential to reduce smoking and reduce exposure to second hand smoking.

\section{Adjusting prices}

Increasing prices of cigarettes is a priority to decrease the consumption of cigarettes. GATS in Jordan shows that the quantity of cigarettes smoked is 
negatively related to its price. The over all price elasticity suggested that an increase in price by $10 \%$ would result in a decrease by $6 \%$ of quantity consumed.

\section{Repeating GATS}

Conducting GATS every year or so is a way to keep tracking of tobacco prevalence and factors affecting tobacco consumption for a better understanding of policy implications and as a way to evaluate the policies effect on tobacco use. Due to time and money constraint we were not able to conduct GATS to reveal information by urban and rural regions since this required at least a sample size of 8000 individuals. Taking this into account will add to the analysis a lot.

Reinforce Media role

Reinforce the media role in educating the public about hazards of smoking other than the known cancer that might be more effective than the current knowledge which includes increase facial wrinkles in women, premature aging, breast cancer risk, effect on fertility and deleterious effects on pregnancy.

Urgent intervention in Women is needed

The prevalence of smoking among women in Jordan is alarming and increasing since 2007. The price elasticity for women compared to men is -0.008 and -.081 respectively. Women are less price sensitive than men and so other factors rather than price will affect their smoking behaviors more. It will be helpful to use current specialized centers for women health in Jordan to provide educational material to combat smoking and prevent initiation among nonsmoker's women. 
It's worth mentioning that women as the current and the future mother, is of high priority to understand why they smoke and try to decrease this phenomena in Jordan. By helping women stop smoking we believe we are helping half of the society.

Reinvest in Men- the case is not hopeless

Although our data indicates that cigarette smoking has not changed from 2007 to 2011, however smoking related chronic diseases are on the rise, thus its beneficial from en economics and health stand point to reinvest in men. At a national level one of the interventions that worked to combat smoking is to portray the smoker in a bad light. However this may not address psychosocial addiction and genetic aspects of smoking.

Reeducate Youth

Given the young age of smoking initiation for both cigarettes and water pipes and the higher price sensitivity for young than for old, it's important to reinforce laws of prohibiting selling and buying tobacco products by minors.

Providing smoking educational sections in the curriculums at school is essential.

\subsection{International Level}

Revisiting GATS with some modifications to some of the questions is highly recommended. Adding some questions about income, family smoking history and other important issues will not add much to the cost of conducting the survey but it will add a lot to the analysis and the database of each country. 


\section{CITED LITERATURE}

1. (2009). "Cigarette Smoking Among Adults and Trends in Smoking CessationUnited States, 2008." Morbidity and Mortality Weekly Report 58(44): 12271232.

2. Abu-Baker, N. N., L. Haddad, et al. (2010). "The influence of secondhand smoke exposure on birth outcomes in Jordan." Int I Environ Res Public Health 7(2): 616-634.

3. Al-Kayed, S. and M. B. Qasem (2006). Lung Cancer. Cancer Incidence in Four Member Countries (Cyprus, Egypt, Israel, and Jordan) of the Middle East Cancer Consortium (MECC) Compared with US SEER. L. Freedman, B. Edwards, L. Ries and J. Young. Bethesda, MD, National Cancer Institute. NIH Pub No 06-5873.

4. Al-Matubsi, H. Y., R. A. Kanaan, et al. (2011). "Smoking practices in Jordanian people and their impact on semen quality and hormonal levels among adult men." Cent Eur J Public Health 19(1): 54-59.

5. Azab, M., O. F. Khabour, et al. (2010). "Water pipe tobacco smoking among university students in Jordan." Nicotine Tob Res 12(6): 606-612.

6. Belbeisi, A., M. Al Nsour, et al. (2009). "A surveillance summary of smoking and review of tobacco control in Jordan." Global Health 5(18): 18.

7. Blecher, E. H. and C. P. van Walbeek (2004). "An international analysis of cigarette affordability." Tob Control 13(4): 339-346.

8. Centers for Disease Control and Prevention (2002). "Cigarette smoking among adults--United States, 2000." MMWR 51: 642-645.

9. Centers for Disease Control and Prevention (2011). "Ten Great Public Health Achievements---Worldwide, 2001--2010." Morbidity and Mortality Weekly Report 60(24): 814-818.

10. Central Intelligence Agency. (2010, July 28, 2010). "The World Factbook: Jordan." from https://www.cia.gov/library/publications/the-worldfactbook/geos/jo.html.

11. Chaloupka, F. J. (1991). "Rational Addictive Behavior and Cigarette Smoking." The Journal of Political Economy 99(4): 722-742.

12. Chaloupka, F. J. (1999). "Macro-social influences: the effects of prices and tobacco-control policies on the demand for tobacco products." Nicotine Tob Res 1 Suppl 1(1): S105-109. 
13. Chaloupka, F. J., K. M. Cummings, et al. (2002). "Tax, price and cigarette smoking: evidence from the tobacco documents and implications for tobacco company marketing strategies." Tob Control 11 Suppl 1(1): I62-72.

14. Chaloupka, F. J. and R. Nair (2000). "International issues in the supply of tobacco: recent changes and implications for alcohol." Addiction 95 Suppl 4(4): S477-489.

15. Chaloupka, F. J., K. Straif, et al. (2011). "Effectiveness of tax and price policies in tobacco control." Tob Control 20(3): 235-238.

16. Chaouachi, K. and K. M. Sajid (2010). "Cancer risks of hookah (shisha, narghile) tobacco use require further independent sound studies." Int I Cancer 127(7): 1737-1739; author reply 1739-1740.

17. Conrad, K. M., B. R. Flay, et al. (1992). "Why children start smoking cigarettes: predictors of onset." Br J Addict 87(12): 1711-1724.

18. Dar-Odeh, N. S. and O. A. Abu-Hammad (2009). "Narghile smoking and its adverse health consequences: a literature review." Br Dent I 206(11): 571573.

19. Dar-Odeh, N. S. and O. A. Abu-Hammad (2011). "The changing trends in tobacco smoking for young Arab women; narghile, an old habit with a liberal attitude." Harm Reduct I 8(24): 24.

20. Dar-Odeh, N. S., F. G. Bakri, et al. (2010). "Narghile (water pipe) smoking among university students in Jordan: prevalence, pattern and beliefs." $\underline{\text { Harm }}$ Reduct I 7(10): 10.

21. Edwards, B. K., M. L. Brown, et al. (2005). "Annual report to the nation on the status of cancer, 1975-2002, featuring population-based trends in cancer treatment." L Natl Cancer Inst 97(19): 1407-1427.

22. Eissenberg,T., Shihadeh, A.,2009 " Waterpipe tobacco and cigarette smoking: direct comparison of toxicant exposure". Am J Prev Med.2009 Dec;37(6):518-23

23. El-Khushman, H. M., A. M. Sharara, et al. (2008). "Cigarette smoking among health care workers at King Hussein Medical Center." LHosp Med 3(3): 281284.

24. Eriksen, M. and F. Chaloupka (2007). "The economic impact of clean indoor air laws." CA Cancer I Clin 57(6): 367-378. 
25. Fagan, P., E. T. Moolchan, et al. (2007). "Identifying health disparities across the tobacco continuum." Addiction 102 Suppl 2: 5-29.

26. Farmer, P., J. Frenk, et al. (2010). "Expansion of cancer care and control in countries of low and middle income: a call to action." Lancet 376(9747): 1186-1193.

27. Global Tobacco Surveillance System (GTSS) (2008). "Global Adult Tobacco Survey (GATS): Core questionnaire with optional questions."

28. Global Tobacco Surveillance System (GTSS) (2010). "Tobacco Questions for Surveys: A subset of Key Questions from the Global Adult Tobacco Survey (GATS)."

29. Grossman, M. and F. J. Chaloupka (1997). "Cigarette taxes. The straw to break the camel's back." Public Health Rep 112(4): 290-297.

30. Haddad, L. G. and M. Z. Malak (2002). "Smoking habits and attitudes towards smoking among university students in Jordan." Int I Nurs Stud 39(8): 793802.

31. Hammoudeh, A. J., H. Al-Tarawneh, et al. (2006). "Prevalence of conventional risk factors in Jordanians with coronary heart disease: the Jordan Hyperlipidemia and Related Targets Study (JoHARTS)." Int J Cardiol 110(2): 179-183.

32. Hu, T. W., Z. Mao, et al. (2010). "The role of taxation in tobacco control and its potential economic impact in China." Tob Control 19(1): 58-64.

33. Jemal, A., M. J. Thun, et al. (2008). "Annual report to the nation on the status of cancer, 1975-2005, featuring trends in lung cancer, tobacco use, and tobacco control." ¿ Natl Cancer Inst 100(23): 1672-1694.

34. Jha, P. and F. Chaloupka, Eds. (2000). Tobacco control in developing countries. New York, NY, Oxford University Press.

35. Jha, P. and F. J. Chaloupka (2000). "The economics of global tobacco control." Bmi 321(7257): 358-361.

36. Jha, P., F. J. Chaloupka, et al. (2006). "Tobacco Addiction."

37. Johnson,D. and L. A. Elliott,1998," Sampling design effects: Do they affect the analysis of data from the national survey of families and households?" University of Nebraska Lincoln. 
38. Khader, Y. S. and A. A. Alsadi (2008). "Smoking habits among university students in Jordan: prevalence and associated factors." East Mediterr Health I 14(4): 897-904.

39. Kofahi, M. M. and L. G. Haddad (2005). "Perceptions of lung cancer and smoking among college students in Jordan." L Transcult Nurs 16(3): 245-254.

40. Liang, L. and F. J. Chaloupka (2002). "Differential effects of cigarette price on youth smoking intensity." Nicotine Tob Res 4(1): 109-114.

41. Madanat, H. N., M. D. Barnes, et al. (2008). "Current smoking practices among Jordanian college students: a pilot study." Int Q Community Health Educ 29(1): 89-100.

42. Maziak, W. (2008). "The waterpipe: time for action." Addiction 103(11): 1763-1767.

43. Merrill, R. M., H. Madanat, et al. (2010). "Smoking prevalence, attitudes, and perceived smoking prevention and control responsibilities and practices among nurses in Amman, Jordan." Int J Nurs Pract 16(6): 624-632.

44. Merrill, R. M., H. Madanat, et al. (2008). "Nurse and physician patient counseling about tobacco smoking in Jordan." Promot Educ 15(3): 9-14.

45. Merrill, R. M., H. Madanat, et al. (2006). "Smoking prevalence, attitudes, and perceived smoking prevention and control responsibilities and behaviors among physicians in Jordan." Int Q Community Health Educ 26(4): 397-413.

46. Naddaf, A. (2007). "The social factors implicated in cigarette smoking in a Jordanian community." Pak J Biol Sci 10(5): 741-744.

47. Nassar, H. (2003). The Economics of Tobacco in Egypt: A New Analysis of Demand. Washington, D.C., The World Bank.

48. Pacula, R. L. and F. J. Chaloupka (2001). "The effects of macro-level interventions on addictive behavior." Subst Use Misuse 36(13): 1901-1922.

49. Ross, H. and F. J. Chaloupka (2003). "The effect of cigarette prices on youth smoking." Health Econ 12(3): 217-230.

50. Schroeder, S. A. and K. E. Warner (2010). "Don't forget tobacco." N Engl J Med 363(3): 201-204.

51. Smith, K. C., C. Siebel, et al. (2008). "News on tobacco and public attitudes toward smokefree air policies in the United States." Health Policy 86(1): 4252. 
52. Smokefree Partnership. (2011). "The cost of tobacco use." Retrieved September 7, 2011.

53. Steenland, K., J. Henley, et al. (2002). "All-cause and cause-specific death rates by educational status for two million people in two American Cancer Society cohorts, 1959-1996." Am J Epidemiol 156(1): 11-21.

54. Tauras JA (2005). "An Empirical Analysis of Adult Cigarette Demand." Eastern Economic Journal 31: 361-375.

55. Tauras JA (2006). "Smoke Free Air Laws, Cigarette Prices, and Adult Cigarette Demand." Economic Inquiry 44: 333-342.

56. Terry-McElrath, Y. M., M. A. Wakefield, et al. (2007). "State anti-tobacco advertising and smoking outcomes by gender and race/ethnicity." Ethn Health 12(4): 339-362.

57. The Task Force on Community Preventive Services. (2005). "The guide to community preventive services: what works to promote health?" Retrieved July 30, 2010, from, http://www.thecommunityguide.org/tobacco/tobacco.pdf.

58. US Dept of Agriculture (2010). "USDA Cigarette and Tobacco Research."vanWalbeek, C., E. Lewis-Fuller, et al. (2005). The Economics of Tobacco Control in Jamaica: Will the Pursuit of Public Health Place a Fiscal Burden on the Government? Ottowa, Canada.

59. Warren, C. W., L. Riley, et al. (2000). "Tobacco use by youth: a surveillance report from the Global Youth Tobacco Survey project." Bull World Health Organ 78(7): 868-876.

60. Winston GC (1980). "Addiction and Backsliding: A Theory of Compulsive Consumption." Journal of Economic Behavior and Organization 1: 295-324.

61. World Health Organization (2008). "Economics of Tobacco Toolkit: Economic Analysis of Demand Using Data from the Global Adult Tobacco Survey (GATS)."

62. World Health Organization (2008). "Smoke alarm from Afghanistan to Morocco." World Health Organization Bulletin 86(2): 89-90.

63. World Health Organization (2008). "WHO Report on the Global Tobacco Epidemic, 2008: The MPOWER package." Genever, Switzerland: WHO Press.

64. World Health Organization (2009). "Global Adult Tobacco Survey (GATS): Egypt Fact Sheet." 
65. World Health Organization (2010). "Global Adult Tobacco Survey (GATS): Sample weights manual".

66. World Health Organization (2010). "Global Adult Tobacco Survey (GATS): Sample design manual".

67. World Health Organization (2009). "WHO Report on the Global Tobacco Epidemic, 2009: Implementing smoke-free environments." WHO Press.

68. World Health Organization (2010). "Economic Analysis of Demand using Data from the Global Adult Tobacco Survey (GATS)."

69. World Health Organization. (2010). "World Health Organizations' Tobacco Free Initiatve " Retrieved July 28, 2010, from http://www.who.int/tobacco/en/.

70. World Health Organization (2011). "WHO Report on the Global Tobacco Epidemic, 2011: Implementing smoke-free environments." WHO Press. 


\section{APPENDIX A}

\section{Approval Notice \\ Initial Review (Response to Modifications)}

June 23, 2011

Nadia Sweis

Economics

10745 S Lockwood Ave

Oaklawn, IL 60453

Phone: (708) 357-6762

RE: Protocol \# 2011-0008

"Economics of Cigarettes Use in Jordan"

Dear Ms. Sweis:

Your Initial Review (Response to Modifications) was reviewed and approved by the Expedited review process on June 21, 2011. You may now begin your research

Please note the following information about your approved research protocol:

Protocol Approval Period: June 21, 2011 - June 19, 2012

Approved Subject Enrollment \#: 4000

Additional Determinations for Research Involving Minors: The Board determined that this research satisfies 45CFR46.404, research not involving greater than minimal risk. Therefore, in accordance with 45CFR46.408, the IRB determined that only one parent's/legal guardian's permission/signature is needed.

Performance Sites: UIC, Ministry of Health-Ala Basheer Hospital

Sponsor: None

PAF\#:

Not Applicable

\section{Research Protocol(s):}

a. The Economics of Cigarette Use in Jordan; 10/1/2010

\section{Recruitment Material(s):}

a. Recruitment Script (English); Version 1; 04/25/2011

b. Recruitment Script (Arabic); Version 1; 04/25/2011

c. Adult Consent Script (Arabic); Version 1; 04/28/2011

d. Adult Consent Script (Arabic); Version 1; 04/28/2011

e. Minor_Parent Consent Script (English); Version 2; 06/04/2011

f. Adult Consent Script (English); Version 2; 06/08/2011

\section{Informed Consent(s):}

a. Parent Consent (Arabic); Version 2; 04/22/2011

b. Consent (English); Version 4;06/05/2011

c. Waiver of Informed Consent granted under 45 CFR 46.116(d) for recruitment and screening Assent(s):

a. Waiver of Child Assent granted under 45 CFR 46.116(d) for recruitment and screening Parental Permission(s): 

a. Parent Consent (Arabic); Version 2; 04/22/2011
b. Parent Consent (English); Version 3;06/05/2011

Your research meets the criteria for expedited review as defined in 45 CFR 46.110(b)(1) under the following specific category:

(7) Research on individual or group characteristics or behavior (including but not limited to research on perception, cognition, motivation, identity, language, communication, cultural beliefs or practices and social behavior) or research employing survey, interview, oral history, focus group, program evaluation, human factors evaluation, or quality assurance methodologies.

Please note the Review History of this submission:

\begin{tabular}{l|l|l|l|l|}
\hline Receipt Date & Submission Type & Review Process & Review Date & Review Action \\
\hline $02 / 18 / 2011$ & Initial Review & Expedited & $02 / 24 / 2011$ & Modifications Required \\
\hline $03 / 15 / 2011$ & $\begin{array}{l}\text { Response to } \\
\text { Modifications }\end{array}$ & Expedited & $04 / 14 / 2011$ & Modifications Required \\
\hline $05 / 03 / 2011$ & $\begin{array}{l}\text { Response to } \\
\text { Modifications }\end{array}$ & Expedited & $05 / 05 / 2011$ & Modifications Required \\
\hline $06 / 17 / 2011$ & $\begin{array}{l}\text { Response to } \\
\text { Modifications }\end{array}$ & Expedited & $06 / 21 / 2011$ & Approved \\
\hline
\end{tabular}

Please remember to:

$\rightarrow$ Use your research protocol number (2011-0008) on any documents or correspondence with the IRB concerning your research protocol.

$\rightarrow$ Review and comply with all requirements on the enclosure,

"UIC Investigator Responsibilities, Protection of Human Research Subjects"

Please note that the UIC IRB has the prerogative and authority to ask further questions, seek additional information, require further modifications, or monitor the conduct of your research and the consent process.

Please be aware that if the scope of work in the grant/project changes, the protocol must be amended and approved by the UIC IRB before the initiation of the change.

We wish you the best as you conduct your research. If you have any questions or need further help, please contact OPRS at (312) 996-1711 or me at (312) 996-9299. Please send any correspondence about this protocol to OPRS at $203 \mathrm{AOB}, \mathrm{M} / \mathrm{C} 672$.

Sincerely,

Marissa Benni-Weis, M.S.

IRB Coordinator, IRB \# 2

Office for the Protection of Research Subjects

Enclosure(s):

1. UIC Investigator Responsibilities, Protection of Human Research Subjects

2. Informed Consent Document(s): 
a. Parent Consent (Arabic); Version 2; 04/22/2011

b. Consent (English); Version 4; 06/05/2011

\section{Parental Permission(s):}

a. Parent Consent (Arabic); Version 2; 04/22/2011

b. Parent Consent (English); Version 3;06/05/2011

4. Recruiting Material(s):

a. Recruitment Script (English); Version 1; 04/25/2011

b. Recruitment Script (Arabic); Version 1; 04/25/2011

c. Adult Consent Script (Arabic); Version 1; 04/28/2011

d. Adult Consent Script (Arabic); Version 1; 04/28/2011

e. Minor_Parent Consent Script (English); Version 2; 06/04/2011

f. Adult Consent Script (English); Version 2; 06/08/2011

cc: David Merriman, Economics, M/C 144

Frank J. Chaloupka, Economics, M/C 275

November 9, 2011

Nadia Sweis

Economics

10745 S Lockwood Ave

Oaklawn, IL 60453

Phone: (708) 357-6762

RE: $\quad$ Research Protocol \# 2011-0008

"Economics of Cigarettes Use in Jordan"

Dear Ms. Sweis:

Review and acknowledgement of the following Protocol Violation occurred on October 26, 2011.

The protocol violation involved the following:

During the collection of the data, a very small number of respondents refused to sign a consent form, but they wanted to fill out the survey, as they said their verbal approval is enough and their signature is something they are afraid of. Some of the student assistants took the respondents' answers and the investigator has about 20 out of the 4,000 respondents who filled out a survey without signing a consent document.

Student assistants were required to re-take a training course online in obtaining consents. Certificates of student assistant training were submitted.

Subjects who did not sign a consent form provided their names and the names were written in the blank space available in the consent form. Subjects were willing to answer all of the questions in the survey. Subjects kept a copy of the consent. Student assistants informed subjects of the 
privacy of their information but subjects stated they would participate and provision of their names should be enough.

The review was conducted by expedited review procedures 45 CFR 46.110(b)(2).

We would like to thank you for complying with UIC's Human Subject Protection policies in the submission of any adverse event or unanticipated problem.

If you have any questions or need further help, please contact me at (312) 996-2014 or the OPRS

office at (312) 996-1711. Please send any correspondence about this protocol to OPRS at 203 AOB, $\mathrm{M} / \mathrm{C} 672$.

Sincerely,

Sandra Costello

Assistant Director

Office for the Protection of Research Subjects

Cc: David Merriman, Economics, M/C 144

Frank Chaloupka (faculty advisor), Economics, M/C 275 


\title{
ENGLISH CONSENT FORM
}

\author{
Adult Participant
}

You have been randomly selected to participate in this study. Before the interview can begin I will need to get your permission, which is also called your consent.

We are going to get started with the interview in a few minutes. Remember that you can decide to be in this study or not to, and may stop at any time. You can also ask questions at any time.

[Begin using the consent form]

[For those potential subjects who cannot read or write you will read the consent form to the subject with a witness present who is able to read and write. If the subject agrees to participate in the study, a thumbprint will used as mark of consent for the subject and the witness must sign the consent form too.]

\section{ARABIC CONSENT FORM}

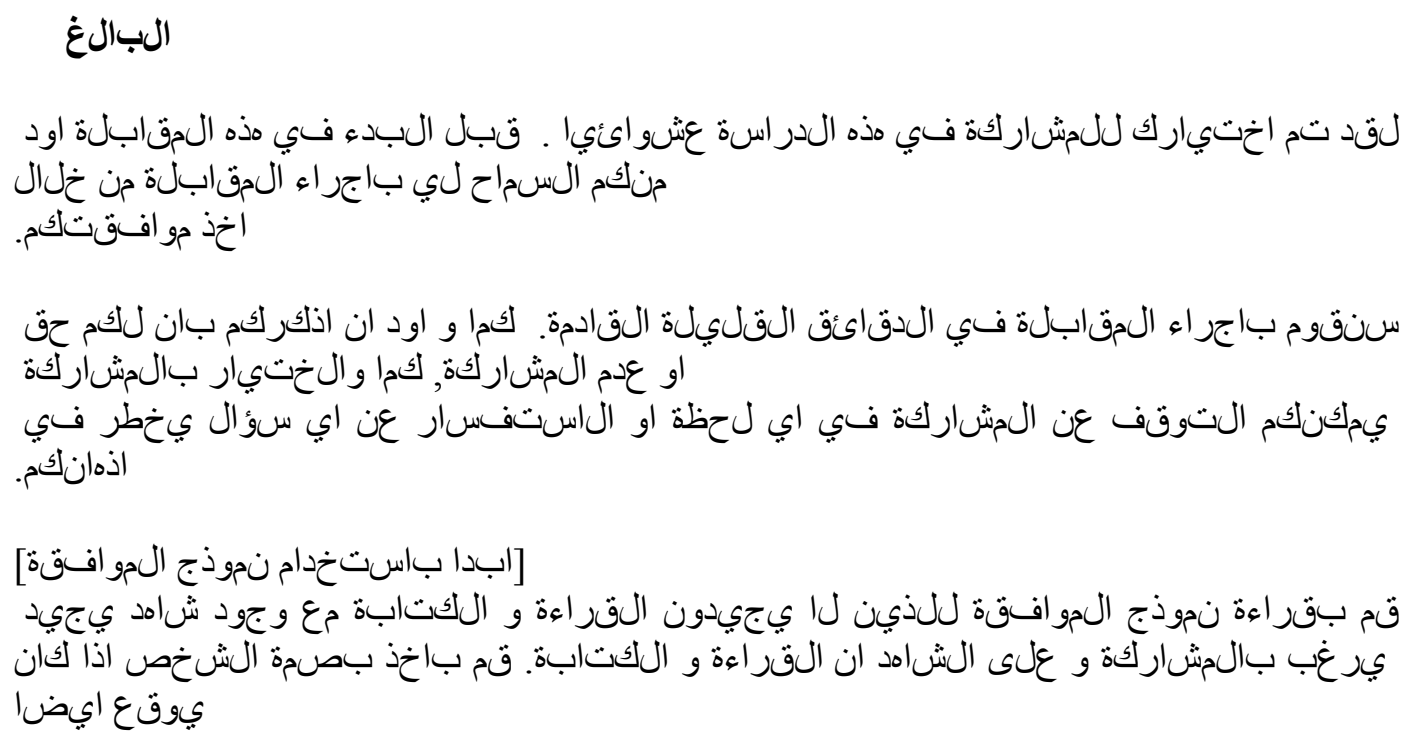




\section{University of Illinois at Chicago Assent to participate in Research Protocol Title: Economics of Cigarette Use in Jordan IRB\# 2011-0008}

Name of Subject

I am working with Nadia Sweis, a PhD student researcher. She is collecting information about tobacco use in Jordan. The results of the information from this study will be used for public health purposes by the Ministry of Health.

Your household and you have been selected at random (like the flip of a coin). Your responses are very important to us and the community, as these answers will represent many other persons. The interview will last around 30 minutes. To keep your information private the answers you give will not be labeled with information that can identify you such as your name. No one will be able to match your answers to you. We will not share the personal information you give with anyone else, not even other family members. You do not have to be in this study if you do not want. You can stop being in this study at any time.

Some questions may make you feel uncomfortable and you do not have to answer these.

There is a risk that your private information could be seen by people who are not allowed to access this information. We will do our best to keep this from happening.

Your participation in this study will not provide any benefit to you. We hope this study provides more information about tobacco use and health.

If you have questions about this survey you ask your parents or you can contact Nadia Sweis at (0775310030).

If you agree to participate, we will conduct a private interview with you.

Signing your name at the bottom means that you agree to be in this study. You and your parents will be given a copy of this form after you have signed it. 
Signature

Signature /thumb impression:

of Subject (if subject cannot read or write)

Signature of Witness (if subject cannot read or write) same as subject's)

$\overline{\text { Printed name of Witness (if subject cannot read or write) }}$

* Sign 2 copies of assent and leave one copy with the subject.
Date (must be 
جامعة البينوي في شيكاغو

النششاركة في الستب اسبيان مو افقة

الاردن"عنو ان البحث:" اقتصاديات استخدام التبغ في

0008-رقم: 2011ل جنة اخلاقيات



ان اعجل مع السيدة ناديه صويص ,طالبة دكتور اة تقوم بجمجع معلومات عن استخدام

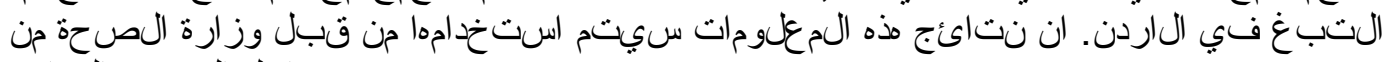

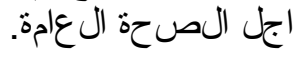

لقد تم اختيار اسرتكم عثو ائيا. ان مشاركتكم في مذا البحث في غاية الفامية لن إنا

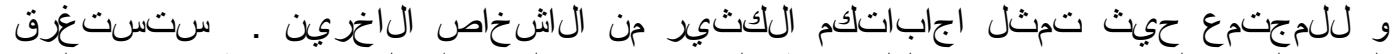

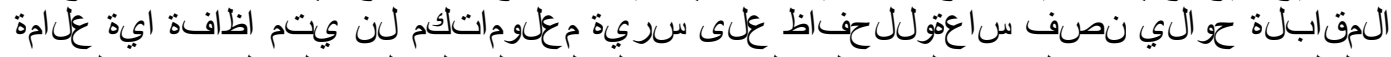

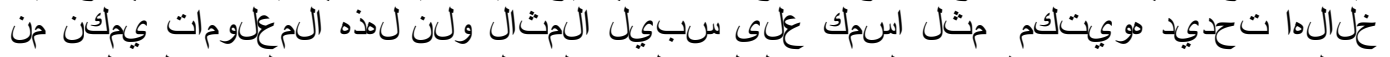

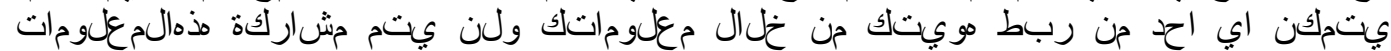

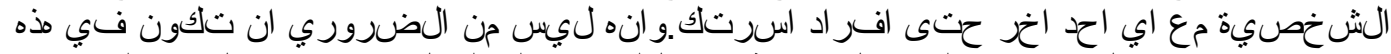

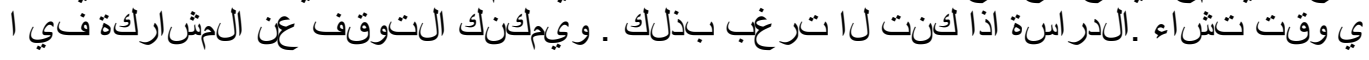

ان منالك بعض السئلة التي قد تسبب لك شعوراً بعدم الراحة اود اعلعامكم

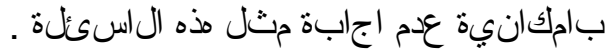

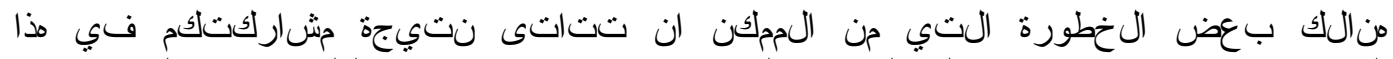

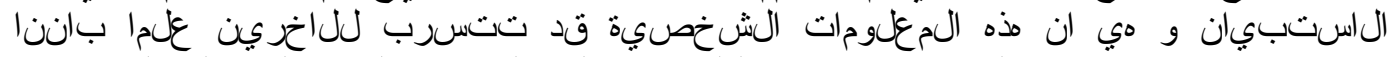

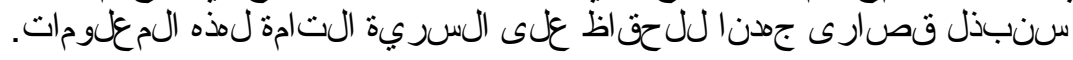

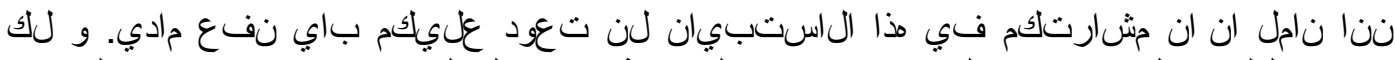

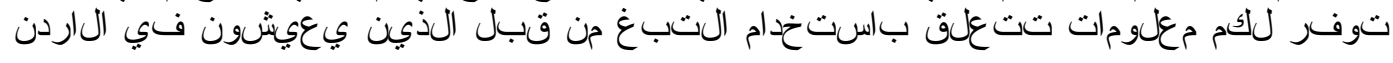

ة يجكنك سو ال والديك او الاتصال مع ناديه اذا كان لديكتم اي اسئلة عن مذه الدر اس

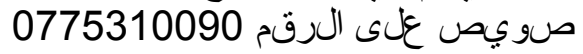

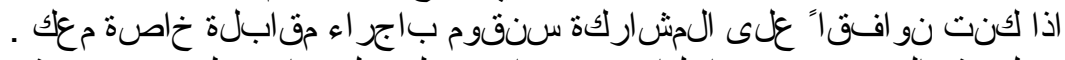

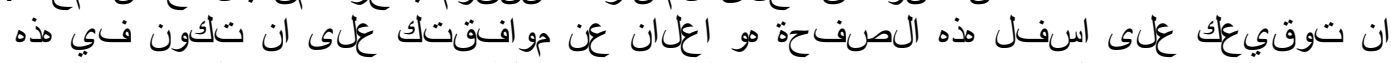

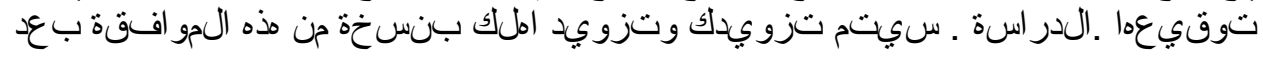




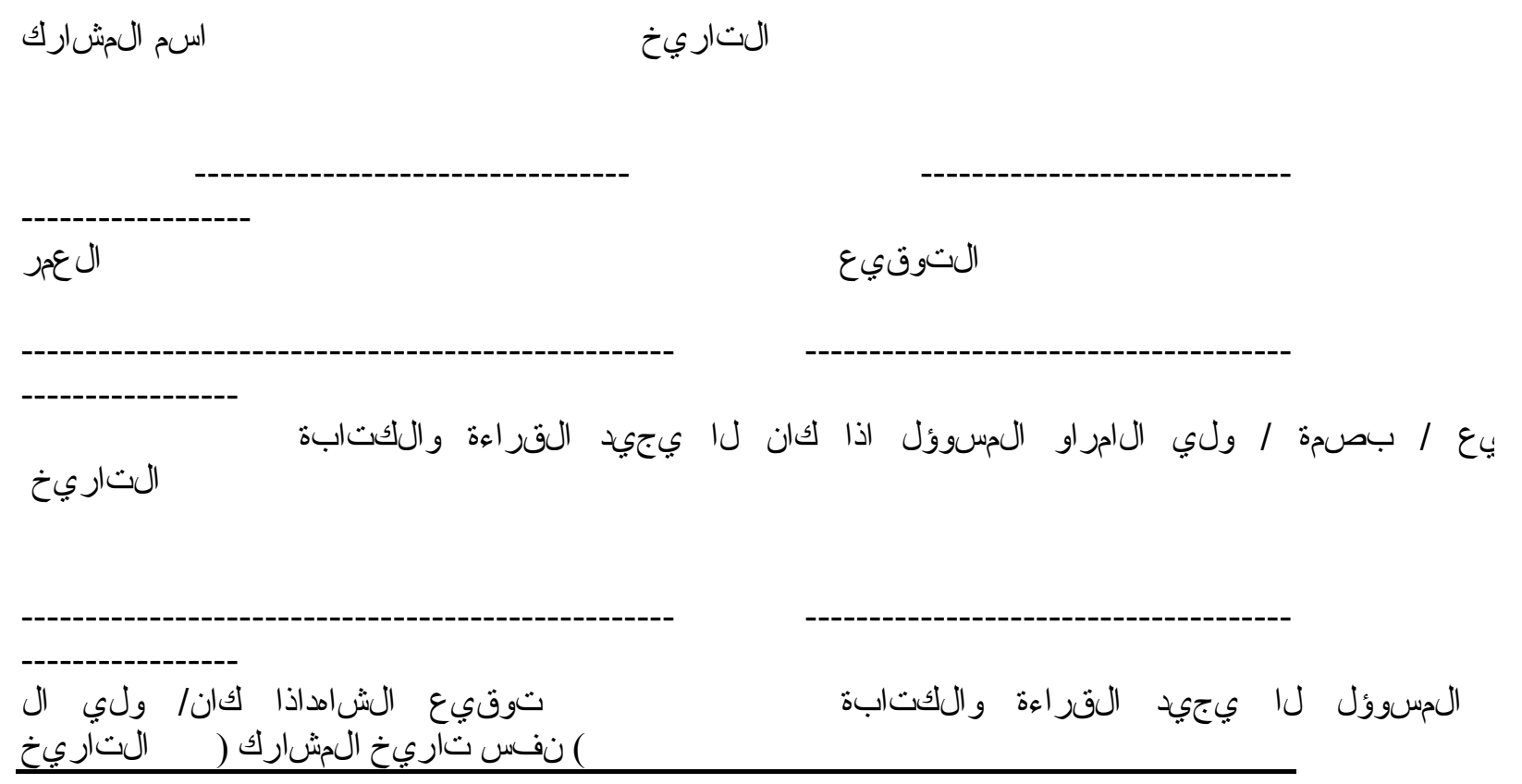

* بنسخقم بتوقب نس ختبين و زود المشارك 


\section{University of Illinois at Chicago}

\section{Consent for Participation}

in Research

Protocol Title: The Economics of Cigarette

Use in Jordan

IRB\# 2011-0008

Name of Subject

I am working with Nadia Sweis, a PhD student researcher. She is collecting information about tobacco use in Jordan. The results of the information from this study will be used for public health purposes by the Ministry of Health.

Your household and you have been selected at random to participate in a research study which involves answering questions about tobacco use. Your responses are very important to us and the community, as these answers will represent many other persons.

The interview will last around 30 minutes. Your participation in this survey is entirely voluntary. The information that you will provide us will be kept strictly confidential, and you will not be identified by your responses. Personal information will not be shared with anyone else, not even other family members. You can withdraw from the study at any time, and may refuse to answer any question.

If you agree to participate, we will conduct a private interview with you.

Participation in this study will not provide any benefit to you. We hope this study will provide more information about the tobacco use and health of people who live in Jordan.

There is a risk of that a breach of privacy and confidentiality may occur but every effort will be made to keep your information confidential.

The people who will know that you are a research subject are members of the research team. Otherwise information about you will only be disclosed to others with your written permission, or if necessary to protect your rights or welfare or if required by law 
Study information which identifies you and the consent form signed by you will be looked at and/or copied for checking up on the research by: review boards including the University of Illinois at Chicago Institutional Review Board and the Ministry of Health-Ala Basheer Hospital.

When the results of the research are published or discussed in conferences, no information will be included that would reveal your identity. The results of this study will be shared with Dr. Dr. Malek Habushneh and the Jordanian Government, no information will be included that would reveal your identity.

The information which is collected for this study will be coded with a number. No one will be able to identify you from this number. The consent forms and sheets on the GATS survey which contain your name, birth date and other identifying information will be stored and locked away in a separate place from the GATS survey to prevent access by unauthorized personnel.

After the end of study analysis and publications of the study results all codes will be destroyed and removed from the study data. All the identifying information will be destroyed. The research data will be kept until Nadia Sweis completes her work as a Ph.D student researcher. After this work is completed the research data will be destroyed.

The researcher leading this study is Nadia Sweis. If you have questions about this survey you may contact her at (0775310030). You may also contact Professor Frank Chaloupka of the University of Illinois at Chicago at (001-312-413-2287) or fjc@uic.edu, or Dr. Malek Habushneh of the Ministry of Health at (0799050244).

This questionnaire has been reviewed and approved by the Ministry of Health and the University of Illinois at Chicago ethics committees. These committees are concerned with the protection of subjects in research projects. If you have any questions about your rights as a research subject you can reach the Ministry of Health-Ala Basheer Hospital at (+962795565723) or the Office for the Protection of Research Subjects (OPRS) at the University of Illinois at Chicago at (001-312996-1711) or e-mail at uicirb@uic.edu.

I have read (or someone has read to me) the above information. I have been given an opportunity to ask questions and my questions have been answered to my satisfaction. I agree to participate in this research. I will be given a copy of this signed and dated form.

Subject Signature Date

Printed name of Subject 
Signature /thumb impression:

$\overline{\text { of Subject (if subject cannot read or write) }}$

Date

Signature of Witness (if subject cannot read or write) same as subject's)

Date (must be

Printed name of Witness (if subject cannot read or write) 


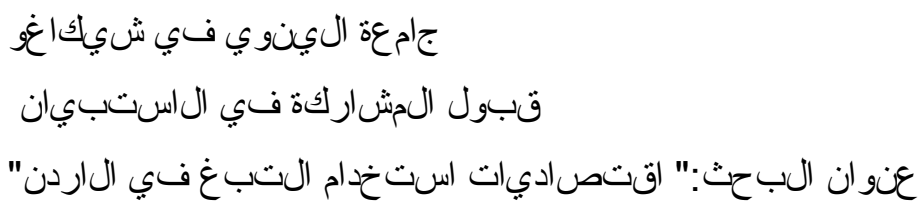

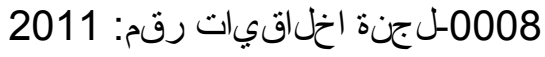

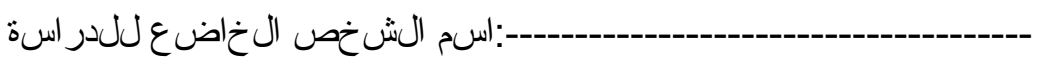

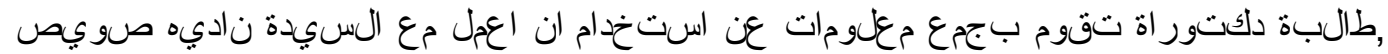

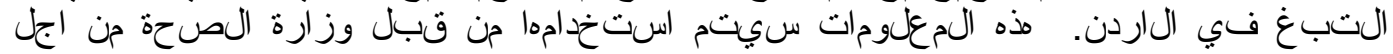

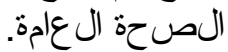

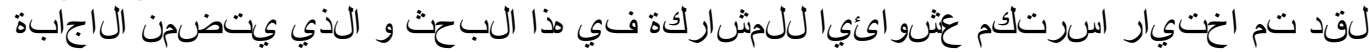

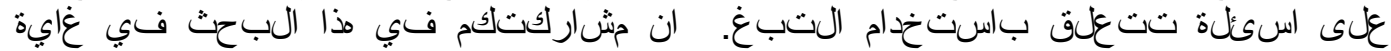

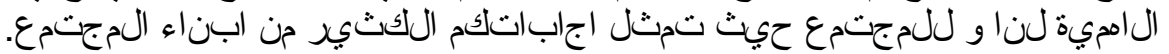

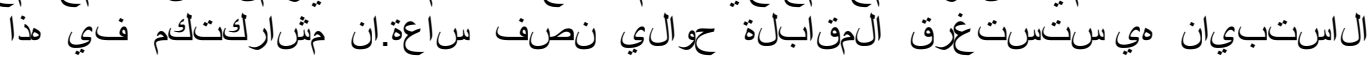

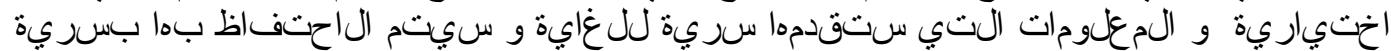

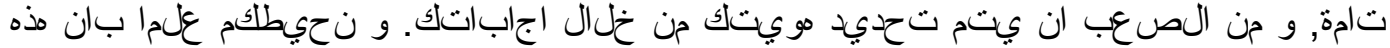

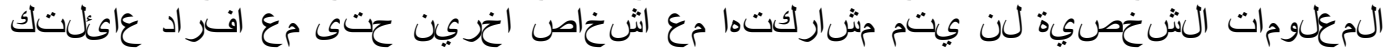

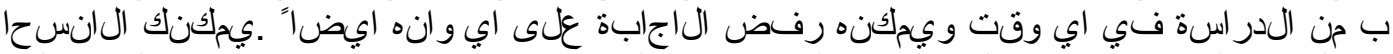

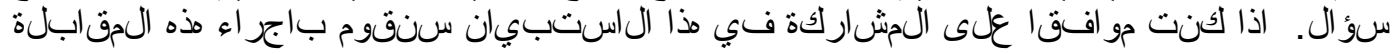

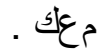

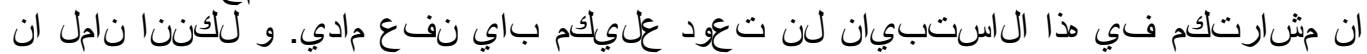

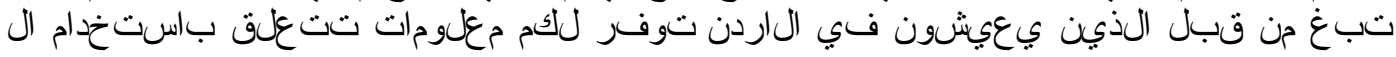

منالك بعض الخطورة التي من الجمكن ان تتاتى نتيجة مشاركتكم في هذا

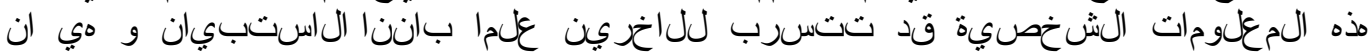

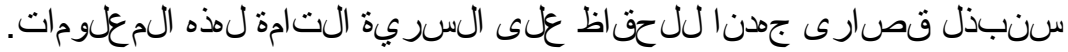

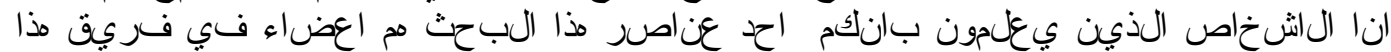

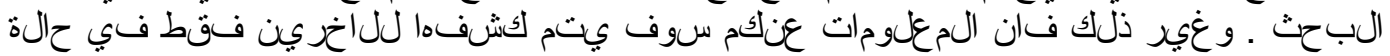

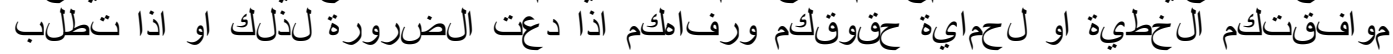

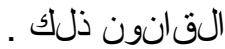

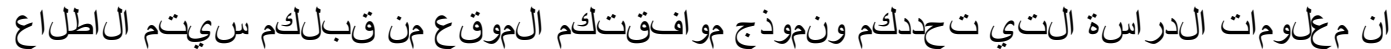

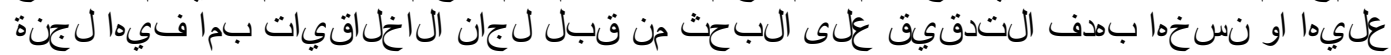

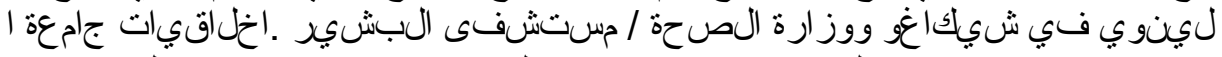

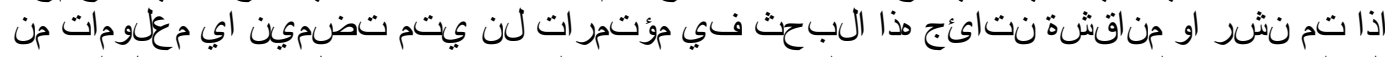

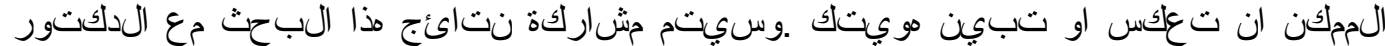

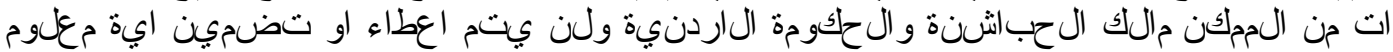

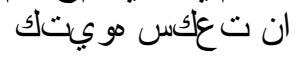




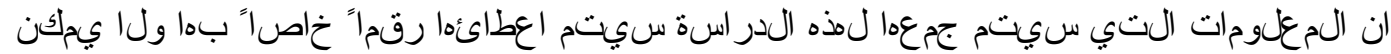

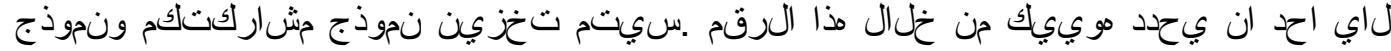

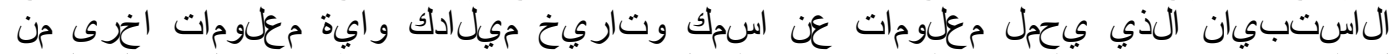

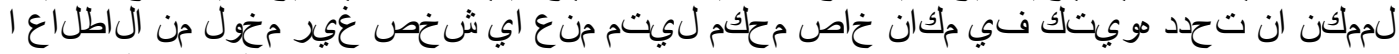

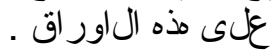

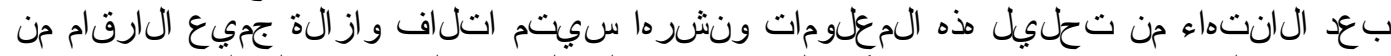

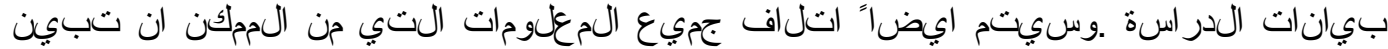

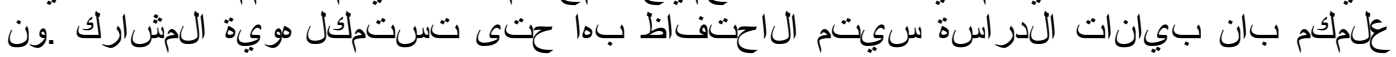

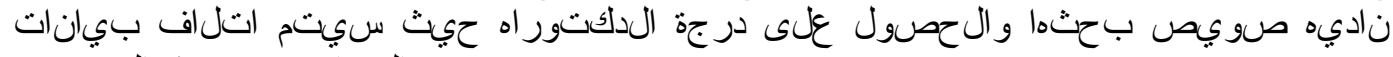

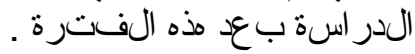

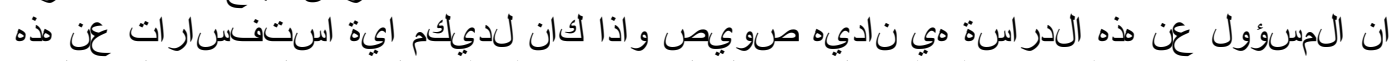

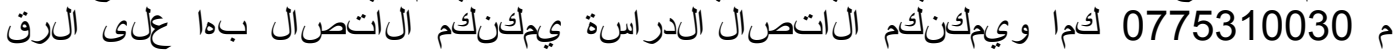

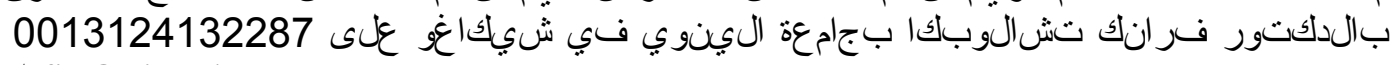
و fjc@uic.edu

الدكتور مالك الحباشنة في وزارة الصحة على الرقم 0799050244

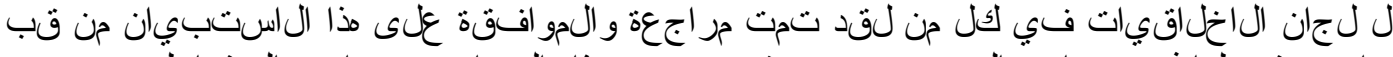

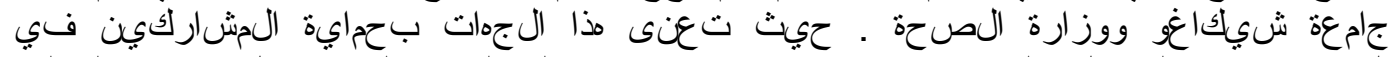

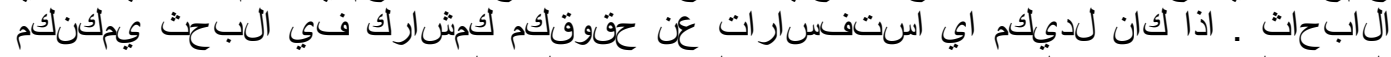

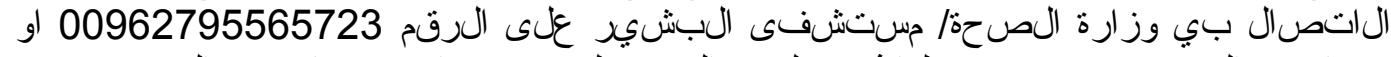

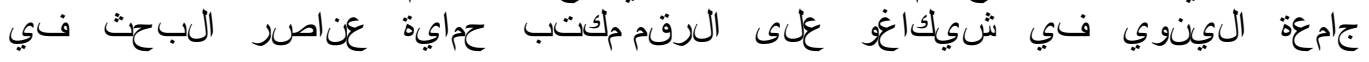

uicirb@uic.edu

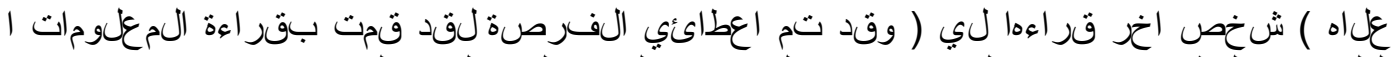

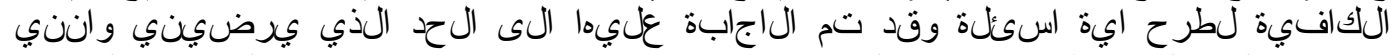

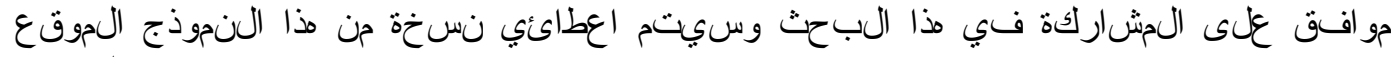

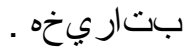

توقيع المشارك

التثاريخ

اسم الحشارك

$$
\text { زشارك اذار الكان }
$$




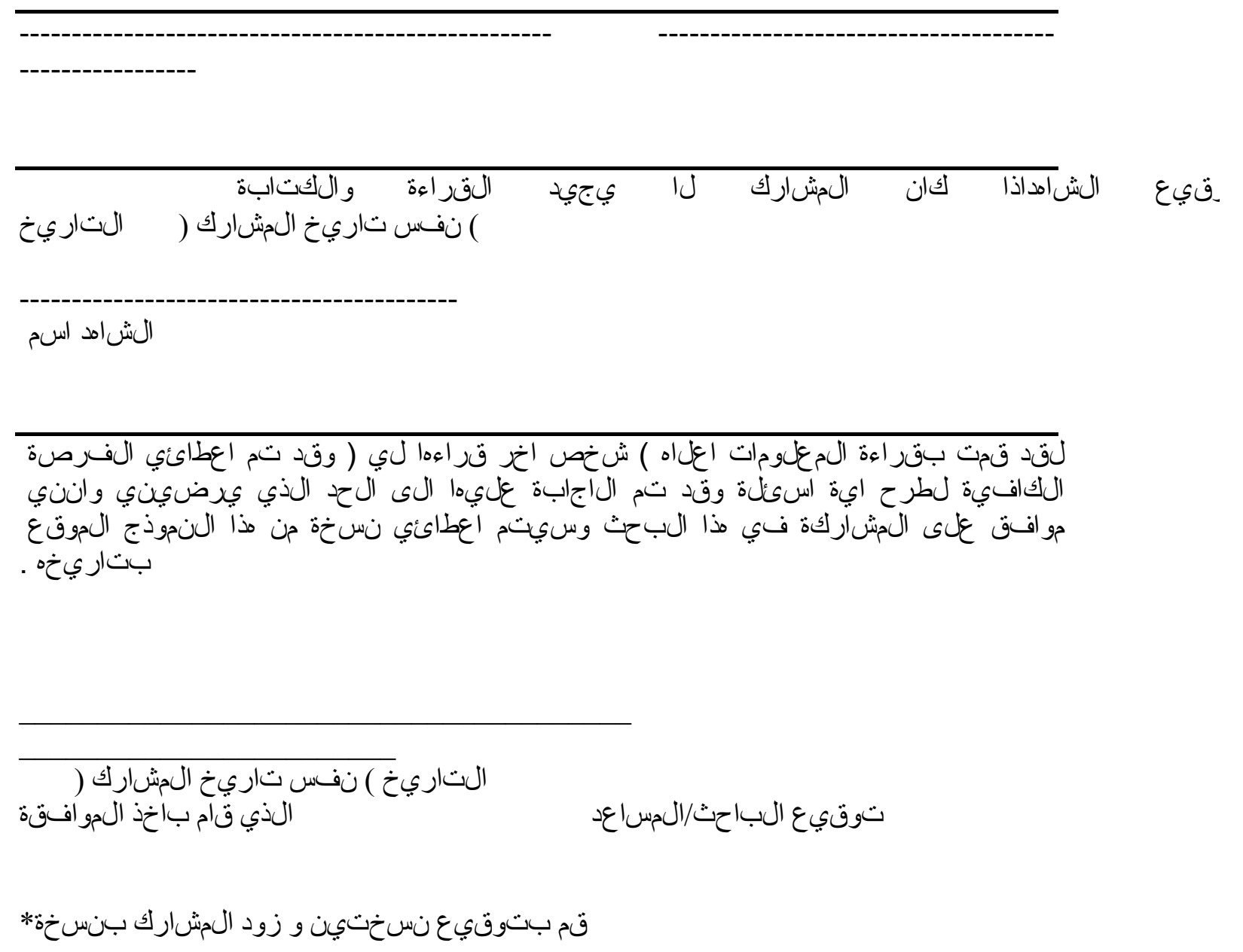

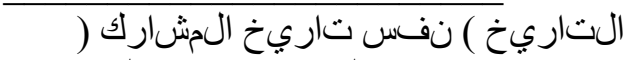

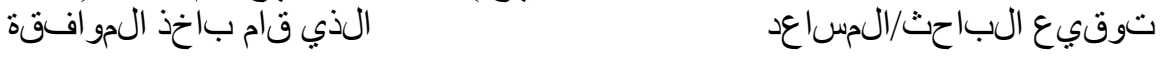

قم بتوقي نسختين و زود المشارك بنسخة

I assure that I have fully explained to the above study subject the nature and purpose, procedures and the possible risk and potential benefits of this research study subject's) 
Printed Name of Person Obtaining Consent

*Sign two copies of consent and leave one copy with the subject.

\section{Minor Participant and Parent Assent/Consent Script}

[For those parents or children who cannot read or write you will read the consent/assent form to the parent/child with a witness present who is able to read and write. If the parent/child agrees to participate in the study, a thumbprint will used as mark of consent for the parent/child and the witness must sign the consent/assent form too.]

Both the parent and selected child must be present during the assent/consent process.

[Speaking to child]

You have been randomly selected which means like flipping a coin to be the person who is interviewed for this study. Before the interview can be started I will need to get the permission of your parents first and then your permission.

[Speaking to parent with child present]

As I have already said, your permission is also needed before your son/daughter can be interviewed for this study. You will give your permission by signing this consent. If you do not want your son/daughter to be interviewed then you will not sign the consent form and our time with you will end.

The interview will be done in private with your son/daughter and we will not share any of the answers that he/she gives during the interview. Before the interview begins you can ask any questions you may have.

[Begin using the consent form. If the parent provides consent, then continue the consent process and present the assent to the child and follow the information below. If the parent does not provide consent then the interview is over. Thank the family for their time and leave.] 
[Speaking to child]

I will read over this document (give assent to child) with you. If you would like to be interviewed you will sign this document. If you do not want to be interviewed you will not sign this document and our time with you will end. Your parent has already given his/her permission for you to be interviewed. In order for you to participate you must give us permission to interview you. If you do not give us permission the interview cannot be done.

You do not have to answer any questions that make you uncomfortable. I don't expect the questions to make you uncomfortable, but it could happen and you should feel free to not answer.

The interview will be in private and the answers you give will not be shared with your parent(s) or anyone else in your family. You may ask me or your parents any questions you have at any time.

[Begin using the assent form. If the child gives assent, then the interview can begin. If the child does not give assent then the interview is over. Thank the family for their time and leave.]

\section{نص موافقة ولني المر والحدث}

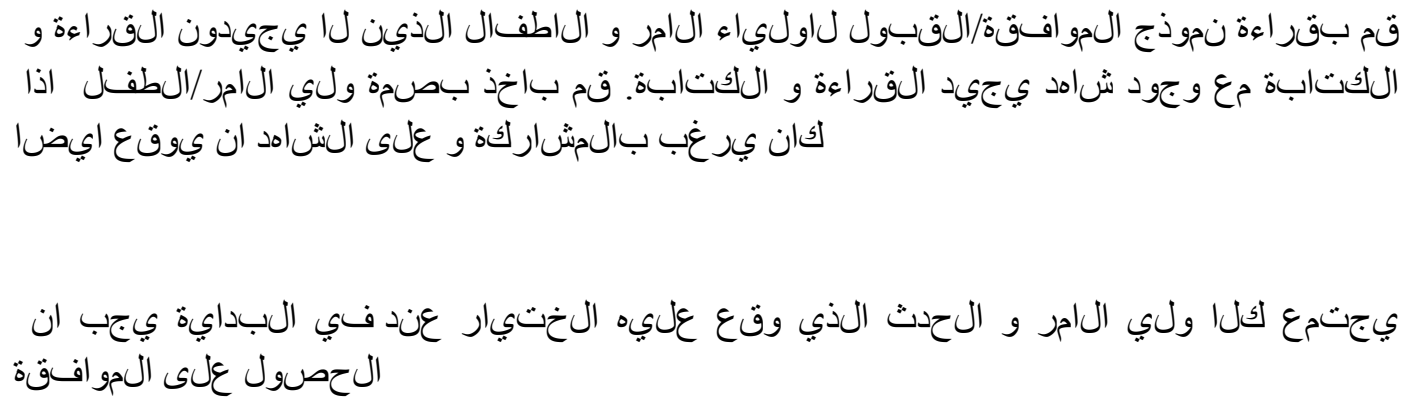




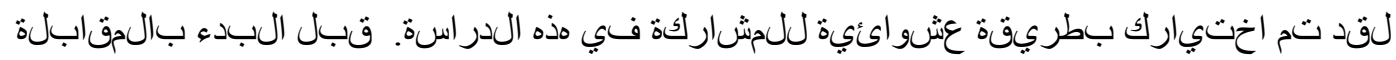

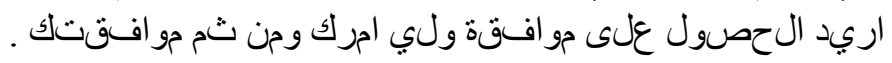

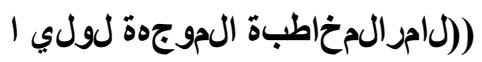

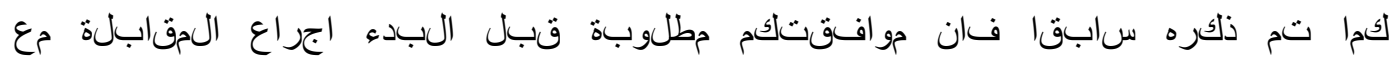

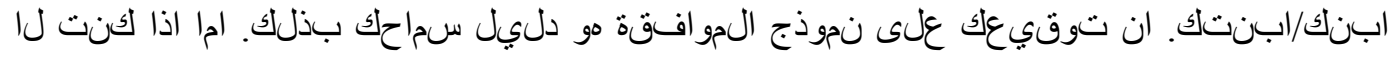

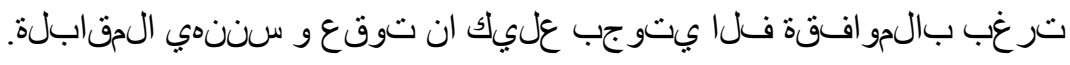

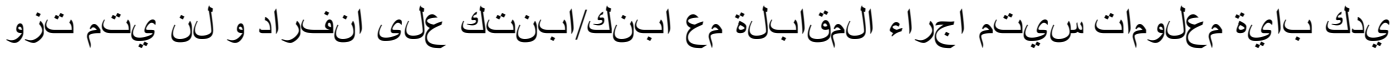

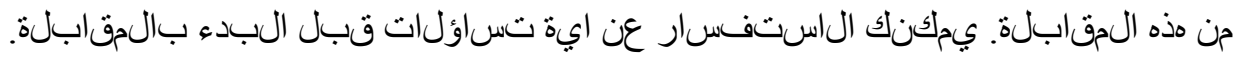

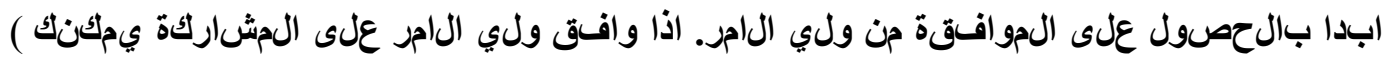

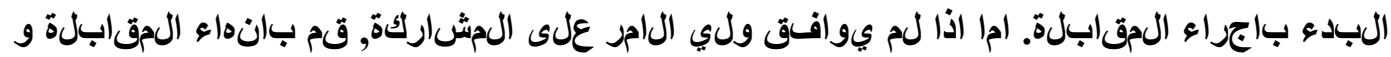

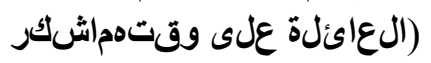

\section{(الجخاطبة الجوجة للزحدث)}

ساقوم بقراءة المو افقة لك)تزويده بنسخة( ـ اذا كنت ترغب بالحشاركة يتو جب

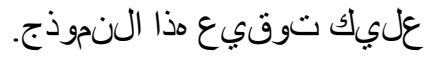

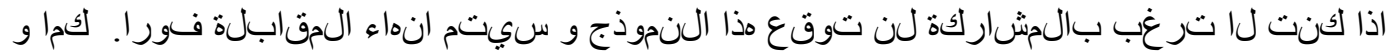

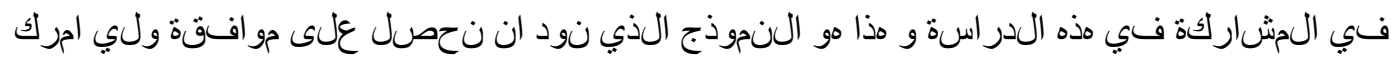

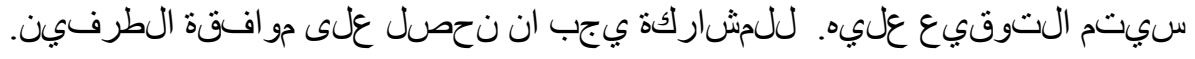

يمكنك رفض الاجابة على اية سؤال لا تر اه مناسبا, لا تشعر بالحراج من ذلك.

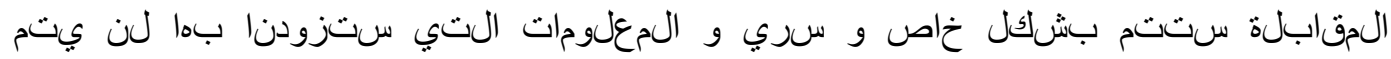

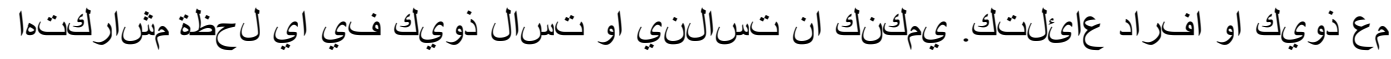
تشاء.

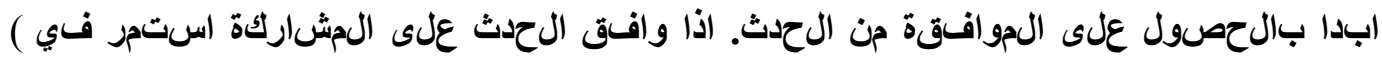

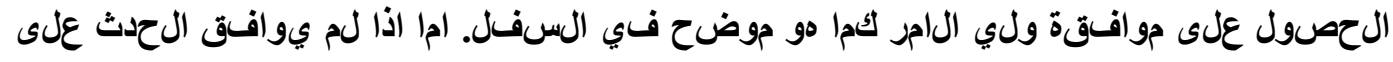

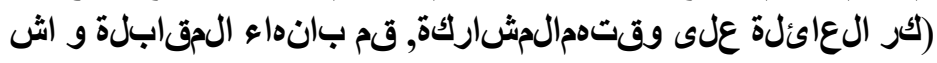




\section{نص موافقة ولي المر والحدث}

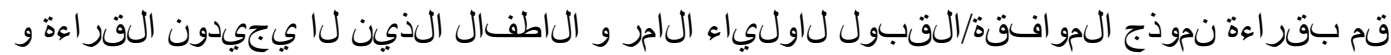

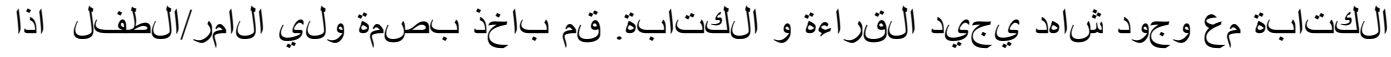

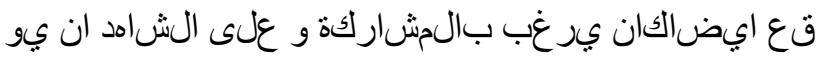

في البداية يجب ان يجتمع كلا ولي الامر و الحدث الذي وقع عليه الختيار عند

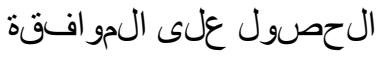

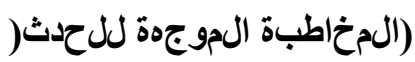

لقد تم اختيارك بطريقة عشو ائية للحشاركة في مذه الدراسة. قبل البداء بالمقابلة

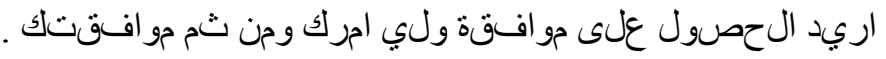

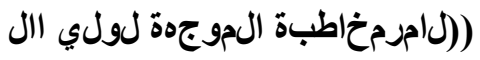

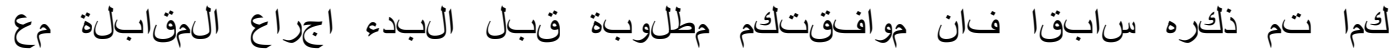

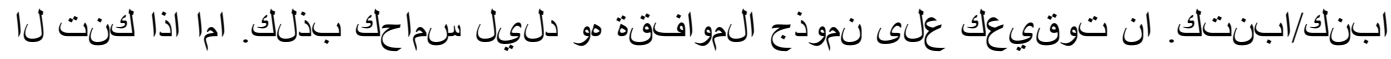

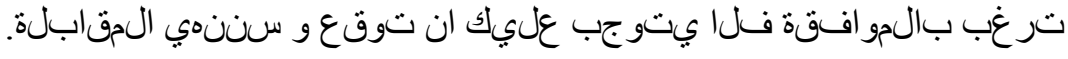

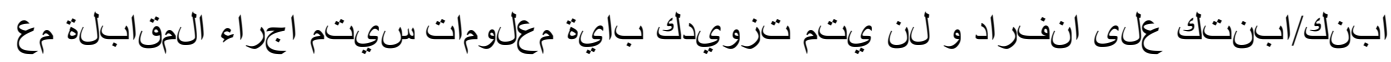

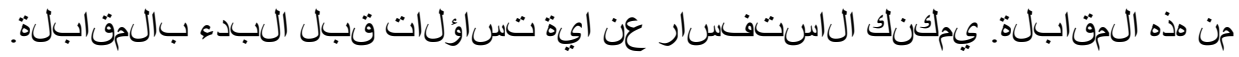

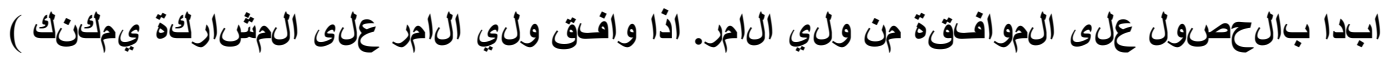

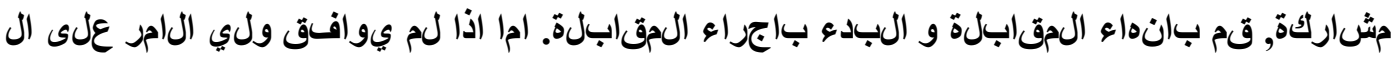

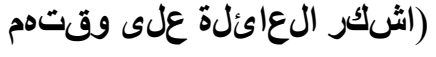

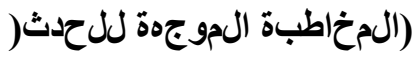

ساقوم بقراءة المو افقة لكك)تزويده بنسخة( ـ اذا كنت ترغب بالهشاركة يتوجب

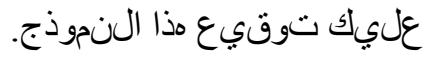




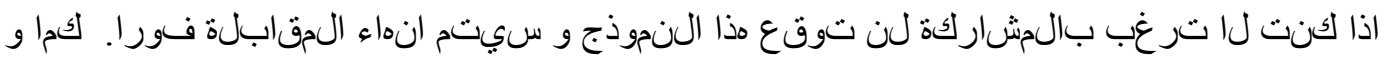

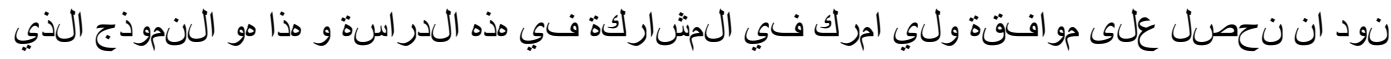

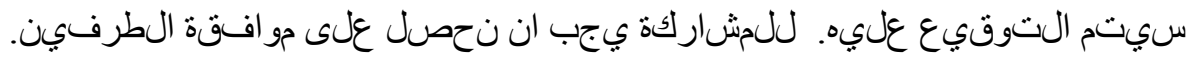

يمكنك رفض الاجابة على اية سؤال لا تر اه مناسبا, لا تشعر بالحراج من ذلك.

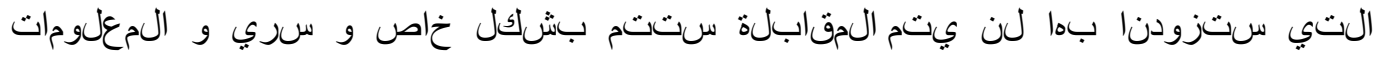

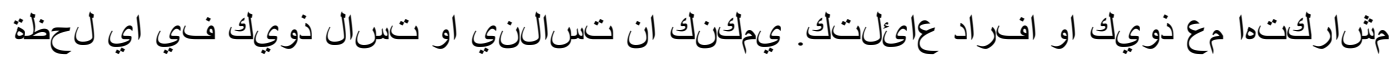

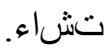

ابدا بالحصول على الموافقة من الحدث. اذا وافق الحدث على المشاركة استمر في )

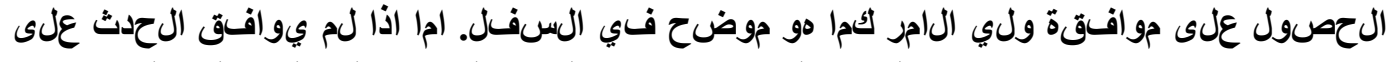

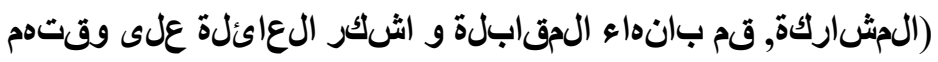

جامعة البنوي في شيكاغو

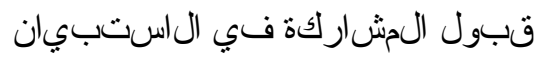

عنوان البحث:" اقتصاديات استخدام التبغ غني الاردن"

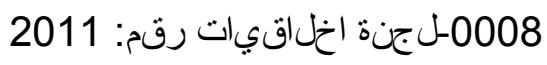

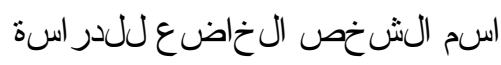

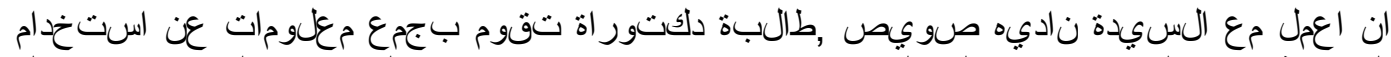

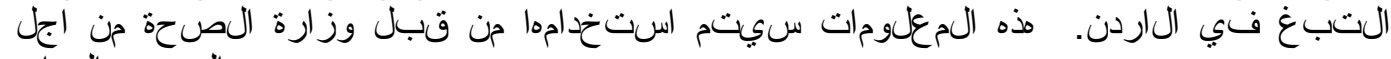

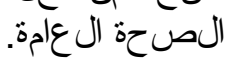

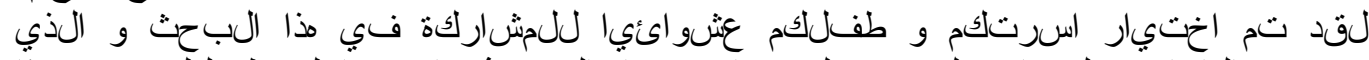

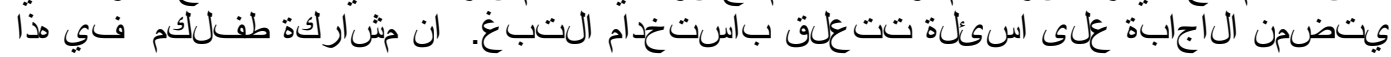

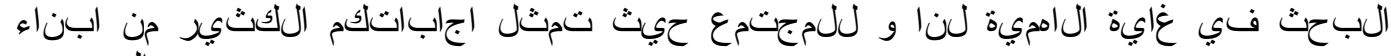

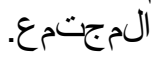

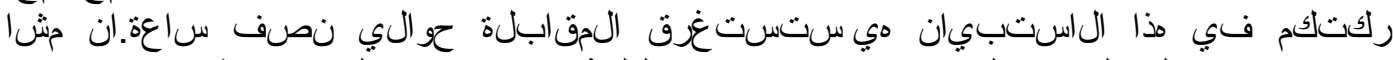

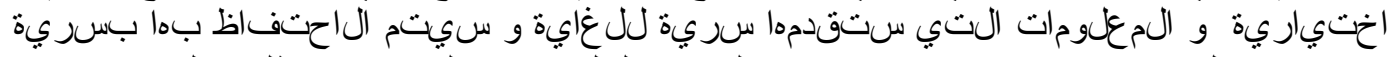

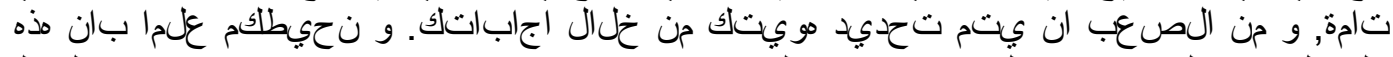

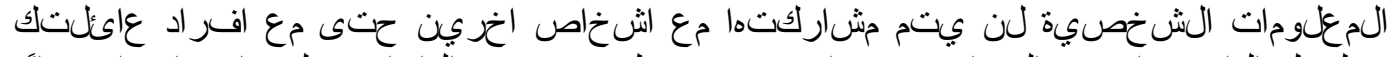

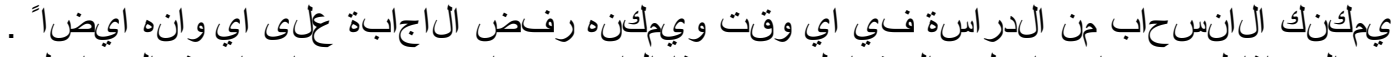

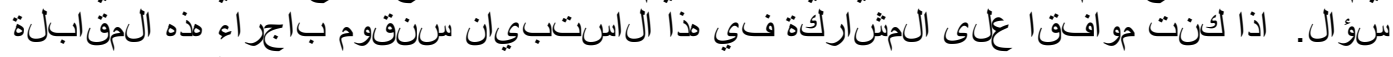
. ske 


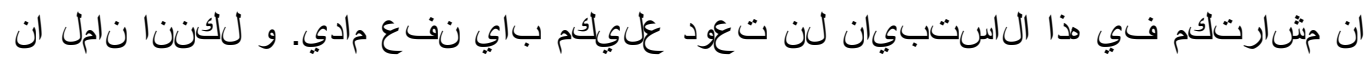

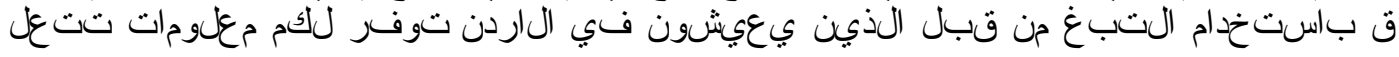

منالك بعض الخطورة التي من المجكن ان تتاتى نتيجة مشاركتك فكم في هذا

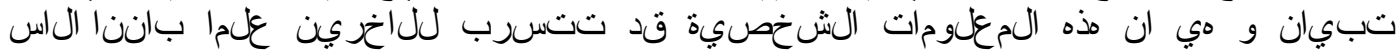

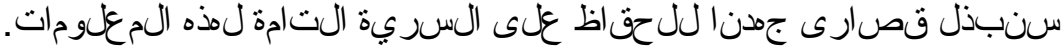

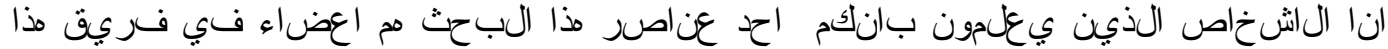

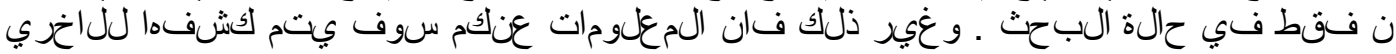

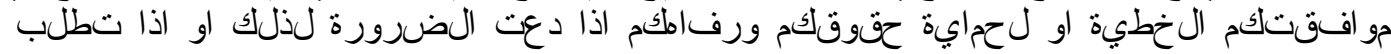

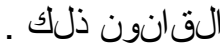

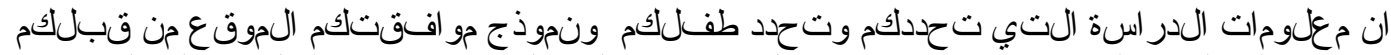

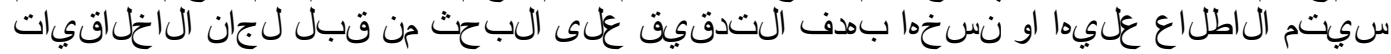

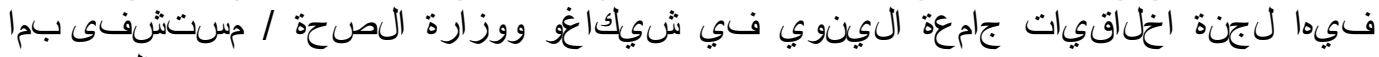

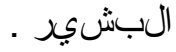

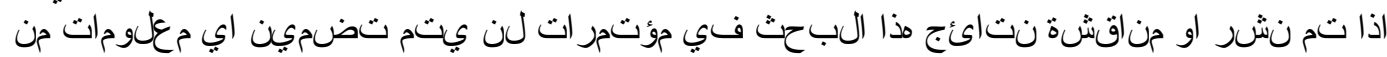

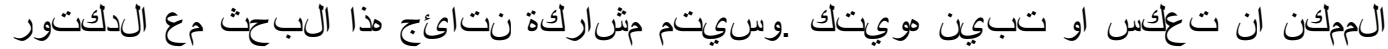

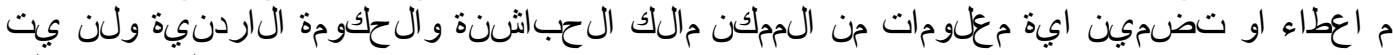

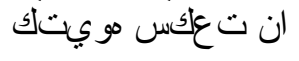

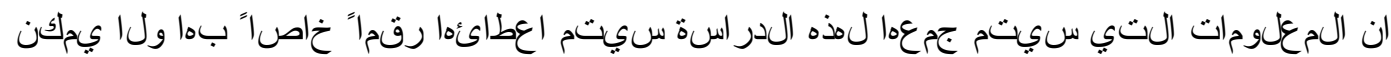

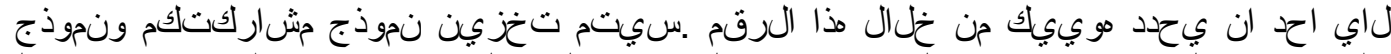

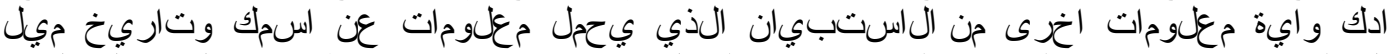

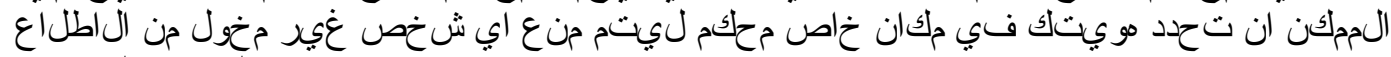

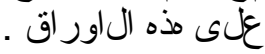

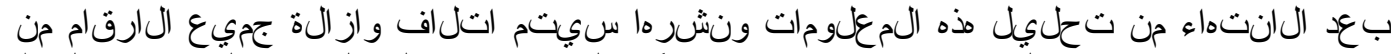

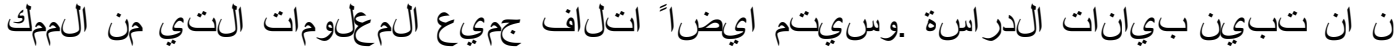

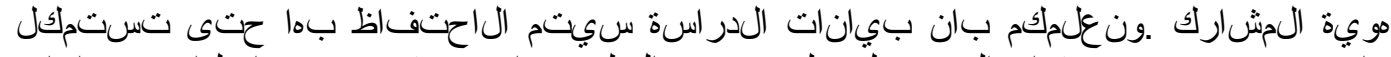

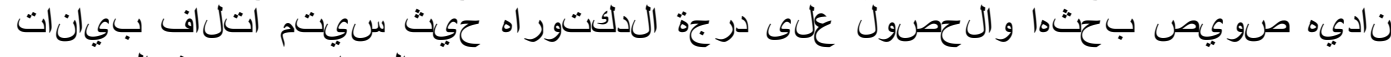

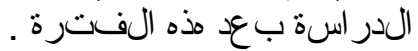

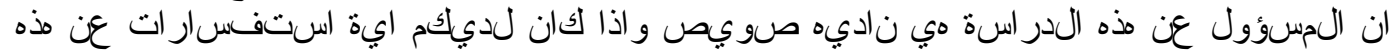

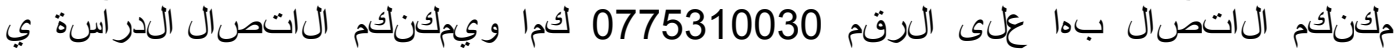
بالدكتور فرانك تشالكوبكا بجامعة البينوي في شيكاغٔو على 0773124132287 و) fjc@uic.edu

الدكتور مالك الحباشنة في وزارة الصحة على الرقم 0799050244

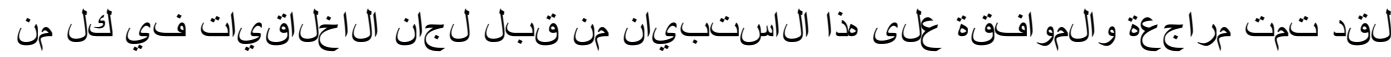

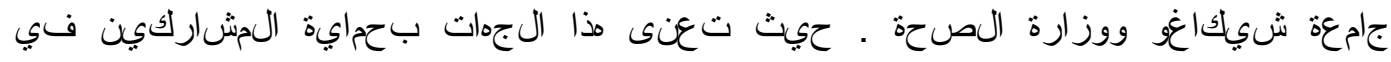

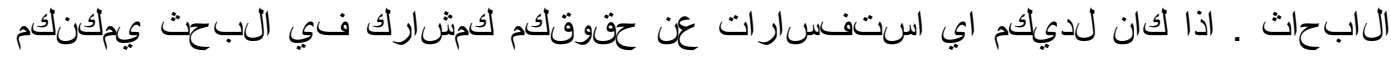

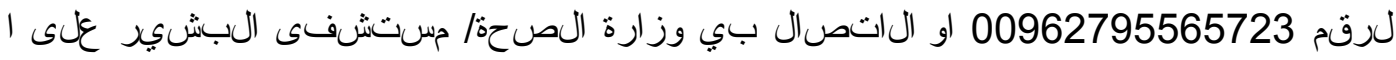

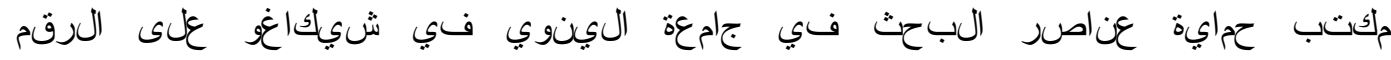

uicirb@uic.edu

لقد قجت بقر اءة المعلومات اعلاه ) شخص اخر قراءها لي ( وقد تم اعطائي الففرصة

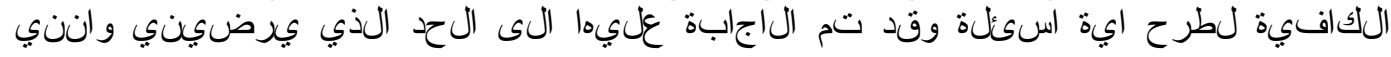


موافت على الجشاركة في مذا البحث وسيتم اعطائي نسخة من ذذا النموذج الموقع

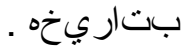

توقيع ولي الجر /المربي او المسؤول المجثل للحشارك

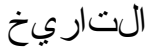

اسم ولي الجر/الحربي او الجسؤول الجمثل للمشارك

علاقة المشارك المسؤول الجمثل للشخص بذذا المشارك)اختر واحدة:(

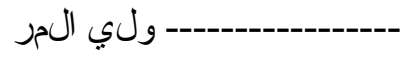

-----------النجمل او الوكيل الصحي

-----------النمندوب الصحي

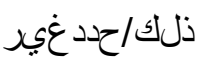

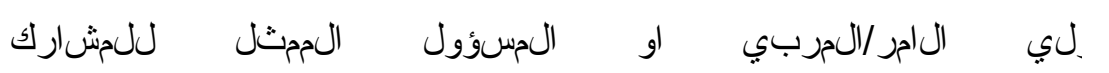




ـقيع الشاهداذا

لقد قمت بقر اءة المعلومات اعلاه ) شخص اخر قر اءها لي ( وقد تم اعطائي الفرصدة

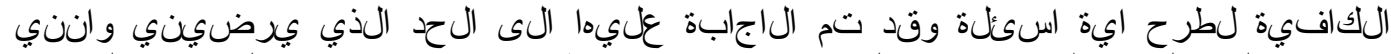

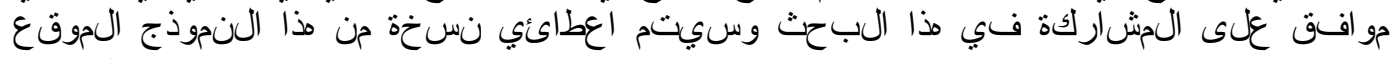

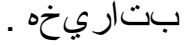

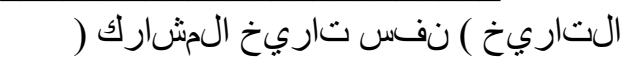

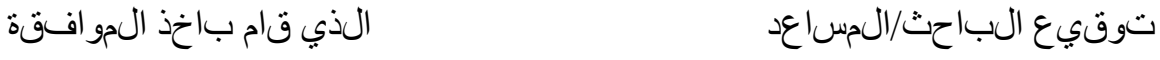

شارك بنسخةق بتوقيع نس ختين و زود الم* 


\section{Recruitment Script}

Hello, my name is [ ] and this [ ]. We are here to tell you about a research study called, "The Economics of Cigarette Use in Jordan". This study is being conducted by Nadia Sweis who is a PhD candidate at the University of Illinois in Chicago. Your household has been randomly selected to be part of this study.

Can we talk to you more about this research study?

If the answer is:

[No] then stop the interview and note the appropriate code under the household result on page 1 .

[Yes] then continue below:

The purpose of this study is to collect information about tobacco use of people who live in Jordan. We hope the information learned during this study will help researchers understand if the cost of tobacco affects tobacco use. This study is taking place in many parts of Jordan and we are asking people like you to take part in this study. We are interested in collection information from a member of your household during a private interview. This private interview would take about 30 minutes to complete and any member of your family who is age 15 or older could be interviewed for this study.

We would like to ask you questions about your household. [Begin the Household Questionnaire Section on page 4]

[If at any time during the Household Questionnaire if the household representative changes his/her mind about continuing with the study and wishes to stop the questions, thank the family for their time and enter the appropriate code under the household result on page 1]

[After completing the Household Questionnaire on page 7 if the interview is to be conducted use the appropriate consent(s) and the script form to go with it] 


\section{نص التوظيف}

اود اعلاحكم ( و نحن نقوم باجر اء دراسة و مذه مويتي.--------------مرحبا انا اسمي ) )

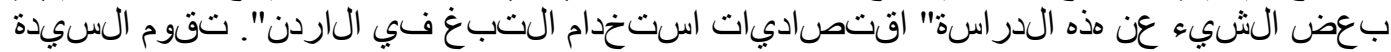

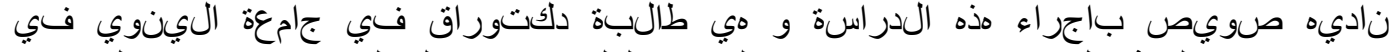

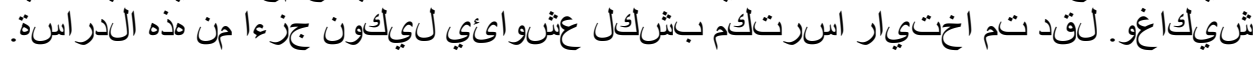

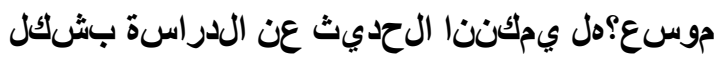

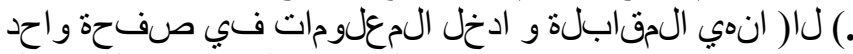

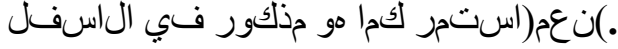

تعنى مذه الدراسة بجمع المعلومات حول استخدام التببغ في الاردن. نامل ان نستطيع

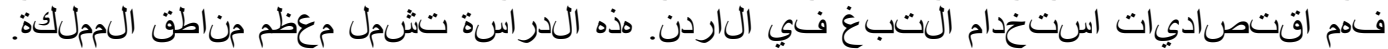

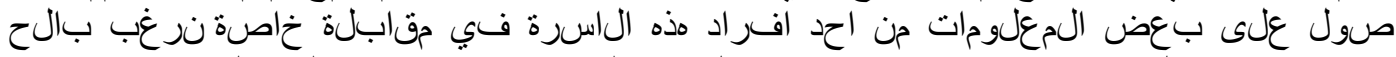

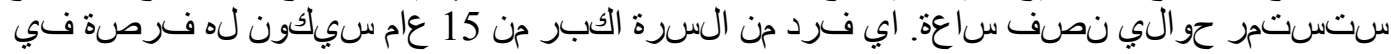

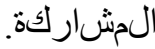

في البداية نود الستفسار عن اسرتكم

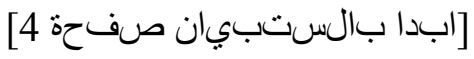

ي الجشاركة قم بانهاء المقابلة و في اية لحظة اذا شعرت ان المشارك قد عيد رايه ف )

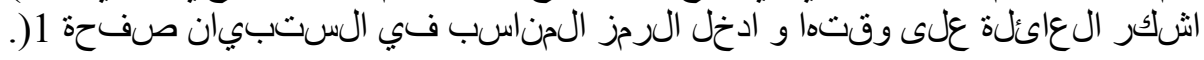

بعد استكمال استبيان السرة صفحة 7 و تم اجراء المقابلة قم باستخدام نموذج )

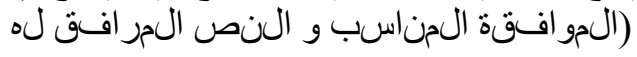




\section{Global Adult Tobacco Survey (GATS) Core Questionnaire with Optional Questions}

Jordan

Modified 2/10/2010 
Begin by reading recruitment script and signing appropriate consent form.

\author{
Household Questionnaire \\ TIME HH INTERVIEW STARTED

$\overline{\mathrm{HRS}}-\frac{-}{\mathrm{MINS}}{ }^{[24 \text { HOUR CLOCK] }}$

INTERVIEWER: THE HOUSEHOLD SCREENING RESPONDENT MUST BE 18 YEARS OF AGE OR OLDER AND YOU MUST BE CONFIDENT THAT THIS PERSON CAN PROVIDE ACCURATE INFORMATION ABOUT ALL MEMBERS OF THE HOUSEHOLD. IF NEEDED, VERIFY THE AGE OF THE HOUSEHOLD SCREENING RESPONDENT TO MAKE SURE HE/SHE IS 18 YEARS OF AGE OR OLDER

HH1. First, I'd like to ask you a few questions about your household. In total, how many persons live in this household?

INTERVIEWER: INCLUDE ANYONE WHO CONSIDERS THIS HOUSEHOLD THEIR PRIMARY PLACE OF RESIDENCE LAST NIGHT PERSONS

HH2. How many of these household members are 15 years of age or older? PERSONS

HH3. How many (male/female) household members are 15 years of age or older? PERSONS

IF HH3 $=0 / 0$ (NO ELIGIBLE MALES/FEMALES IN HOUSEHOLD), END INTERVIEW AND THANK THEM.

HH4. I now would like to collect information about the (males/females) that live in this household who are 15 years of age or older. Let's start listing the (males/females) from oldest to youngest.

ASK THE FOLLOWING QUESTIONS AND RECORD ANSWERS IN TABLE BELOW

\begin{tabular}{|c|c|c|c|}
\hline $\begin{array}{l}\text { a. What } \\
\text { is this } \\
\text { person's } \\
\text { first } \\
\text { name? }\end{array}$ & $\begin{array}{l}\text { b. What is this } \\
\text { person's age? } \\
\text { IF } \\
\text { RESPONDENT } \\
\text { DOESN'T } \\
\text { KNOW, } \\
\text { PROBE FOR } \\
\text { AN } \\
\text { ESTIMATE }\end{array}$ & $\begin{array}{l}\text { c. IF } \\
\text { REPORTED } \\
\text { AGE IS 15 } \\
\text { THROUGH 17, } \\
\text { ASK FOR } \\
\text { BIRTH DATE: } \\
\text { What is the } \\
\text { month and year } \\
\text { of this person's } \\
\text { date of birth? }\end{array}$ & $\begin{array}{l}\text { Male/F } \\
\text { emale }\end{array}$ \\
\hline 1 & & & \\
\hline 2 & & & \\
\hline 3 & & & \\
\hline 4 & & & \\
\hline 5 & & & \\
\hline
\end{tabular}




\begin{tabular}{|r|l|l|l|}
\hline 6 & & & \\
\hline 8 & & & \\
\hline 9 & & & \\
\hline 1 & & & \\
\hline 0 & & & \\
\hline
\end{tabular}

SELECTION OF INDIVIDUAL RESPONDENT USING RANDOMIZATION TABLE:

NUMBER OF

ELIGIBLE

LAST DIGIT OF QUESTIONNAIRE ID NUMBER

MALES/

FEMALES

IN

HOUSEHOLD

\begin{tabular}{llllllllll}
1 & 2 & 3 & 4 & 5 & 6 & 7 & 8 & 9 & 0 \\
\hline
\end{tabular}

\begin{tabular}{|c|c|c|c|c|c|c|c|c|c|c|}
\hline 0 & \multicolumn{10}{|c|}{ End Interview } \\
\hline 1 & 1 & 1 & 1 & 1 & 1 & 1 & 1 & 1 & 1 & 1 \\
\hline 2 & 1 & 2 & 1 & 2 & 1 & 2 & 1 & 2 & 1 & 2 \\
\hline 3 & 3 & 1 & 2 & 3 & 1 & 2 & 3 & 1 & 2 & 3 \\
\hline 4 & 1 & 2 & 3 & 4 & 1 & 2 & 3 & 4 & 1 & 2 \\
\hline 5 & 1 & 2 & 3 & 4 & 5 & 1 & 2 & 3 & 4 & 5 \\
\hline 6 & 6 & 1 & 2 & 3 & 4 & 5 & 6 & 1 & 2 & 3 \\
\hline 7 & 5 & 6 & 7 & 1 & 2 & 3 & 4 & 5 & 6 & 7 \\
\hline 8 & 1 & 2 & 3 & 4 & 5 & 6 & 7 & 8 & 1 & 2 \\
\hline 9 & 8 & 9 & 1 & 2 & 3 & 4 & 5 & 6 & 7 & 8 \\
\hline 10 & & 9 & 10 & 1 & 2 & 3 & 4 & 5 & 6 & 7 \\
\hline
\end{tabular}

USE RANDOMIZATION TABLE ABOVE TO SELECT INDIVIDUAL RESPONDENT AND WRITE THE SELECTED NUMBER IN HH5 BELOW

-IF ONLY ONE ELIGIBLE (MALE/FEMALE) LIVES IN THE HOUSEHOLD, WRITE “1” IN HH5

-IF NO ELIGIBLE (MALES/FEMALES) LIVE IN THE HOUSEHOLD, WRITE "0" IN HH5 AND END INTERVIEW

-IF MORE THAN 10 (MALES/FEMALES) LIVE IN THE HOUSEHOLD, END THE INTERVIEW AND CONSULT WITH YOUR SUPERVISOR BEFORE SELECTING ANYONE FOR THE INDIVIDUAL INTERVIEW

HH5. HOUSEHOLD ROSTER NUMBER OF THE SELECTED ELIGIBLE MALE/FEMALE

HH6. FILL IN QUESTIONNAIRE ID NUMBER QUESTIONNAIRE ID NUMBER: 
INT: IF YOU DO NOT SPEAK WITH THE SELECTED RESPONDENT OR IF HE/SHE IS NOT AVAILABLE FOR AN INTERVIEW AT THAT TIME, WRITE DOWN HIS/HER NAME AND SCHEDULE ANOTHER VISIT (DATE AND TIME)

NAME

DATE OF THE NEXT VISIT:

DATE OF THE NEXT VISIT:

DATE OF THE NEXT VISIT:

DATE OF THE NEXT VISIT:

TIME HH INTERVIEW ENDED

HRS $-\overline{M I N S}$

[24 HOUR CLOCK]

Individual Questionnaire

QUESTIONNAIRE ID NUMBER

Begin by taking the write consent

\section{SECTION A. BACKGROUND CHARACTERISTICS}

INTRO: I am going to first ask you a few questions about your background.

A1. INTERVIEWER: RECORD GENDER FROM OBSERVATION. ASK IF NECESSARY.

MALE......... 1

FEMALE .... 2

A2. What is the month and year of your date of birth?

MONTH:_ IF DON'T KNOW, ENTER “77"

YEAR:— IF DON'T KNOW, ENTER “7777”

INT: IF MONTH=77 OR YEAR=7777 IN A2, ASK A3. OTHERWISE SKIP TO A4.

A3. How old are you?

INTERVIEWER: IF RESPONDENT IS UNSURE, PROBE FOR AN ESTIMATE AND RECORD AN ANSWER

YEARS OLD

A3a. INTERVIEWER: WAS RESPONSE ESTIMATED?

YES …................... 1

NO …..................... 2

DON'T KNOW ........ 7

A4. What is the highest level of education you have completed?

INTERVIEWER: SELECT ONLY ONE CATEGORY

NO FORMAL SCHOOLING ……......................................

LESS THAN PRIMARY SCHOOL COMPLETED ………….........

PRIMARY SCHOOL COMPLETED …………………........

LESS THAN SECONDARY SCHOOL COMPLETED ...... 4

SECONDARY SCHOOL COMPLETED.............................

HIGH SCHOOL COMPLETED ......................................... . 6

COLLEGE/UNIVERSITY COMPLETED ……..................... 7 
A5. Which of the following best describes your main work status over the past 12 months? Government employee, non-government employee, self-employed, student, homemaker, retired, unemployed-able to work, or unemployed-unable to work?

INTERVIEWER: INCLUDE SUBSISTENCE FARMING AS SELF-EMPLOYED

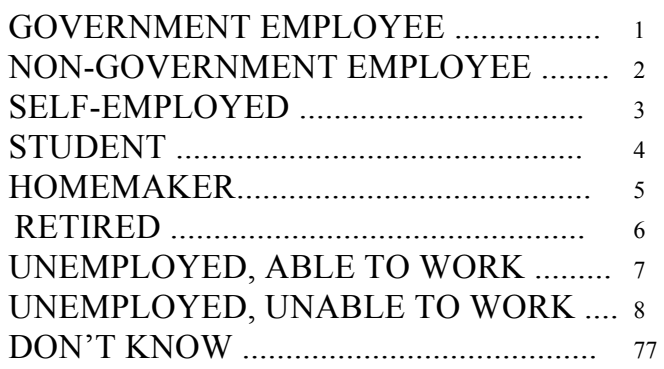

A6. Please tell me whether this household or any person who lives in the household has the following items

READ EACH ITEM:

ITEM

a. Electricity?

b. Flush toilet

c. Fixed telephone

d. Cell telephone?

e. Television

f. Radio?

g. Refrigerator?

h. Car?

i. Moped/scooter/motorcycle? ...

j. Washing machine?

$\begin{array}{ccc}\text { YES } & \text { NO } & \text { DON'T KNOW } \\ 1 \ldots \ldots . & 2 \ldots \ldots \ldots \ldots . . & 7 \\ 1 \ldots \ldots . & 2 \ldots \ldots \ldots \ldots . . & 7 \\ 1 \ldots \ldots . & 2 \ldots \ldots \ldots \ldots . & 7 \\ 1 \ldots \ldots . & 2 \ldots \ldots \ldots \ldots . & 7 \\ 1 \ldots \ldots . & 2 \ldots \ldots \ldots \ldots . & 7 \\ 1 \ldots \ldots . & 2 \ldots \ldots \ldots \ldots . & 7 \\ 1 \ldots \ldots . & 2 \ldots \ldots \ldots \ldots . & 7 \\ 1 \ldots \ldots . & 2 \ldots \ldots \ldots \ldots . & 7 \\ 1 \ldots \ldots . & 2 \ldots \ldots \ldots \ldots . & 7 \\ 1 \ldots \ldots . & 2 \ldots \ldots \ldots \ldots . & 7\end{array}$

\section{SECTION B. TOBACCO SMOKING}

INTRO: I would now like to ask you some questions about smoking tobacco, including Cigarettes ,Water pipe, Hishi, pipes and cigars.

B1. Do you currently smoke tobacco on a daily basis, less than daily, or not at all?

\begin{tabular}{|c|c|}
\hline DAILY & $1 \rightarrow$ SKIPTOB4 \\
\hline LES & 2 \\
\hline & $3 \rightarrow$ SKIPTOB3 \\
\hline KNOW & $7 \rightarrow$ SKIP TO NEXT SECTION \\
\hline
\end{tabular}

B2. Have you smoked tobacco daily in the past?

\begin{tabular}{|c|c|}
\hline 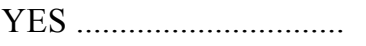 & $1 \rightarrow$ SKIPTOB8 \\
\hline NO. & $\ldots .2 \rightarrow$ SKIPTOB10 \\
\hline ON'T KNOW & 7 $\rightarrow$ SKIPTOB10 \\
\hline
\end{tabular}

B3. In the past, have you smoked tobacco on a daily basis, less than daily, or not at all? INTERVIEWER: IF RESPONDENT HAS DONE BOTH "DAILY” AND "LESS THAN 
DAILY” IN THE PAST, CHECK “DAILY”

DAILY

$1 \rightarrow$ SKIP TO B11

LESS THAN DAILY

$2 \rightarrow$ SKIP TO B13

NOT AT ALL.

$3 \rightarrow$ SKIP TO NEXT SECTION

DON'T KNOW

$7 \rightarrow$ SKIP TO NEXT SECTION

\section{[CURRENT DAILY SMOKERS]}

B4. How old were you when you first started smoking tobacco daily? YEARS OLD IF DON'T KNOW, ENTER “99”

INT: $\quad$ IF B4 = 99, ASK B5. OTHERWISE SKIP TO B6.

B5. How many years ago did you first start smoking tobacco daily? YEARS

B6. On average, how many of the following products do you currently smoke each day? Also, let me know if you smoke the product, but not every day.

INTERVIEWER: IF RESPONDENT REPORTS SMOKING THE PRODUCT BUT NOT EVERY DAY, ENTER 888

IF RESPONDENT REPORTS IN PACKS OR CARTONS, PROBE TO FIND OUT HOW MANY ARE IN EACH AND CALCULATE TOTAL NUMBER

READ EACH ITEM:

\begin{tabular}{|c|c|}
\hline $\begin{array}{l}\text { a. Manufactured cigarettes? a1. [IF B6a=888] } \\
\text { On average, how many manufactured cigarettes } \\
\text { do you currently smoke each week? }\end{array}$ & $\begin{array}{l}\text { PER } \\
\text { DAY } \\
\text { PER } \\
\text { WEEK }\end{array}$ \\
\hline \multicolumn{2}{|l|}{ b. Hand-rolled cigarettes? } \\
\hline \multicolumn{2}{|l|}{$\begin{array}{l}\text { d. Pipes full of tobacco? } \mathrm{d} 1 \text {. [IF B6d=888] On } \\
\text { average, how many pipes full of tobacco do } \\
\text { you currently smoke each week? }\end{array}$} \\
\hline \multicolumn{2}{|l|}{$\begin{array}{l}\text { e. Cigars,?e1. [IF B6e }=888] \text { On average, how } \\
\text { many cigars do you currently smoke each } \\
\text { week? }\end{array}$} \\
\hline \multicolumn{2}{|l|}{$\begin{array}{l}\text { f. Number of water pipe sessions per day? } \\
\text { f1. [IF B6f }=888 \text { ] On average, how many water } \\
\text { pipe sessions do you currently participate in } \\
\text { each week? }\end{array}$} \\
\hline 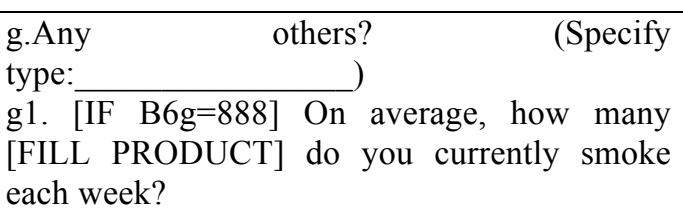 & \\
\hline
\end{tabular}


B7. How soon after you wake up do you usually have your first smoke? Would you say within 5 minutes, 6 to 30 minutes, 31 to 60 minutes, or more than 60 minutes?

WITHIN 5 MINUTES

6 TO 30 MINUTES

31 TO 60 MINUTES.................... 3

MORE THAN 60 MINUTES ....... 4

INT: SKIP TO NEXT SECTION

\section{[CURRENT LESS THAN DAILY SMOKERS]}

B8. How old were you when you first started smoking tobacco daily? YEARS OLDIF DON'T KNOW, ENTER “99”

B9. How many years ago did you first start smoking tobacco daily? YEARS

B10. How many of the following do you currently smoke during a usual week?

INTERVIEWER: IF RESPONDENT REPORTS DOING THE ACTIVITY WITHIN THE PAST 30 DAYS, BUT LESS THAN ONCE PER WEEK, ENTER 888

IF RESPONDENT REPORTS IN PACKS OR CARTONS, PROBE TO FIND OUT HOW MANY ARE IN EACH AND CALCULATE TOTAL NUMBER

INT: $\quad$ IF B8 = 99, ASK B9. OTHERWISE SKIP TO B10.

READ EACH ITEM:

\begin{tabular}{|l|l|l|}
\hline a. Manufactured cigarettes? & & PER WEEK \\
\hline b. Hand-rolled cigarettes? & & PER WEEK \\
\hline d. Pipes full of tobacco? & & PER WEEK \\
\hline e. Cigars? & & PER WEEK \\
\hline f. Number of water pipe sessions per day? & & PER WEEK \\
\hline g. Any others? (Specify type: & & PER WEEK \\
\hline
\end{tabular}

INT: $\quad$ SKIP TO NEXT SECTION

[FORMER SMOKERS]

B11. How old were you when you first started smoking tobacco daily?

YEARS OLD IF DON'T KNOW, ENTER “99" 
B12. How many years ago did you first start smoking tobacco daily? YEARS

B13. How long has it been since you stopped smoking?

INTERVIEWER: ONLY INTERESTED IN WHEN RESPONDENT STOPPED SMOKING

REGULARLY -- DO NOT INCLUDE RARE INSTANCES OF SMOKING

ENTER UNIT AND NUMBER

YEARS ….... 1

MONTHS.... 2

WEEKS ...... $\quad 3$

DAYS.......... 4

LESS THAN ONE DAY (24 HOURS) ..... 5

DON'T KNOW …...................................... 7

INT: $\quad$ IF B11 = 99, ASK B12. OTHERWISE SKIP TO B13.

INT: $\quad$ IF B13 $<1$ YEAR $(<12$ MONTHS), THEN CONTINUE WITH B14. OTHERWISE SKIP TO NEXT SECTION.

B14. Have you visited a doctor or other health care provider in the past 12 months?

YES ........... 1

NO............. $\quad 2 \rightarrow$ SKIP TO B18

B15. How many times did you visit a doctor or health care provider in the past 12 months? Would you say 1 or 2 times, 3 to 5 times, or 6 or more times?

1 OR $2 \ldots \ldots \ldots \ldots . . .1$

3 TO 5 …......... 2

6 OR MORE ... 3

B16. During any visit to a doctor or health care provider in the past 12 months, were you asked if you smoke tobacco?

YES ........... 1

NO............ $\quad 2 \rightarrow$ SKIP TO B18

B17. During any visit to a doctor or health care provider in the past 12 months, were you advised to quit smoking tobacco?

YES …........ 1

$\mathrm{NO}$.............. 2

B18. During the past 12 months, did you use any of the following to try to stop smoking tobacco?

READ EACH ITEM:

YES NO

a. Counseling, including at a smoking cessation clinic? ...................... $1 \ldots \ldots \ldots . .2$

b. Nicotine replacement therapy, such as the patch or gum?............ 1 1....... 2

c. Other prescription medications, for example 1 1...... 2

d. Traditional medicines, for example (WELBUTERN) ....................... 1 1....... 2

g. Anything else? Specify:__ …........ $1 \ldots \ldots \ldots . .2$

SECTION D1. CESSATION - TOBACCO SMOKING

INT: CHECK THE ANSWER TO B1 AND RECORD BELOW:

$\mathbf{B 1}=$ 


\section{IF B1 $=1$ or 2 (RESPONDENT CURRENTLY SMOKES TOBACCO), THEN CONTINUE WITH THIS SECTION}

\section{IF $B 1=3$ or 7 (RESPONDENT DOES NOT CURRENTLY SMOKE TOBACCO), THEN SKIP TO \\ NEXT SECTION........... 2}

INTRO: The next questions ask about any attempts to stop smoking that you might have made during the past 12 months. Please think about tobacco smoking.

D1. During the past 12 months, have you tried to stop smoking?

YES .......... 1

NO............. $\quad 2 \rightarrow$ SKIP TO INT INSTRUCTION BEFORE D4

D2. Thinking about the last time you tried to quit, how long did you stop smoking? INTERVIEWER: ENTER UNIT AND NUMBER

MONTHS.... 1 WEEKS ...... 2 DAYS.......... 3 LESS THAN ONE DAY (24 HOURS) ..... 4 DON'T KNOW 7 25

D3. During the past 12 months, did you use any of the following to try to stop smoking tobacco?

READ EACH ITEM:

a. Counseling, including at a smoking cessation clinic? .................. 1 1....... 2

b. Nicotine replacement therapy, such as the patch or gum?........... 1 ........ 2

c. Other prescription medications, for example? .........................................

d. Traditional medicines, for example......................................... 1 ......... 2

e. A quit line or a smoking telephone support line? ....................... 1 1....... 2

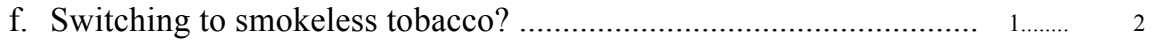

g. Anything else? Specify: $\begin{array}{lll}1 \ldots \ldots \ldots \ldots \ldots & 1 \ldots \ldots \ldots\end{array}$

D4. Have you visited a doctor or other health care provider in the past 12 months?

YES ........... 1

NO............ $\quad 2 \rightarrow$ SKIP TO D8

D5. How many times did you visit a doctor or health care provider in the past 12 months? Would you say 1 or 2 times, 3 to 5 times, or 6 or more times?

1 OR $2 \ldots \ldots \ldots . . .1$

3 TO 5 ........... 2

6 OR MORE ... 3

D6. During any visit to a doctor or health care provider in the past 12 months, were you asked if you smoke tobacco?

YES ........... 1

NO............. $\quad 2 \rightarrow$ SKIP TO D8

D7. During any visit to a doctor or health care provider in the past 12 months, were you advised to quit smoking tobacco?

YES ........... 1

NO ............. 2

D8. Which of the following best describes your thinking about quitting smoking? I am planning to quit within the next month, I am thinking about quitting within the next 12 months, I will quit someday but not within the next 12 months, or I am not interested in quitting?

QUIT WITHIN THE NEXT MONTH....................... 1 THINKING WITHIN THE NEXT 12 MONTHS......... 2 QUIT SOMEDAY, BUT NOT NEXT 12 MONTHS. .. 3 


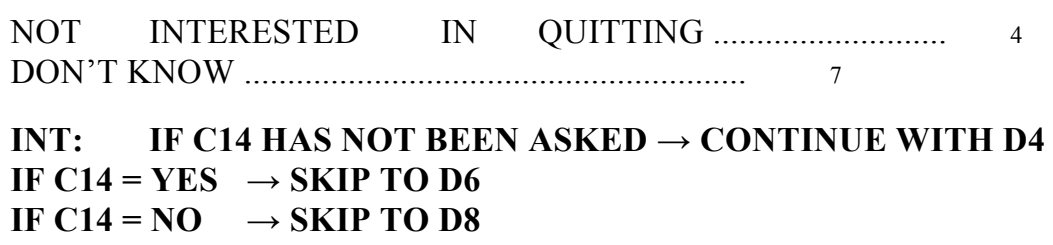

\section{SECTION D2. CESSATION - SMOKELESS TOBACCO \\ INT: CHECK THE ANSWER TO C1 AND RECORD BELOW: \\ $\mathrm{C} 1=$ \\ IF C $1=1$ or 2 (RESPONDENT CURRENTLY USES SMOKELESS TOBACCO), THEN CONTINUE WITH THIS SECTION..........1

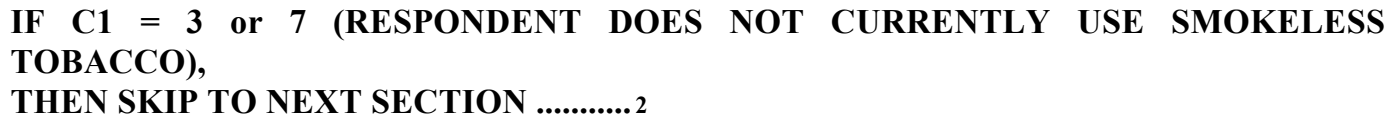

INTRO: The next questions ask about any attempts to stop using smokeless tobacco that you might have made during the past 12 months. Please think about your use of smokeless tobacco.

D9. During the past 12 months, have you tried to stop using smokeless tobacco?

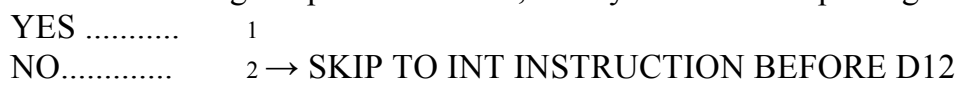

D10. Thinking about the last time you tried to quit, how long did you stop using smokeless tobacco? INTERVIEWER: ENTER UNIT AND NUMBER

MONTHS.... 1

WEEKS ....... 2

DAYS........... 3

LESS THAN ONE DAY (24 HOURS) ..... 4

DON'T KNOW

D11. During the past 12 months, have you used any of the following to try and stop using smokeless tobacco?

READ EACH ITEM:

YES NO

a. Counseling, including at a cessation clinic? ..................................... 1 1........ 2

b. Nicotine replacement therapy, such as the patch or gum?............. 1 1........ $\quad 2$

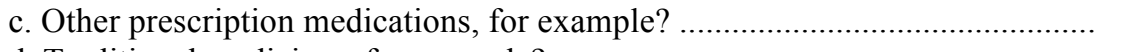

d. Traditional medicines, for example? .......................................... 1 1....... 2

e. A quit line or a telephone support line? .......................................... 1 1........ 2

g. Anything else? Specify: $\begin{array}{llll}\ldots \ldots \ldots \ldots . . . & 1 \ldots \ldots \ldots\end{array}$

D12. Have you visited a doctor or other health care provider in the past 12 months?

YES .......... 1 NO............. $2 \rightarrow$ SKIP TO D16

D13. How many times did you visit a doctor or health care provider in the past 12 months? Would you say 1 or 2 times, 3 to 5 times, or 6 or more times?

1 OR 2........... 13 TO 5 ........... 26 OR MORE ... 3

D14. During any visit to a doctor or health care provider in the past 12 months, were you asked if you use smokeless tobacco?

YES …........ 1 NO............. $2 \rightarrow$ SKIP TO D16

D15. During any visit to a doctor or health care provider in the past 12 months, were you advised to stop using smokeless tobacco? 
YES

$1 \mathrm{NO}$

D16. Which of the following best describes your thinking about quitting smokeless tobacco? I am planning to quit within the next month, I am thinking about quitting within the next 12 months, I will quit someday but not within the next 12 months, or I am not interested in quitting?

QUIT WITHIN THE NEXT MONTH......................... 1 THINKING WITHIN THE NEXT 12 MONTHS......... 2 QUIT SOMEDAY, BUT NOT NEXT 12 MONTHS. .. 3

NOT INTERESTED IN QUITTING …..................... 4

DON'T KNOW

INT: IF BOTH B14 AND D4 HAVE NOT BEEN ASKED $\rightarrow$ CONTINUE WITH D12

IF B14 OR D4 $=$ YES $\rightarrow$ SKIP TO D14

IF B14 OR D4 $=$ NO $\rightarrow$ SKIP TO D16

\section{SECTION E. SECONDHAND SMOKE}

INTRO: I would now like to ask you a few questions about smoking in various places.

E1. Which of the following best describes the rules about smoking inside of your home: Smoking is allowed inside of your home, smoking is generally not allowed inside of your home but there are exceptions, smoking is never allowed inside of your home, or there are no rules about smoking in your home?

\begin{tabular}{|c|c|}
\hline D.. & \\
\hline DT ALLOWE & 2 \\
\hline . & $3 \rightarrow$ SKIP TO E4 \\
\hline RULES . & $4 \rightarrow$ SKIP TO E3 \\
\hline
\end{tabular}

E2. Inside your home, is smoking allowed in every room?

YES ….................... 1

NO …........................ 2

DON'T KNOW ........ 7

E3. How often does anyone smoke inside your home? Would you say daily, weekly, monthly, less than monthly, or never?

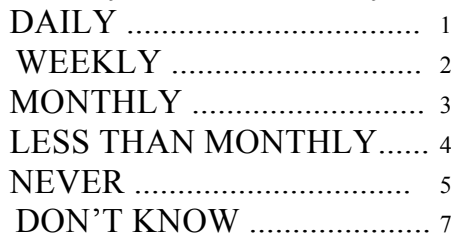

E4. Do you currently work outside of your home?

YES ……............................ 1

NO/DON'T WORK ……….... $2 \rightarrow$ SKIP TO E9

E5. Do you usually work indoors or outdoors?

$\begin{array}{ll}\text { INDOORS ............... } & 1 \rightarrow \text { SKIPTOE7 } \\ \text { OUTDOORS …....... } & 2 \\ \text { BOTH ….................... } & 3 \rightarrow \text { SKIPTOE7 }\end{array}$

E6. Are there any indoor areas at your work place?

YES ........................1

NO …..................... $\quad 2 \rightarrow$ SKIPTOE9

DON'T KNOW …..... $7 \rightarrow$ SKIPTOE9 
E7. Which of the following best describes the indoor smoking policy where you work: Smoking is allowed anywhere, smoking is allowed only in some indoor areas, smoking is not allowed in any indoor areas, or there is no policy?

ALLOWED ANYWHERE........................................1

ALLOWED ONLY IN SOME INDOOR AREAS....2

NOT ALLOWED IN ANY INDOOR AREAS ..........3

THERE IS NO POLICY ..........................................

DON'T KNOW ......................................................

E8. During the past 30 days, did anyone smoke in indoor areas where you work?

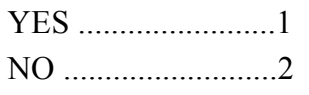

DON'T KNOW ........7

E9. During the past 30 days, did you visit any government buildings or government offices?

$\begin{array}{ll}\text { YES } & 1 \\ \text { NO } & 2 \rightarrow \text { SKIP TO E11 } \\ \text { DON'T KNOW } & 7 \rightarrow \text { SKIP TO E11 }\end{array}$

E10. Did anyone smoke inside of any government buildings or government offices that you visited in the past 30 days?

YES …...................1

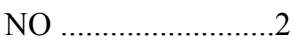

DON'T KNOW .........7

E11. During the past 30 days, did you visit any health care facilities?

$\begin{array}{ll}\text { YES } & 1 \\ \text { NO } & 2 \rightarrow \text { SKIP TO E13 } \\ \text { DON'T KNOW } & 7 \rightarrow \text { SKIP TO E13 }\end{array}$

E12. Did anyone smoke inside of any health care facilities that you visited in the past 30 days?

YES …....................1

NO ……...................

DON'T KNOW .........7

E13. During the past 30 days, did you visit any restaurants? 
$\begin{array}{ll}\text { YES } & 1 \\ \text { NO } & 2 \rightarrow \text { SKIP TO E15 } \\ \text { DON'T KNOW } & 7 \rightarrow \text { SKIP TO E15 }\end{array}$

E14. Did anyone smoke inside of any restaurants that you visited in the past 30 days?

YES …....................1

NO ….....................2

DON'T KNOW (........7

E15. During the past 30 days, did you use any public transportation?

$\begin{array}{ll}\text { YES } & 1 \\ \text { NO } & 2 \rightarrow \text { SKIP TO E17 }\end{array}$

DON'T KNOW $7 \rightarrow$ SKIP TO E17

E16. Did anyone smoke inside of any public transportation that you used in the past 30 days?

YES ......................1

NO …......................2

DON'T KNOW ........7

E17. Based on what you know or believe, does breathing other people's smoke cause serious illness in nonsmokers?

YES …...................1

NO ….....................2

DON'T KNOW ........7

SECTION F. ECONOMICS - MANUFACTURED CIGARETTES

INT: CHECK THE ANSWERS TO B1, B6a, AND B10a. RECORD BELOW:

B1 =

$\mathbf{B 6 a}=$

$\mathbf{B 1 0 a}=$

IF B1 $=1$ OR 2 (RESPONDENT CURRENTLY SMOKES DAILY OR LESS THAN DAILY)

AND 
[B6a OR B10a] $>0$ OR $=888($ RESPONDENT SMOKES MANUFACTURED CIGARETTES)

THEN CONTINUE WITH THIS SECTION

OTHERWISE, SKIP TO NEXT SECTION

INTRO: The next few questions are about the last time you purchased cigarettes for yourself.

F1. The last time you bought cigarettes for yourself, how many cigarettes did you buy? INTERVIEWER:

ENTER UNIT AND NUMBER

\section{CIGARETTES}

....1

\section{PACKS}

…….........................................2

CARTONS

....3

OTHER

SPECIFY:

NEVER BOUGHT CIGARETTES .........7

In total, how much money did you pay for this

\begin{tabular}{l}
\multicolumn{2}{c}{ purchase? } \\
INTERVIEWER: IF DON'T \\
KNOW, ENTER \\
999
\end{tabular}

What brand did you buy the last time
[MANDATORY

WHERE

RELEVANT:]

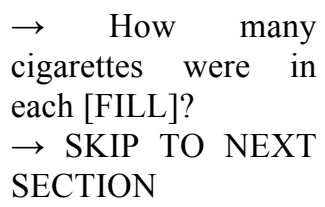


you purchased cigarettes for

yourself?

F4. The last time you purchased cigarettes for yourself, where did you buy them?

VENDING MACHINE 1

STORE 2

STREET VENDOR 3

MILITARY STORE 4

DUTY-FREE SHOP 5

OUTSIDE THE COUNTRY 6

KIOSKS 7

INTERNET 8

FROM ANOTHER PERSON 9

OTHER $\quad 10 \rightarrow$ SPECIFY:

DON'T REMEMBER 77

\section{SECTION G. MEDIA}

STRUCTURE \#1 - ASKING ABOUT ONLY ONE PRODUCT (E.G., CIGARETTES)

INTRO: The next few questions ask about your exposure to the media and advertisements in the last 30 days.

G1. In the last 30 days, have you noticed information about the dangers of smoking cigarettes or that encourages quitting in any of the following places?

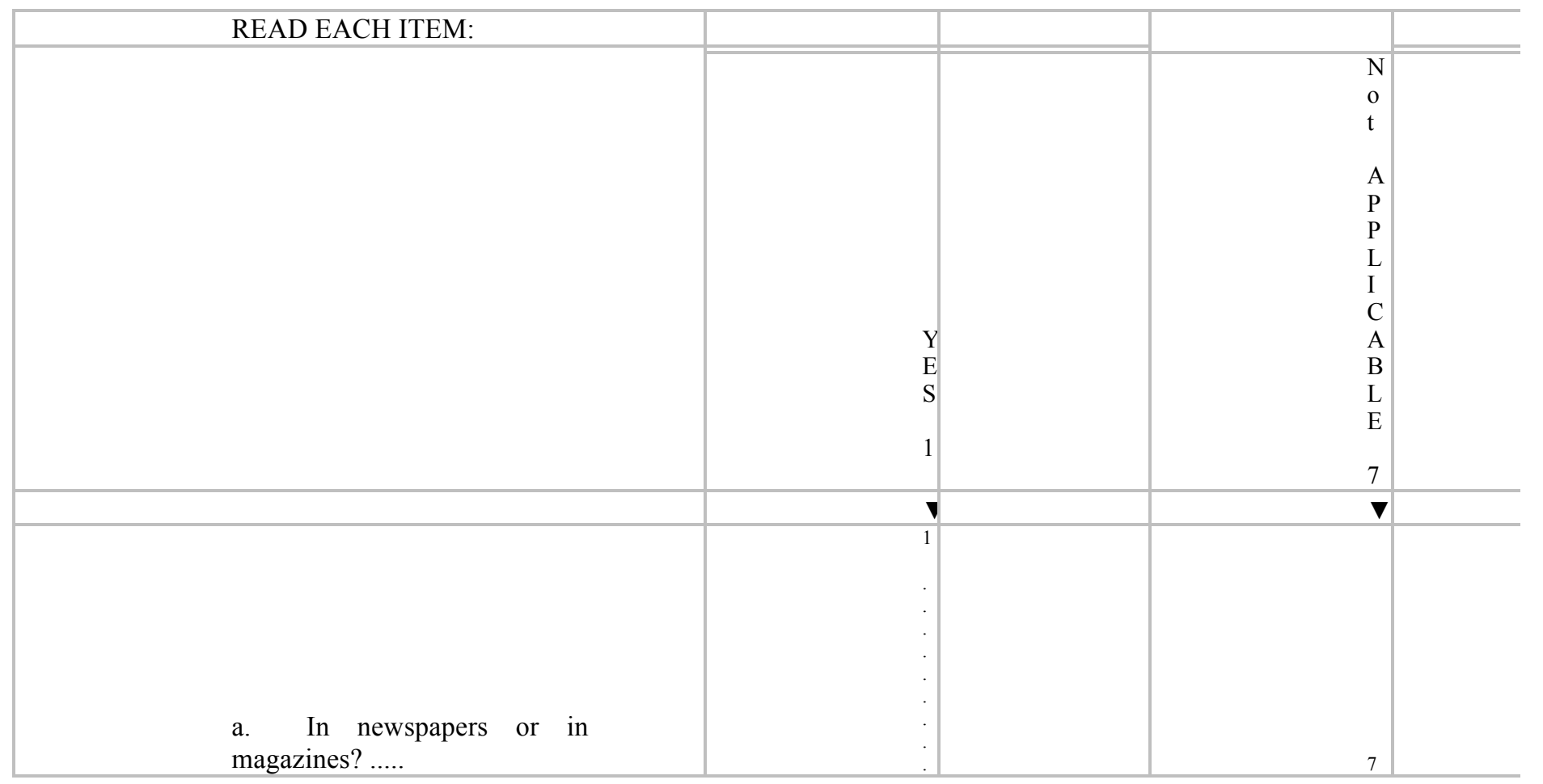




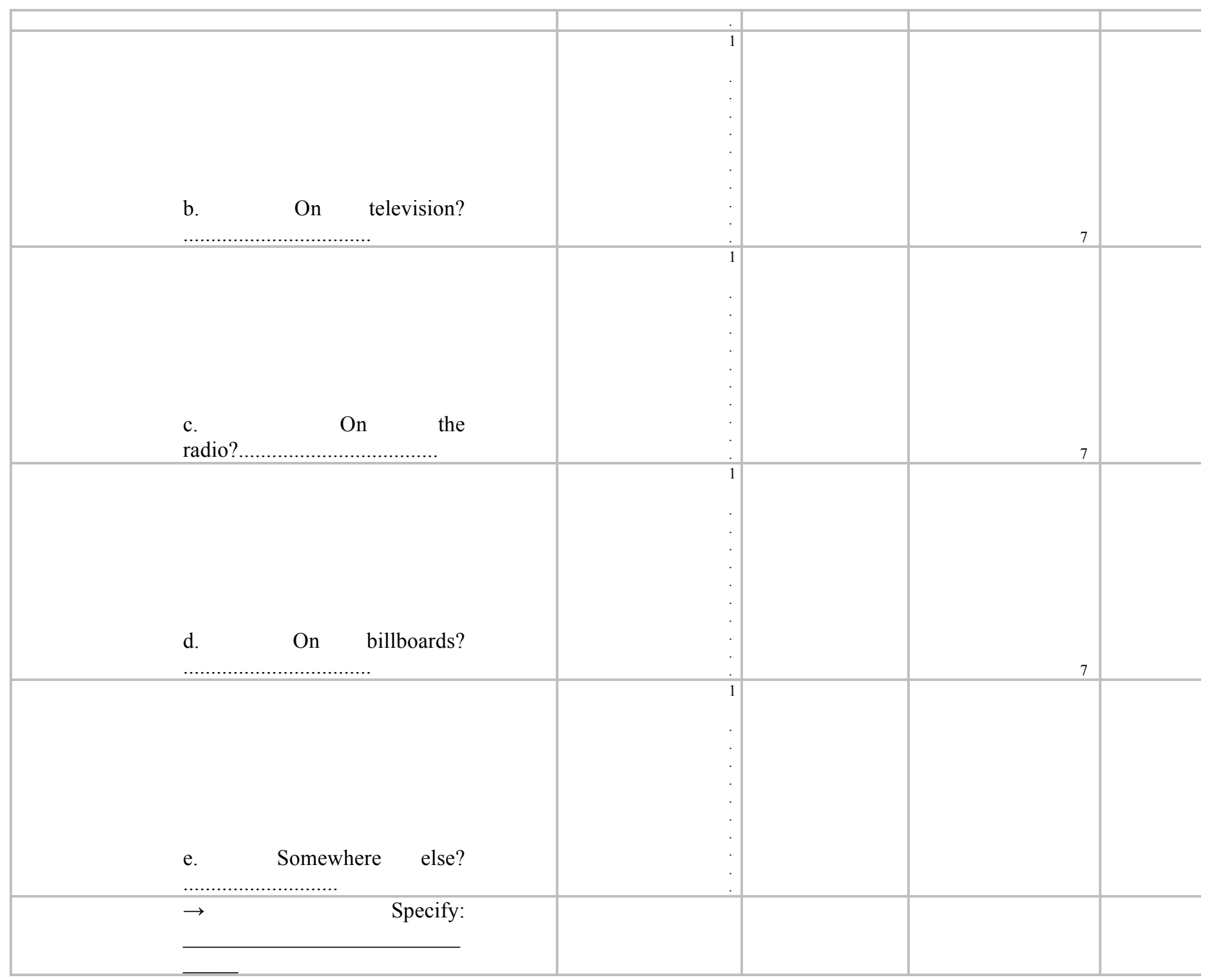

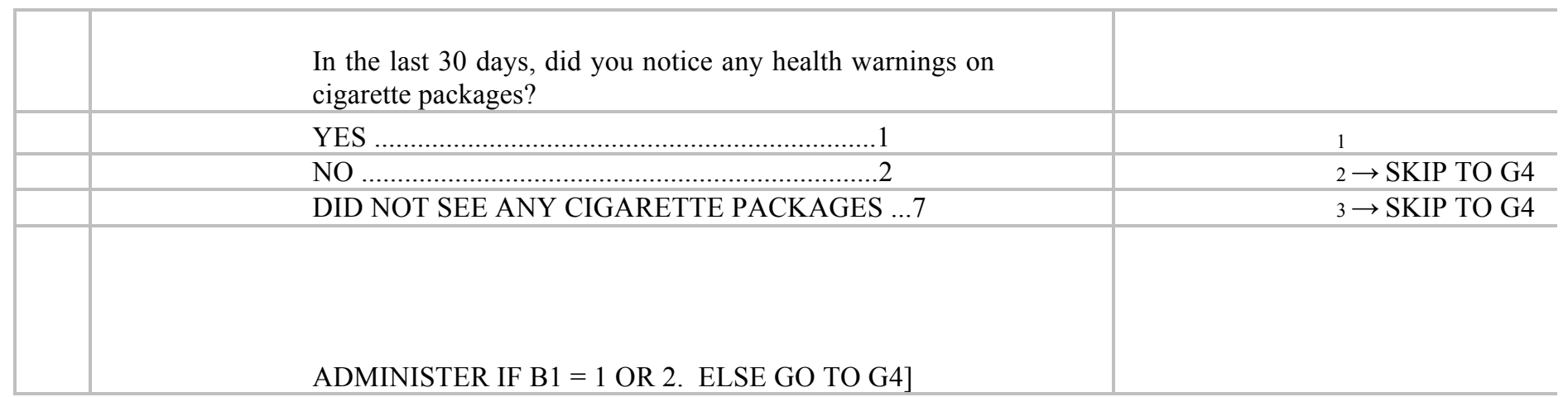

G3. In the last 30 days, have warning labels on cigarette packages led you to think about quitting?

YES ......................1

NO ........................2 
DON'T KNOW ........7

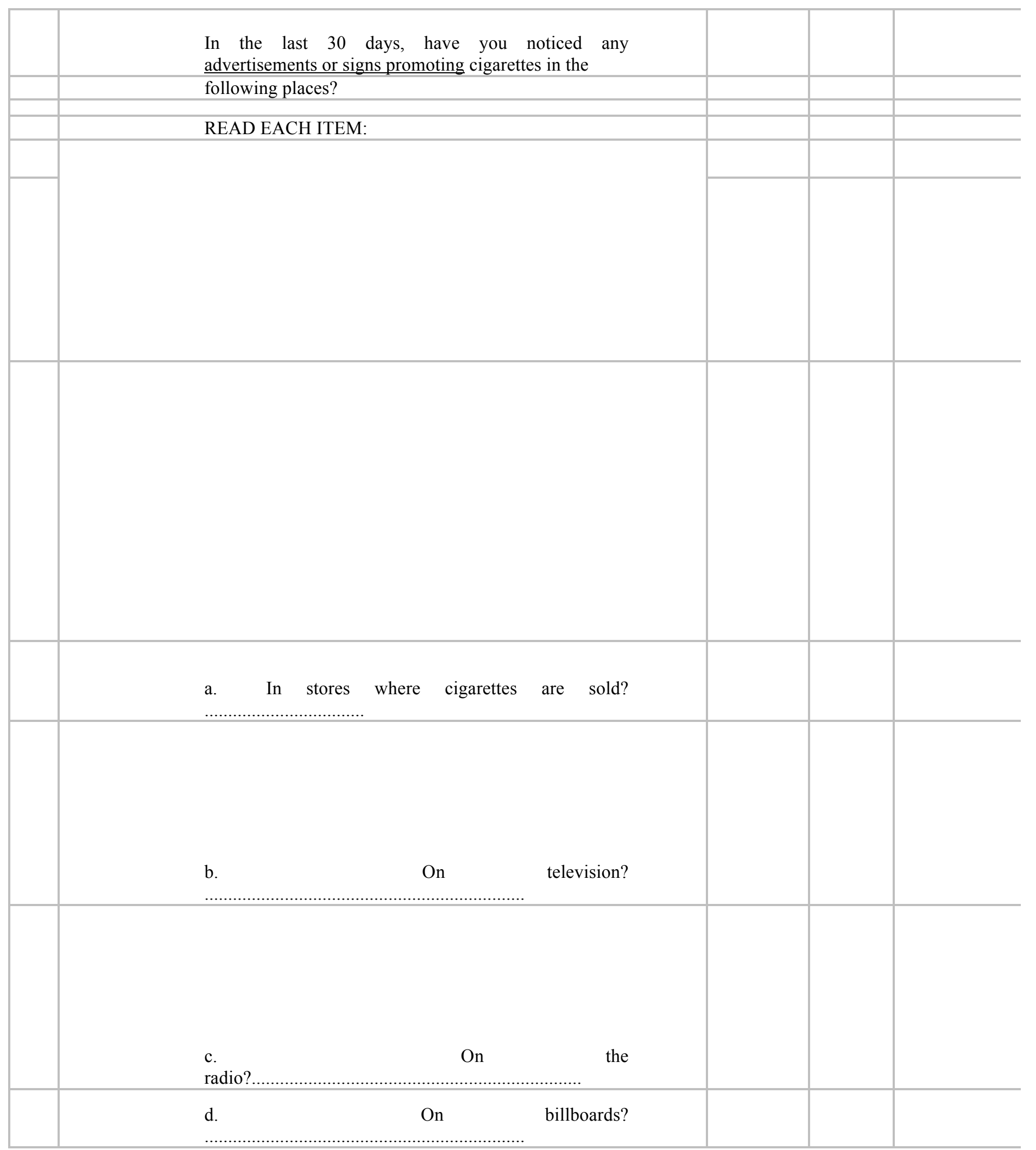




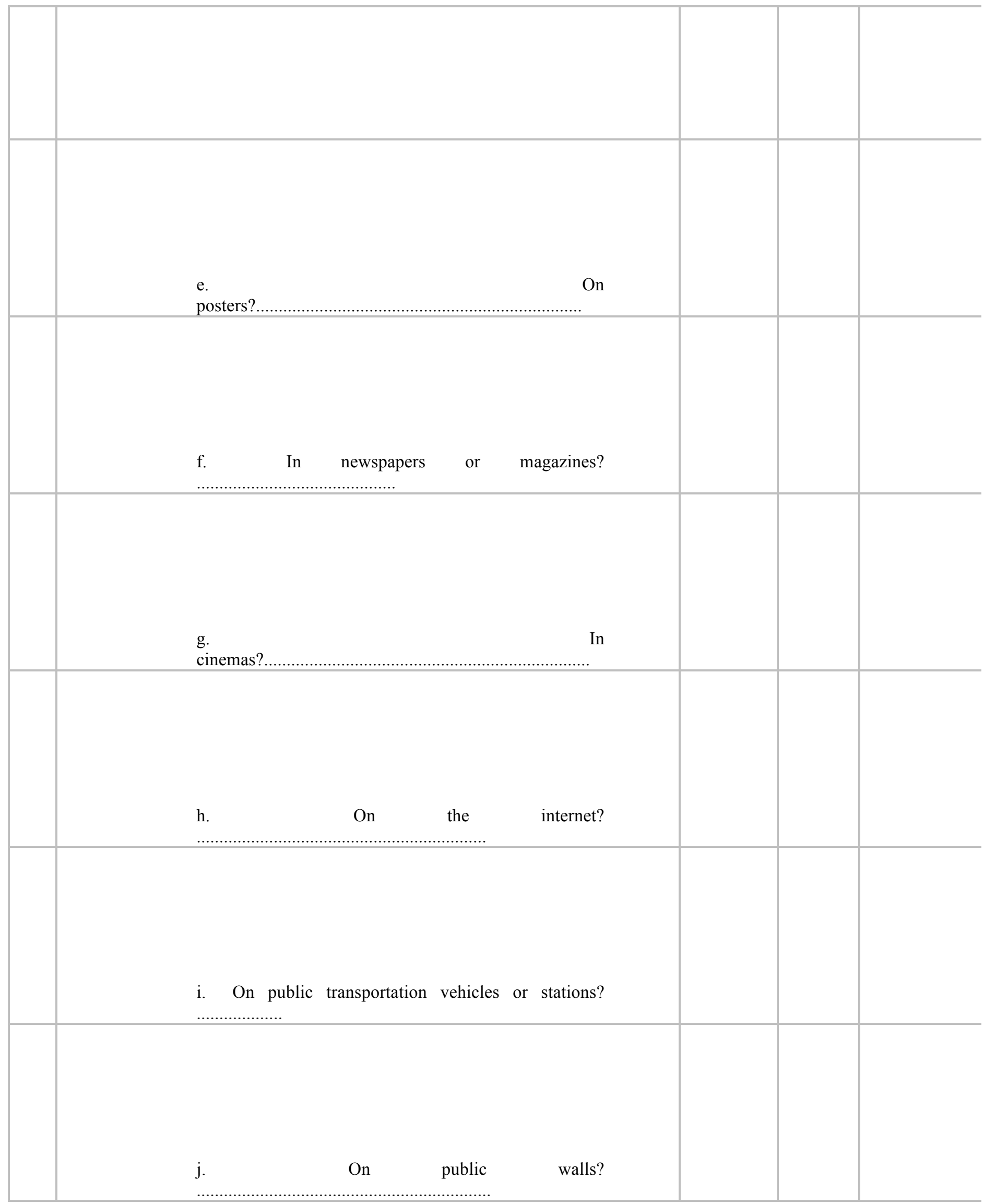




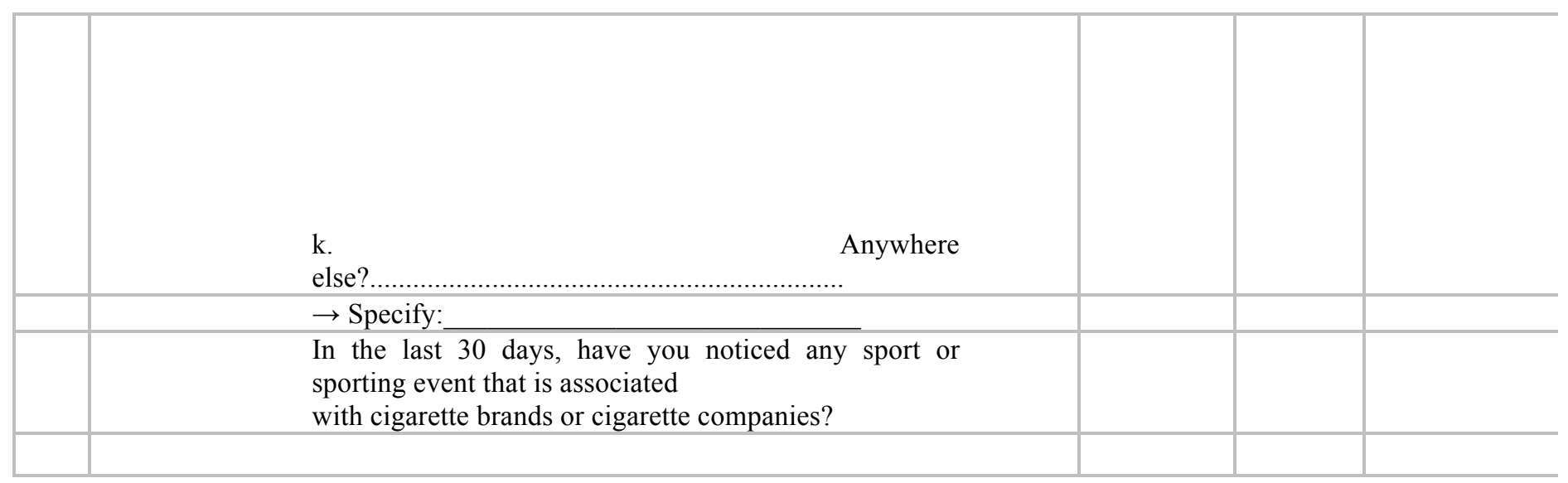

YES …...................1

NO …......................2

DON'T KNOW …....7

G6. In the last 30 days, have you noticed any of the following types of cigarette promotions?

\section{READ EACH ITEM:}

know

Yes No Don't

$1 \quad 2$

a. Free samples of cigarettes?

b. Cigarettes at sale prices?

c. Coupons for cigarettes?

d. Free gifts or special discount offers on other

e .products when buying cigarettes?

f. Clothing or other items with a cigarette

g.brand name or logo?

$\mathrm{h}$. Cigarette promotions in the mail?

\section{SECTION H. KNOWLEDGE, ATTITUDES \& PERCEPTIONS}

H1. [IF SMOKELESS TOBACCO QUESTIONS HAVE JUST BEEN ASKED, ADD:] The next question is asking about smoking tobacco.

Based on what you know or believe, does smoking tobacco cause serious illness?

\begin{tabular}{|l|l|}
\hline Y & \\
E & \\
S & 1 \\
\hline
\end{tabular}




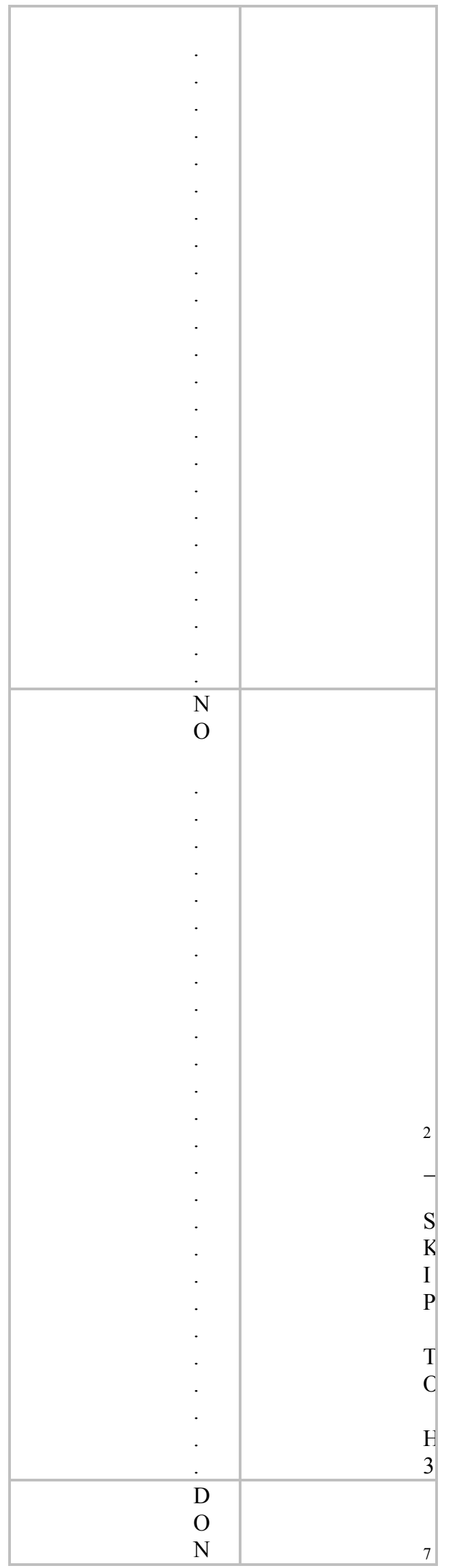




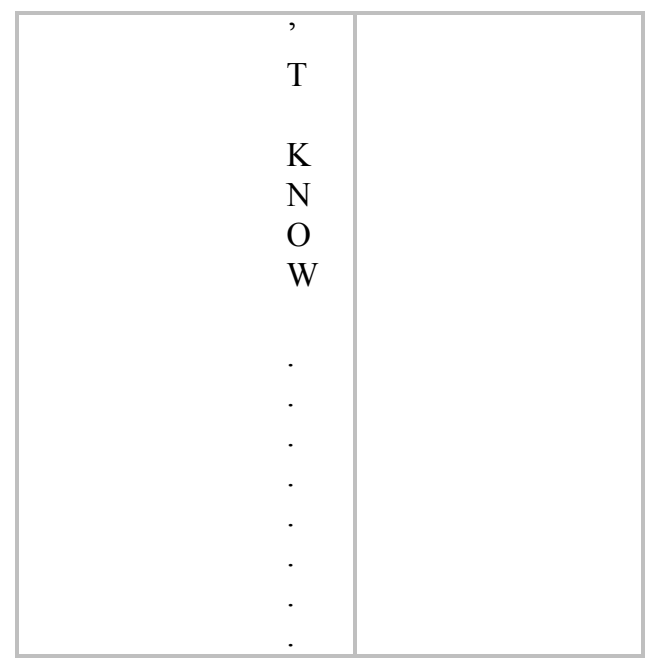

H2. Based on what you know or believe, does smoking tobacco cause the following...

\begin{tabular}{|l|l|l|l|l|}
\hline READ & & & & \\
EACH & & & & \\
ITEM: & & & & \\
\hline & & & & \\
\hline & & & & \\
\hline
\end{tabular}

a. Stroke (blood clots in the brain

that may cause paralysis)? ............1

b. Heart attack?....................................

c. Lung cancer?...................................... 3

H3. Based on what you know or believe, does using smokeless tobacco cause serious illness?

YES …...................1

NO ….........................

DON'T KNOW .........7

\section{END INDIVIDUAL QUESTIONNAIRE}

Those are all of the questions I have. Thank you very much for participating in this important survey.

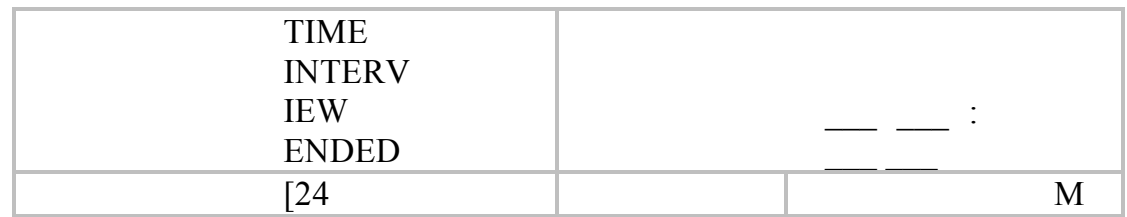




\begin{tabular}{|l|l|l|}
\hline HOUR & $\mathrm{I}$ \\
CLOCK & $\mathrm{N}$ \\
] & $\mathrm{S}$ \\
\hline
\end{tabular}

RECORD ANY NOTES ABOUT INTERVIEW:

\section{GLOBAL ADULT TOBACCO SURVEY (GATS)}

\section{List of Optional Items}

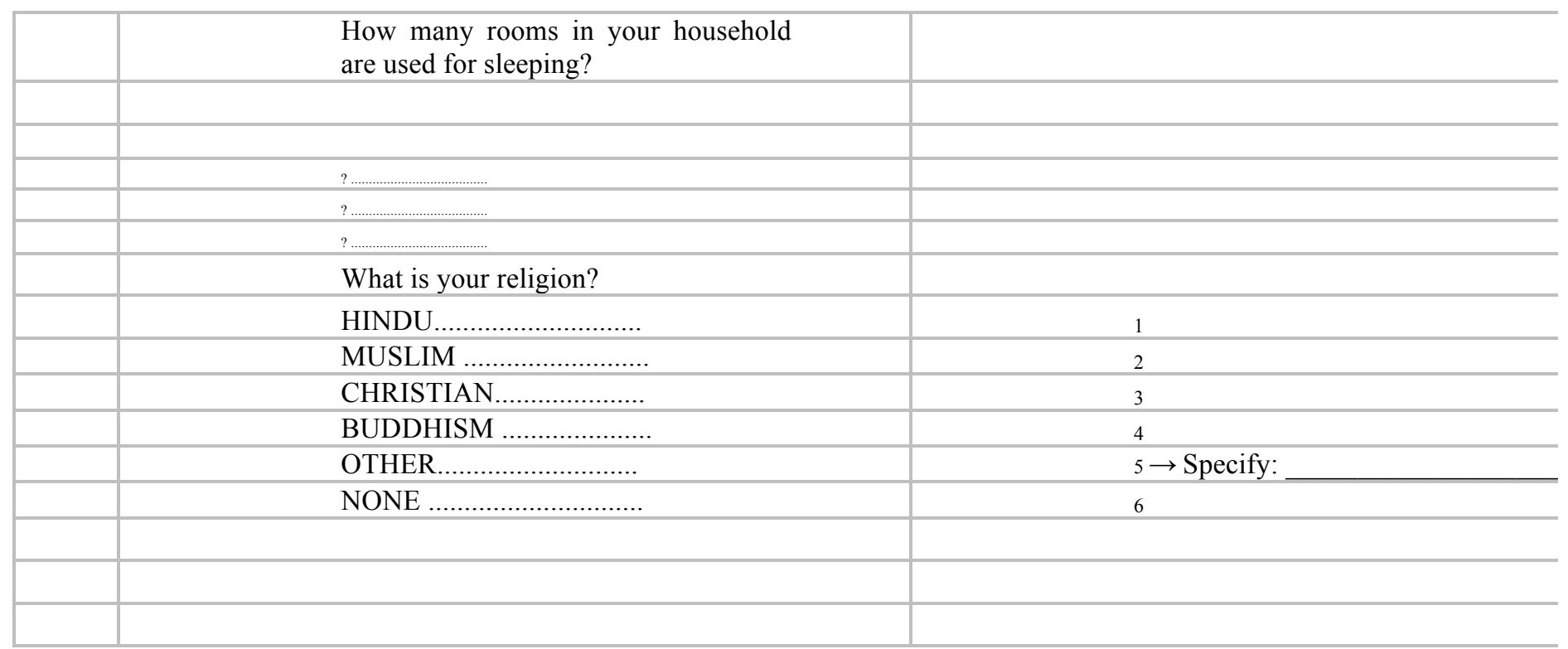

A11. What is your marital status? Would you say...

Single $\quad 1$

Married 2

Separated 3

Divorced 4

Widowed 5

A12. Can you read and write?

YES …...................1

NO …...................... 


\section{SECTION E. SECONDHAND SMOKE}

\section{E8a. [ONLY ADMINISTERED IF E8 = YES]}

How often does anyone smoke in indoor areas where you work? Would you say daily, weekly, monthly, or less than monthly?

DAILY .1

WEEKLY ...............................

MONTHLY ............................. 3.

LESS THAN MONTHLY......4

\section{E18. [ONLY ADMINISTERED IF E17 = YES]}

Based on what you know or believe, does breathing smoke from other people's cigarettes cause any of the following?

\begin{tabular}{|l|l|l|l|l|}
\hline & & & & \\
READ & & & & \\
EACH & & & & \\
\hline & & & & \\
\hline & & & & \\
\hline & & & & \\
\hline
\end{tabular}

a. Heart disease in adults?

b. $\quad$ Lung illnesses in children?................

c. Lung cancer in adults?

E19. During the past 30 days, did you visit any schools?

$\begin{array}{ll}\text { YES } & 1 \\ \text { NO } & 2 \rightarrow \text { SKIP TO E2 } 1\end{array}$

E20. Did anyone smoke inside of any schools that you visited in the past 30 days?

YES ……………....1.

NO .........................2

DON'T KNOW ….....7

E21. During the past 30 days, did you visit any universities?

YES 1 
NO $\quad 2 \rightarrow$ SKIP TO E23

DON'T KNOW $7 \rightarrow$ SKIP TO E23

E22. Did anyone smoke inside of any universities that you visited in the past 30 days?

YES ……................1

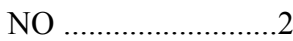

DON'T KNOW …....7

E23. During the past 30 days, did you visit any private workplaces other than your own?

YES $\quad 1$

NO $\quad 2 \rightarrow$ SKIP TO E25

DON'T KNOW $7 \rightarrow$ SKIP TO E25

E24. Did anyone smoke inside of any of these private workplaces you visited in the past 30 days?

YES ……….............1

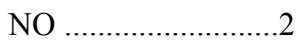

DON'T KNOW .........7

E25. During the past 30 days, did you visit any bars or night clubs?

$\begin{array}{ll}\text { YES } & 1 \\ \text { NO } & 2 \rightarrow \text { SKIP TO E27 } \\ \text { DON'T KNOW } & 7 \rightarrow \text { SKIP TO E27 }\end{array}$

E26. Did anyone smoke inside of any bars or night clubs that you visited in the past 30 days?

YES ….....................

NO ……...................

DON'T KNOW .........7

E27. During the past 30 days, did you visit any cafes, coffee shops, or tea houses?

$\begin{array}{ll}\text { YES } & 1 \\ \text { NO } & 2 \rightarrow \text { SKIP TO E29 } \\ \text { DON'T KNOW } & 7 \rightarrow \text { SKIP TO E29 }\end{array}$

E28. Did anyone smoke inside of any cafes, coffee shops, or tea houses that you visited in the past 30

days?

YES ………….........1

$\mathrm{NO}$.............................

DON'T KNOW ........7

E29. For each of the following public places, please tell me if you think smoking should or should not be 
allowed in indoor areas.

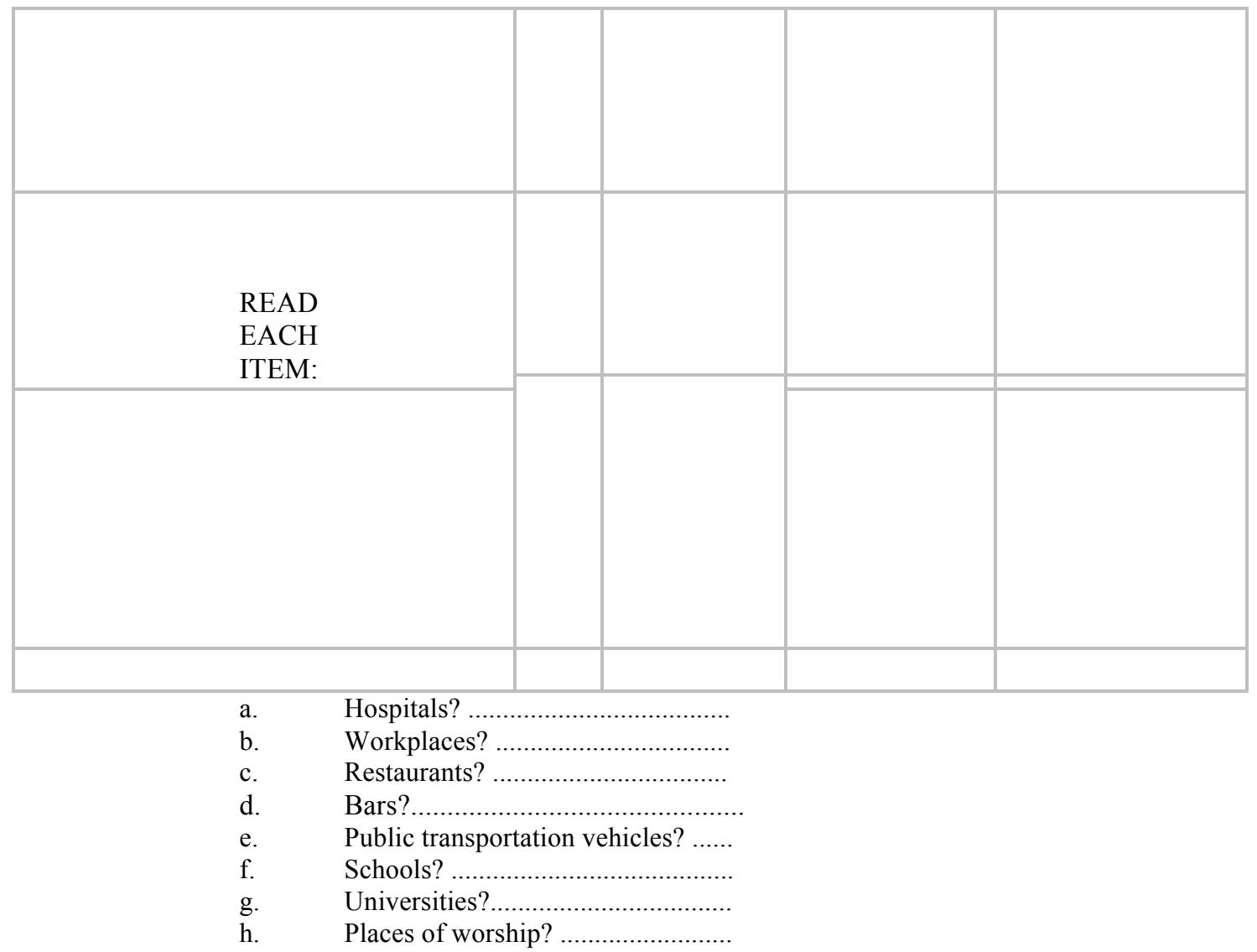

[FOR COUNTRIES WITH EXISTING LAWS PROHIBITING SMOKING, USE THE FOLLOWING ITEMS. MAY NEED TO ADJUST BASED ON REGIONAL AND LOCAL LAWS]

E29a. Do you support the law that prohibits smoking inside of hospitals?

YES …….............1.

NO .......................

DON'T KNOW ....7

E29b. Do you support the law that prohibits smoking inside of workplaces?

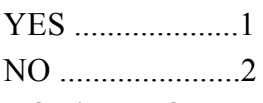

DON'T KNOW …7

E29c. Do you support the law that prohibits smoking inside of restaurants?

YES ...................
NO ....................
DON'T KNOW ....7 
E29d. Do you support the law that prohibits smoking inside of bars?

YES …...............1

NO …..................2

DON'T KNOW ....7

E29e. Do you support the law that prohibits smoking inside of public transportation vehicles?

YES …................1

NO …...................2

DON'T KNOW ....7

E29f. Do you support the law that prohibits smoking inside schools?

YES …................1

NO …..................2

DON'T KNOW ....7

E29g. Do you support the law that prohibits smoking inside universities?

YES …................. 1

NO ….................2

DON'T KNOW ....7

E29h. Do you support the law that prohibits smoking inside places of worship ?

YES ....................1

NO …..................2

DON'T KNOW ....7

\section{SECTION F. ECONOMICS}

F5. Were these cigarettes filtered or non-filtered?

FILTERED. 1.

NON-FILTERED.............2.

F6. Were these cigarettes labeled as light, mild, or low tar?

$\begin{array}{lcl}\text { LIGHT } & 1 \\ \text { MILD } & 2 \\ \text { LOW TAR } & 3 & \\ \text { NONE OF THE ABOVE .. } & 4\end{array}$

DON'T KNOW 7

58

SECTION G. MEDIA 
GG1a - GG1e. [FOLLOW-UP FOR EACH ITEM ANSWERED YES IN G1]

Would you say a lot or sometimes?

A LOT...............1.

SOMETIMES....2

GG5. In the last 30 days, have you noticed any music, theatre, art, or fashion events that are associated with (cigarette/smokeless tobacco) brands or (cigarette/smokeless tobacco) companies?

YES …................1

NO …..................2

DON'T KNOW ....7

SECTION H. KNOWLEDGE, ATTITUDES \& PERCEPTIONS

[H2 1 SHOULD ONLY BE ASKED OF CURRENT TOBACCO SMOKERS WHO BELIEVE THĀT SMOKING CAUSES SERIOUS DISEASE $(\mathrm{H} 1=1)$ OR WHO DON'T KNOW IF SMOKING CAUSES SERIOUS DISEASE $(\mathrm{H} 1=7)]$

H2_1. Based on your experience of smoking, do you think that your current brand might be a little less harmful, is no different, or might be a little more harmful, compared to other cigarettes?

\begin{tabular}{|c|c|}
\hline $\begin{array}{l}\text { A } \\
\text { LIT } \\
\text { TLE } \\
\text { LES } \\
\text { S } \\
\text { HA } \\
\text { RM } \\
\text { FUL } \\
. .\end{array}$ & $\begin{array}{l}1 \\
\rightarrow \\
\mathrm{S} \\
\mathrm{K} \\
\mathrm{I} \\
\mathrm{P} \\
\\
\mathrm{O} \\
\mathrm{V} \\
\mathrm{E} \\
\mathrm{R} \\
\mathrm{H} \\
2 \\
\overline{2}\end{array}$ \\
\hline $\begin{array}{l}\text { NO } \\
\text { DIF } \\
\text { FER } \\
\text { EN } \\
\text { T..... } \\
\ldots \ldots \\
\ldots \ldots . . \\
. .\end{array}$ & 2 \\
\hline $\begin{array}{l}\text { A } \\
\text { LIT }\end{array}$ & $\begin{array}{l}3 \\
\rightarrow\end{array}$ \\
\hline
\end{tabular}




\begin{tabular}{|l|l|}
\hline TLE & S \\
MO & K \\
RE & I \\
HA & P \\
RM & \\
FUL & O \\
$\cdot$ & $\mathrm{V}$ \\
& $\mathrm{E}$ \\
& $\mathrm{R}$ \\
& $\mathrm{H}$ \\
& 2 \\
& - \\
\hline
\end{tabular}

[H2_2 SHOULD BE ASKED OF EVERYONE EXCEPT FOR THOSE FOR WHOM H1 $=2$ AND THOSE FOR WHOM H2_1 = 1 OR 3]

H2_2. Do you think that some types of cigarettes could be less harmful than other types, or are all cigarettes equally harmful?

COULD BE LESS HARMFUL ....1

ALL EQUALLY HARMFUL..........2

H2_3. Do you believe cigarettes are addictive?

YES …......................1

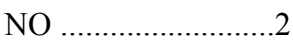

DON'T KNOW .........7

[H2_3 CAN BE REPEATED FOR OTHER RELEVANT PRODUCTS SUCH AS BIDIS, SMOKELESS, ETC.]

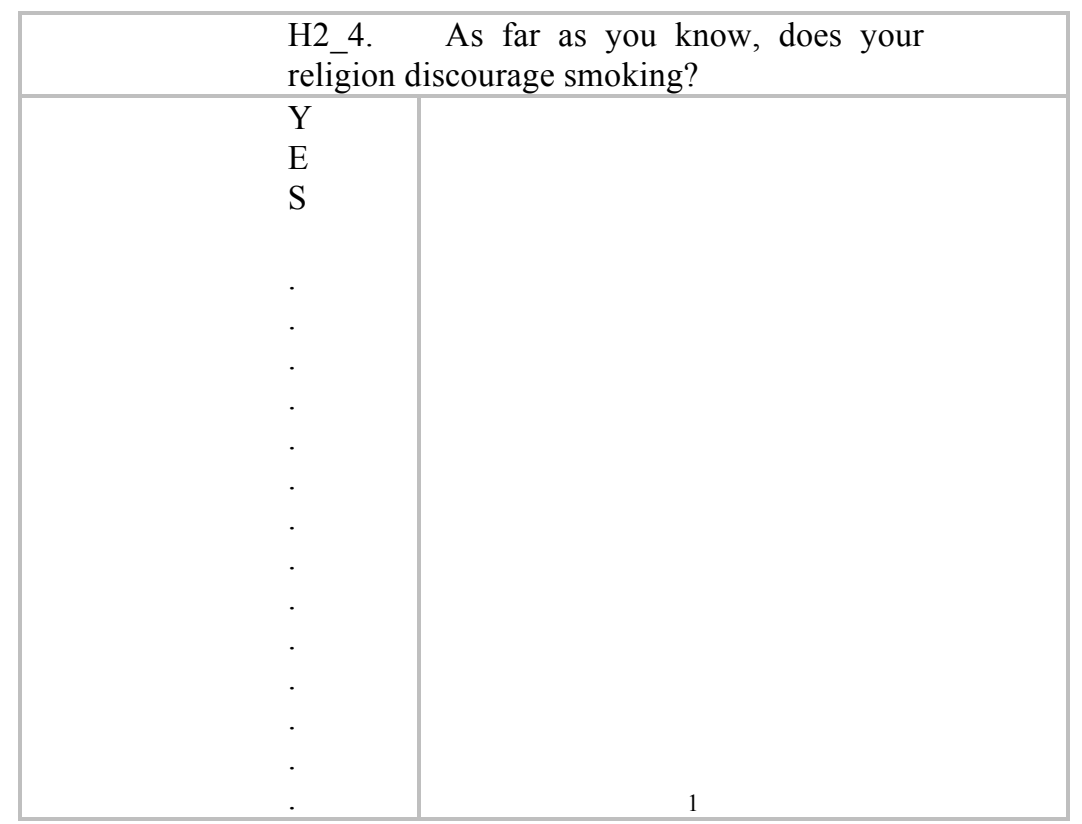




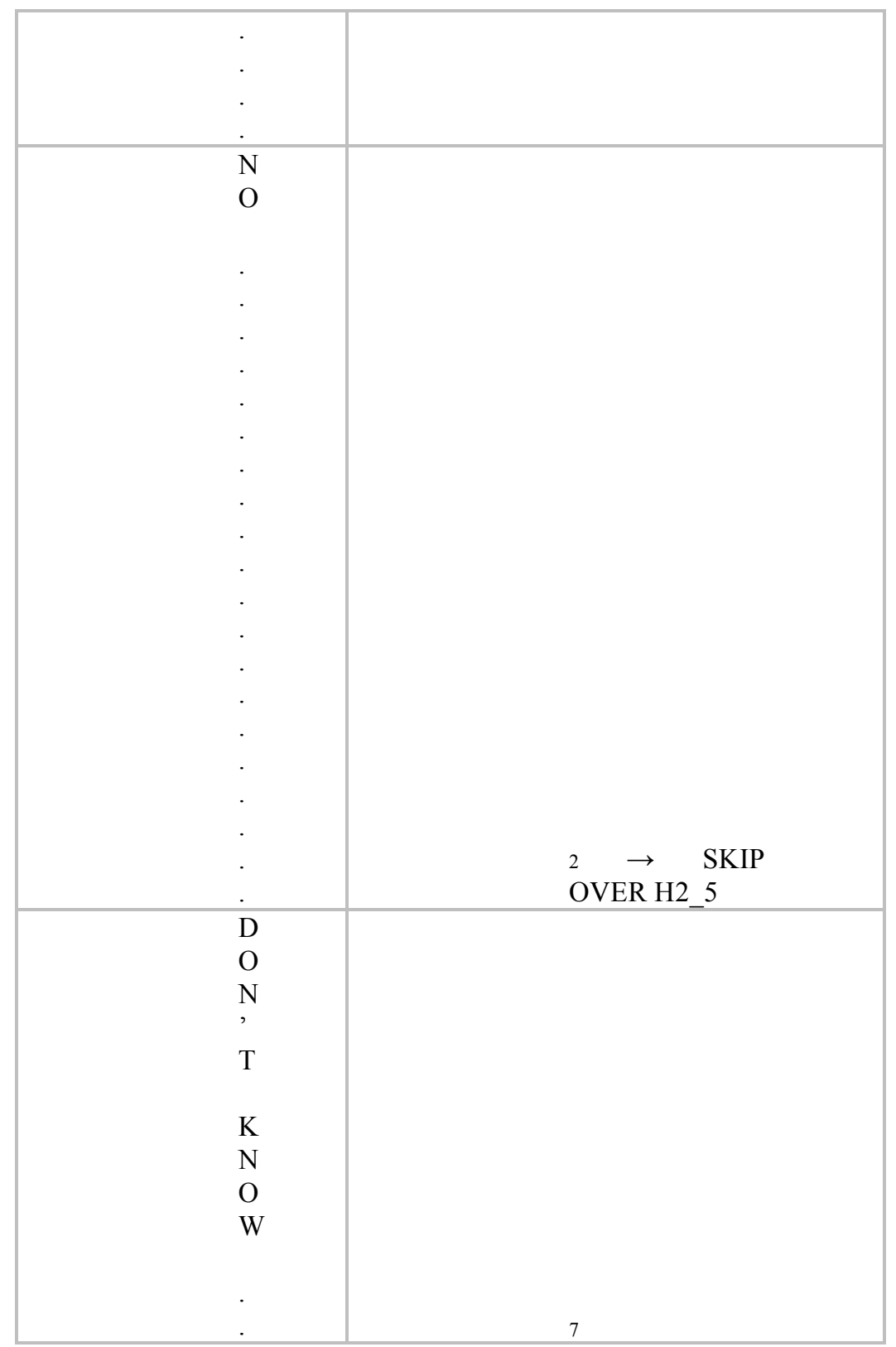

\begin{tabular}{|c|c|}
\hline $\begin{array}{l}\mathrm{H} 2 \text { 5. What is the ruling on } \\
\text { cigarette smoking in Islam? }\end{array}$ & \\
\hline $\begin{array}{lrr}\text { DO } & \text { NOT } & \text { READ } \\
\text { CATEGORIES } & \end{array}$ & \\
\hline $\begin{array}{l}\text { SMOKING IS STRICTLY } \\
\text { FORBIDDEN/SINFUL } \\
\text { (HARAM).... }\end{array}$ & 1 \\
\hline $\begin{array}{l}\text { SMOKING } \\
\text { DISCOURAGED } \\
\text { (MAKRUH)................................ IS }\end{array}$ & 2 \\
\hline 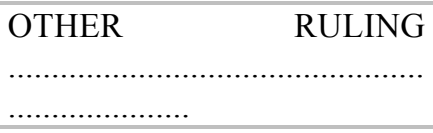 & $\begin{array}{l}3 \rightarrow \overrightarrow{\text { SPEC }} \\
\text { IFY: }\end{array}$ \\
\hline
\end{tabular}




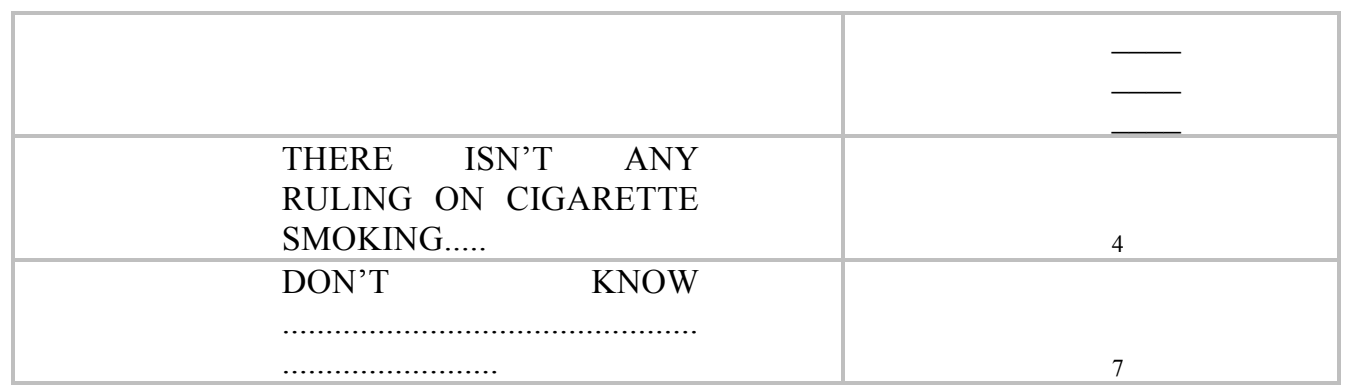

H4. Would you favor or oppose a law that would prohibit smoking in indoor workplaces and public places, such as restaurants and [FILL APPROPRIATE TERM FOR COUNTRY SUCH AS "bars" OR "coffee houses"]?

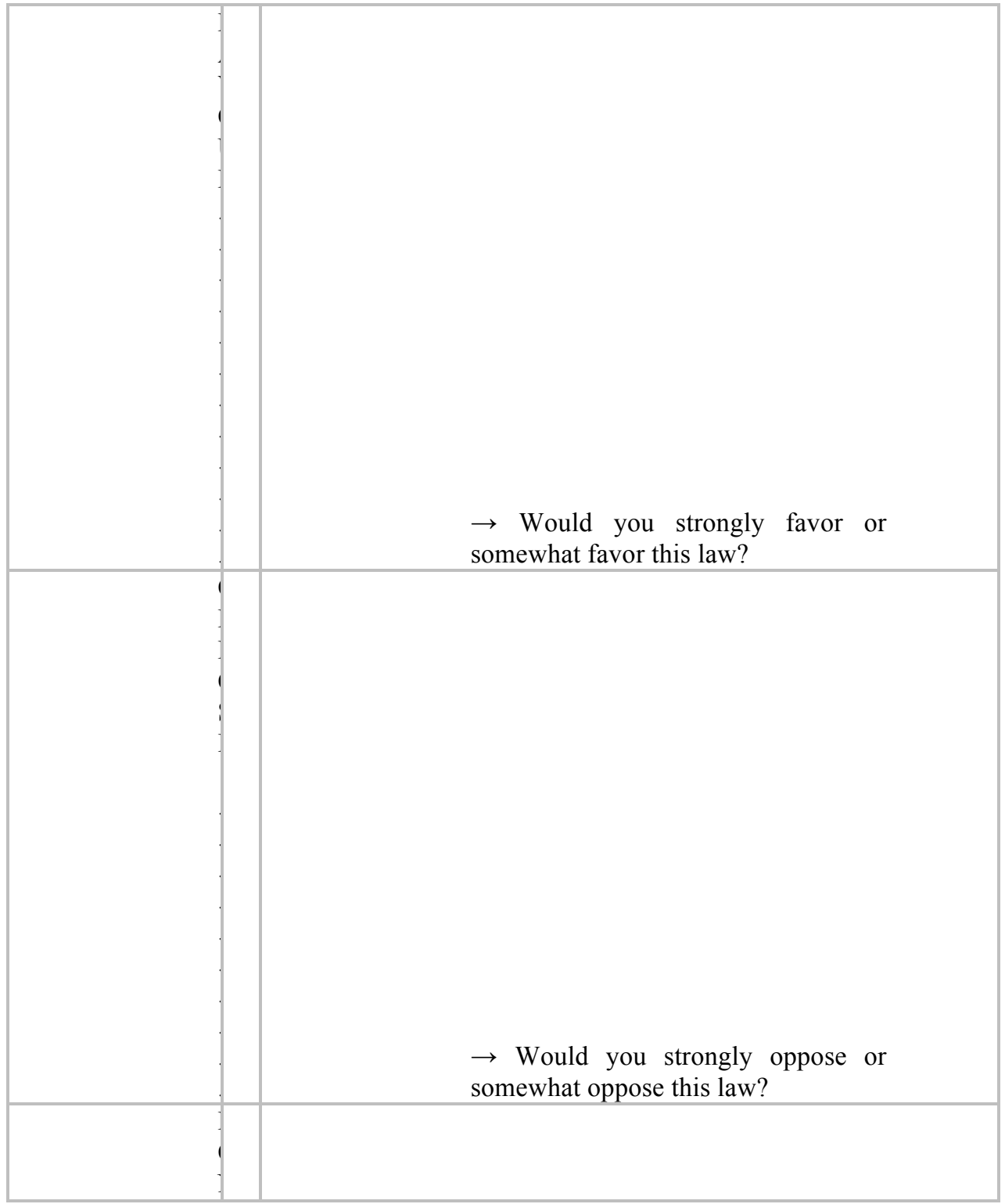




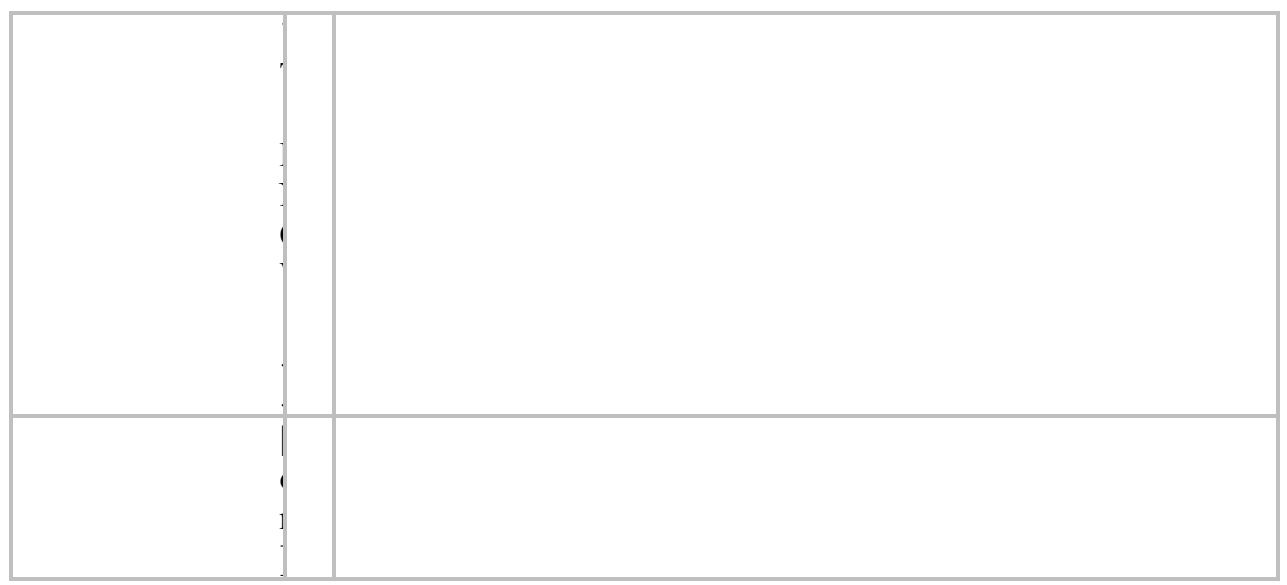

H5. Do you support or oppose the law that prohibits smoking in indoor workplaces and public places, such as restaurants and [FILL APPROPRIATE TERM FOR COUNTRY SUCH AS "bars" OR “coffee houses"]?

\begin{tabular}{|c|c|}
\hline $\begin{array}{l}\mathrm{S} \\
\mathrm{U} \\
\mathrm{P} \\
\mathrm{P} \\
\mathrm{O} \\
\mathrm{R} \\
\mathrm{T} \\
. \\
. \\
. \\
.\end{array}$ & $\begin{array}{l}\rightarrow \text { Do you strongly support or somewhat } \\
\text { support this law? }\end{array}$ \\
\hline $\begin{array}{l}\mathrm{O} \\
\mathrm{P} \\
\mathrm{P} \\
\mathrm{O} \\
\mathrm{S} \\
\mathrm{E}\end{array}$ & $\begin{array}{l}\rightarrow \text { Do you strongly oppose or somewhat } \\
\text { oppose this law? }\end{array}$ \\
\hline $\begin{array}{l}\mathrm{D} \\
\mathrm{O} \\
\mathrm{N} \\
, \\
\mathrm{T}\end{array}$ & \\
\hline
\end{tabular}




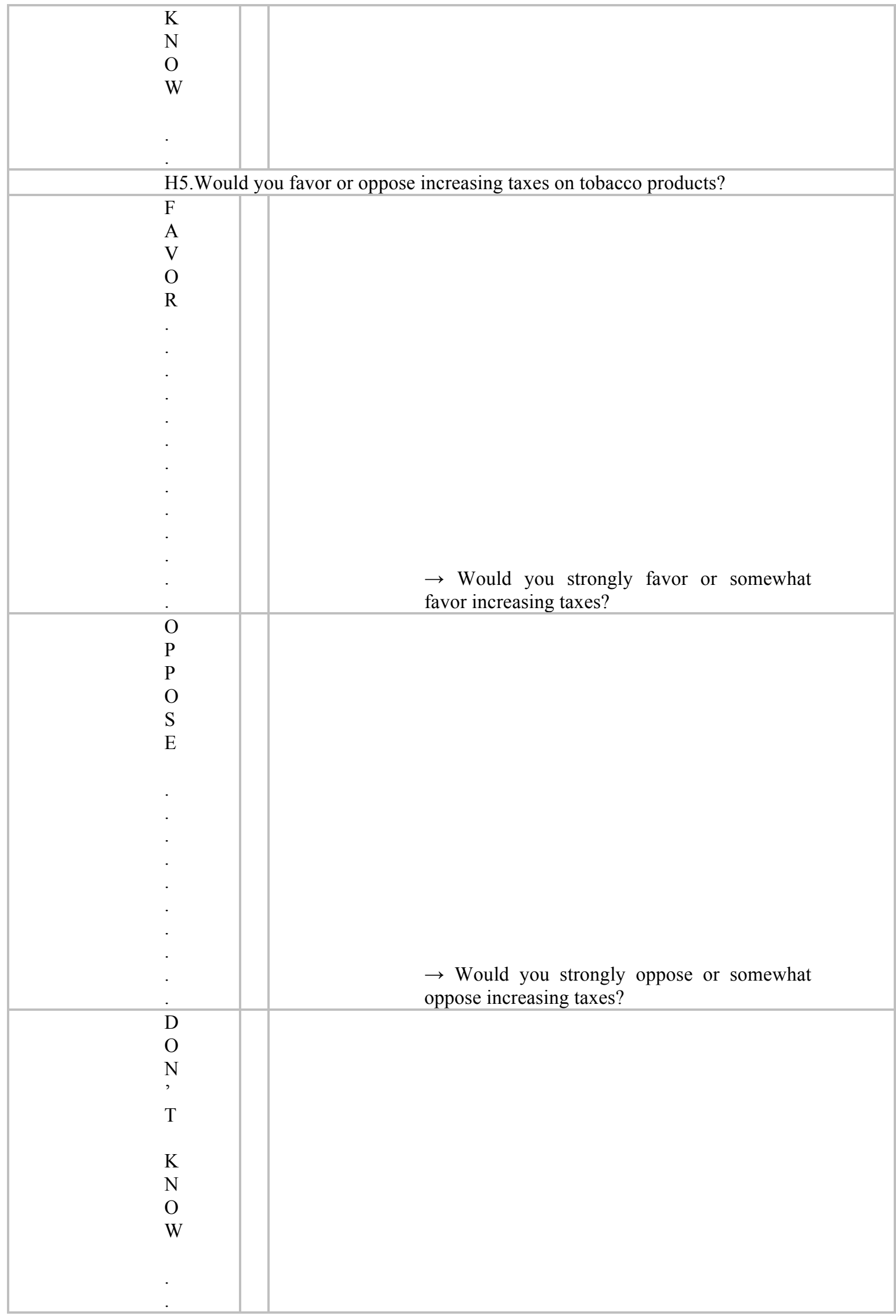




\begin{tabular}{|c|c|}
\hline \multicolumn{2}{|c|}{$\begin{array}{l}\text { H6. Would you favor or oppose a law prohibiting all advertisements for tobacco } \\
\text { products? }\end{array}$} \\
\hline $\begin{array}{l}\mathrm{F} \\
\mathrm{A} \\
\mathrm{V} \\
\mathrm{O} \\
\mathrm{R} \\
\cdot \\
\cdot \\
\cdot \\
\cdot \\
\cdot \\
\cdot \\
\cdot \\
. \\
\cdot \\
\cdot \\
. \\
. \\
. \\
. \\
.\end{array}$ & $\begin{array}{l}\rightarrow \text { Would you strongly favor or somewhat } \\
\text { favor this law? }\end{array}$ \\
\hline $\begin{array}{l}\mathrm{O} \\
\mathrm{P} \\
\mathrm{P} \\
\mathrm{O} \\
\mathrm{S} \\
\mathrm{E} \\
. \\
\cdot \\
\cdot \\
\cdot \\
. \\
. \\
. \\
. \\
.\end{array}$ & $\begin{array}{l}\rightarrow \text { Would you strongly oppose or somewhat } \\
\text { oppose this law? }\end{array}$ \\
\hline $\begin{array}{l}\mathrm{D} \\
\mathrm{O} \\
\mathrm{N} \\
, \\
\mathrm{T} \\
\\
\mathrm{K} \\
\mathrm{N} \\
\mathrm{O} \\
\mathrm{W}\end{array}$ & \\
\hline . & \\
\hline
\end{tabular}

OPTIONAL SECTION WP - WATERPIPE (SHISHA/NARGILE) MODULE (PLACED AFTER SECTION B) 
Routing: B6x/B10x ask for the number of shisha smoking sessions per day/week

-IF B1=3 AND B3=3 (NEVER SMOKERS), SKIP TO NEXT SECTION -IF B1=3 AND B3=1 OR 2 (FORMER SMOKERS), GO TO WP2

-IF B1=1 AND B6x>=1 (CURRENT DAILY SHISHA SMOKERS), GO TO WP3

-IF B1=1 AND B6x=888 (CURRENT LESS THAN DAILY SHISHA SMOKERS), GO TO WP1

-IF B1=2 AND B10x>=1 OR =888 (CURRENT LESS THAN DAILY SHISHA SMOKERS), GO TO WP1

-ELSE, GO TO NEXT SECTION

\section{[CORE ITEMS WP1-WP6 FOR MODULE]}

INTRO: I would now like to ask you some questions about smoking shisha.

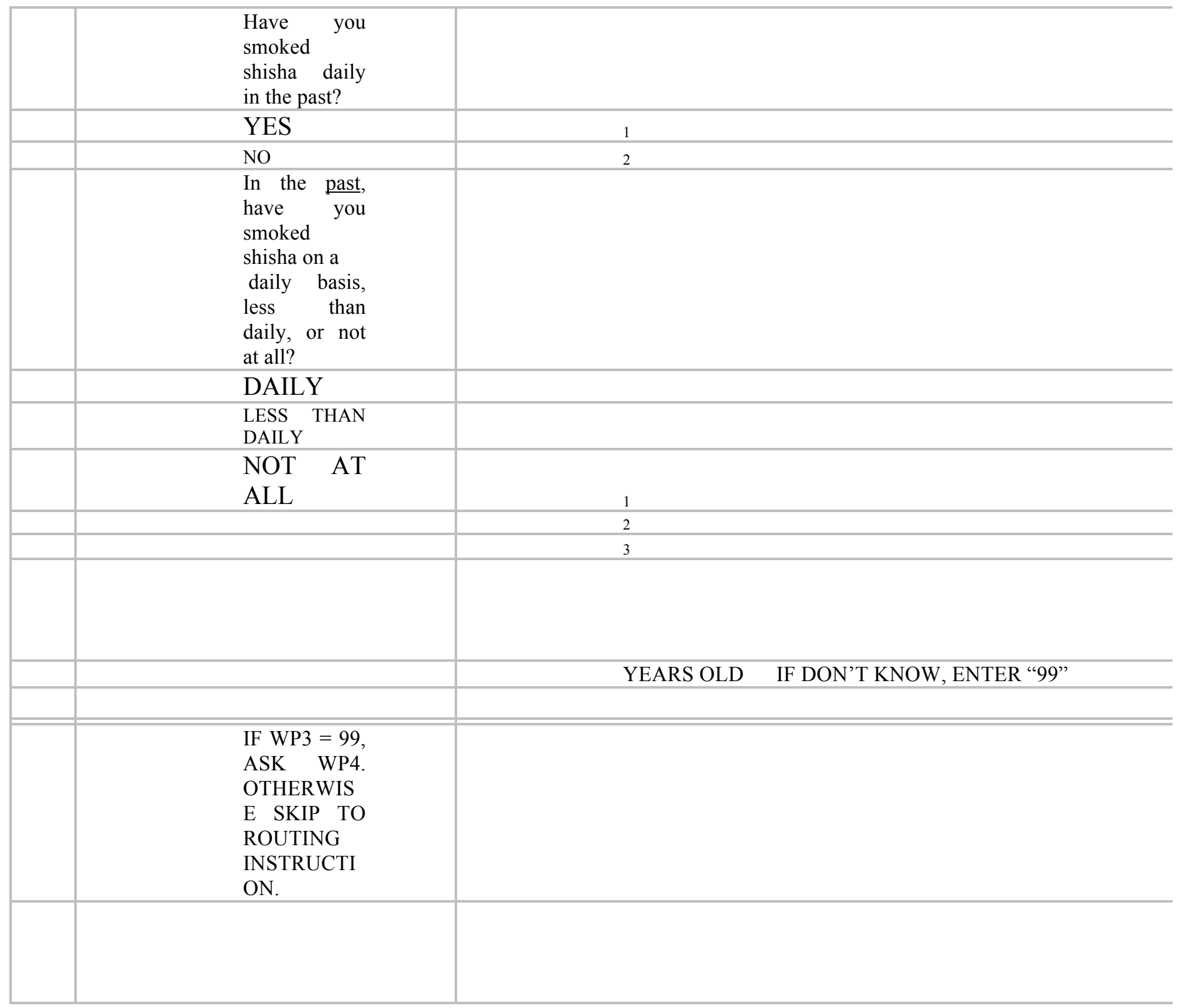


ROUTING:

-CURRENT SHISHA SMOKERS: IF (B1=1 OR 2) AND [(B6x>=1 OR =888) OR (B10x $>=1$ OR =888)], GO TO WP5

-OTHERWISE, GO TO NEXT SECTION

62

WP5. The last time you smoked shisha, how long did you participate in the shisha smoking session?

INTERVIEWER: ENTER UNIT AND NUMBER

HOURS ......1

MINUTES ..

WP6. The last time you smoked shisha, how many other people did you share the same pipe with during the session?

PEOPLE

\section{[WP7-WP10 ARE ADDITIONAL OPTIONAL ITEMS]}

WP7. The last time you smoked shisha, about how many rocks were smoked while you were participating in the session?

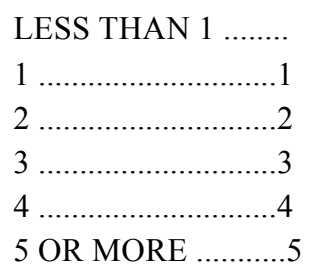

WP8. The last time you smoked shisha, where did you smoke it?

\begin{tabular}{|l|l|}
\hline $\mathrm{H}$ & \\
$\mathrm{O}$ & \\
$\mathrm{M}$ & \\
$\mathrm{E}$ & \\
$\cdot$ & \\
$\cdot$ & \\
$\cdot$ & 1 \\
\hline
\end{tabular}




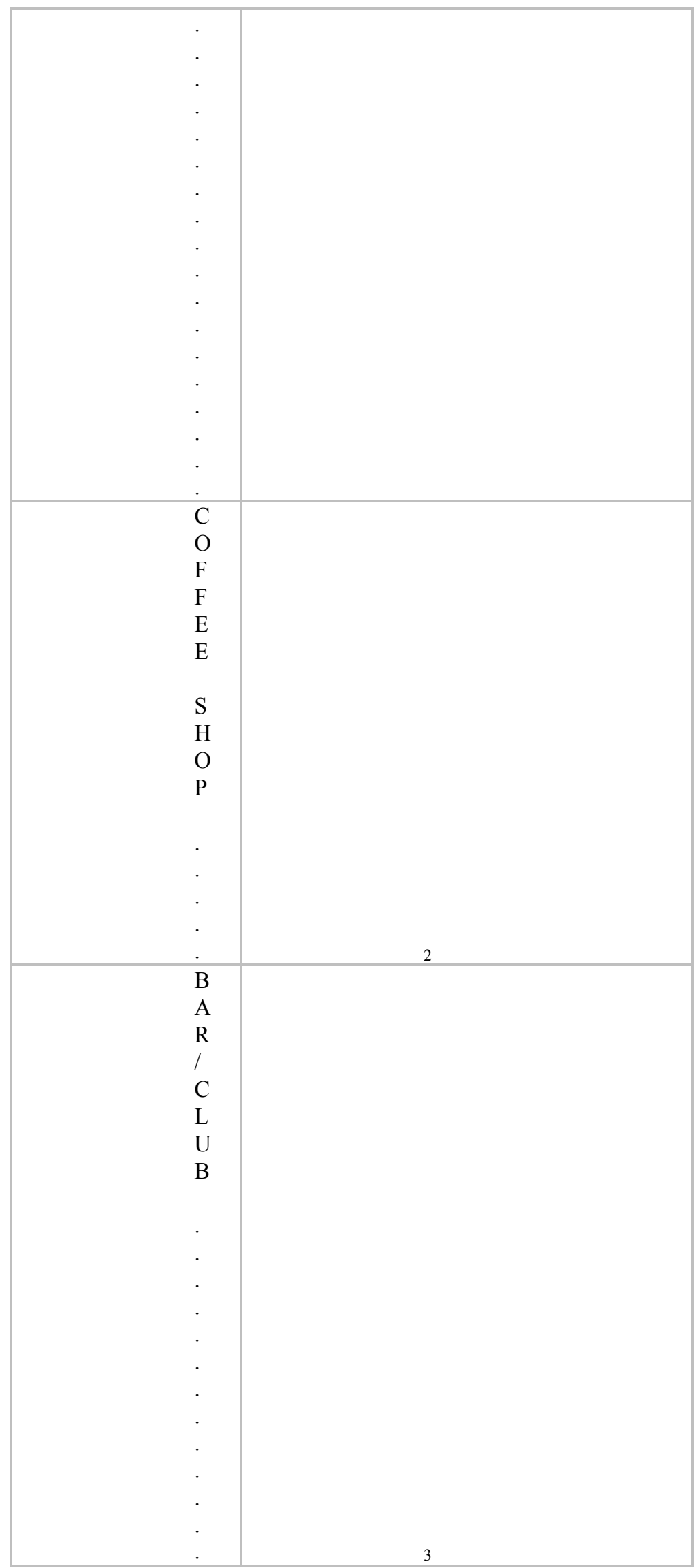




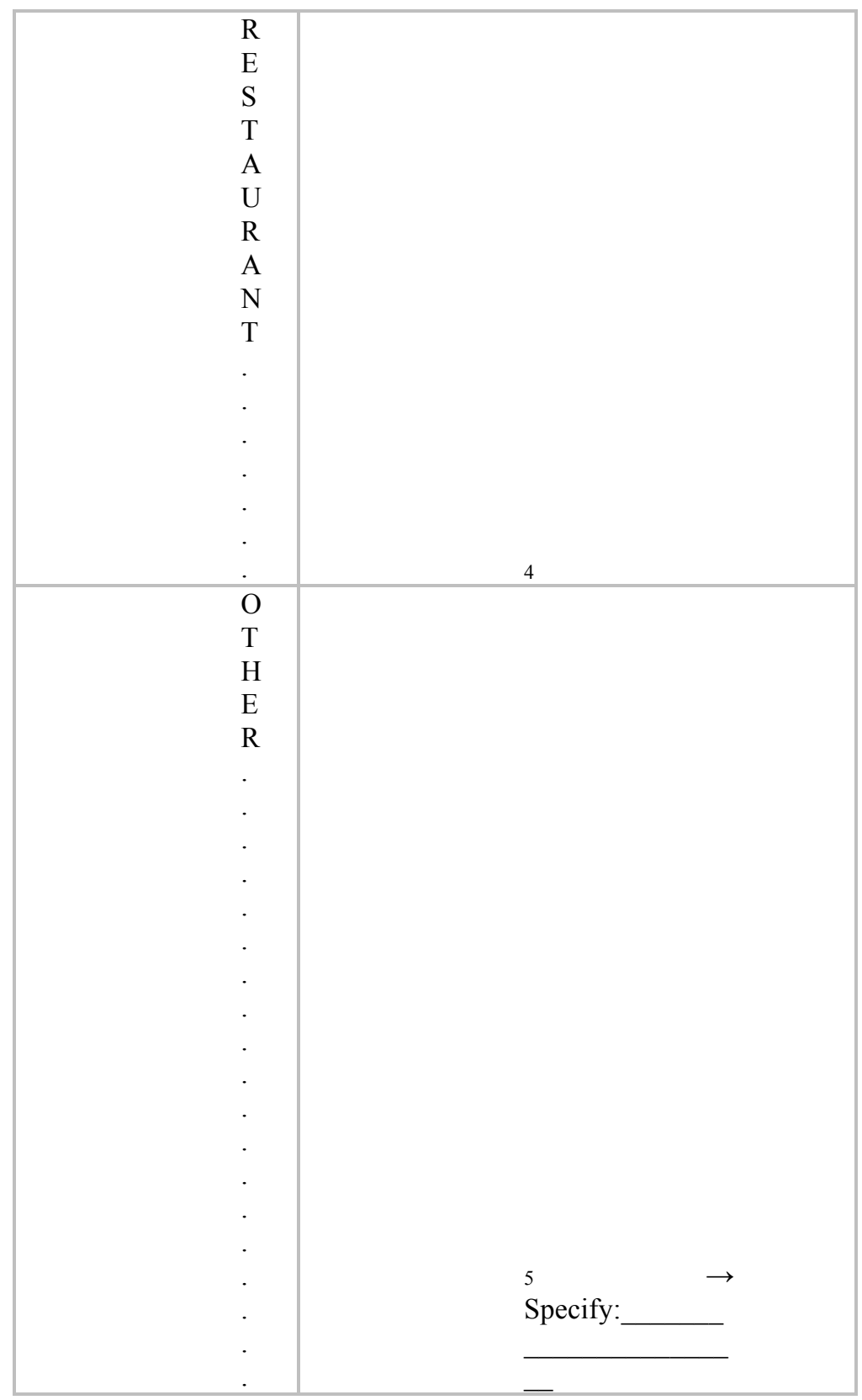

WP9. The last time you smoked shisha, did you smoke it with flavored tobacco, unflavored tobacco, or both?

FLAVORED. $\ldots 1$

UNFLAVORED.......2

BOTH ….................3

WP10. The last time you smoked shisha, did you mix the water in the shisha tank with other substances?

YES .1

NO …....................... 
الجسح العالمي لتعاطي التبغ ببين البالغين
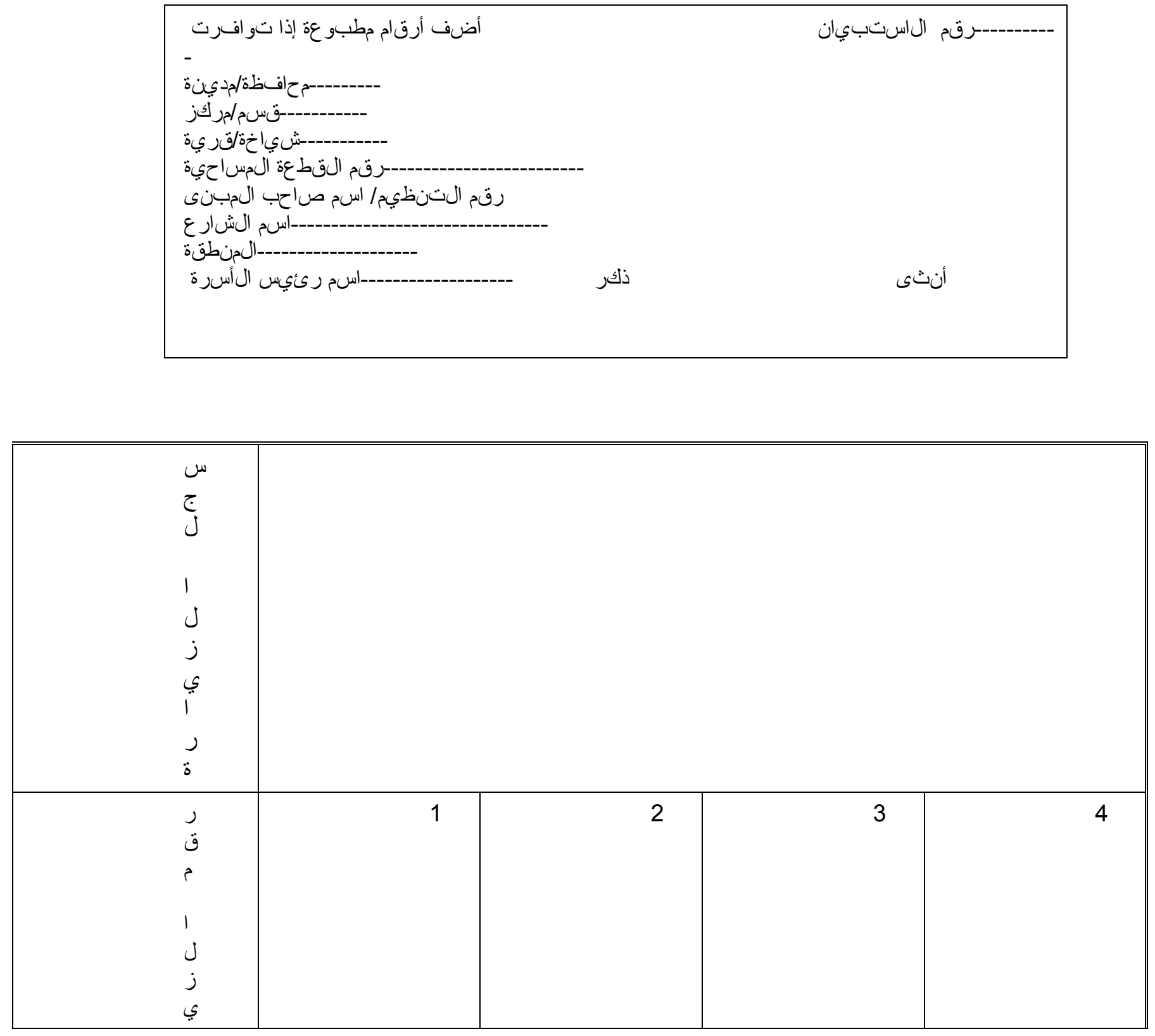


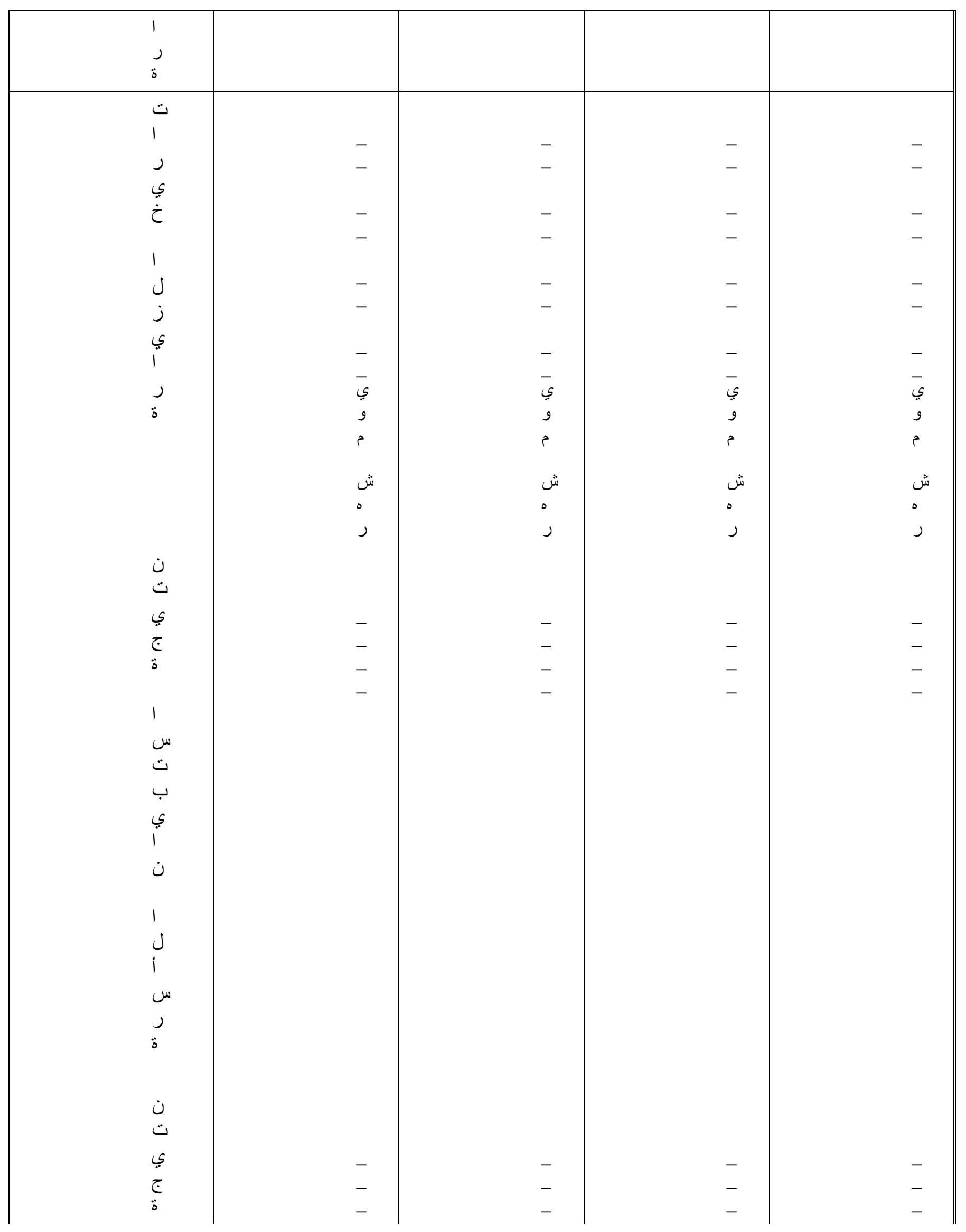




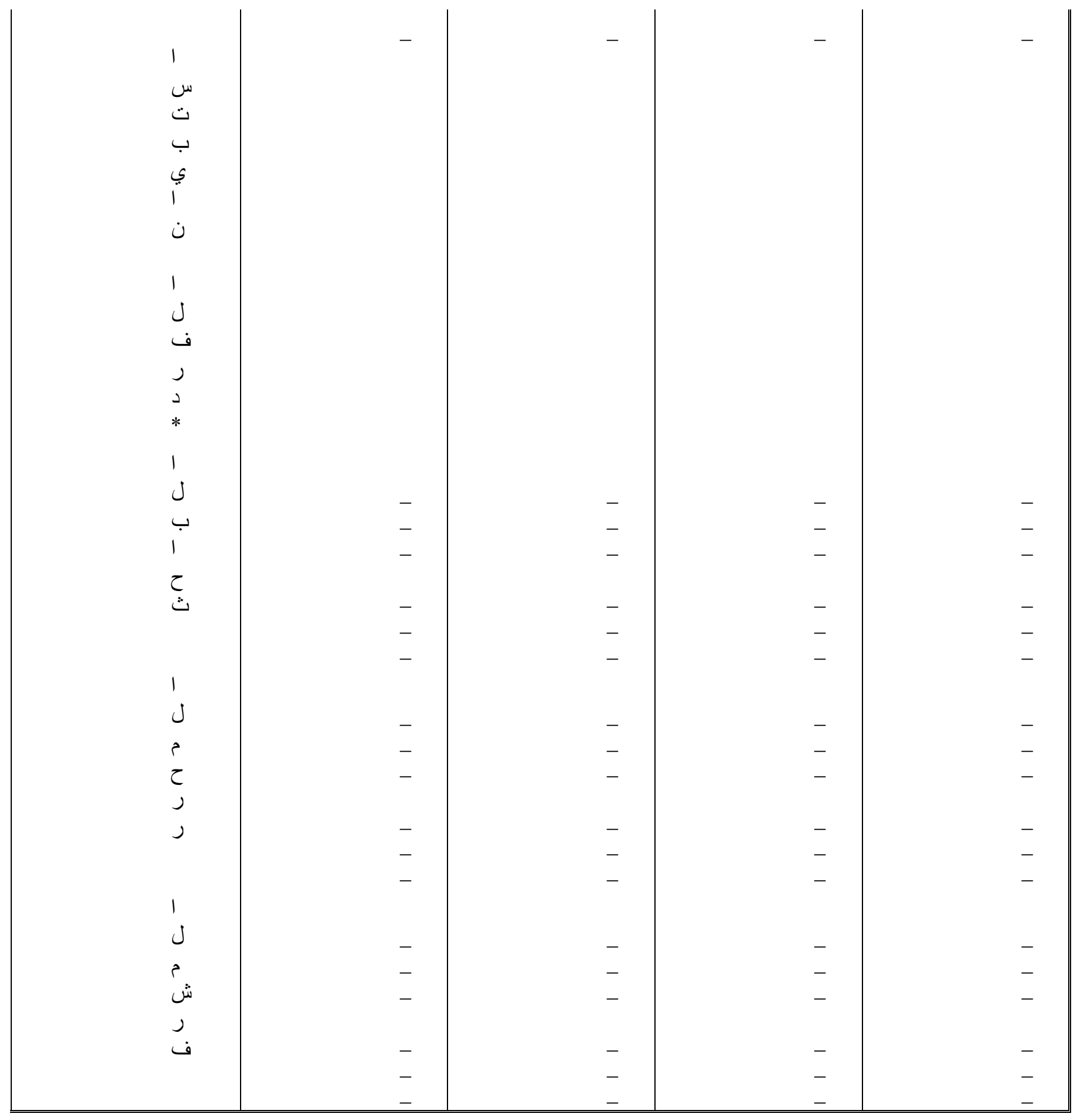




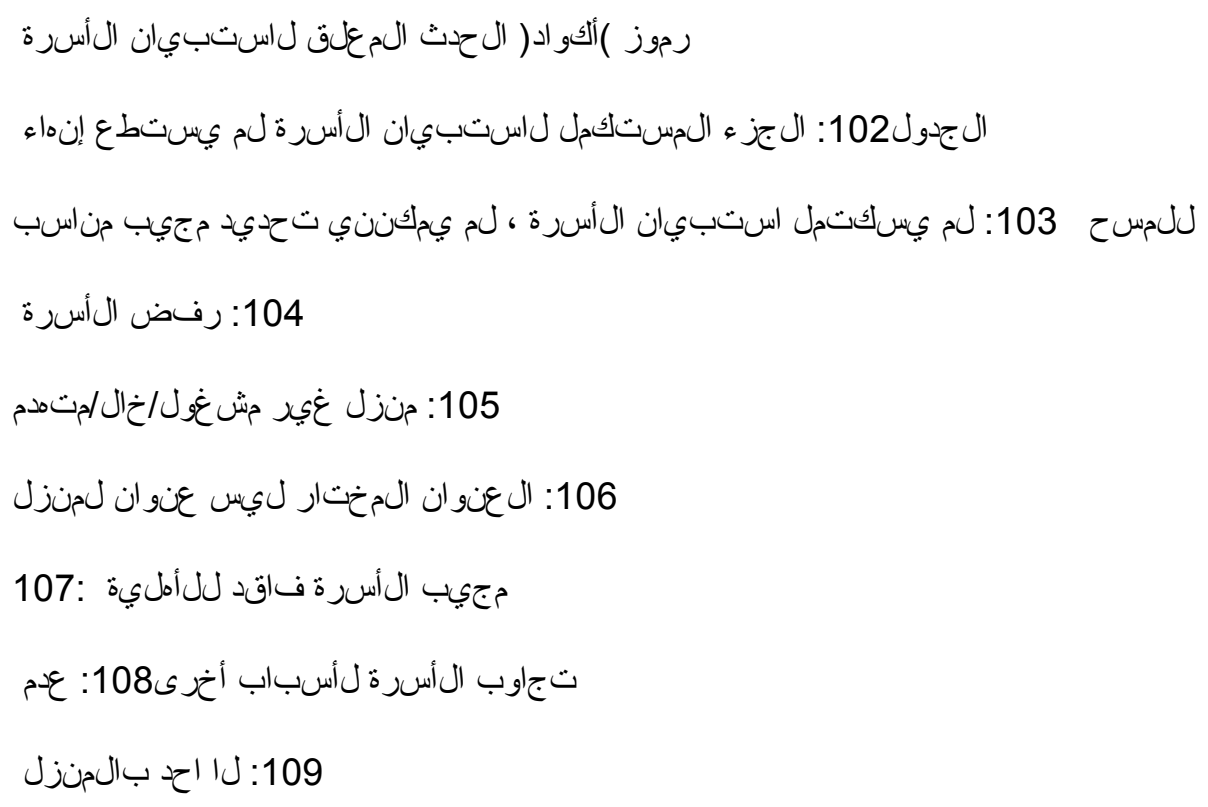

رموز )أكو اد( حدث نهائب ل لستبيان السأسرة

200: استبيان أسرة مكتمل، تم اختبار شخص و احد

201: استبيان أسرة معيشية مكتمل، لا احد تم اختياره

202: جزء مكتمل من استبيان أسرة ، لم استطع استكمال الجدول

203: استبيان أسرة غيد مكتمل/لم استطع ت حديد موية مجيب مناسب للمسح

204: - مفض السرة

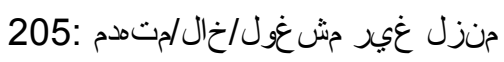

206: العنوان المختار لبيس عنوان لمنزل

207: مجيب السرة المعيشية فاقد للأملية

208: عدم ت جاوب أسرة لأسباب أخرى

اور ميداني أخر 888:تم تحويل السرة: أسرة الى مح

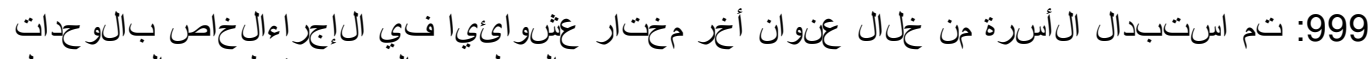
السكن عية التى سقطت من التس إتسيل 


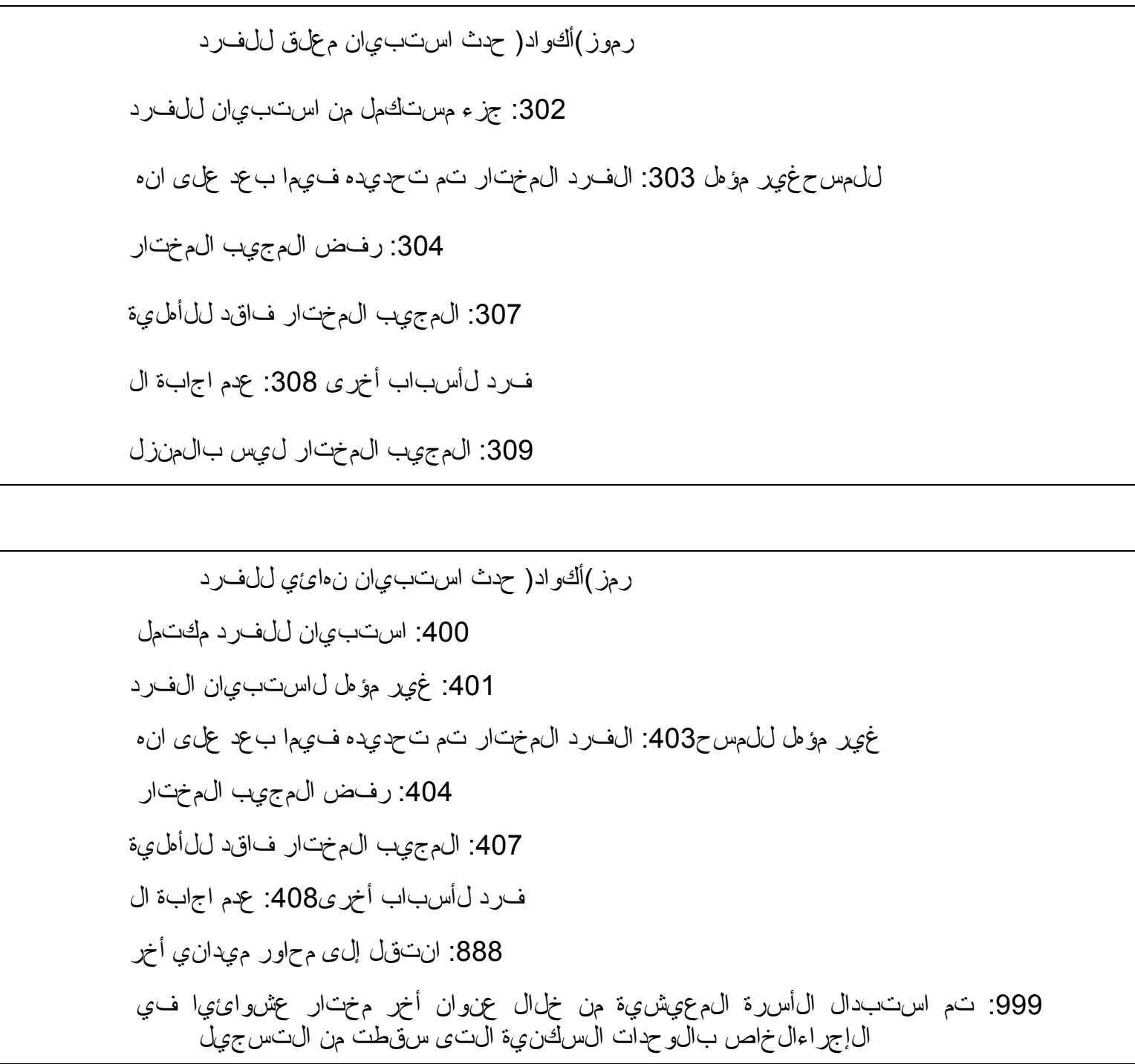


استب الميان السرة

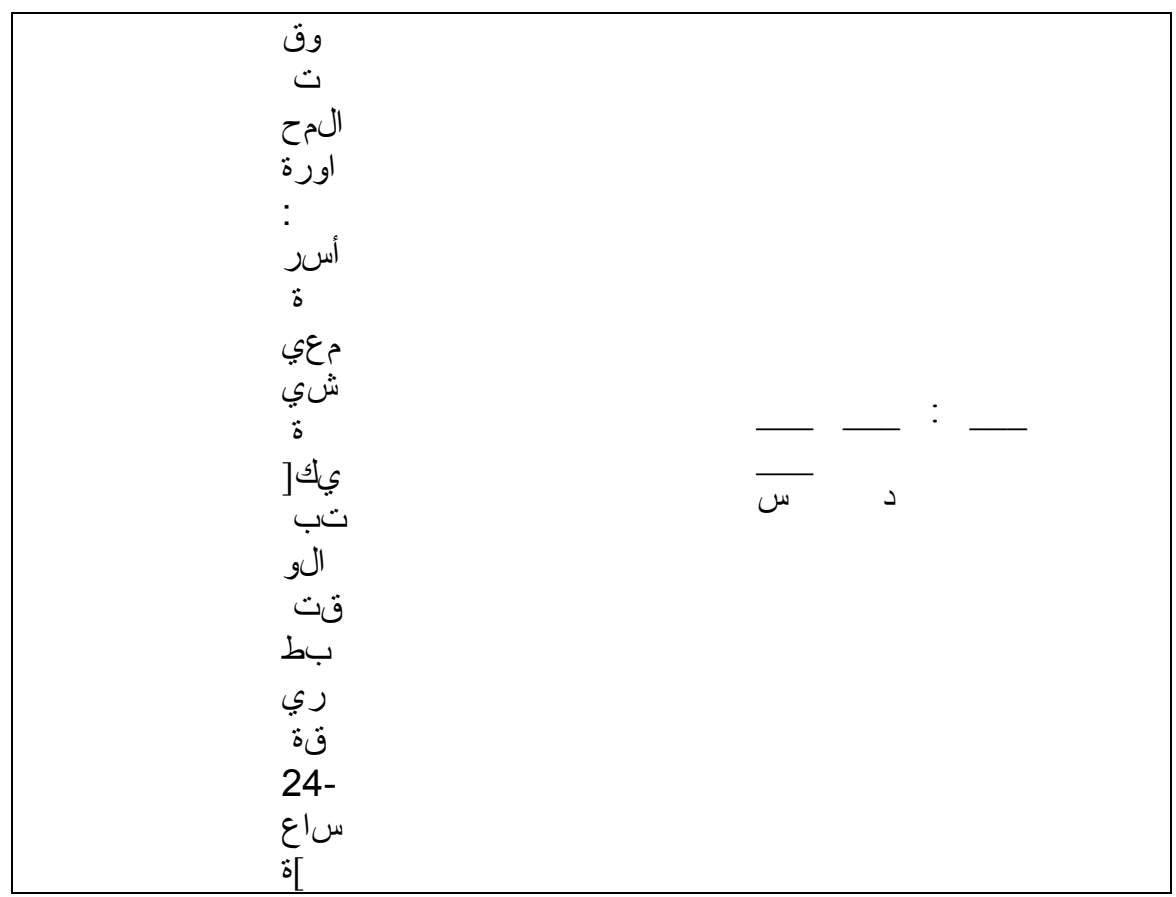

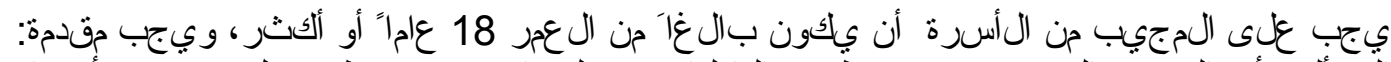

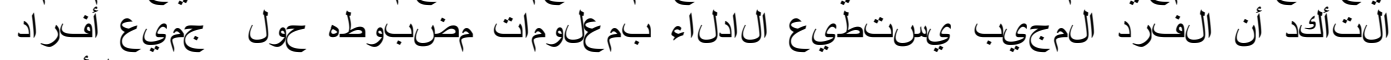

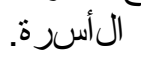

عند الضرورة، تحقق من سن المجيب من السرة للنتأكد من انه يبل غ/ أنها تبل غ 18

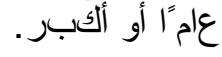

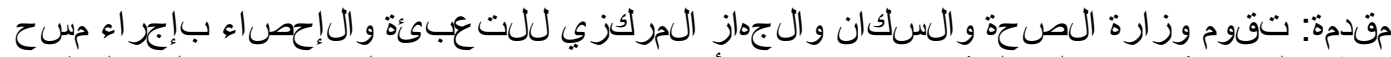

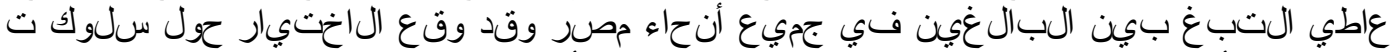

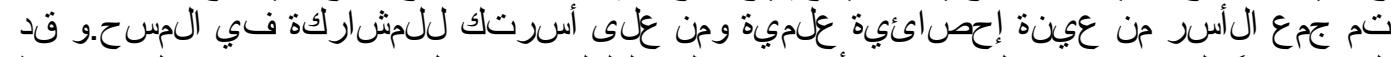

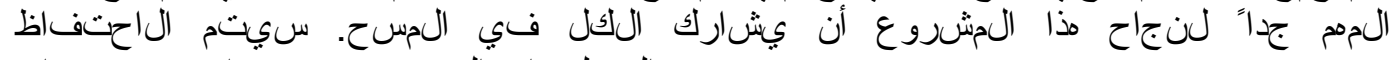

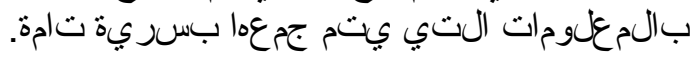

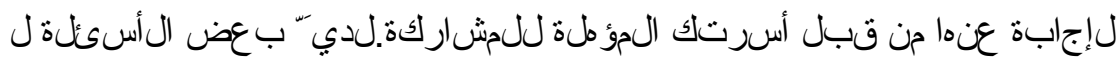

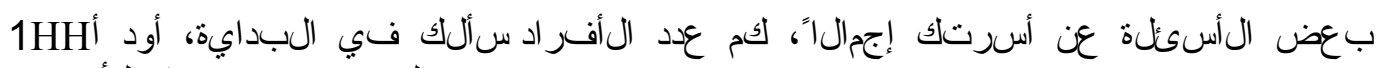

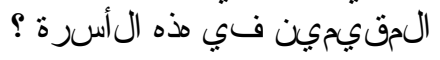

بدءاً من حكان إقاجته الساسيشيشل هذا أي شخص يعتبر هذه السرة المعيشية اللبيلة السابقة العبة. 


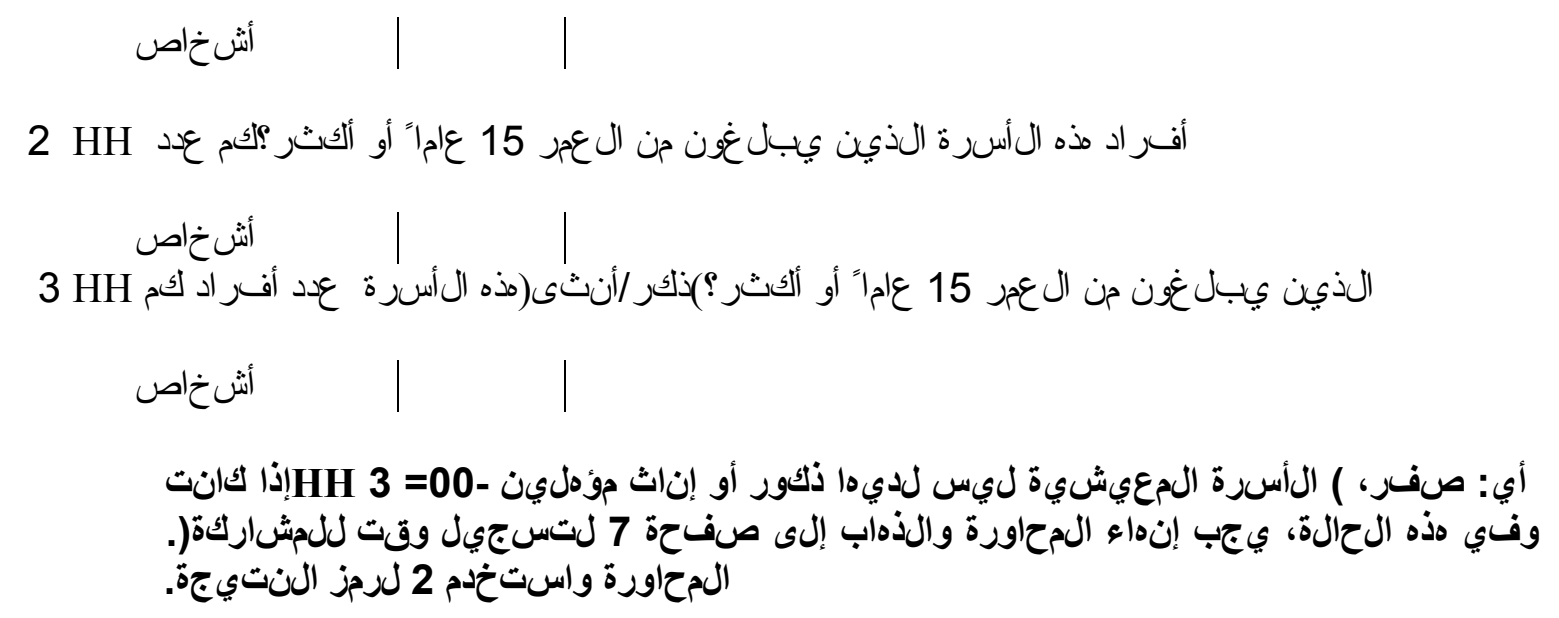




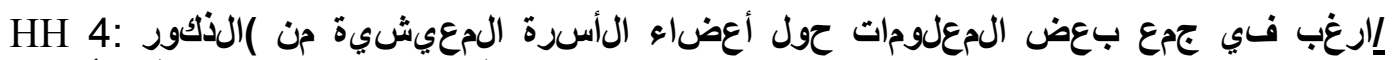

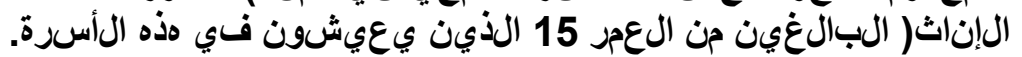

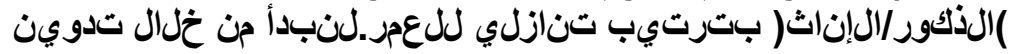

اسل ألسئلة التالية وسجل الجابة في الجنول التالي:

$1-$

$$
\text { ما هو اسم الشخص؟...... }
$$

2كم عקر الشخص؟..

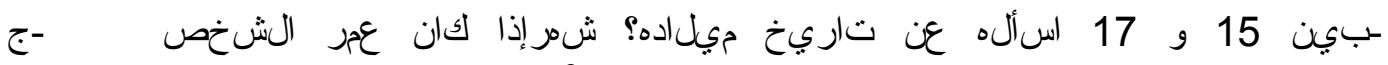
.

يجب التحقق من الإجابة لجراجعة ما إذا حدث تاريخ الجميلاد قبل التهاريخ

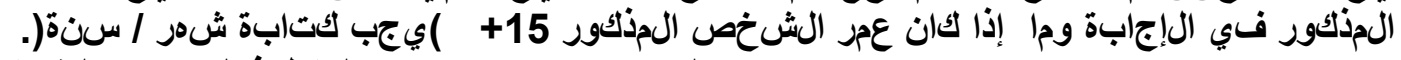

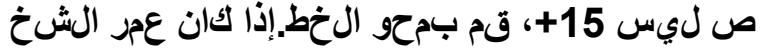

$$
\begin{aligned}
& \text { إذا كان المجيب لا يعرف تاريخ ميلاده/ميل ادها، اذب الى بند )د(. }
\end{aligned}
$$

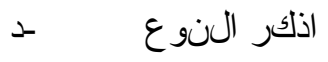

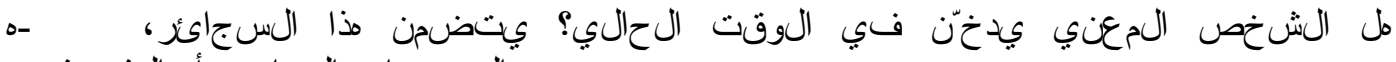

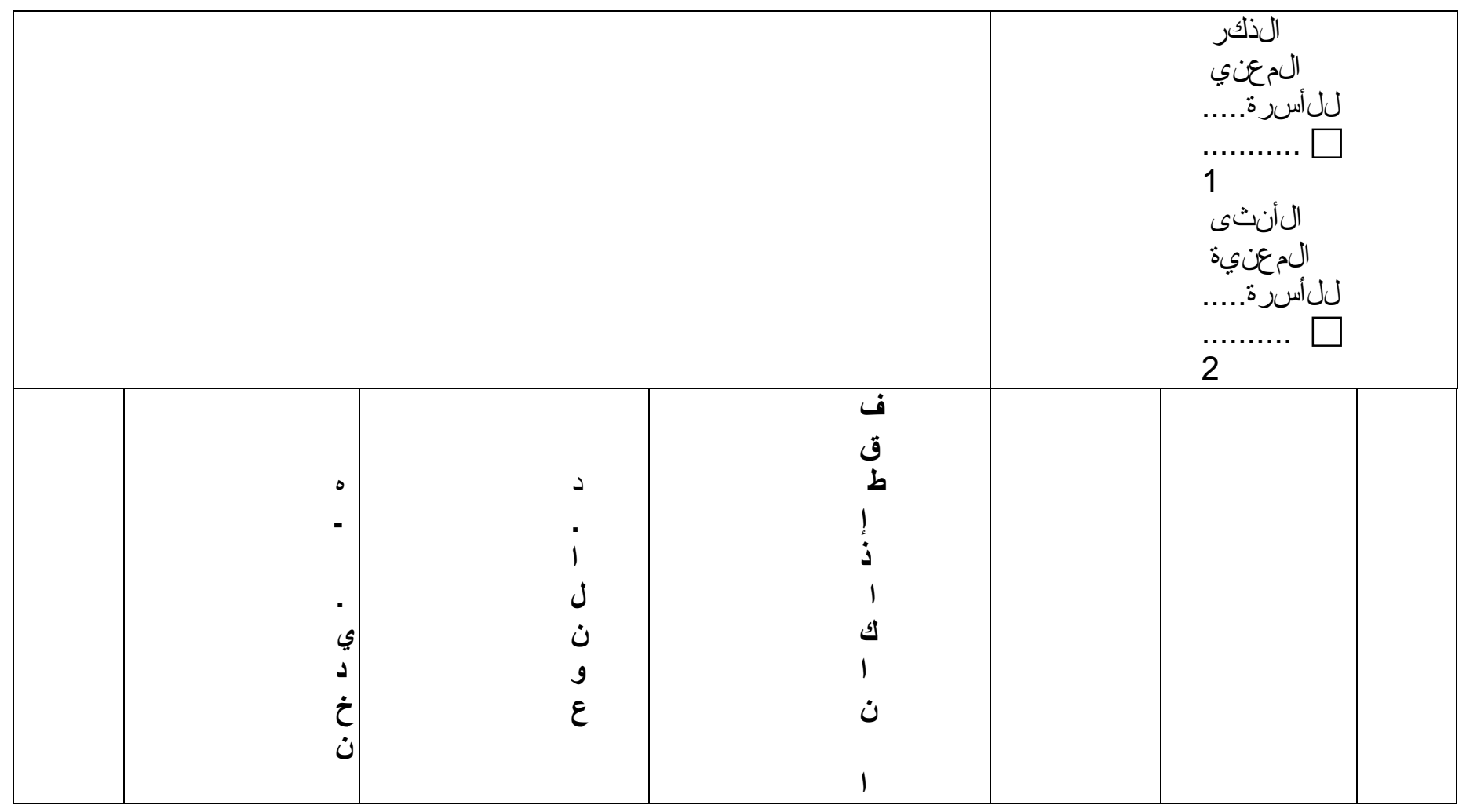




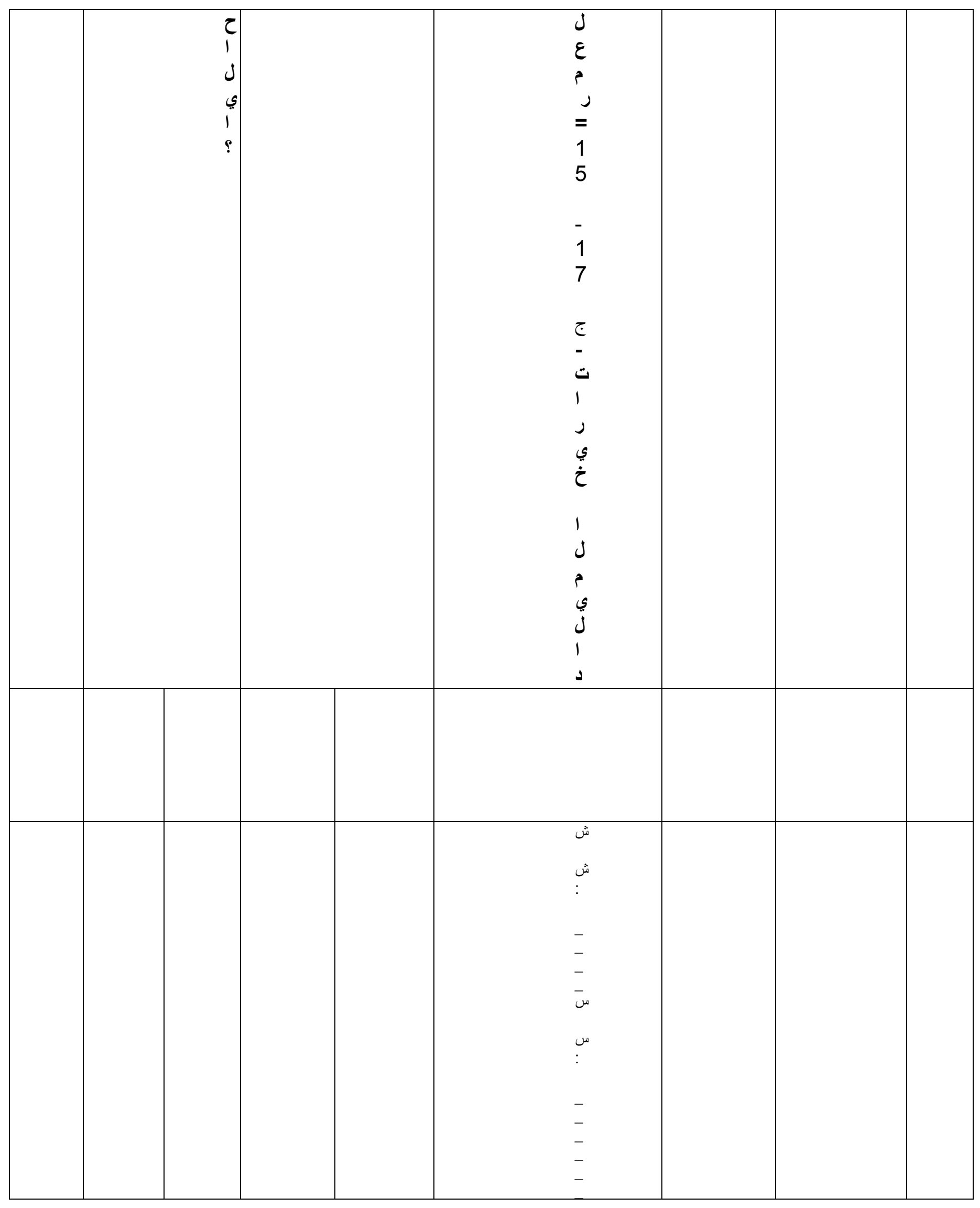




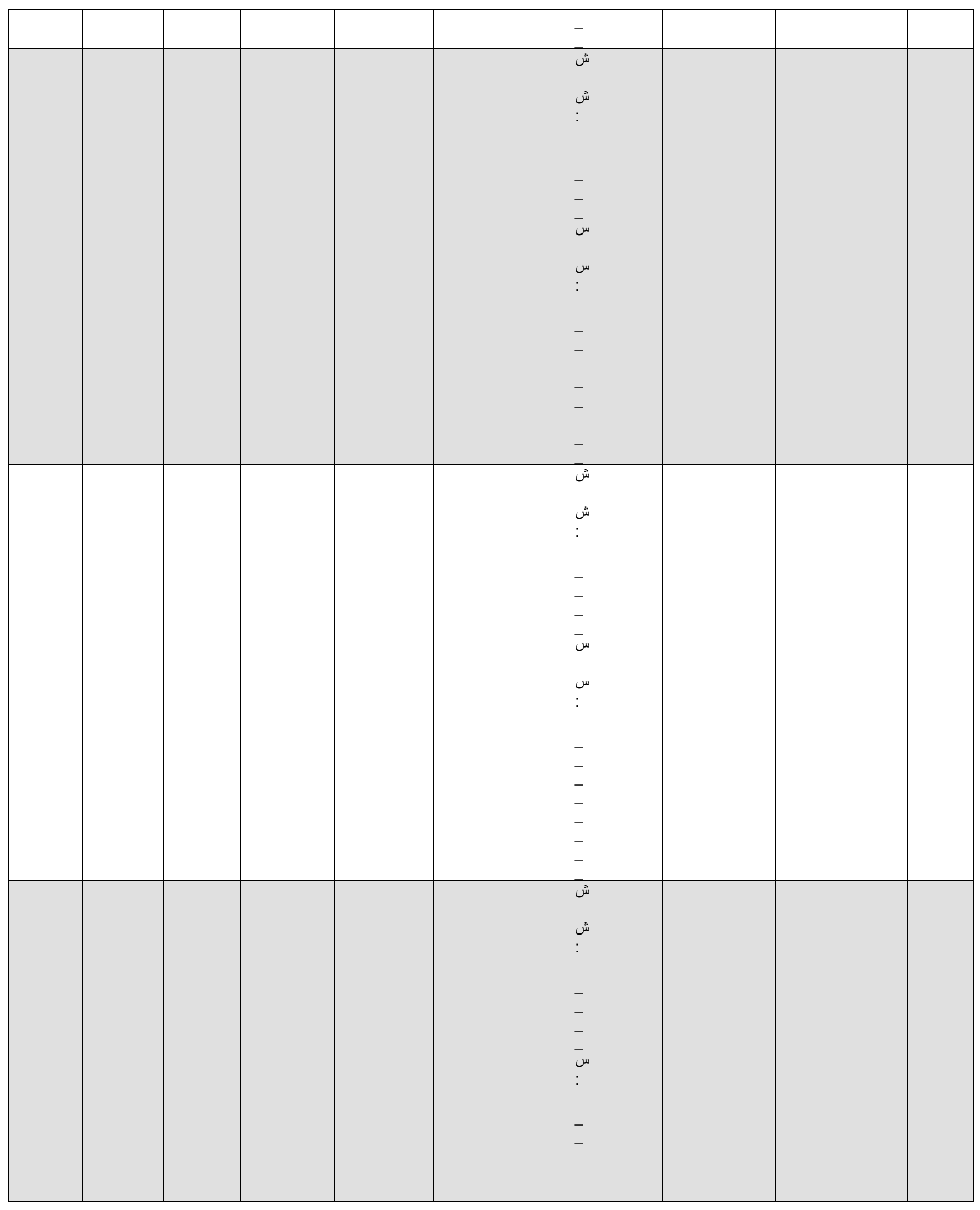




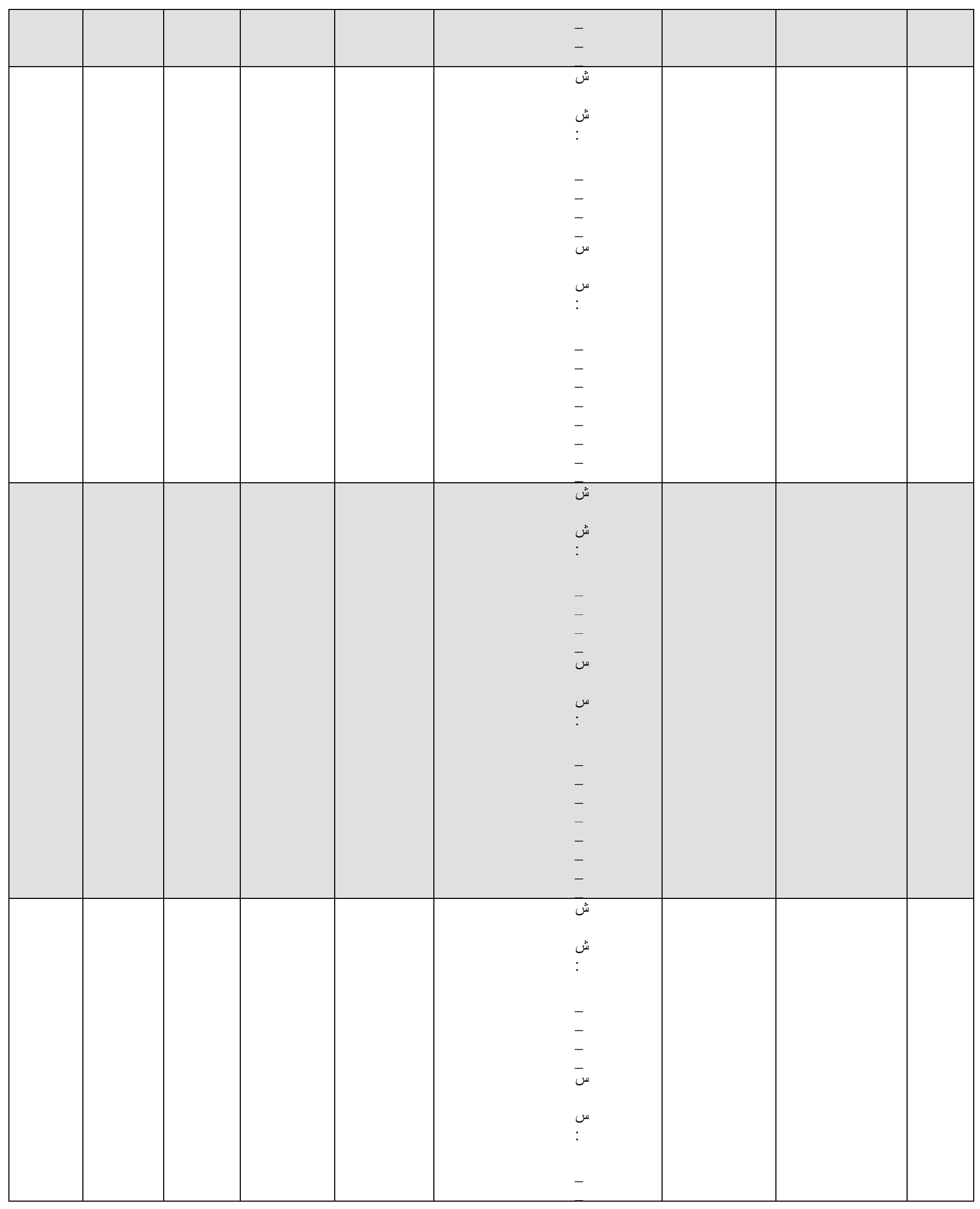




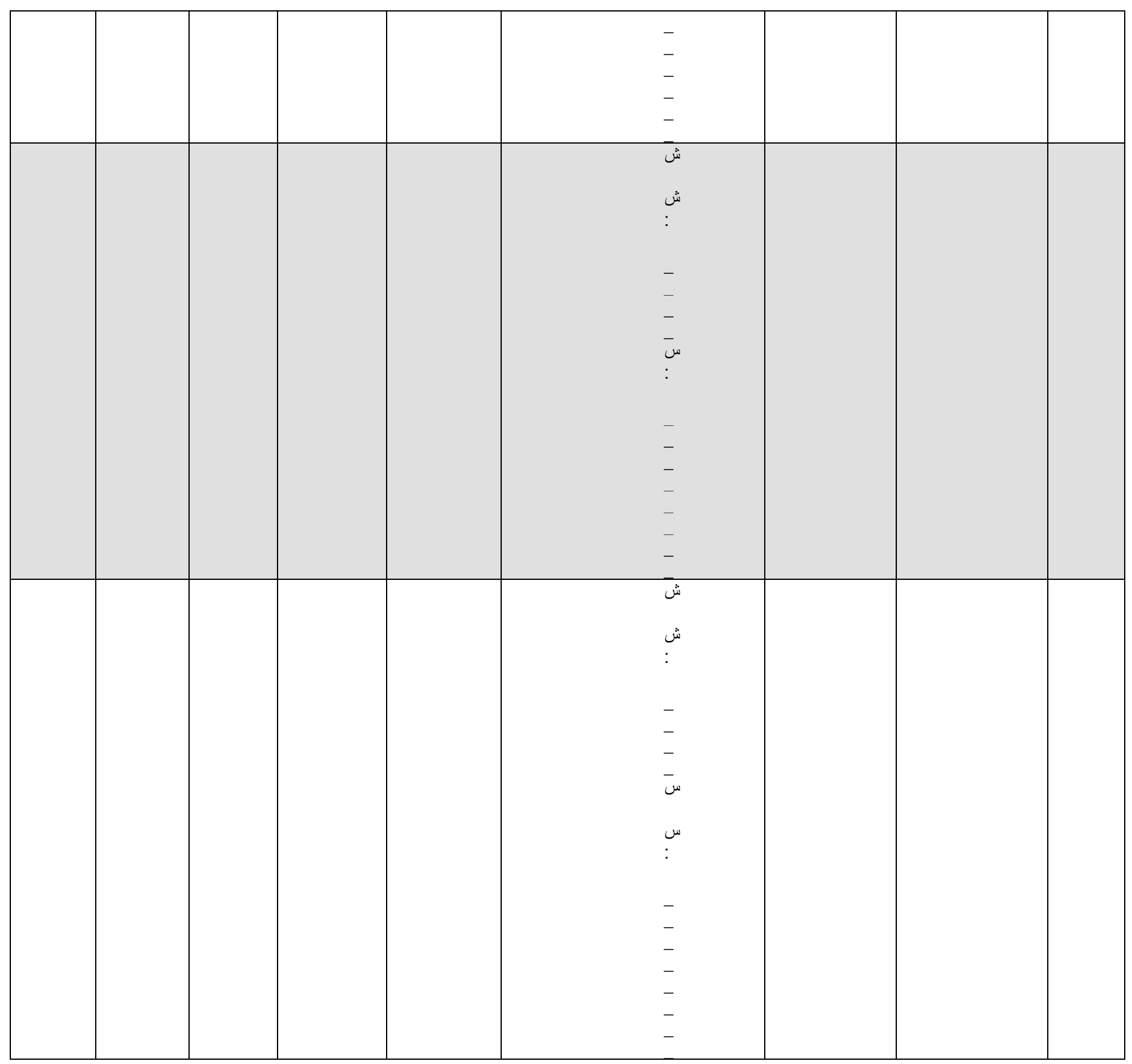


اختيار الججيب باستخدام جدول الرقم العشول كئئي:

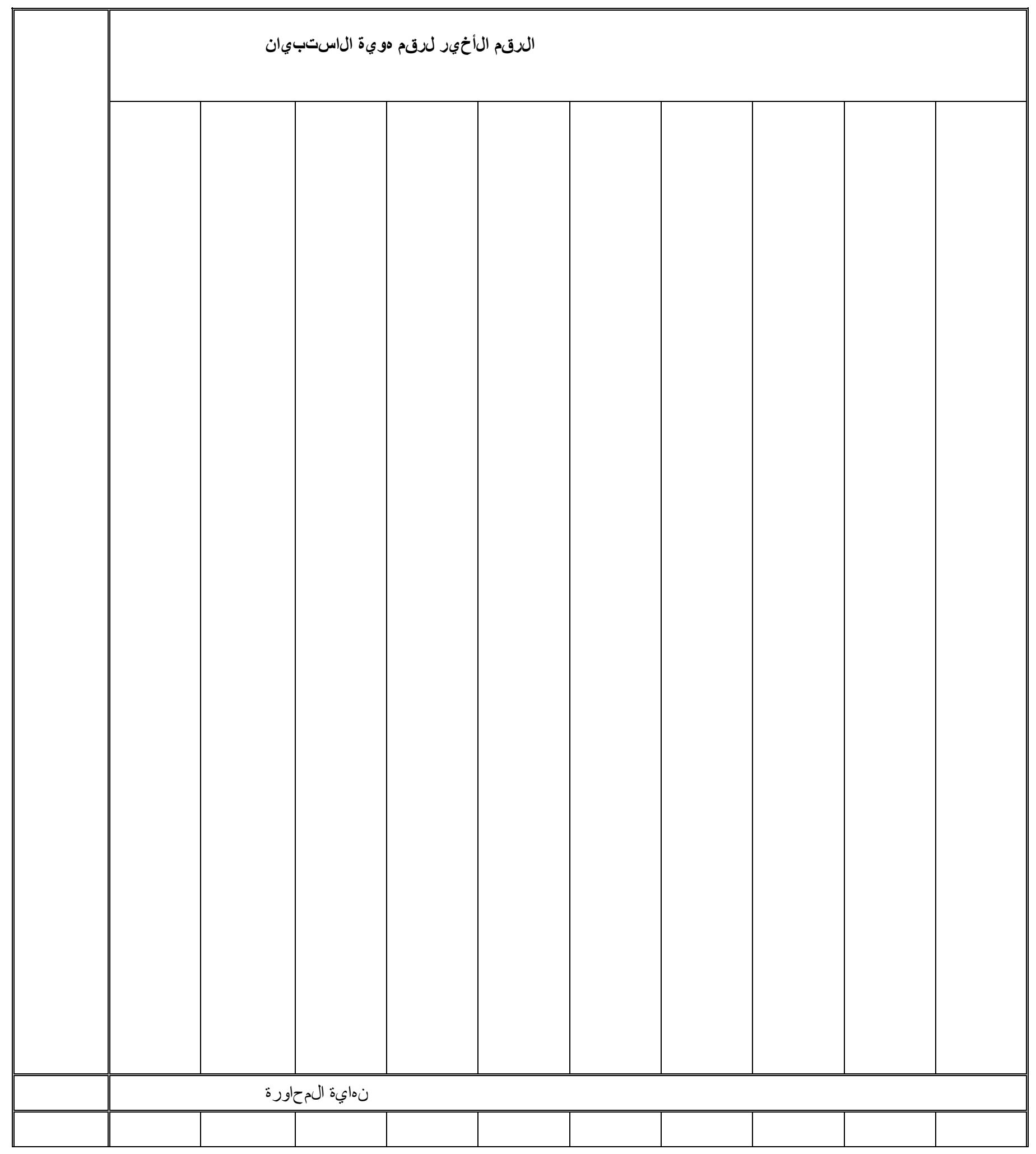




\begin{tabular}{||l|l|l|l|l|l|l|l|l|l|l||}
\hline & & & & & & & & & & \\
\hline
\end{tabular}

وH الكتب الرقم المختار تحت )استخدم جدول الأرقام العشوائي لاختيار المجيب،

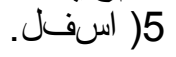

HH 5 و احد )ذك /انثى(، الكتب "1" في بند فردان كان يعيش بالسرة.

5 وانه HHإن كان لا يو جد فرد مؤمل )ذكر /أنثى( يعيش في المنزل، الكتب 0 في -

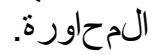

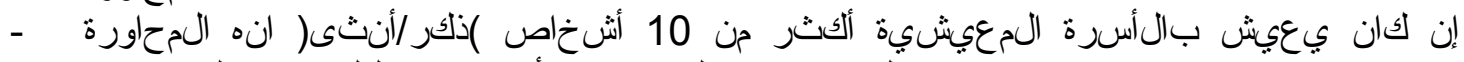

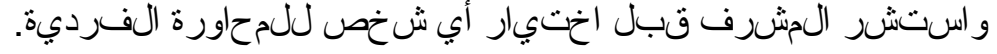

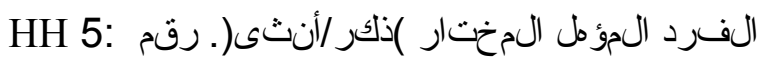

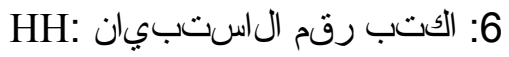

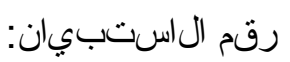




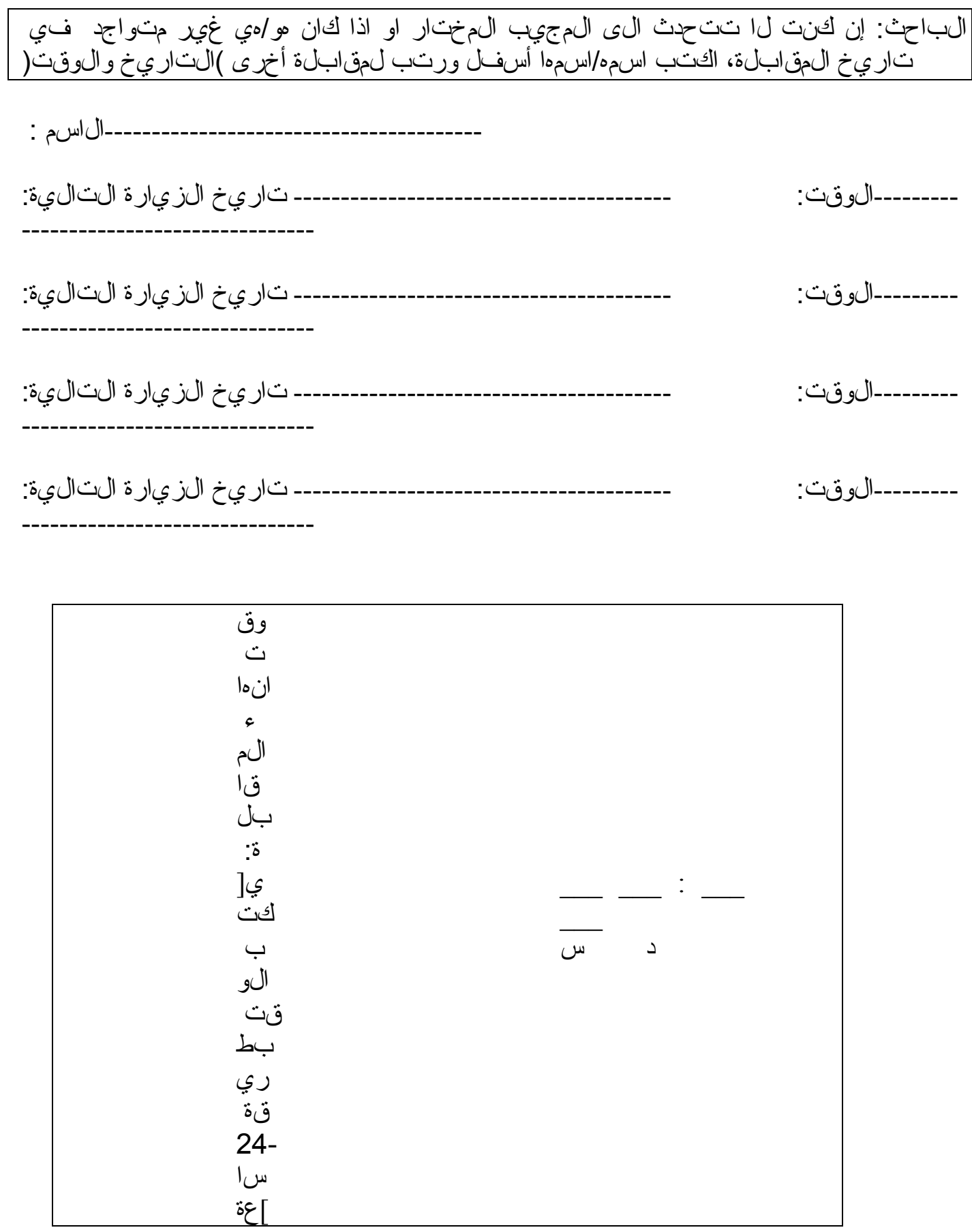




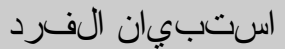

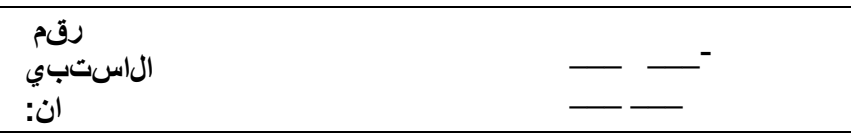

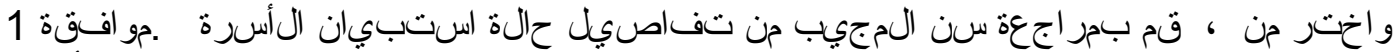

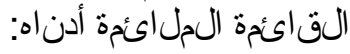

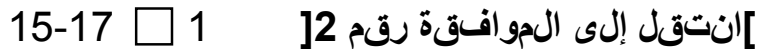

2

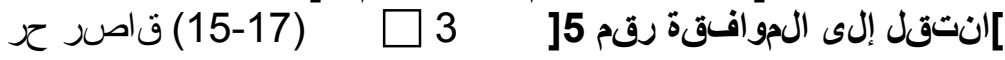

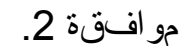

قبل البدء في المقابلة، احتاج أن احصل على موافقة من ولي الأمر او او

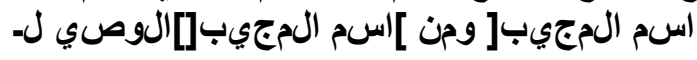

ان كان كل من الججيب المختار وولي الأمرالوصي متواجدين، استمر في المقابلة.

ي المر/الوصي غير متواجدين، اقطع الجقابلة وحدد موعدًا لتعود فيه.إذا كان/ول

إن كان القاصر الججيب غير موجود، استمر في الحصول على موافقة ولي الأمر. 


\section{موافتقة 3.}

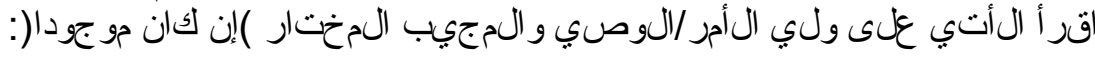

للتعبئة والحصاء. وتقوم هذه المؤسسة بجمع إنني العجل مع الجماز المركزي

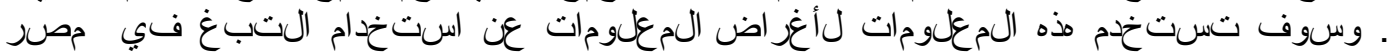
الصحة العامة من قبل وز الت الصة الصحة و السكانكان.

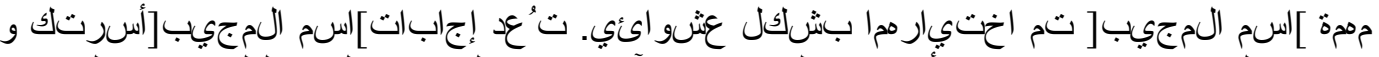

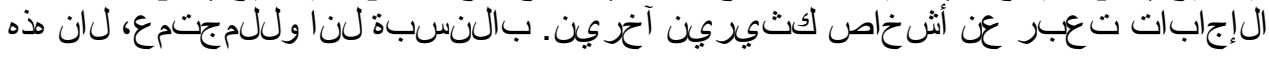

في هذا المسح مي ] سسم المجيب[ان مشاركتسوف تستمر المقابلة حو البي 30 دقيقة.

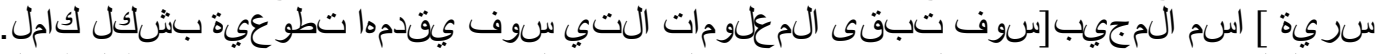

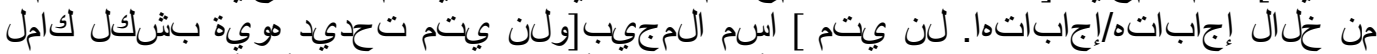

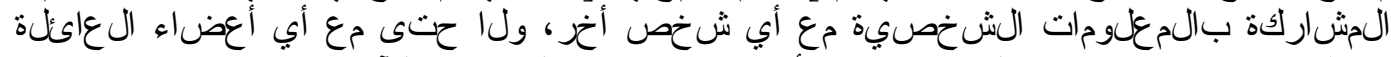

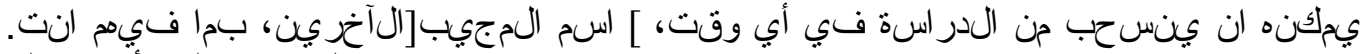
وقد يرفض الإجابة على أي سؤ ال.

ك اية اسئلة عن هذا المسح ان كان لديسوف نترك لك ب بيانات الاتصال الذلازمة

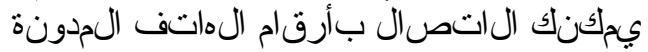

في هذا الحسح، سوف نقوم بإجر اء محاوره ] اسم المجيب[إن كنت تو افق على مشاركة.

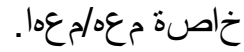

؟] اسم المجيب[اسأل ولب المج /الوصي: مل تو افقق على مشاركة

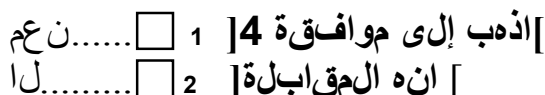

موافققة 4

مل كان المجيب القاصر المختار حاضر ا؟

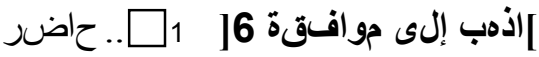

|اذدب إلى موافقة 


\section{: 5 :}

اقر أ هذا على المجيب المختار :

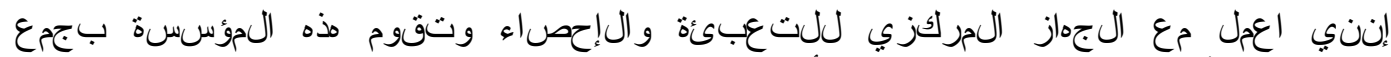

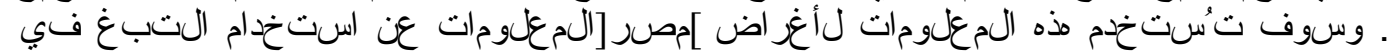

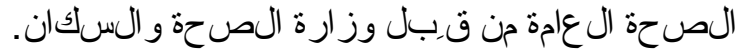

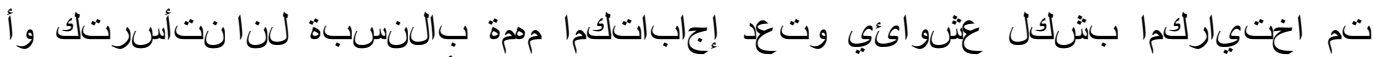

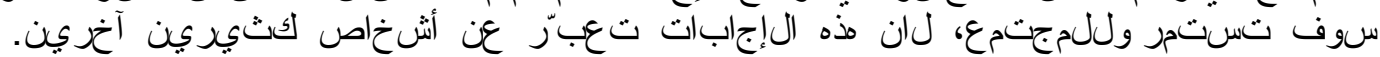

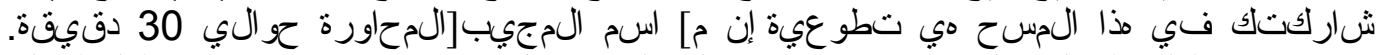

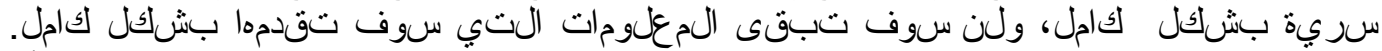

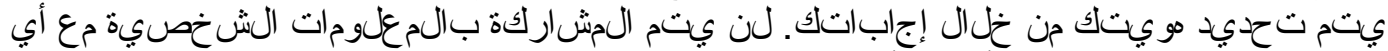

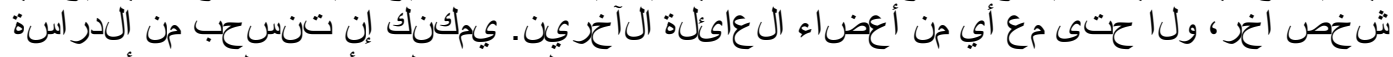
وقد ترفض الإجابة على أي سؤ ال. في أب أب وقن أبن،

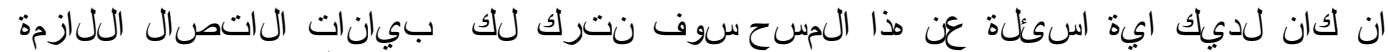

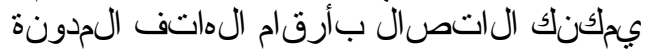

احل أببانات إن كان موافقة4=2: ولي أمرك/وصيك قد أعطى إذنه لك لتشارك في \}

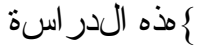

سوف نقوم بإجر اء محاورة خاصة معك. ، إن كنت تو افق على المشاركة

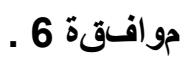

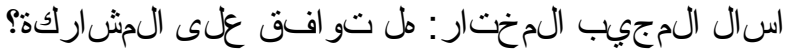

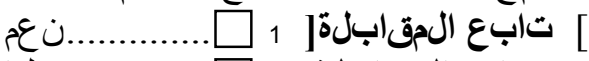

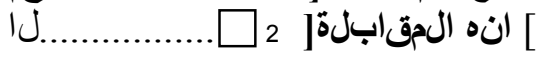

أحلئ البيانات التالبة:

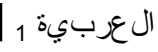

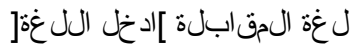




\section{القسم أ. الخصائص الساسية}

بياناتك الشخصية. أولا، سأسألك في البدابة بعض الس سعلة حول مقدمة:

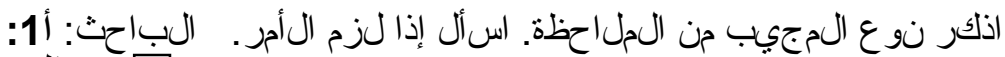

أنى ${ }^{2}$

ما هو تاريخ ميلادك: شر شهر: سنة سنة؟ أم:

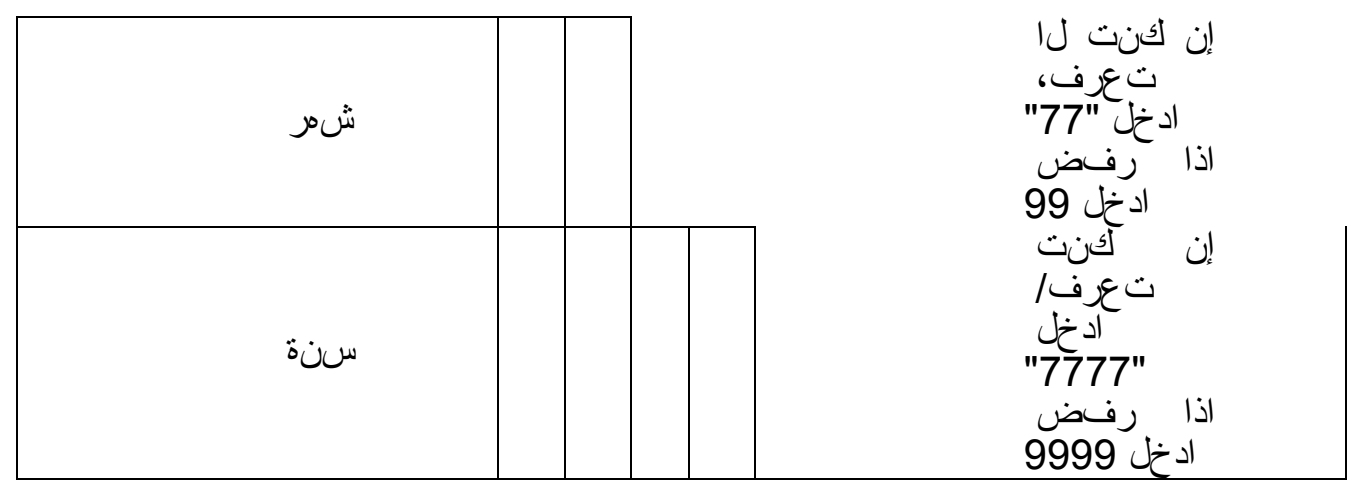

الباحث: إذا كان شهر = 77 أو سنة = 7777، اسأل أ3؛ وإلا انتقل إلى أ.

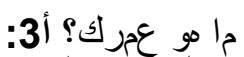

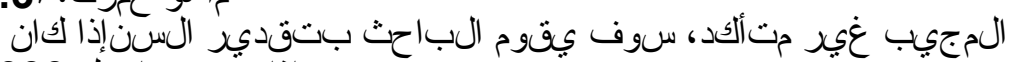
اذذارفض النخل 999
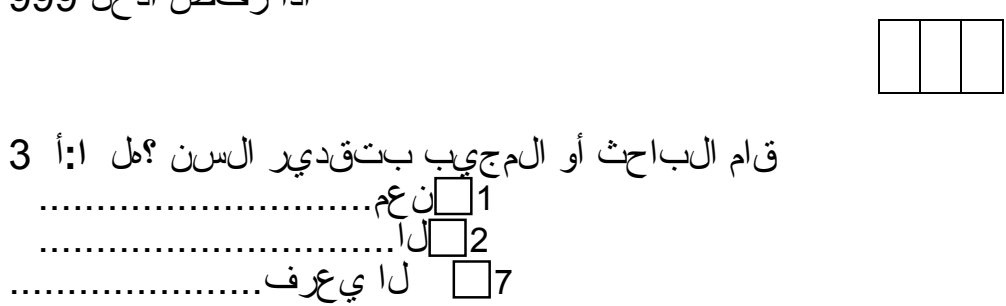

ما مي حالتك التاتماعية؟ مل انت:11

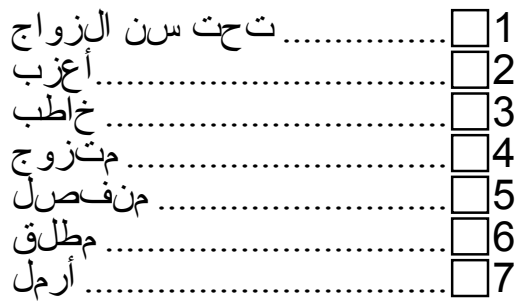

رفض

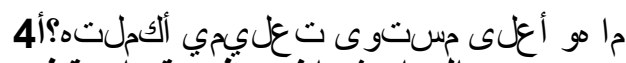

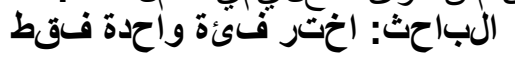


2 1

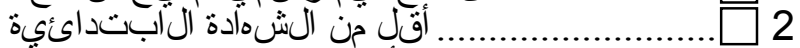

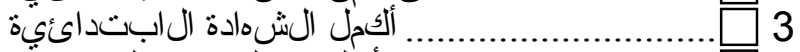

4

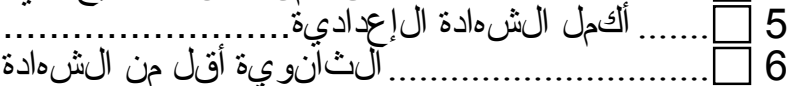

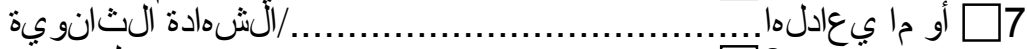

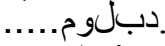

8

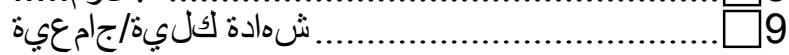

10 $\square$ 1اصل على درجة في الدر اسات العليا...

رف 77

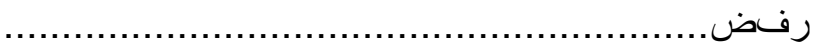

$\square 99$.

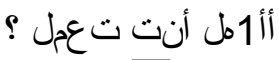

2

ص 9

ة خلال الـ 12 شمراءي أب مما يلبي يصف بشكل أفضل طبيعة عجلك الرئيسأ5:

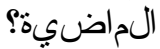

للباحث: ي عجل لحساب نفسه تشمل المزارع

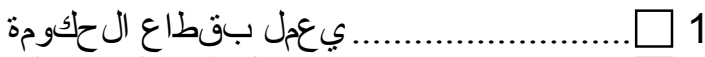

ل 2

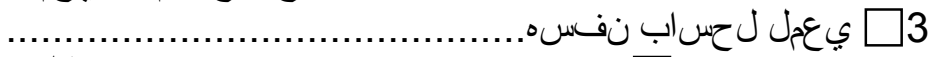

ل 4

(أعرل من المنزل

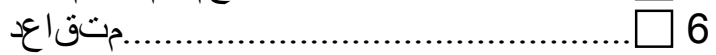

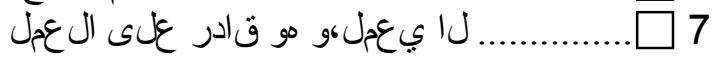

878

ـون........................................ $\square 77$

(1)

سرة المعيشية أو احد أفر ادها لديه أي من الشياء الآتية؟: ل مذه الأل6

قر أ

كاند

بند

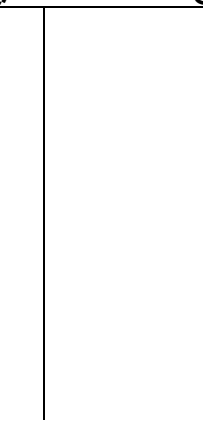

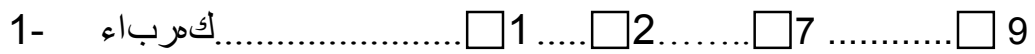

2- -

3-

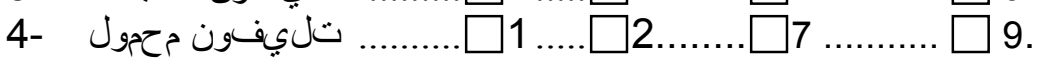

ر - -...... $\square 1 \ldots$.......... $\square 7$.......... $\square 9$. 


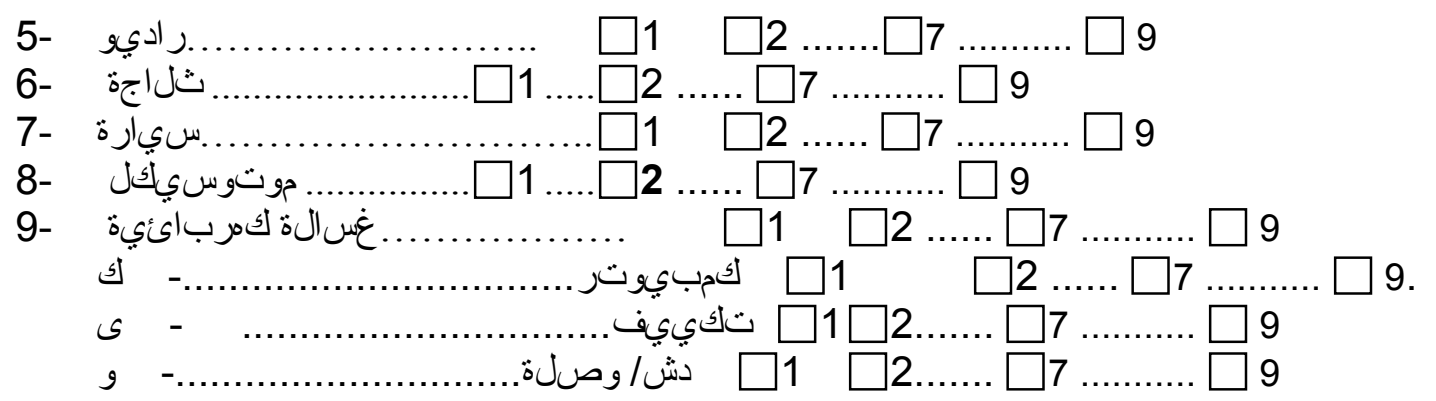

ما مو عُد غرف التى تست عملها أسرتك للنوم فى منزلك؟أ8
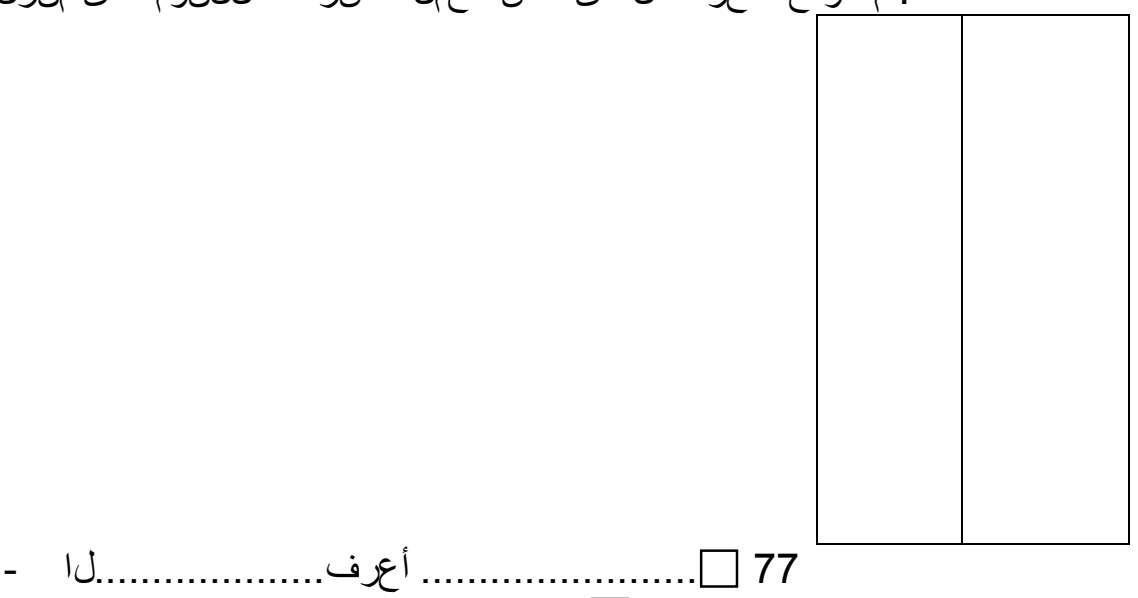

القسم ب. تد خين التب غ

مقدمة: أود أن أسألك بعض السئلة عن تدخين التبغ، وهذا يشمل الس جائز ، السيجار ، إيشة

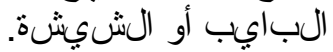

الر جاء عدم الإجابة عن التبغ اللمستعجل عن طريق غير التدخين في مذه المرحلة.

بتدخين التبغ بشكل يومي، اقل من يومي، أو لا تدخن ؟حالياً مل تقوم ب1:

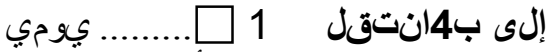

ك2

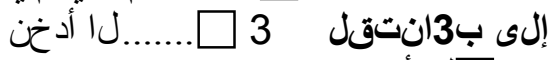

إلى القسم التالي انتقل 7 WP

WP

قدت بتد خين التب غ بشكل يوحي في الماضي؟مل ب2:

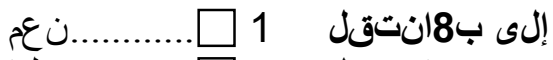

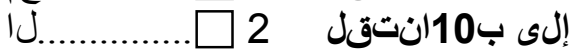




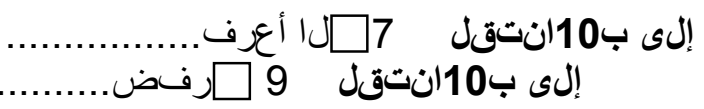

$$
\begin{aligned}
& \text { تدخّن ؟، مل دخنت التب غ بشكل يومي، أقل من يومي، أو لم في الماضي ب3: } \\
& \text { إذا كان المجيب قد أجاب بأنه قام بالتدخين بشكي في "يومي" أو "أقل من الباحث: }
\end{aligned}
$$

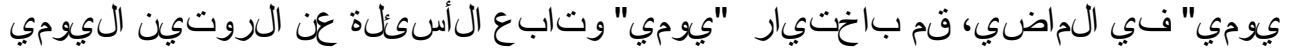

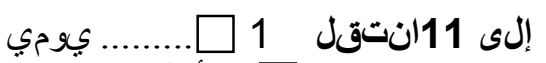

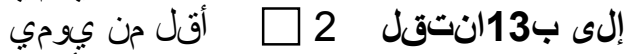

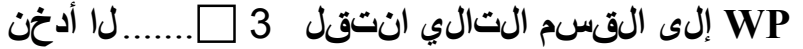

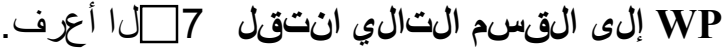

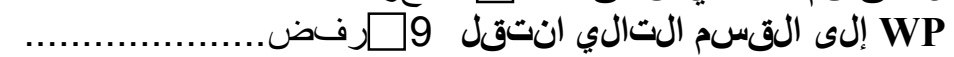


الددخنون حاليا بشكل يومي

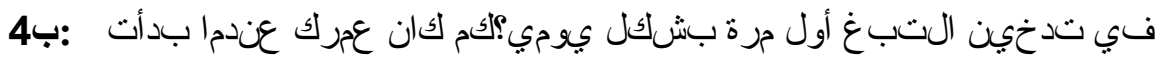

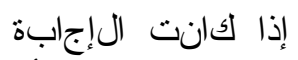

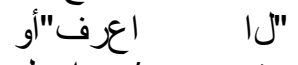

رفض / التخ إنل

"99"

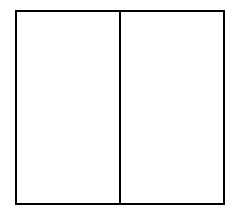

الباحث: إذا كانت ب4=99، اسأل ب5، وإلا اذهب الى ب6.

: كم عدد السنوات التي مضت منذ ان بدات التدخين " بشكل يومي" ؟ ب5

99.

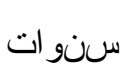

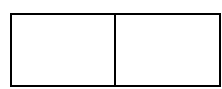

في المتوسط، كم عدد الأنواع التالية تدخنها حالبيا بشكل يومى؟ أيضا ب6:

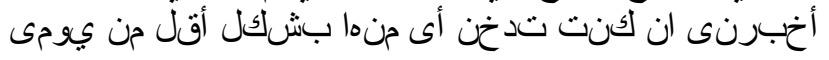

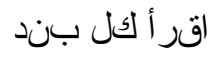

1- مجائز

(1)

) اذا كانت ب أكان =888

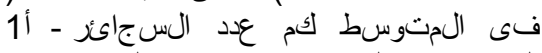

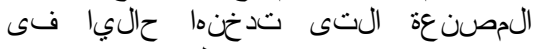

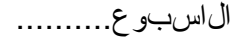

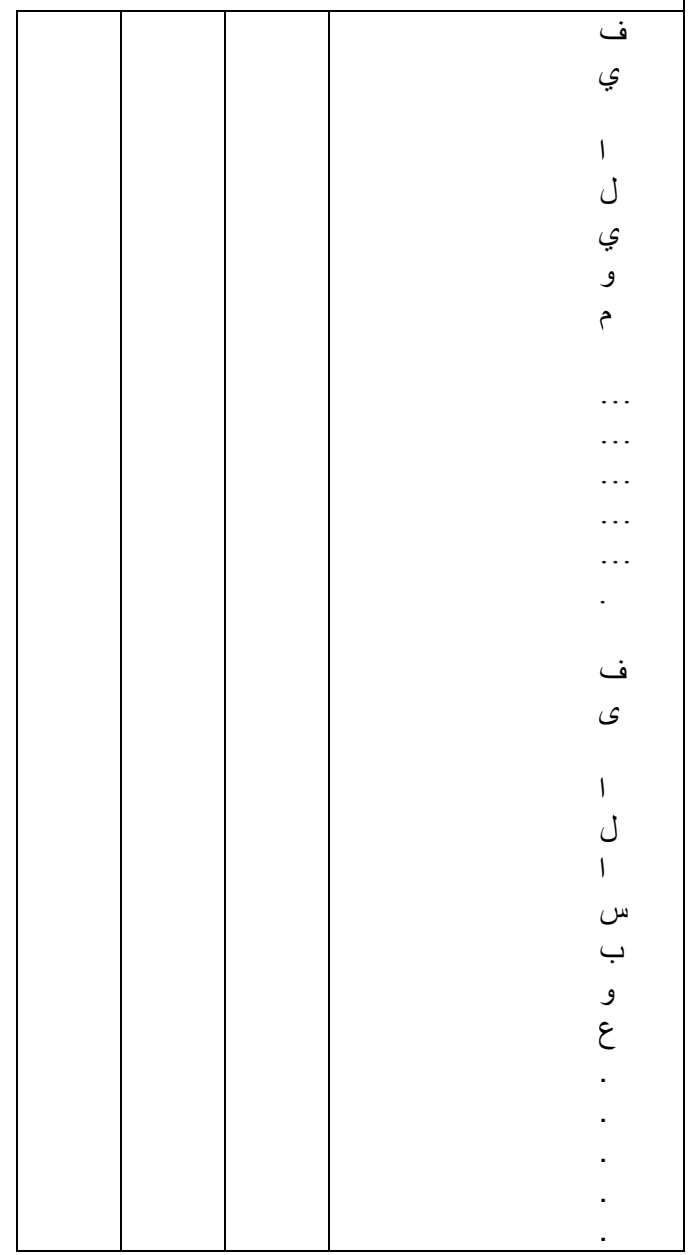



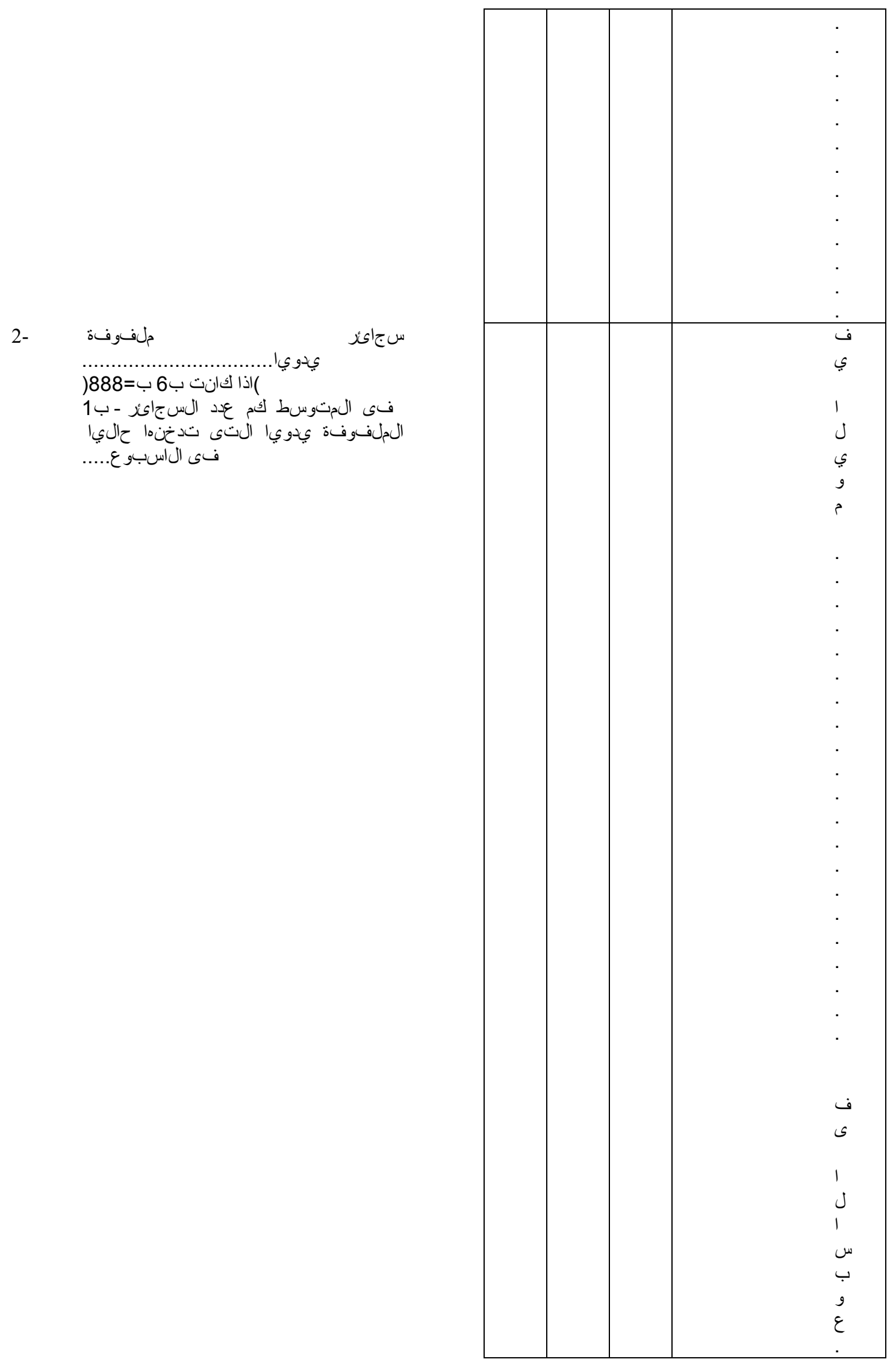
3-
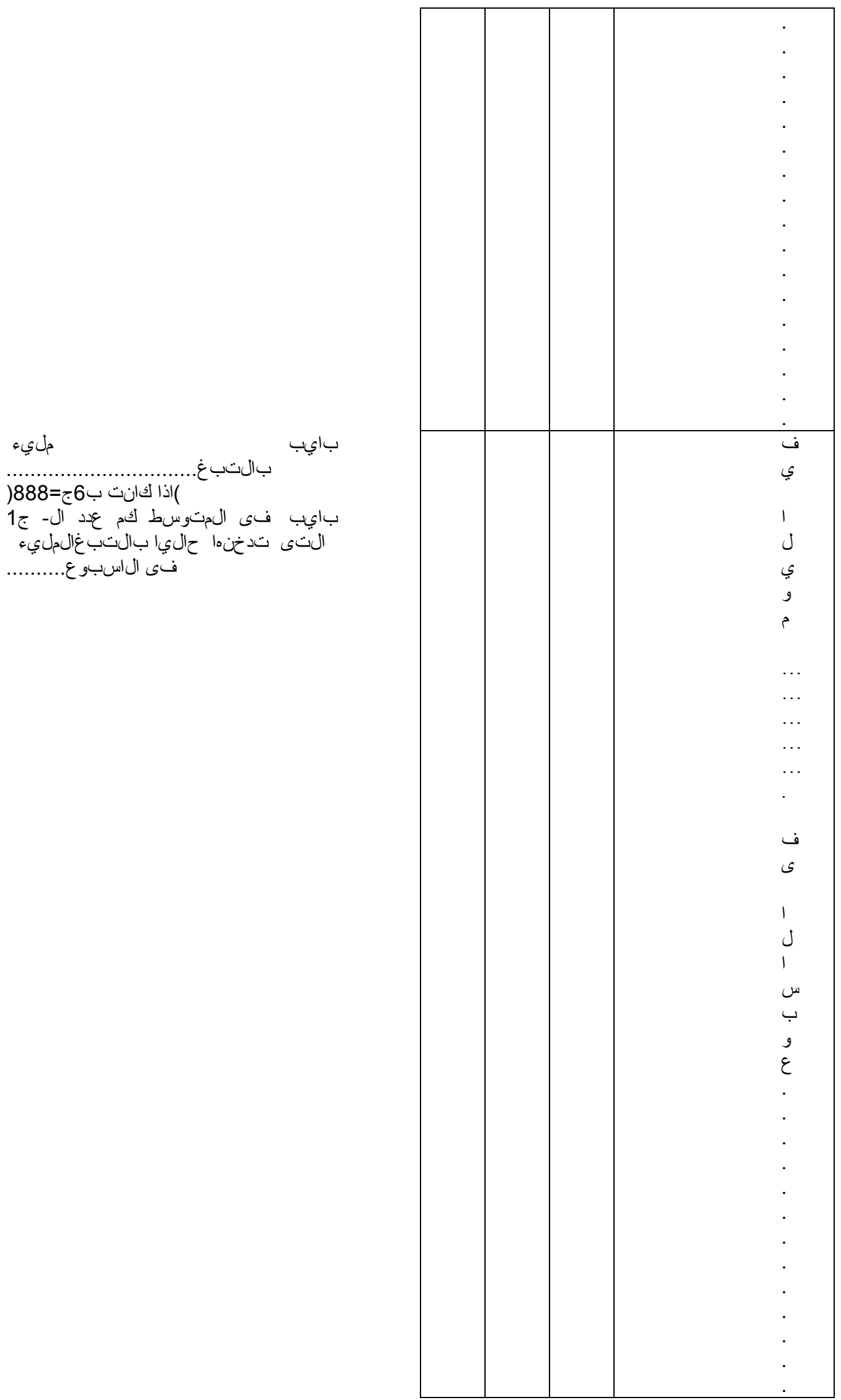


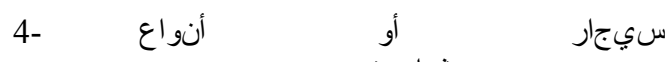 مشابهاة.......................

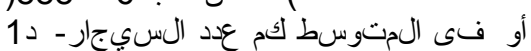

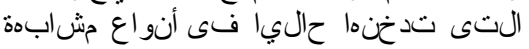

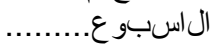

عدد جلسات شيشة في النيوم -5

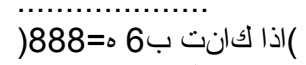

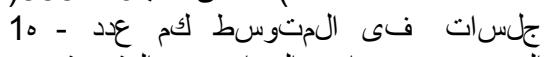

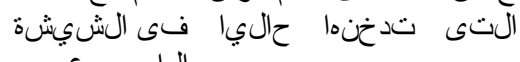
السبوع...............

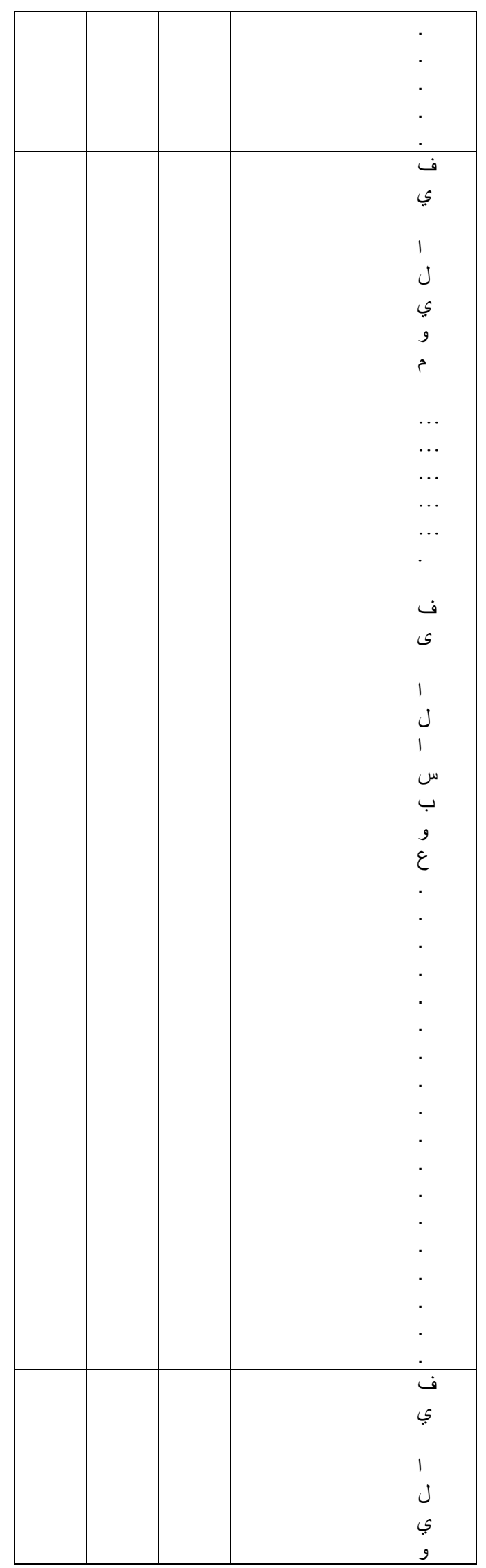




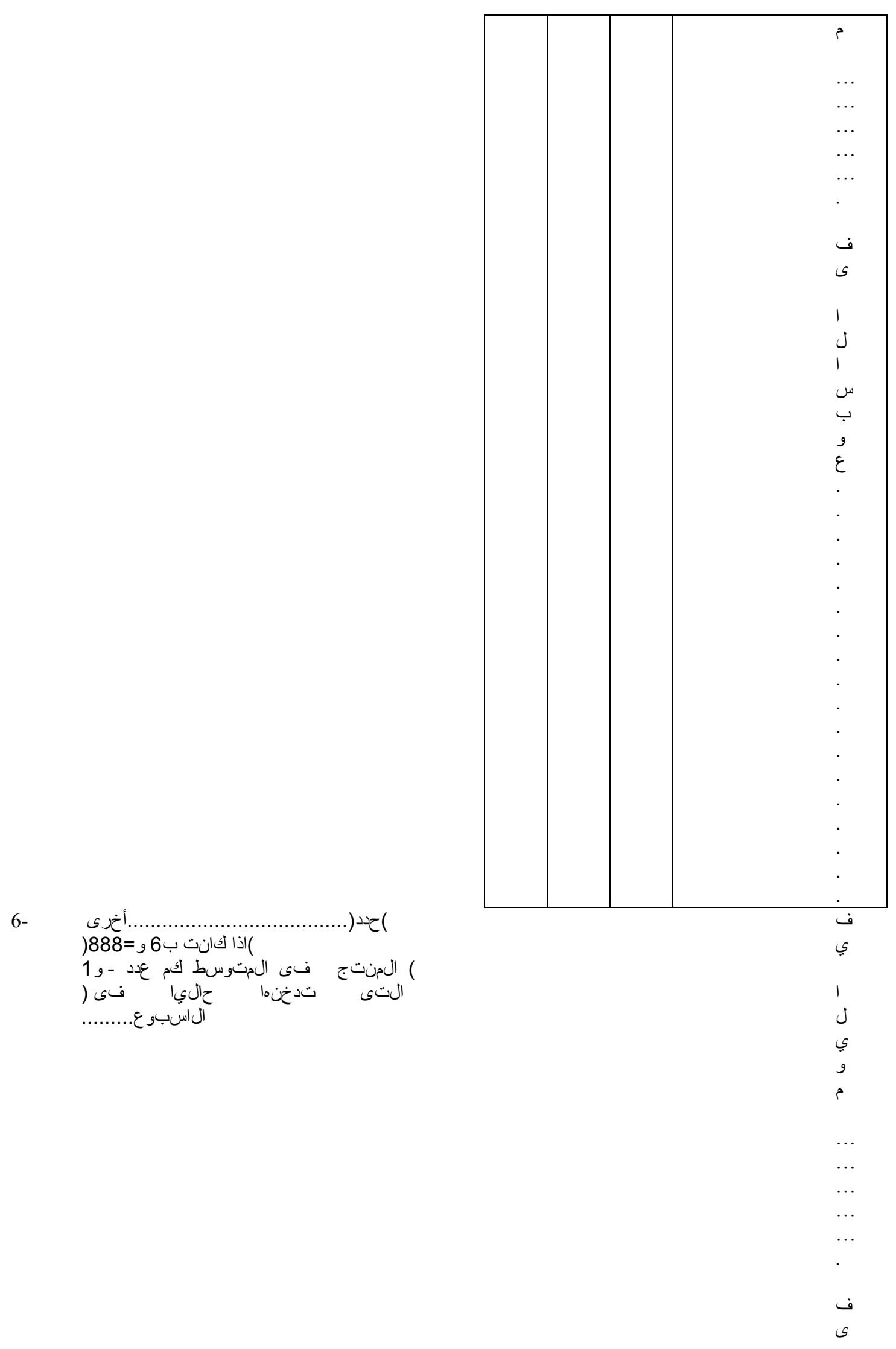




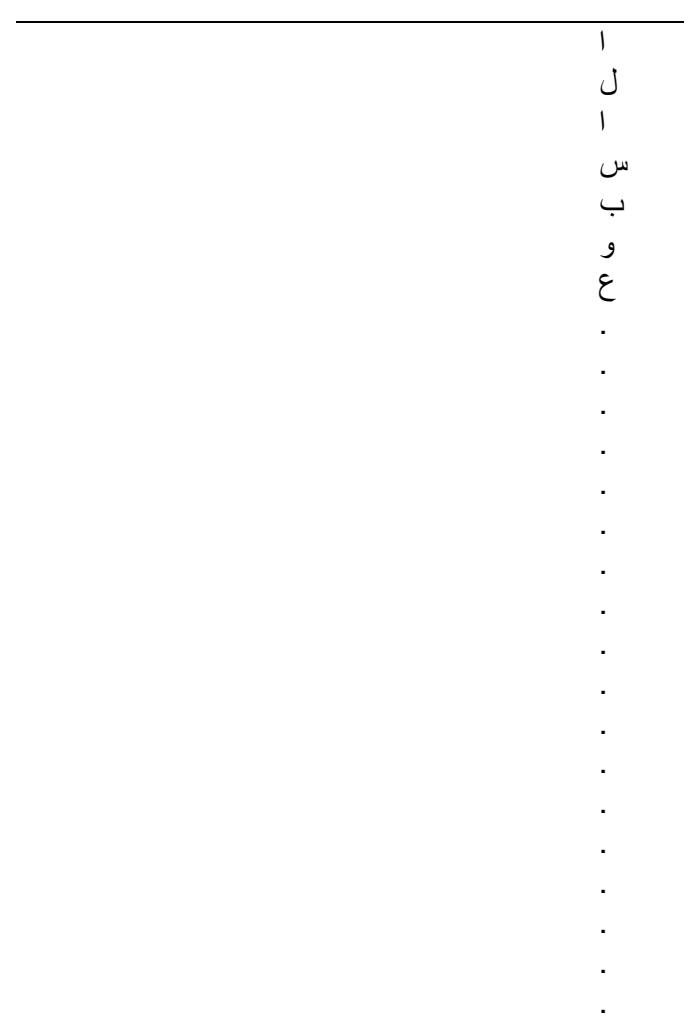

إن أجاب المجيب انه/انها يدخن أيا من الأنواع السابقة من التبغ خُ خلآ الـ 30 الباحث:

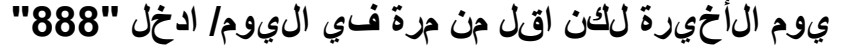

إلى علب أو عبوات، قم بعد الرقم او الوحدات في كل علبة أو المحاور : إذا أشار الباحث

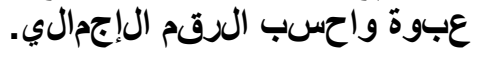

تبدأ في التدخين بعد استبقاظلك؟ بعد:عادة، متى ب7:

خل 5 دقال 30 دقئق

$2 \square 2$ دقائق إلى 30 دقيقة

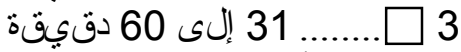

4 ـ....... أكثر من 60 دقيقة

ر $\quad \square 9$

Wالمحاور : انتقل إلى القسم التالي)الشيشة). 
المدخنون حاليا بشكل غير يوجي

كم كان عجرك عندما بدأت أول مرة في تدخين التبغ بشكل يومي؟8:

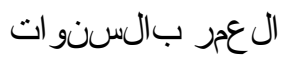

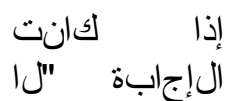

$$
\begin{aligned}
& \text { اعرف" / ادخل }
\end{aligned}
$$

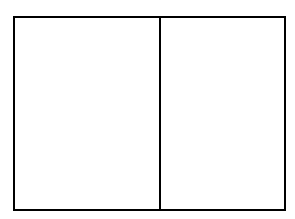

ب8=99، اسأل ب9، أو انتقل الى ب 10.المحاور: اذا كانت

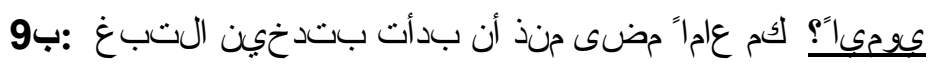

$$
\text { سنوات }
$$

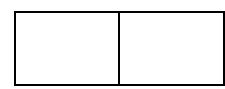

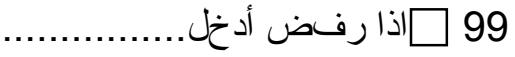

؟ فى خلىال اسبوع: كم عدد وحدات التب غ من الأنو اع التالبية تدخنها حالبيا أب10

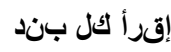



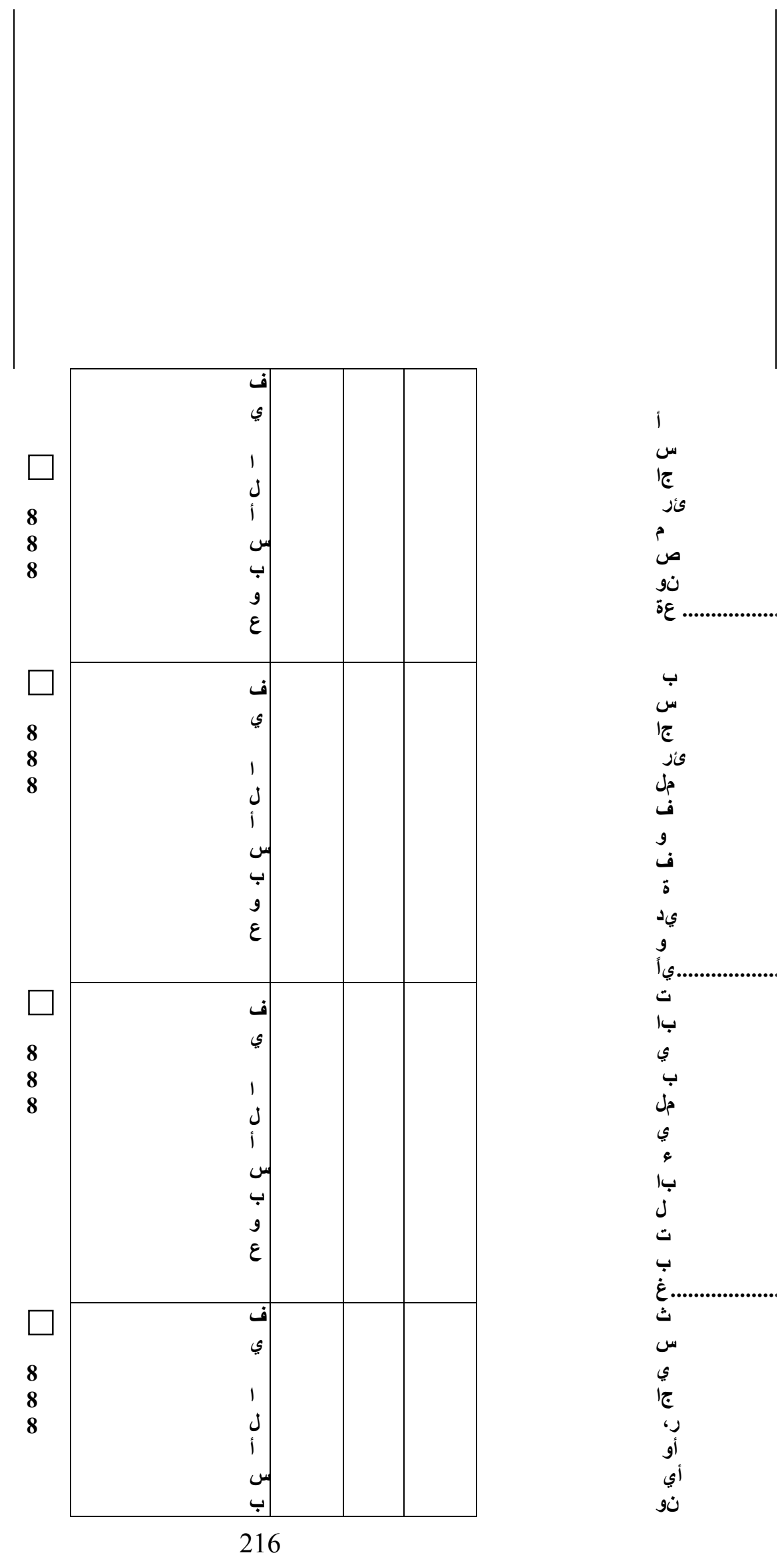

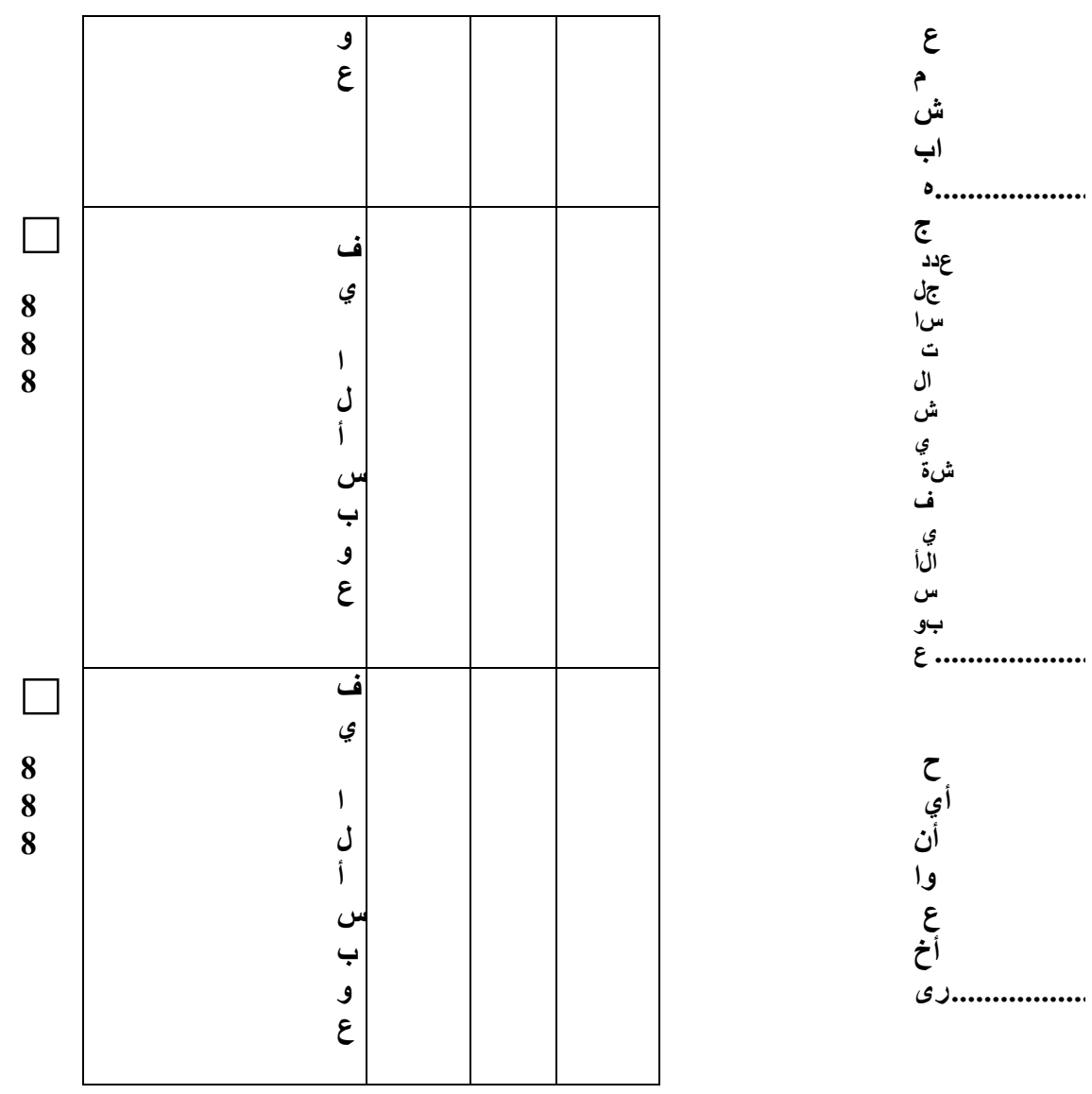

و

أخ

งر.................

إن أجاب الججيب انه/انها يدخن أيا من الأنواع السابقة من التبغ عبر أبر الـ الباحث:

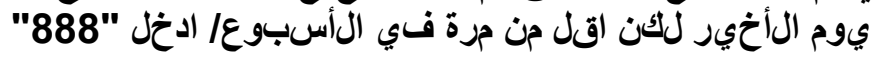

إلى علب أو عبوات، اسأل عن عدد الوحدات في كل علبة أو المحاور : إذا أشار الباحث

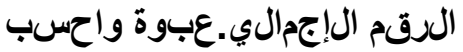

- الباحث: انتقل إلى القسم التالب)(الشيشة) 
الجدنون الس ابققون

كام كان عمرك عندما بدأت تدخين التب غ بشكل بعمي لأول مرة؛ ب11 :

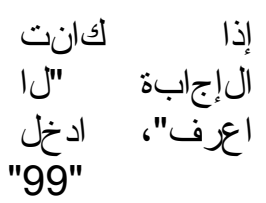

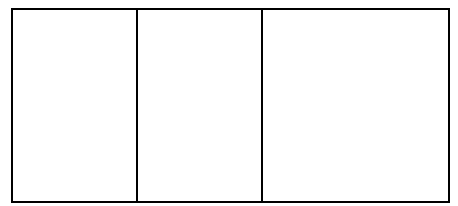

اذذا كانت ب11=99، اسأل ب12؛ غير ذلك اذهب إلى ب13.الباحث:

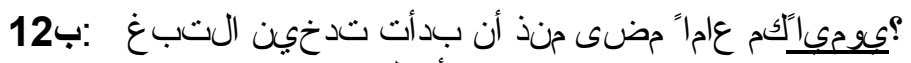

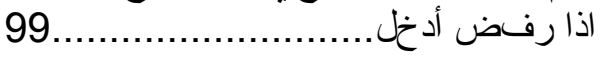

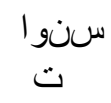

13 كم مضى عليك منذ أن توقفت عن التدخين؟؟

بصورة: اسأل وركز فقط على الوقت الذي توقف فيه الججيب عن التثدخين الباحث

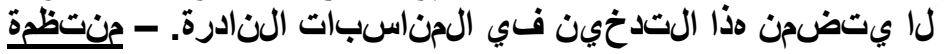

اقرأ كل بند بعناية و الكتب الرقم.

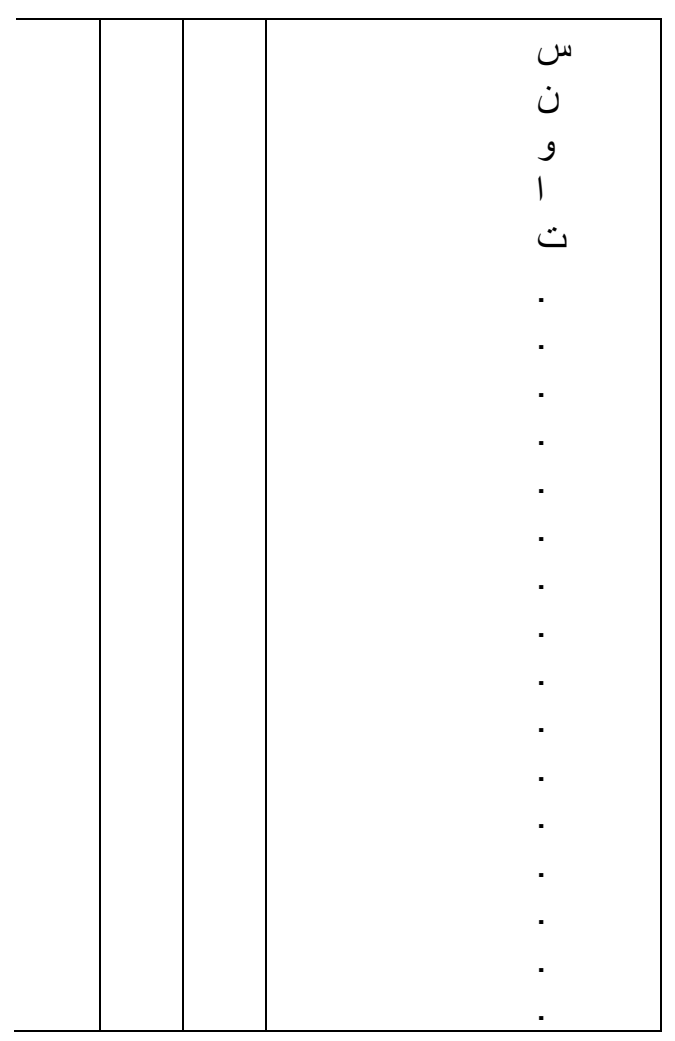




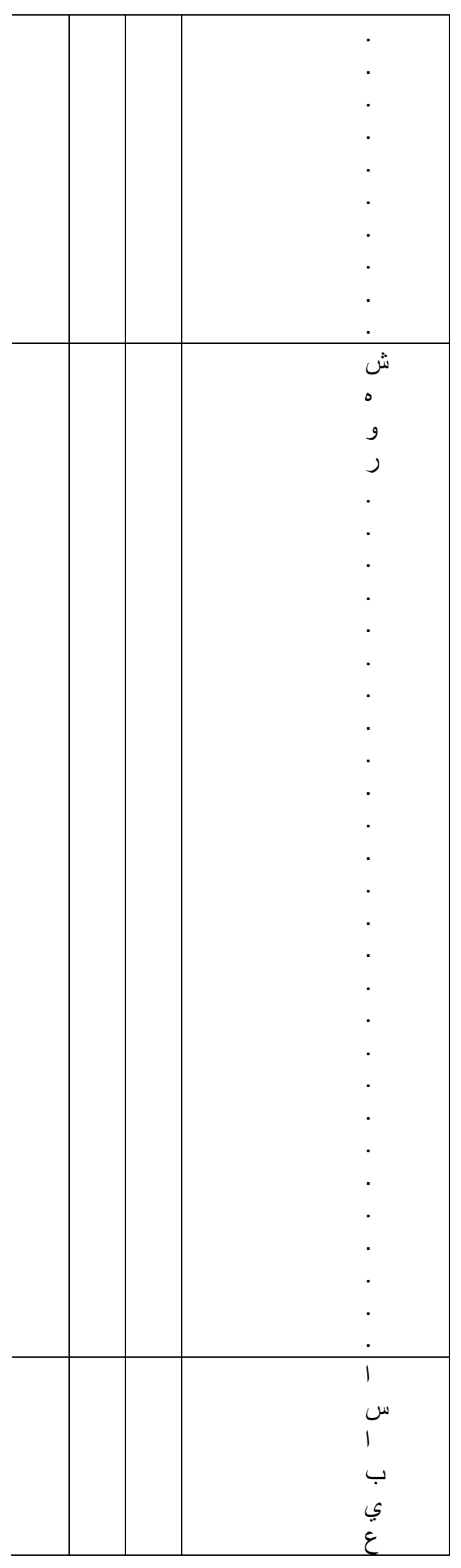




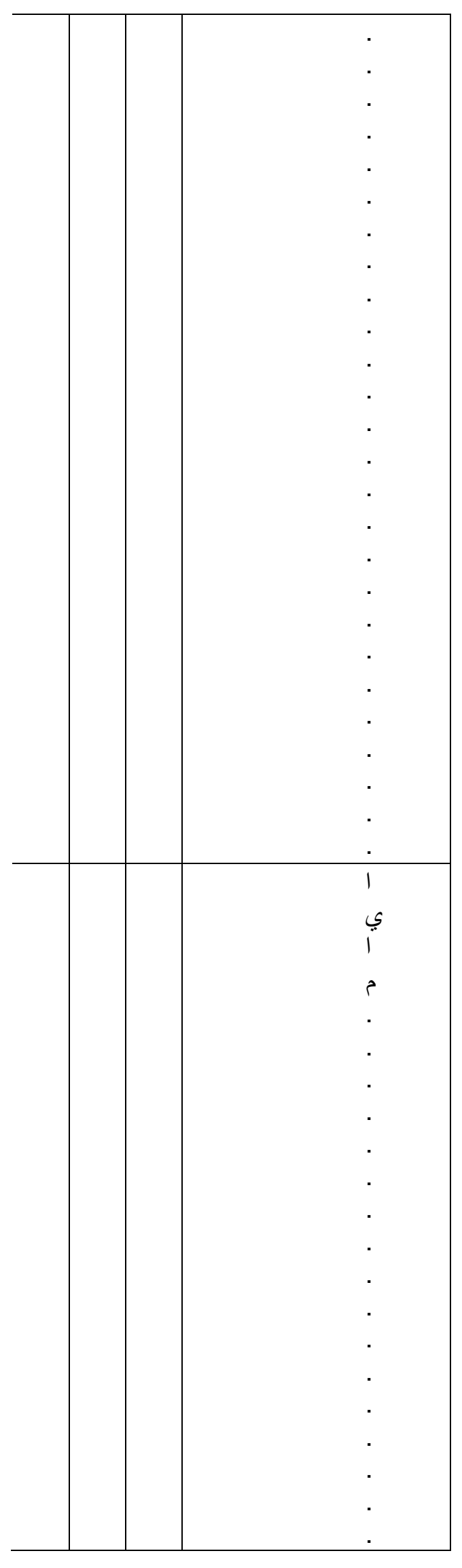




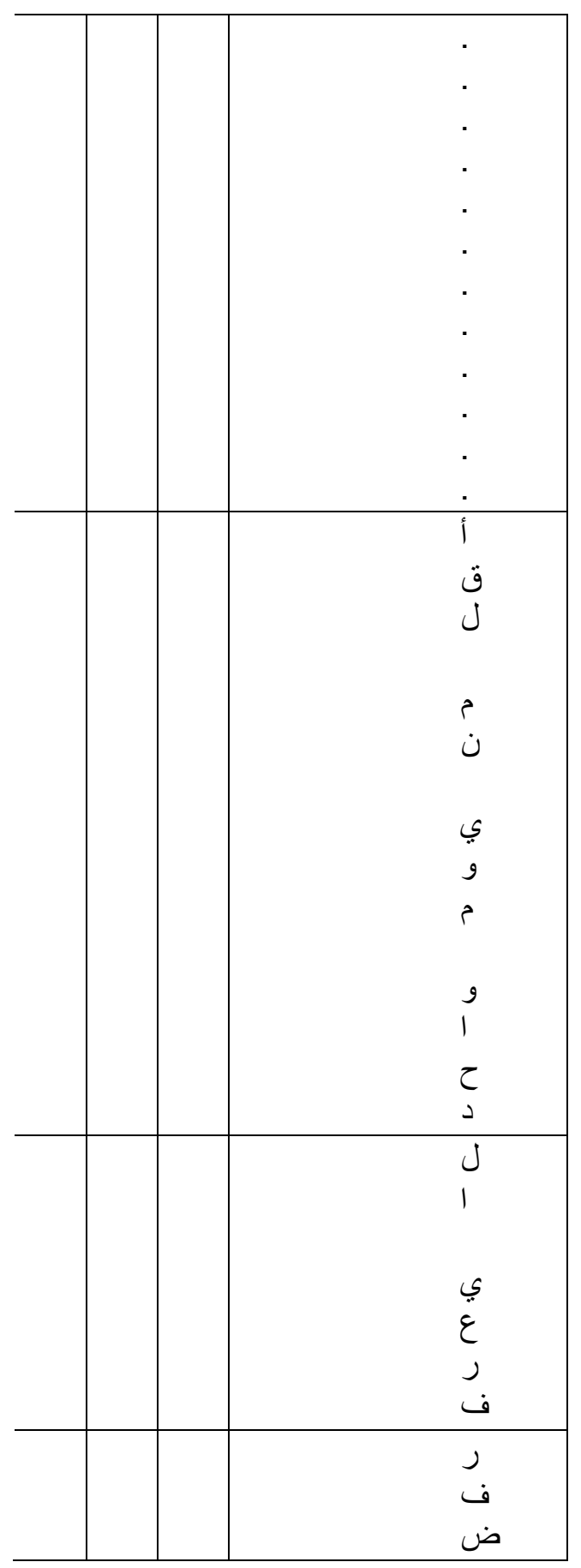

: اذا كانت ب13 اقل من عام واحد )اقل من 12 شهرا(، تابع الى ب14، وإلا اذدب الباحث

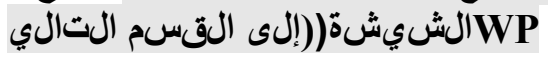


14 مل قجت بزيارة طبيب أو مقدم رعاية صحية خلال الـ 12 شمراء الـاضية؟

¿ن....... $\square 1$

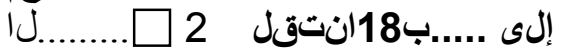

إلى .........................

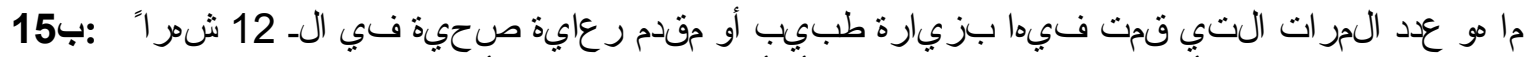

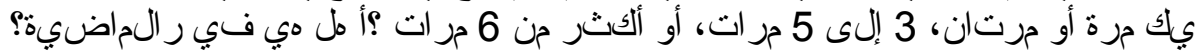

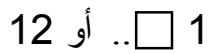

5

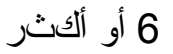

$\square 2$

$\square$
$\square$

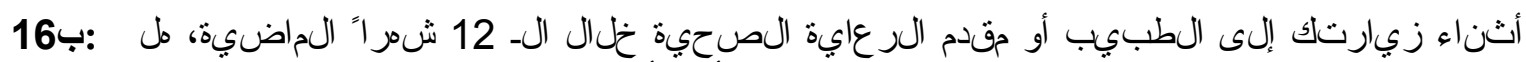

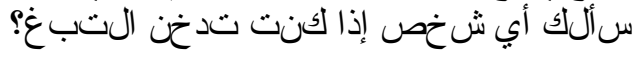

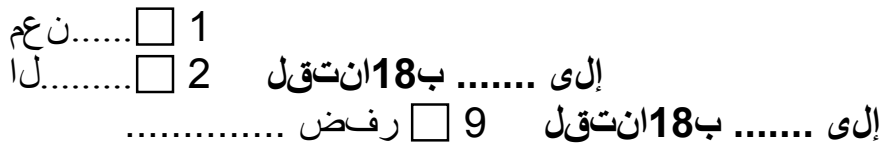

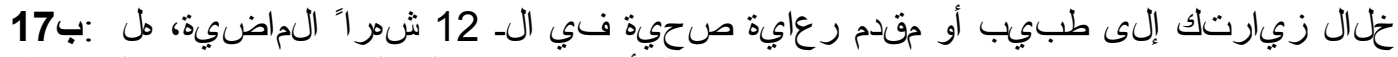
نصحك أي شخص بال القل

¿

……............. $\quad \square 9$

12 شر اء الماضية، مل استخدمت أيًا من الوسائل التالية لمجاولة القإلعاع عن خلخال الـ ب18:

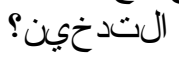

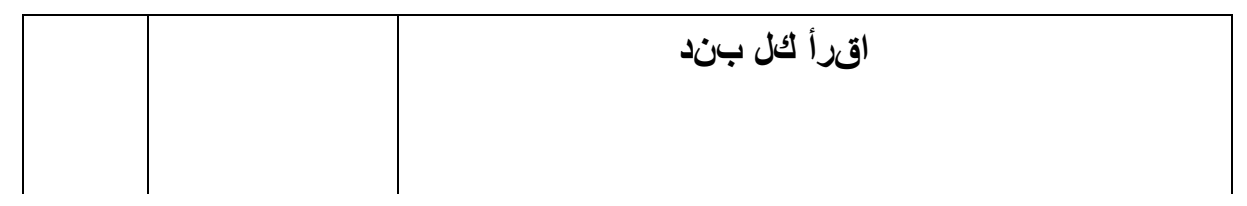

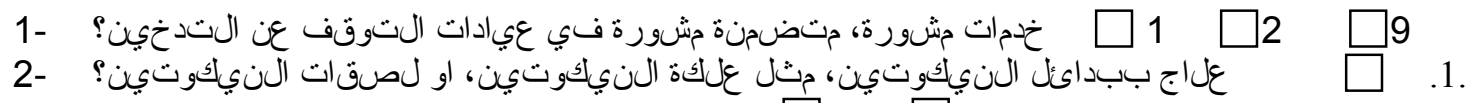

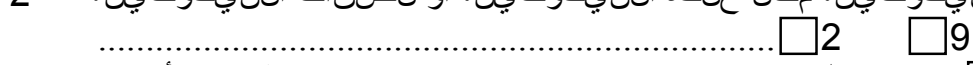

3-

4- -

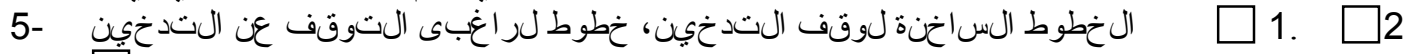
$\square 9$

6 -

7-

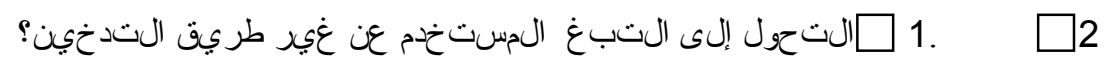

$\square 9$

$$
\text { أخرى: اذكر }
$$


نموذج تد خين الشيشة -

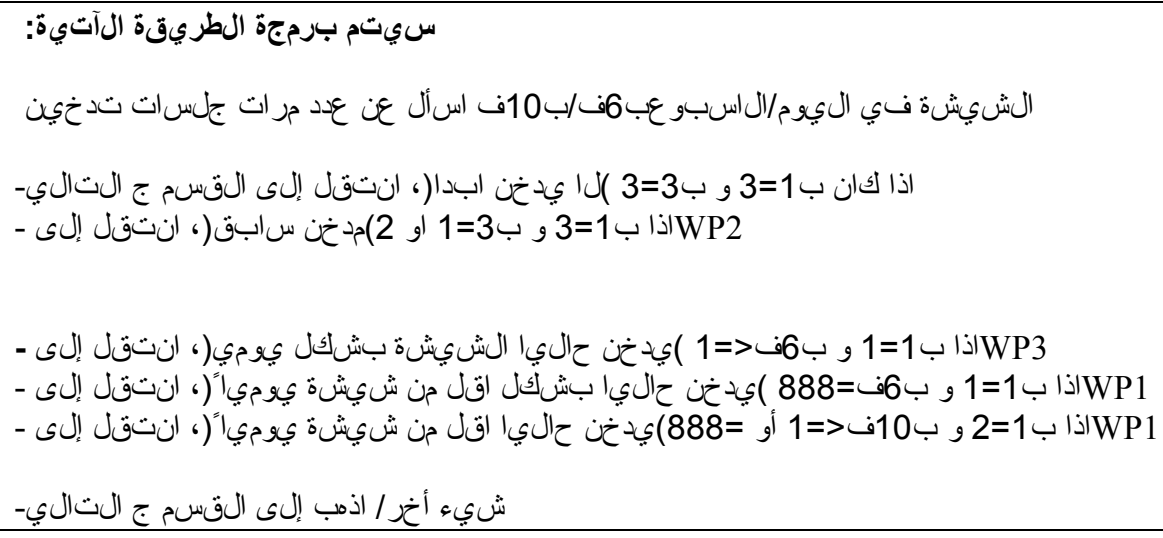

مقدمة: أود أن أسألك بعض السأسلة عن تدخين الشيشة

بشكل يومى فى الم اضى؟مل كنت تدخن الشيشة

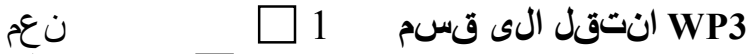

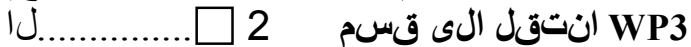

، مل قمت بتدخين الشيشة بشكل يومي، اقل من يومي، أو لم تدخنها؟نـى الماضي الباحث: اذا كان المجيب قد دخن كليهما "يوميا" و"اقل من يومي" في الماضي، اختر

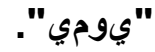

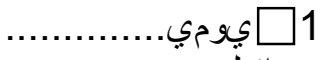

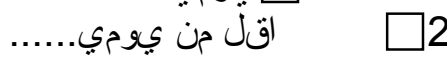

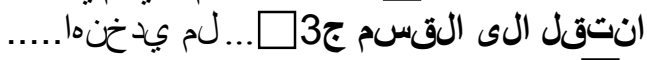

$$
\text { انتق الى القسم ج }
$$

. كم كان عمرك عندما بدأت في تدخين الشيشة:WP3 .

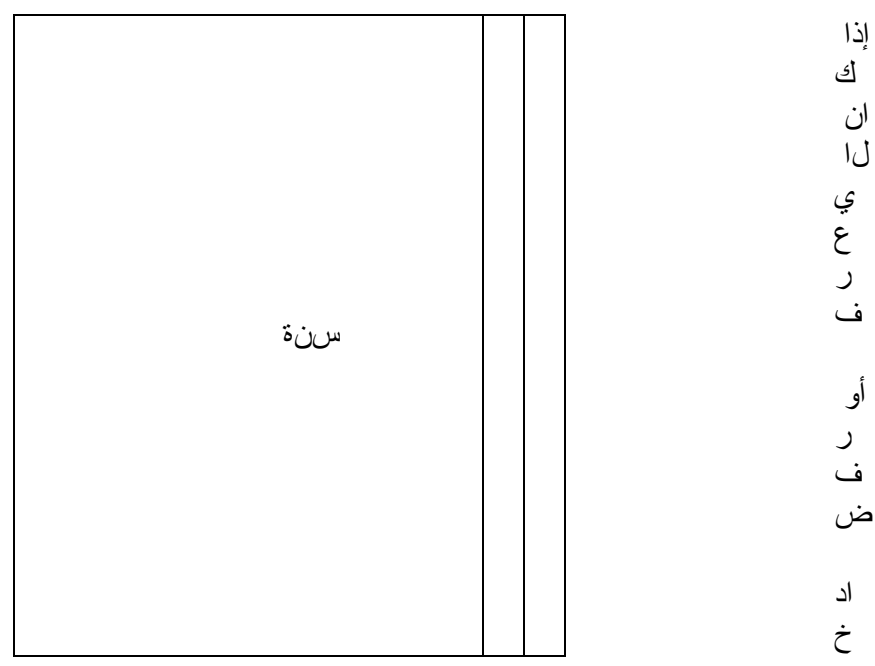




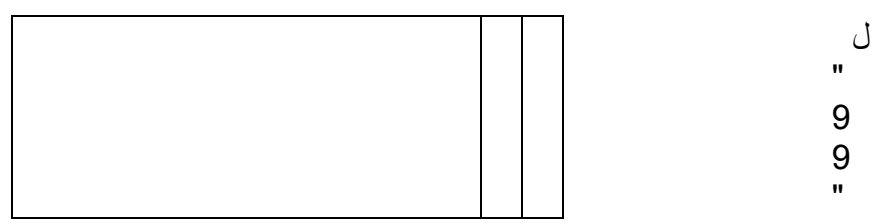

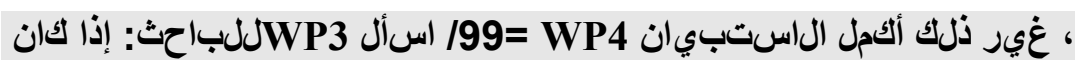

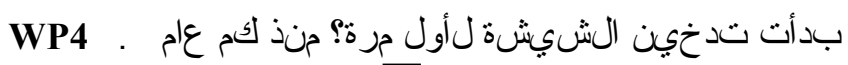
国 99

سنوات

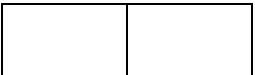

الوطريقة:

، اذهب إلى ]=1 او = 888(=1=1 او =888( او )ب10ف>)ب6ف [حدخنو الشيشة الحالبيون: اذا )ب1=1 او 2(و WP5

و إلا ، اذهب إلى القسم ج التالي-

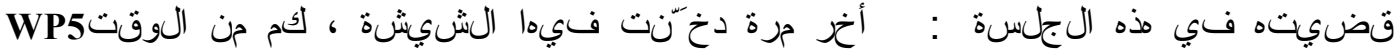

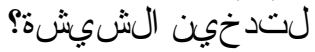

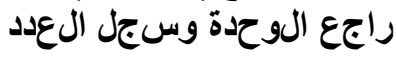

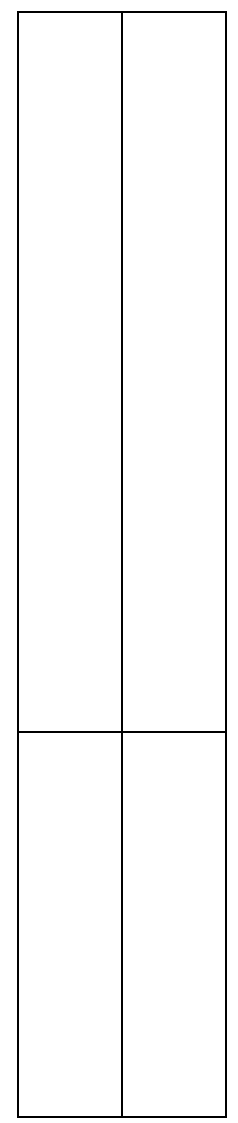

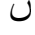



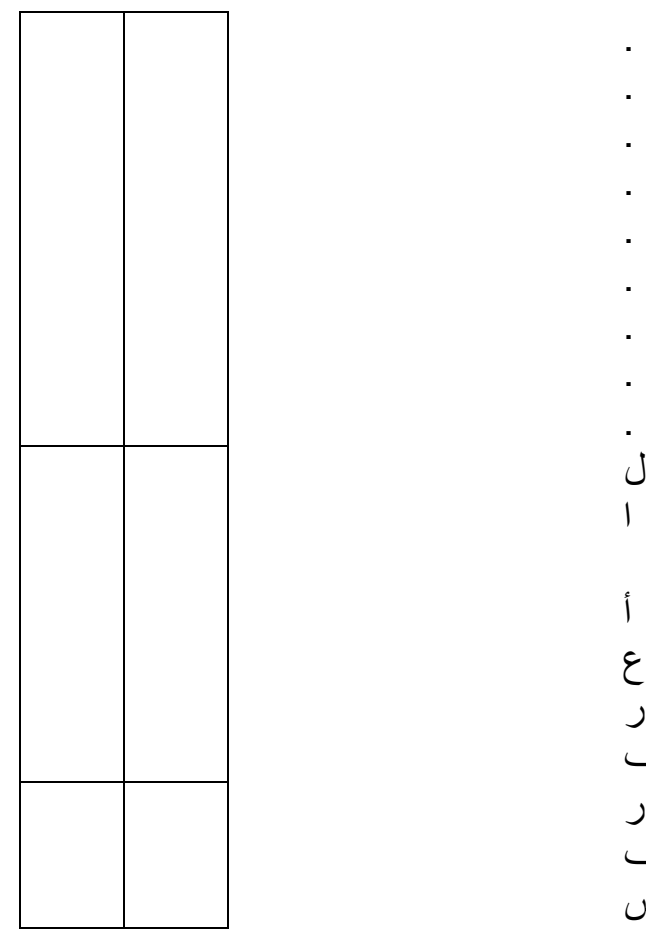

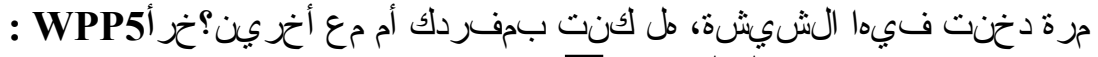

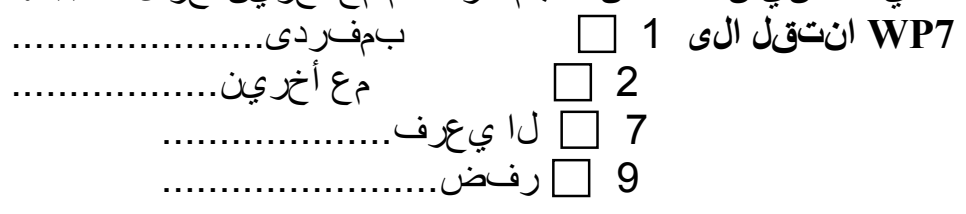

مرة دخنت فيها الشيشة، مل شاركت نفس الشيشة مع أخرين ؟جخ أو : WPP6 ذ ن......... 1

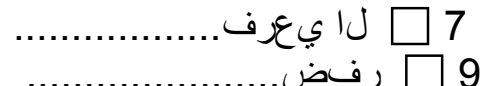

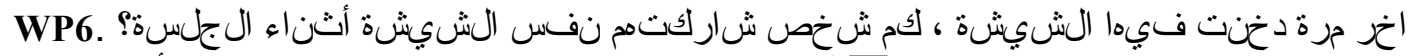
رفض أو أو أون

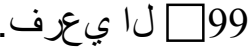

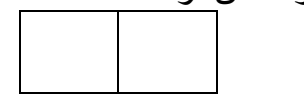

ش خص

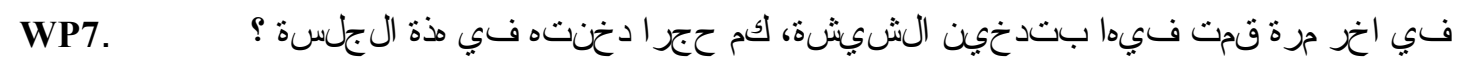

1

1 ................ $\square 2$

2 .............. 3

3 ……....... $\square 4$

4 ............... $\square$

6

7 

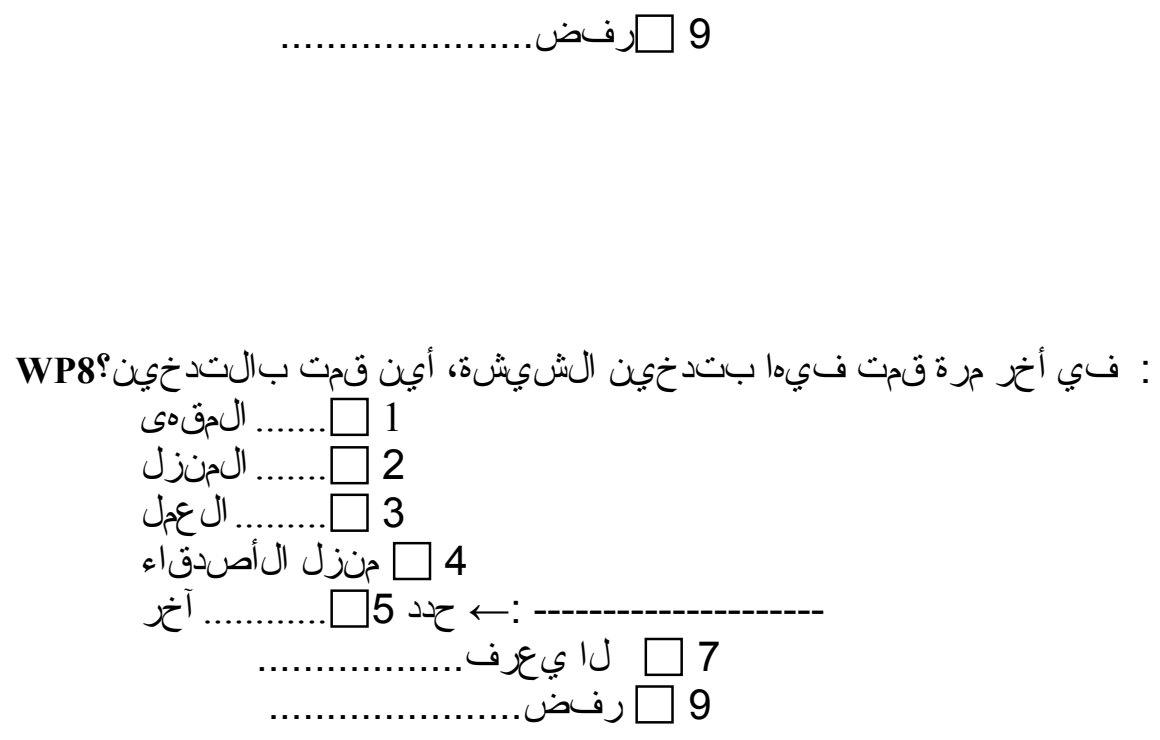

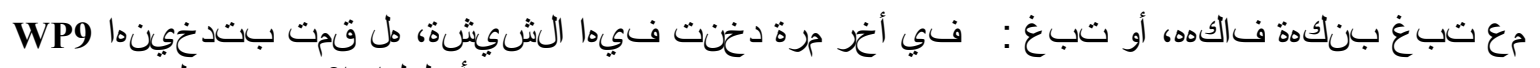

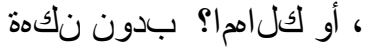

प 1

प 2

(ك)

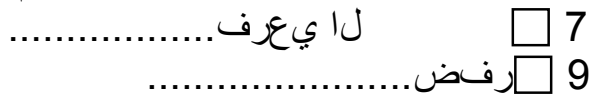

WP10 في أخر مرة قمت فيها بتدخين الشيشة، مل قمت بخلط الماء في زجة :

الشيشة بمو اد أخرى

21

7 ل $\square$

9 


\section{) مضغ التبغ المستخدم عن غيد طريق التدخينالقسم ج. التبغ}

:، أمثلة التبغ عن غير طريق التدخينمقدمة: تدور السأسئة التالية حول استخدام

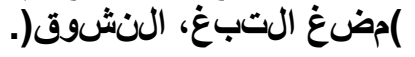

بشكل يومي، أقل من يومي، تبغ عن غير طريق التدخين باستخدام الحالىياً: ل تل تقوم ج1

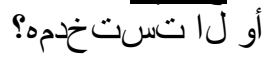

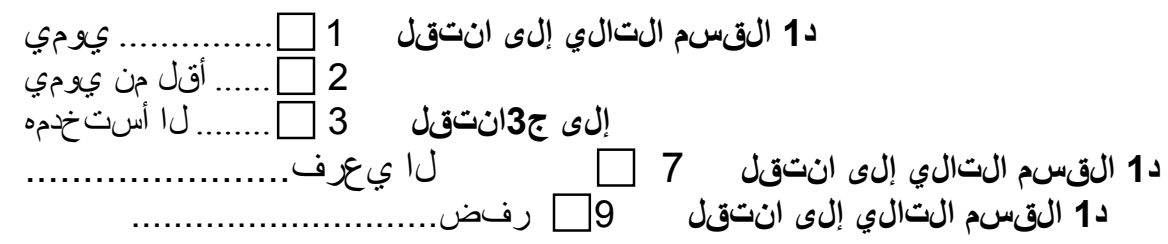

في الماضي:بشكل يومي عن غير طريق التدخينمل قمت باستخدام التبغ ج2 إلى د11انتقلى إنىل

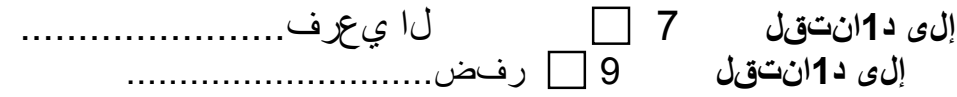

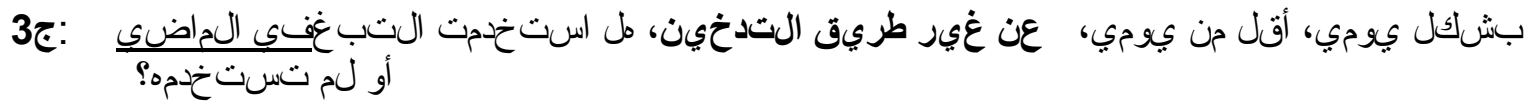
الباحث : إذا كان المجيب قد قام بذلك بشكل "يومي" و "أقل من يومي" في المجاضي، اختر

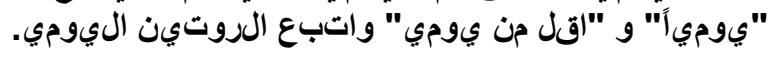

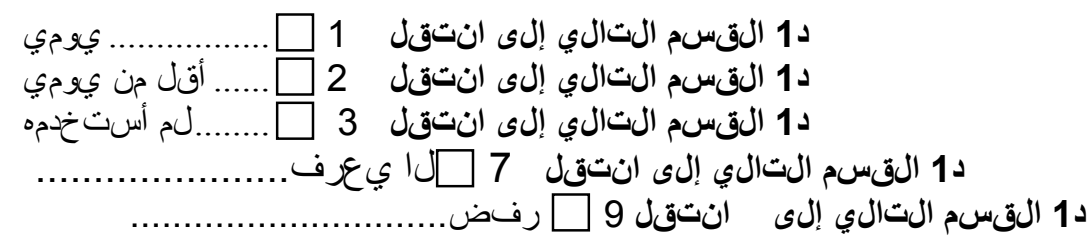




\section{التوقف عن تد خين التب غالقشسمد1:}

و وسجل الأتي: ب1المحاور: راجع الجابة على

=1 ب ب

إذا كان ب1 = 1 أو 2، )المجيب يدخن التبغ حالي'(، استمر مع مذا . $\square 1$

دخن التبغ حالي'(، استمر إلى ي) المجيب لا أو 9 7إذا كان ب1 = 3،

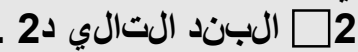

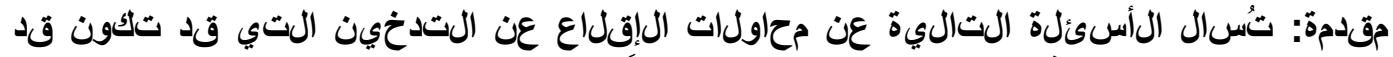

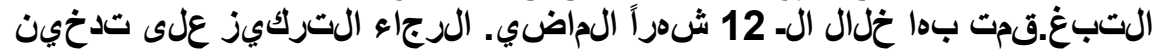

خلال ال- 12 شهر أ الماضي، مل حاولت القلاع عن التدنين؟ 1د:

إلى د4انتقل إل إى دانتقل

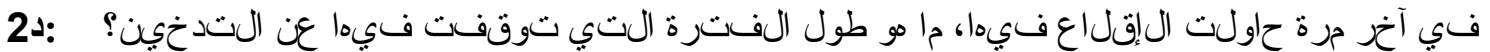

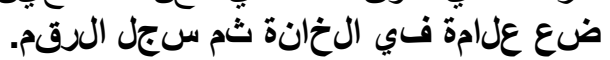

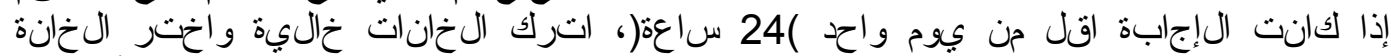

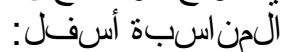

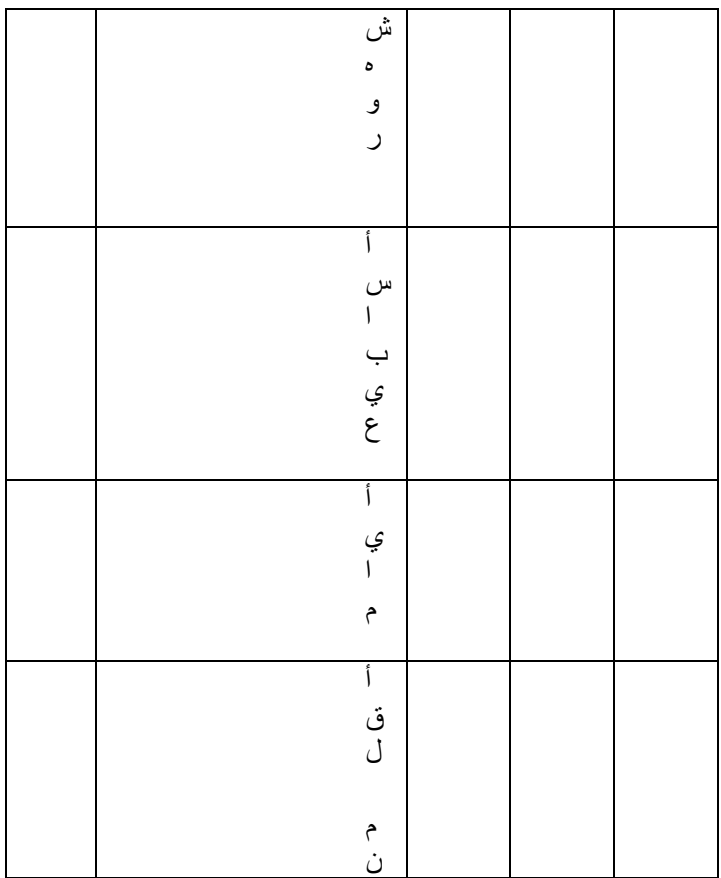




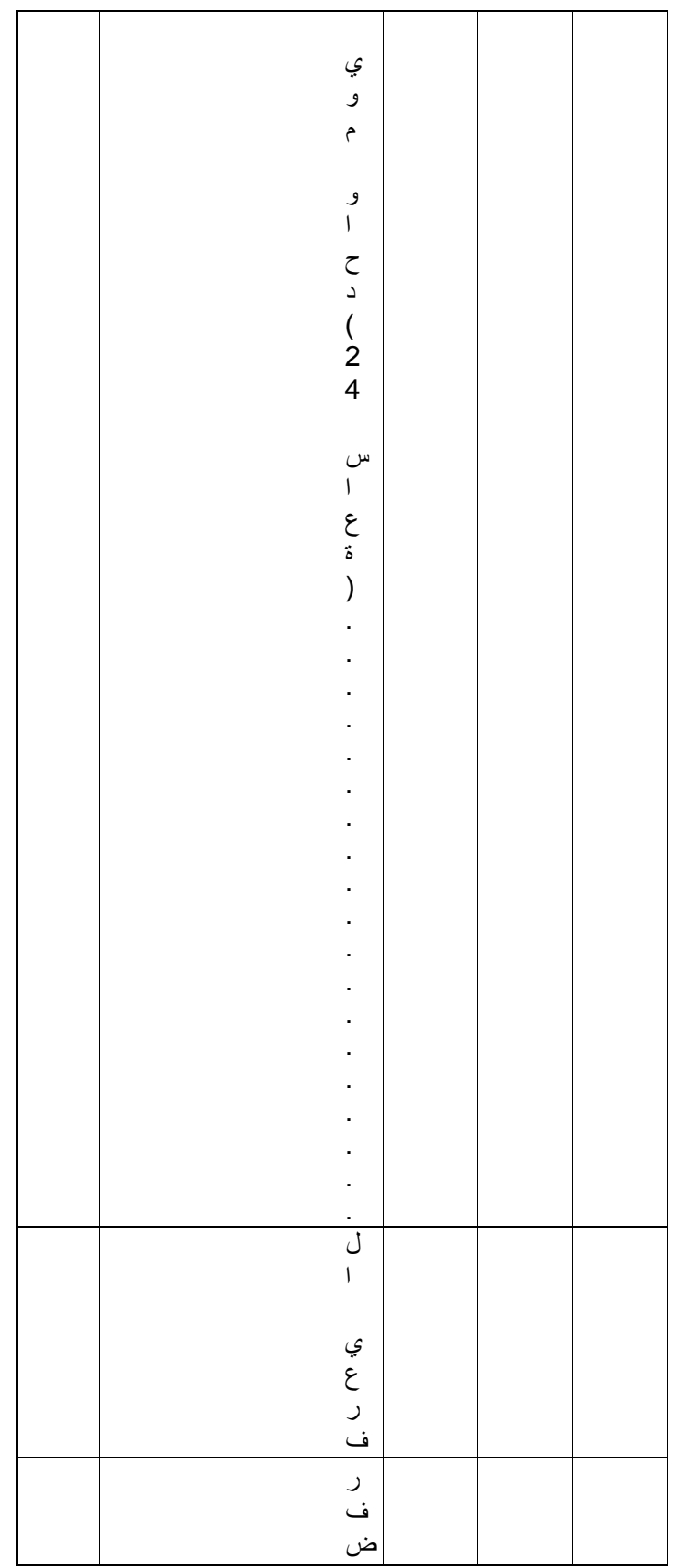

في رأيك، ما السبب الرئيسي الذي كان ور اء محاولتك لل إقلاع عن التدخين دد2:

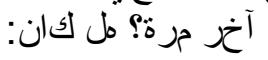

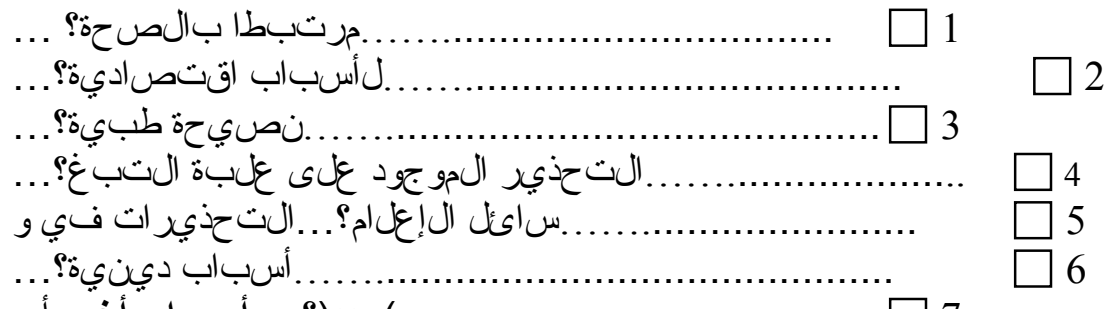

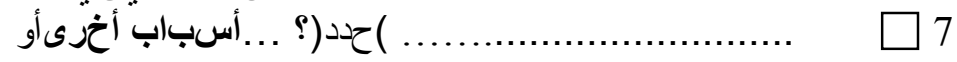




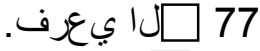

口

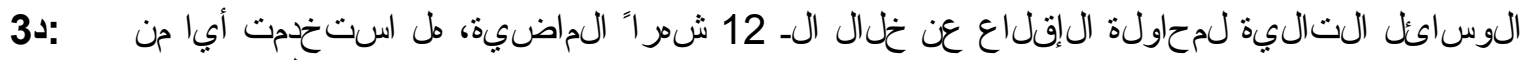
التخدين

\begin{tabular}{|l|l|l|l|}
\hline & & & \\
& & & \\
& & & \\
\hline
\end{tabular}

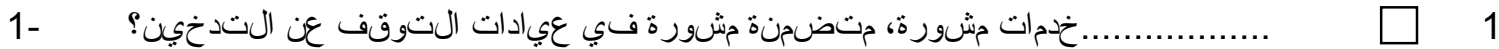

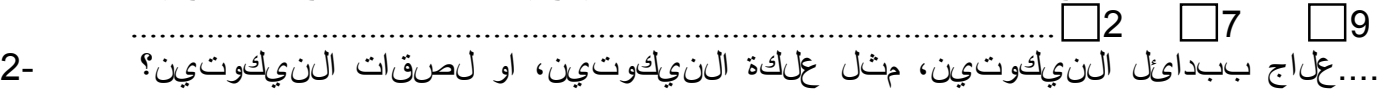

........................................................................ $\square 1 \quad \square 2 \quad \square 7 \quad \square 9$

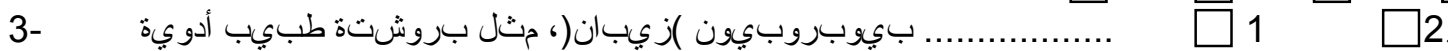

4- $\quad \begin{aligned} & \square \\ & \square\end{aligned}$

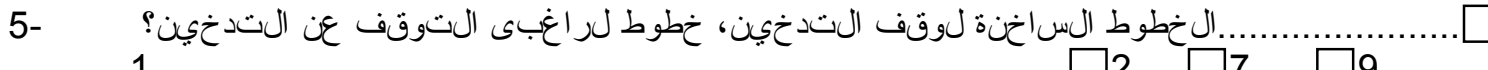

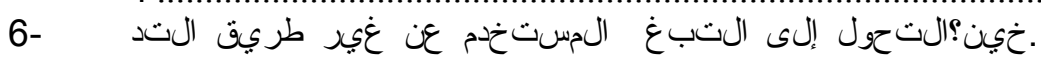

7- أخرى:

$\square_{1} \quad \square_{2} \quad \square_{2} \quad \square 9$

12 شر اء الماضي؟: مل قمت بزيارة طبيب أو مقدم رعاية صحية خلال الـ د4

اذهب إلى دـ 8...... 1

. . اذهب إلى د8...........................

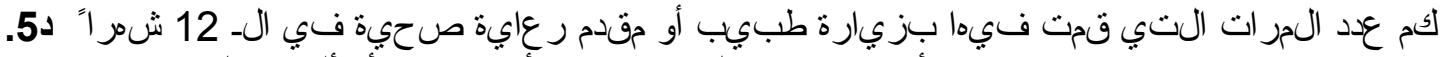

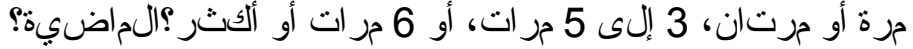

2 أو 1 أو 1 أو 1

5 إلى $3 \square 2$

6

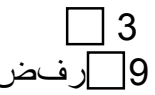

: أثناءزيارتك إلى الطبيب أو مقدم الر عاية الصحية خلال الـ 12 شر اء الماضي، مل تم د6

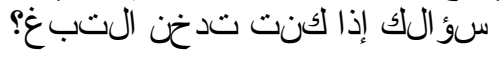

1 


$$
\text { اذدب إلى د8 ...... }
$$

خلال زيارتك إلى طبيب أو مقدم رعاية صحية في الـ 12 شراء الماضي، مل نُصحت د7:

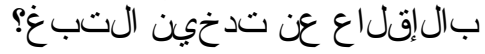

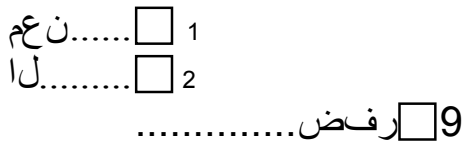

أي من العبارات التالبية تصف على أفضل وجه طريقة تفلكيرك فتى ده:

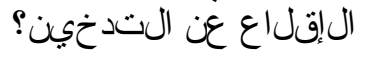

回 1

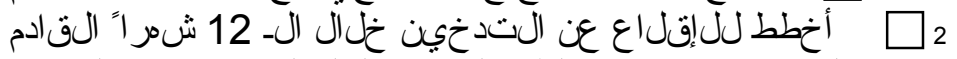
自 $\quad \square_{3}$

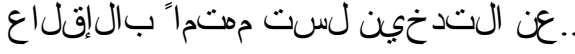




\section{المستخدم عن غيد طريق التدخين القسم د2. التوقف عن التبنغ}

وسجل التي: ج1الجحاور: راجع الجابة على

$=1$ إب

حاليا(، استمر مع دذا البند .......البادخاني، )المجيب يدخن التبغ ج1 = 1 أو 2إذا كان

$\square 1$

حاليا(، انتقل إلى البند التالي هـ ......اللادخاني )المجيب لا دخن التبغ 3 ،7 أو 9، ج1 ج إذا كان

$\square 2$

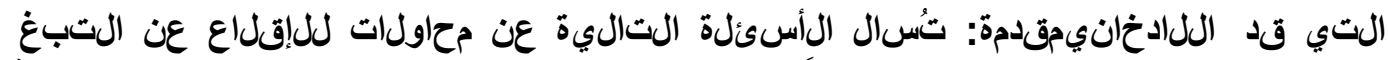

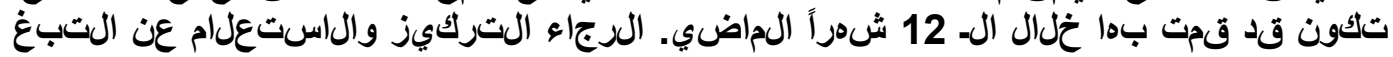
الحستخدم عن غير طريق التدنخين.

الحستخدم عن غيد طريق عن التبغخلال الـ 12 شمراء الماضية، مل حاولت القإلعاع د9:

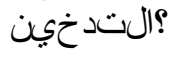

نํ.......

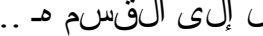

إلى القسم هـ. انتقل...........

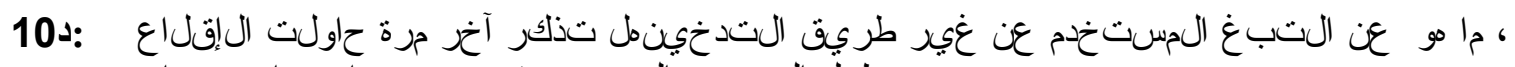

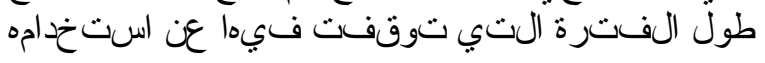

راجع الخانة ثم سجل الرقم

تر الخانة إذا كانت الإجابة اقل من يوم واحد )24 ساعة(، اترك الخانات خالية واخ

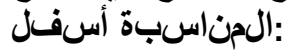




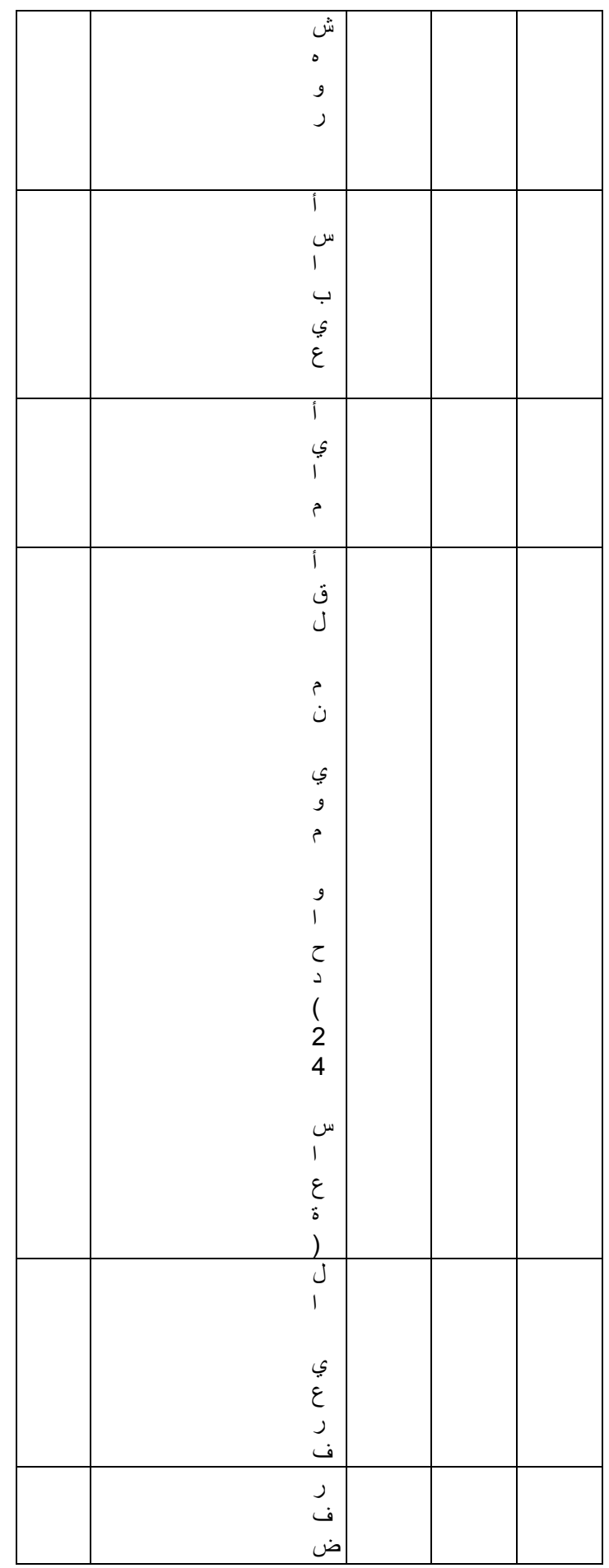


القسم هـ التدخخين السلبي

أود أن أسألك بعض السعئة حول التدخين في عدة أمالكن.

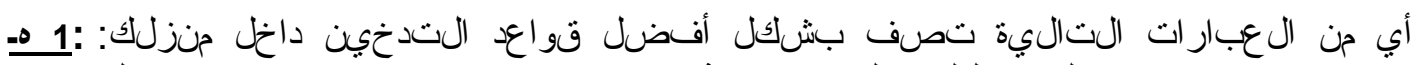

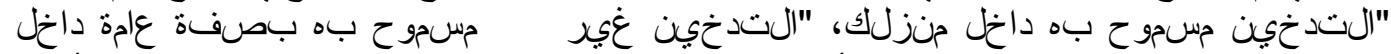

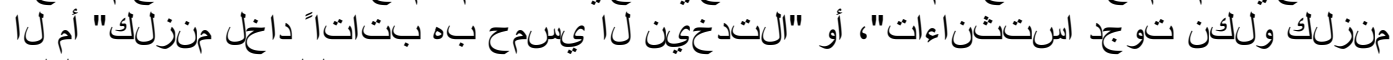

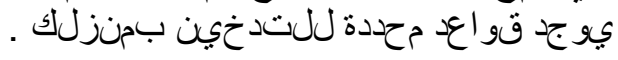

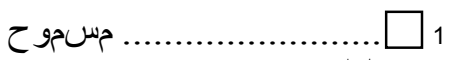

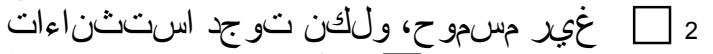

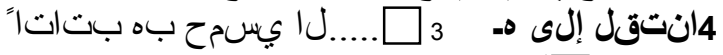

3انتقل إلى هـ

3انتقل إنى الى هـ

3انتقل إنى هـ إلى هوض

داخل منزلك، مل مسجوح بالتدخين في كل غرفة؟:د-2

ن................. $\square 1$

ر ${ }^{2}$

$\square 9$

: كم عدد مرات تدخين أي فرد داخل منزلك؟ يومي، أسبوعي، شهري، أقل من شمري أم لا هـ3 أمن

أحد ي- شند"

1

...........................

ش................

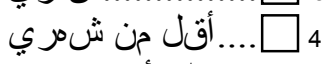

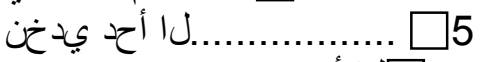

7

...........................

مل ت عجل حالياً خارج المنزل؟هـ:

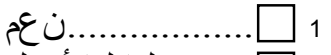

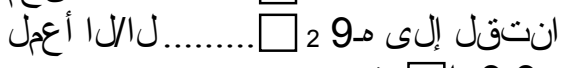

نتقل إلى ه9 9 الصرفض...............................

مل ت عجل في المعتاد في مكان مغلق أم مفتو ح؟ه-5:

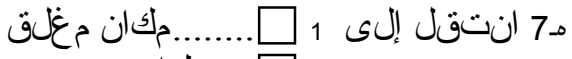

ح 2

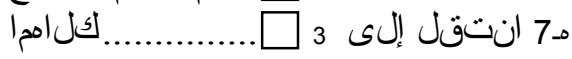

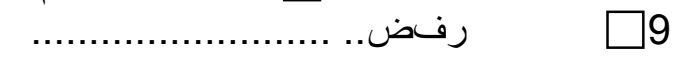


ل من الك أية أمالكن مغلقة في مكان عجلك؟ه ه-6:

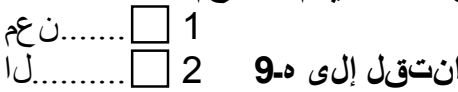

انتقل إلى ه-9...................

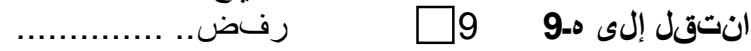

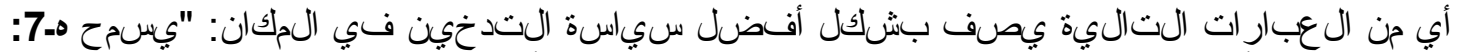

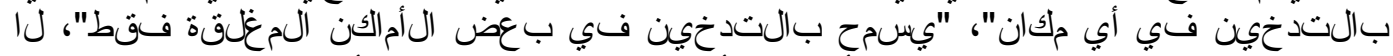

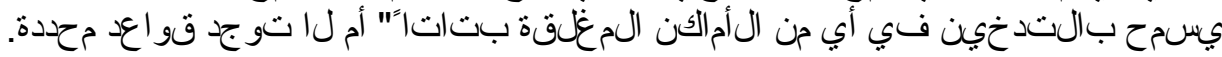

ح 1

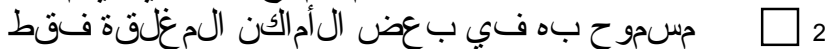

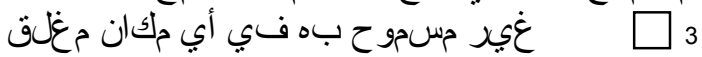

(

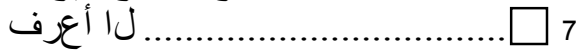

وفض.

خلال الـ 30 يوماً الماضية، مل قام أحد بالتدخين في أماكن مغلقة حيث ت عمل؟ه-8:

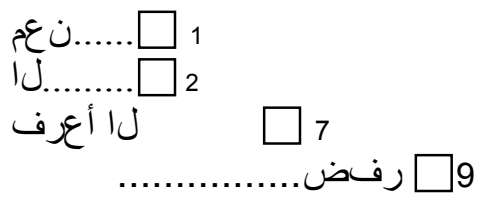

: أثناء ال-30 يوماً الماضي، مل زرت مبنى حكومي او ملتب حكومي ؟هـ9

†ن.......

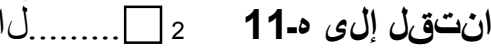

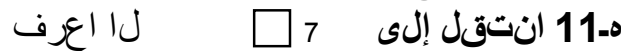

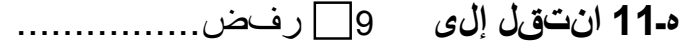

: ل قام أحد بالتدخين في مبانى حكومية أو مكاتب قدت بزيارتها أثناء ال-30 هـ10

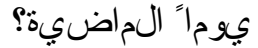

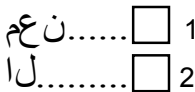

ل ال العرف

.................

: اثناء ال-30 يوما الماضي، مل زرت منشأة رعابة الصحية؛ه-11

انتقل إلى هـ13 


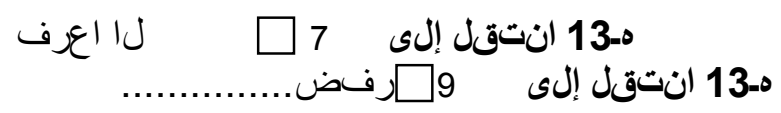

مل دخن شخص ما داخل منشأة الرعاية الصحية التي زرتها أثناء ال-30 يوماء هـ12: الاماضي؟

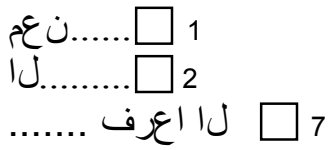



خلال الـ 30 يوماء الماضي، مل قمت بزيارة أية مطاعج؟ : ـ13

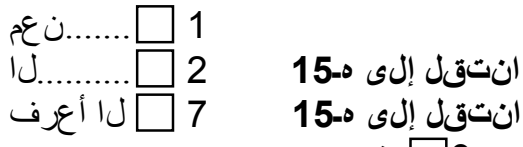

انتقل إلى ه-15

14ه مل قام أحد بالتدخين داخل أية مطاعم قدت بزيارتها خلال الـ 30 يوماً الماضي؟

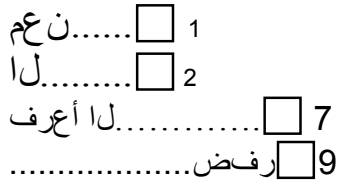

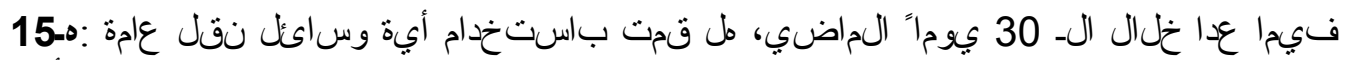
؛جترو الأنفاق :متاق

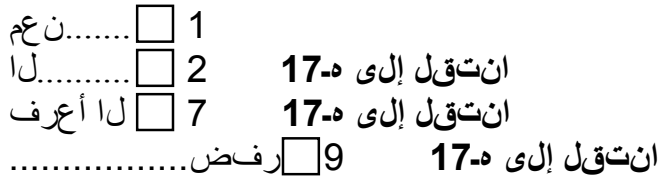

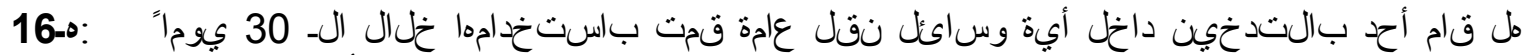

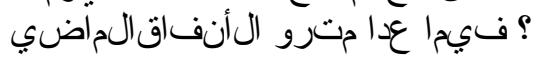

7

: على أساس ما تعرفه أو تؤمن به، مل يؤدي استنشاق دخان الخرين إلى أمر اض هـ

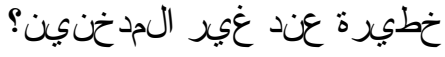

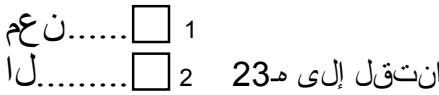


9

18-0

بالإستناد إلى ما تعرفه أو تعتقده، مل استنشاق الدخان عن طريق احد إن إن

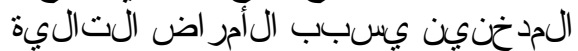

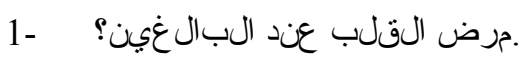

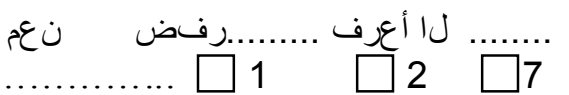
14. 9

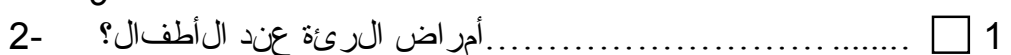
9

3- وسرطان الرئة عند البالغين؟............................ $\square 1 \quad \square 2 \quad \square 7$ 9

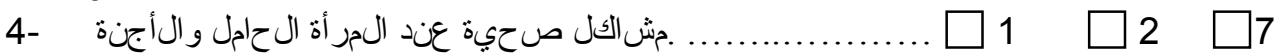
9

: :

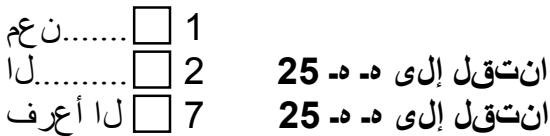

25 انثقل إلى هـ هـ

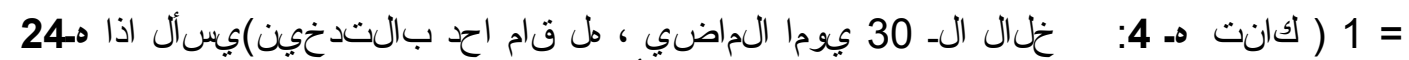

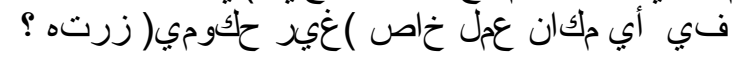

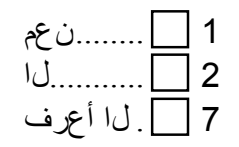
.................... $\square 9$

: 25 : 30 يوما الثناء 25

انت انتقل إلى ه-29 إنى انتقل إلى ه-29

: ل قام أحد بالتدخين في مول التسوق الذي زرته خلال 30 يوما الماضي؟هـ د-26

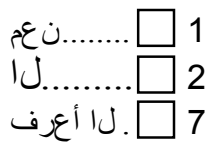

9..................

: فيما يت علق بالأمالكن العامة المغلقة التالية، مل يجكنك ان تخبرنبي اذا كنت هـ 29

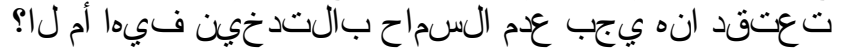



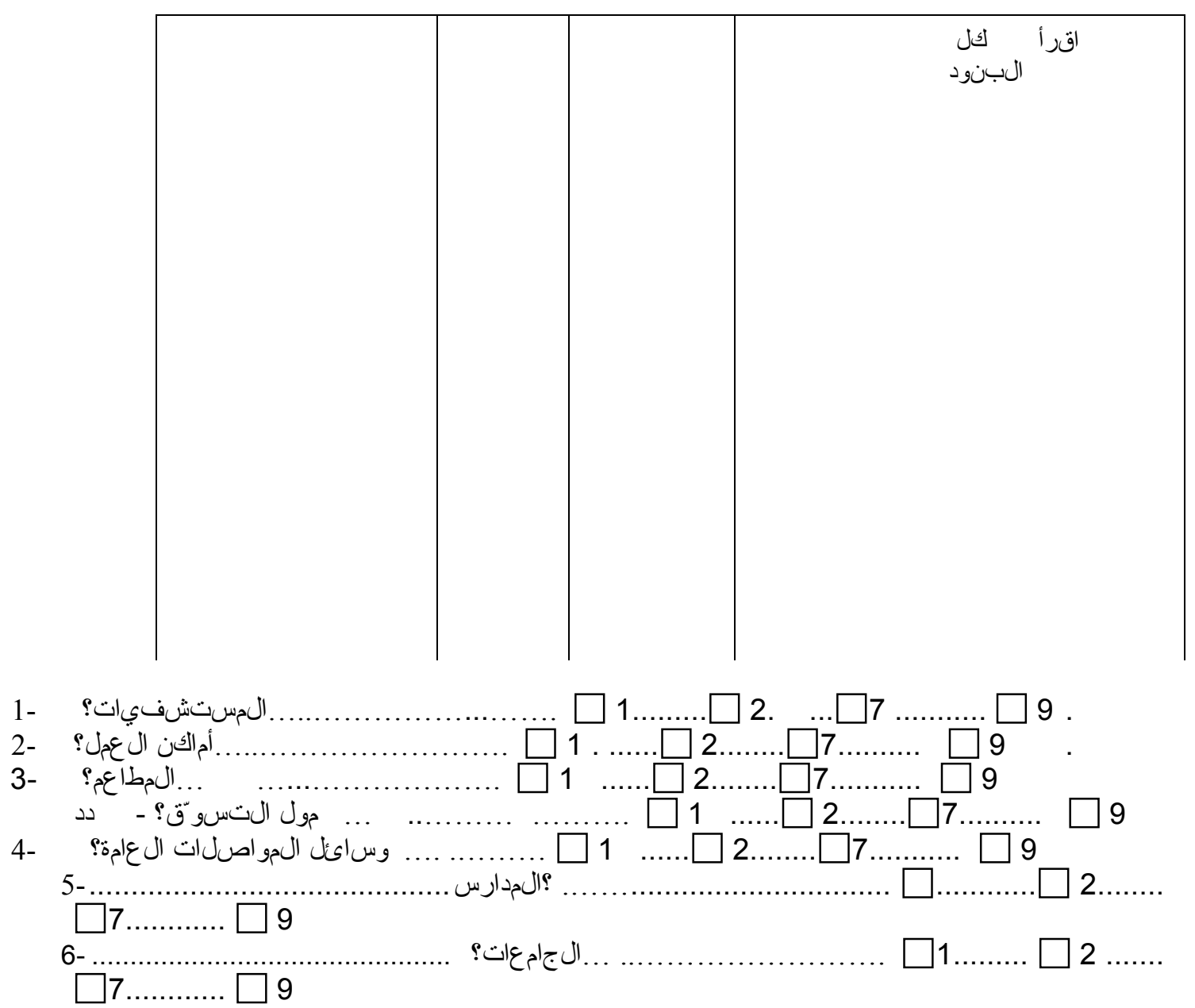

هـ1أ1: مل تو افت على قانونا يحظر التدخين في المستشفيات؟

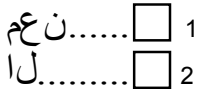

ل $\quad \square 7$

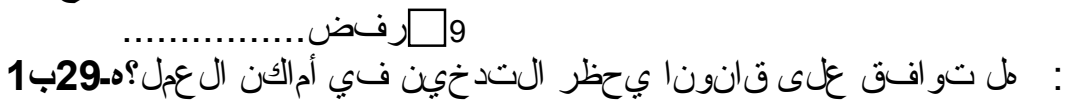

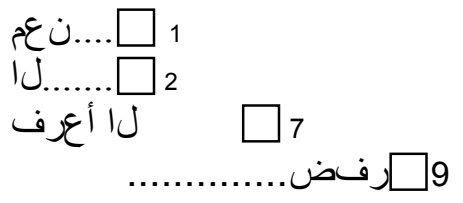

مل ت : :

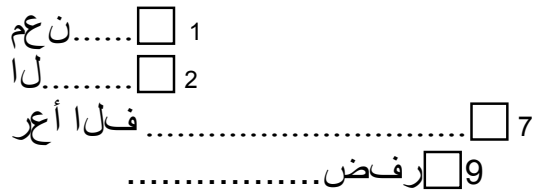

مل تو افق على قانونا ي حظر التدخين في مولات التسوق؟هـ29دد1: 


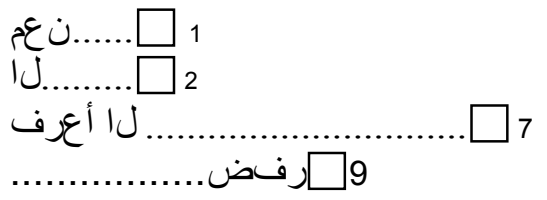

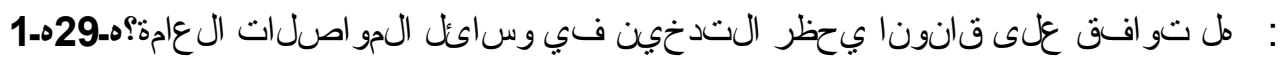

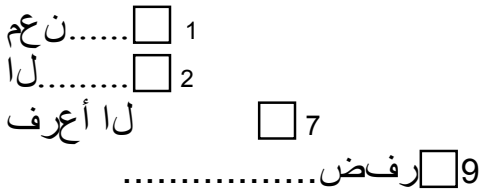

مل تو افت على قانونا يحظر التدخين في المدارس؟ه-29و1:

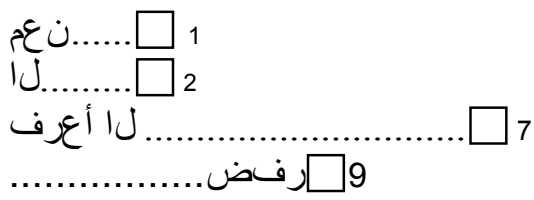

الجامعات؟ : مل تو افق على قانونا يحظر التدخين فيه-1ز29

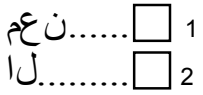

ف ض $\square 9$

\section{تصني ع الس جائز القسم و.}

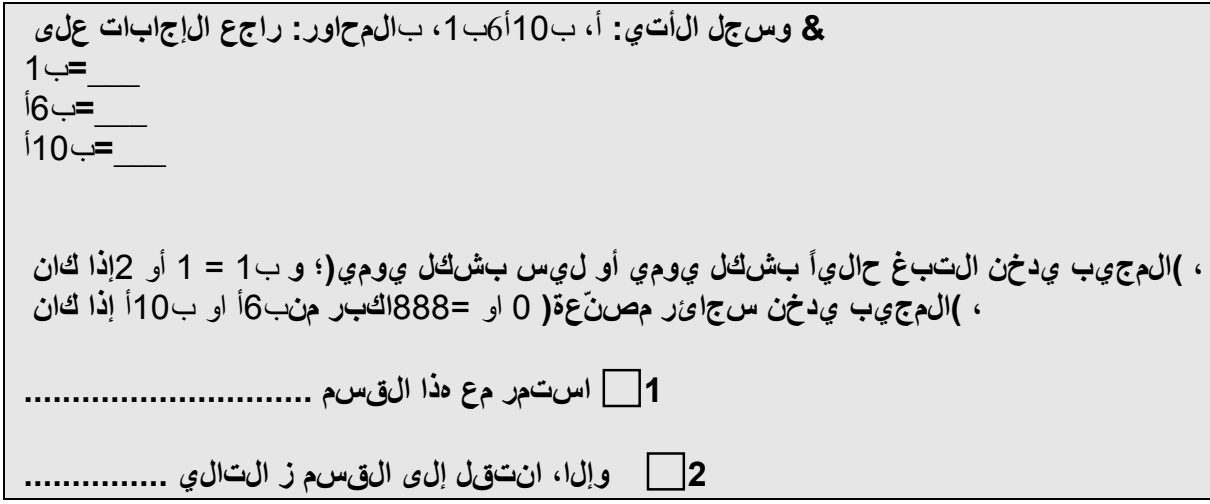

مقدمة: تتعلق مذه السأسئة بآخر مرة اشتريت فيها سجائر لنفسك.

ف : :

سجل الرقم واختر من الوحدة التالية 


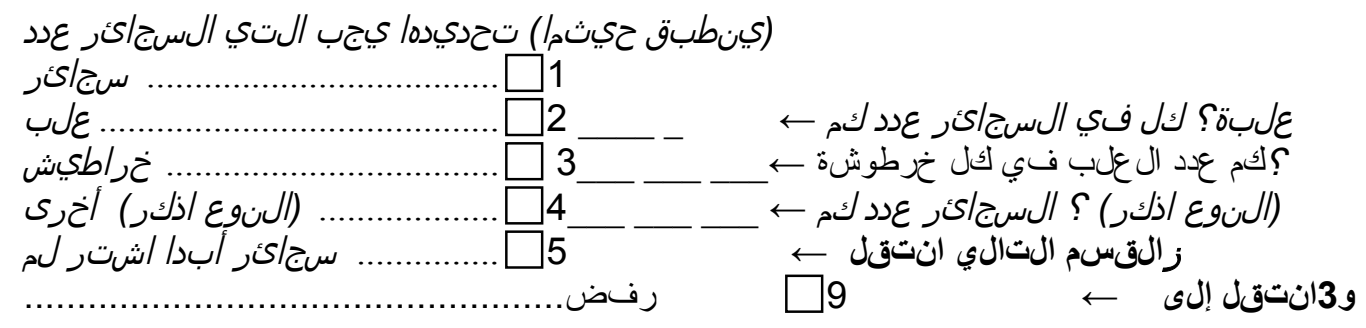

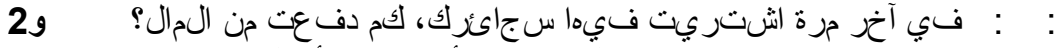
لا ي

\begin{tabular}{|l|l|}
\hline جنيه & \\
مصني & \\
\hline
\end{tabular}




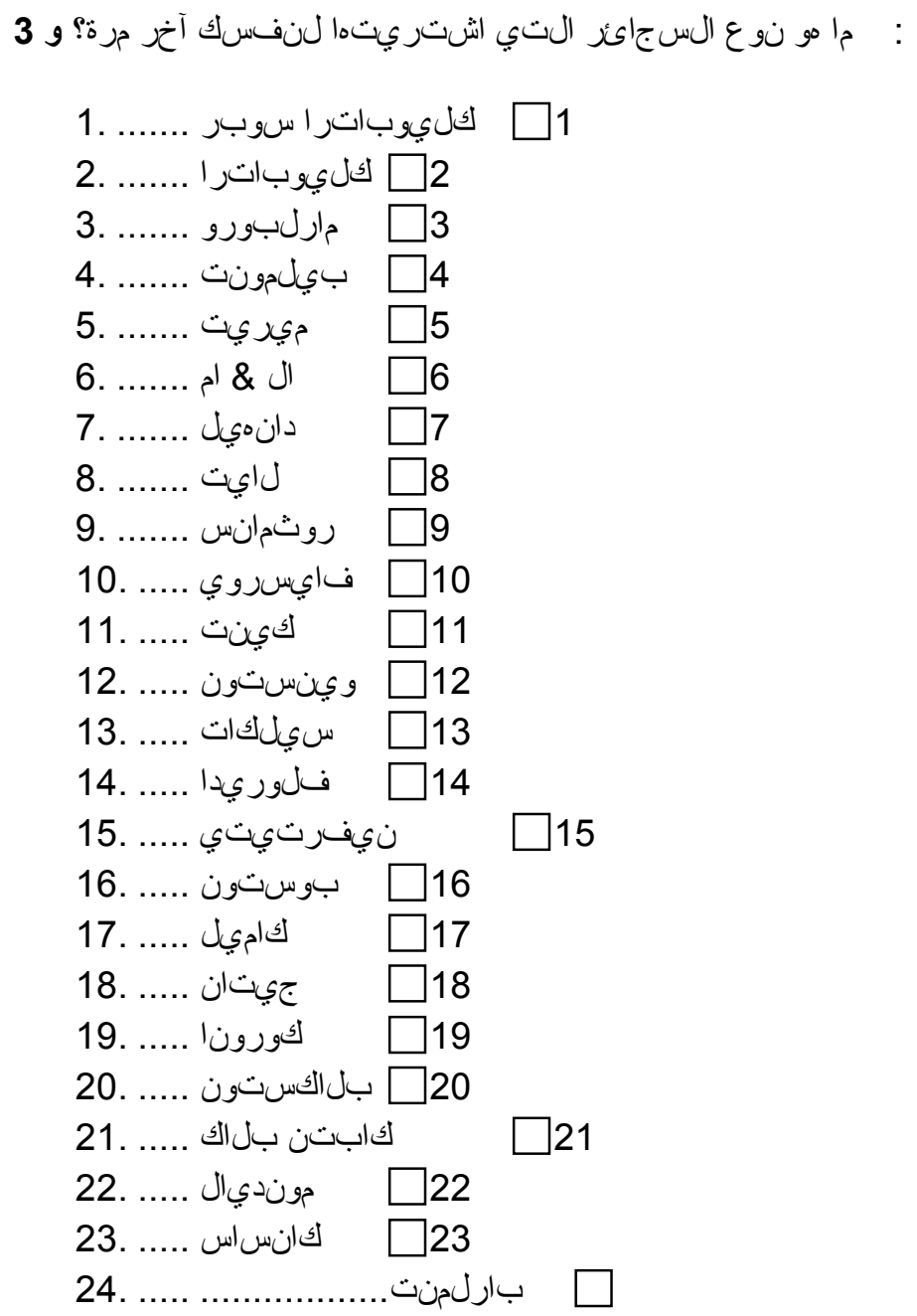




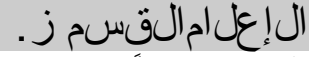

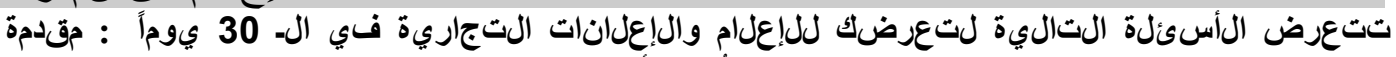

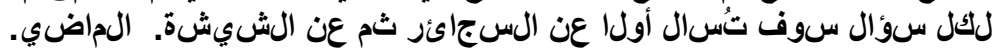

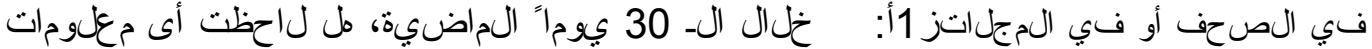

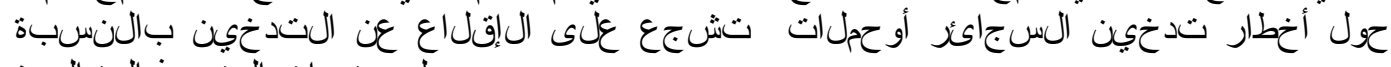
اقدرأ كل بند أند

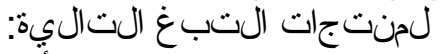

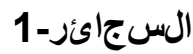

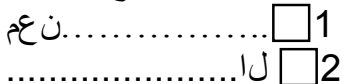

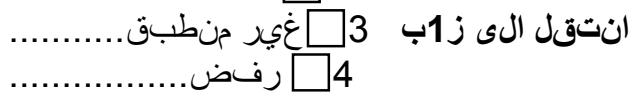

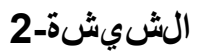

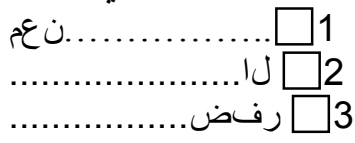

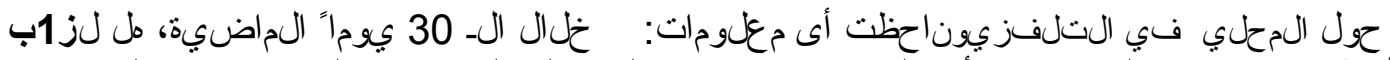

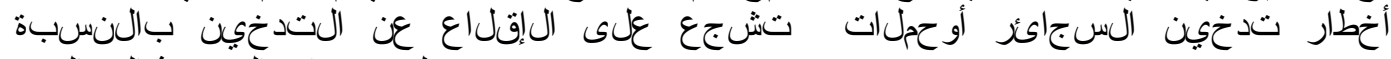

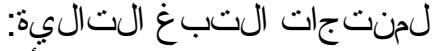

اقر أ كأكل بند

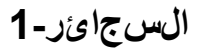

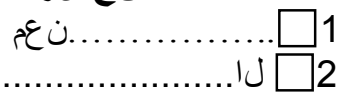

انتقل الى زز1ب 3

.......................... $\square 4$

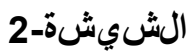

…........................ $\square 1$

.........................

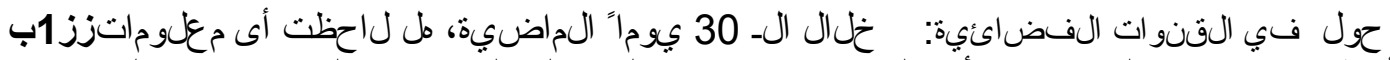

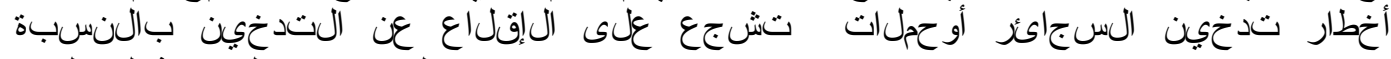

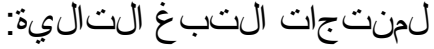

أ أكل بنداقر ل

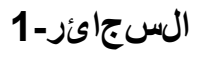

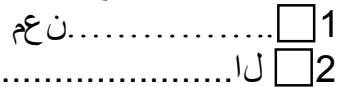

انتقل الى ز1زج

4

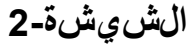



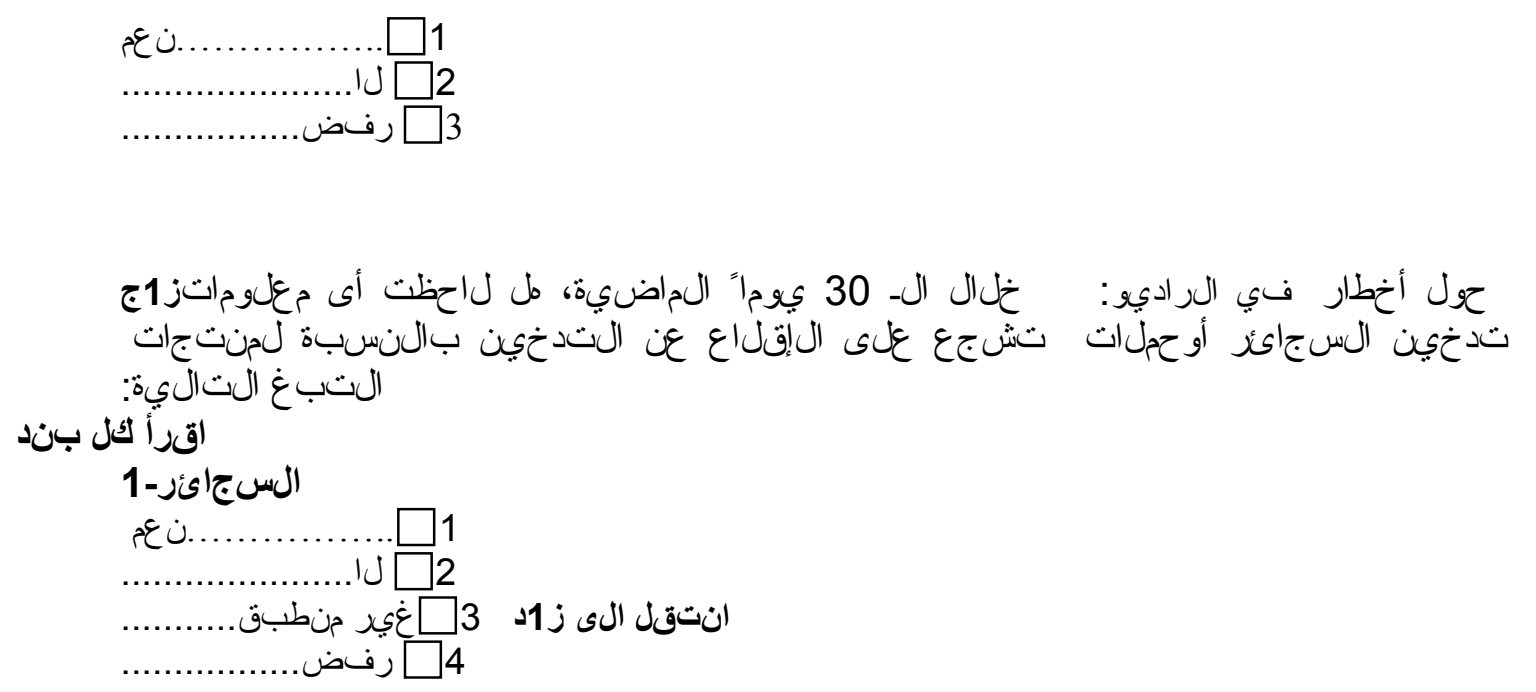

\section{الن}

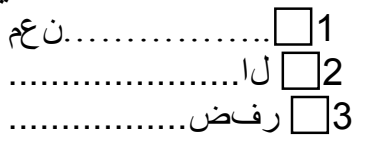

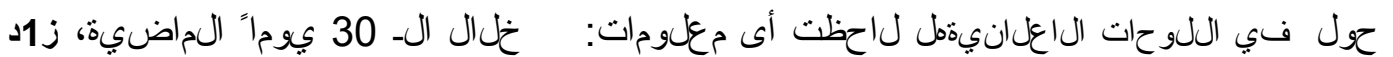

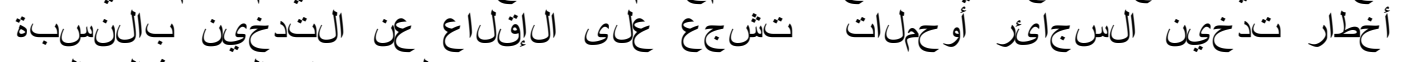
لمنت جات التب عن الت بالبية:

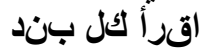

\section{الس جائز}

......................... $\square 1$

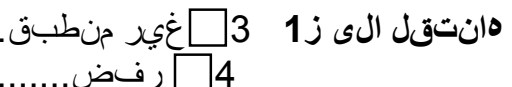

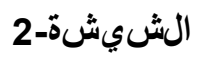

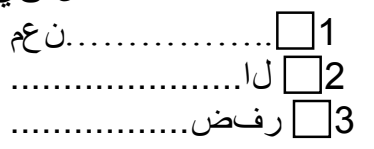

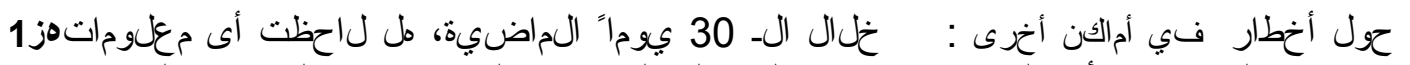

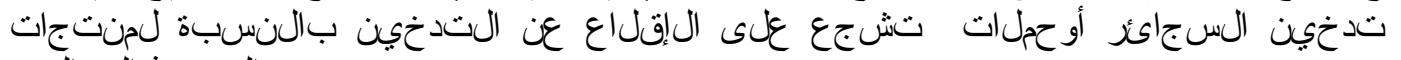

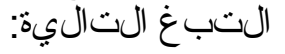

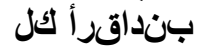

السجائز-1-..........

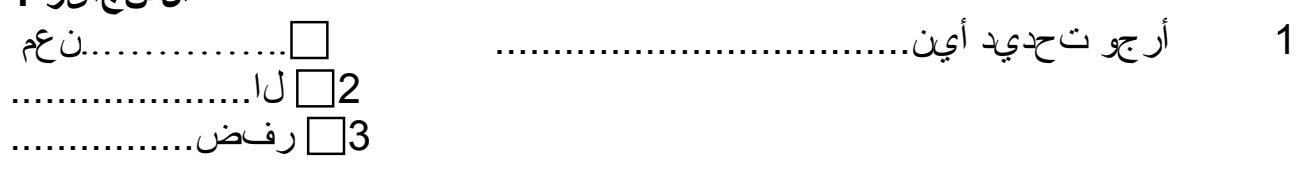

\section{الشيشة -}

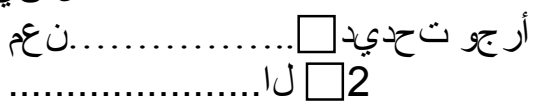


口

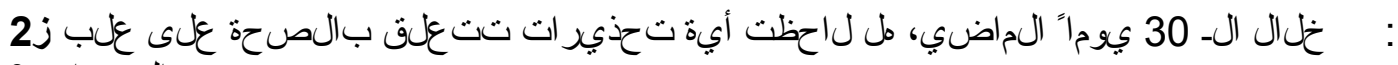

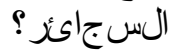

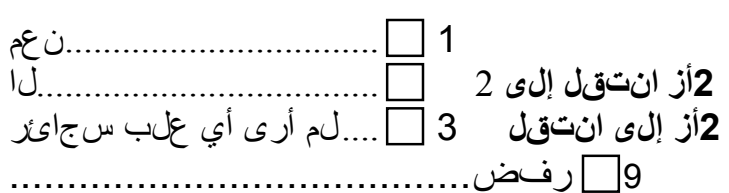

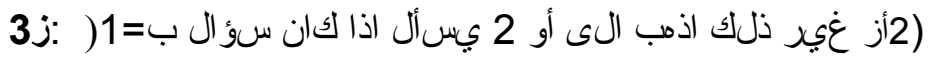

جعلتك على علب السجائر ةيالصح تحذيدات مل لاحظت الخلال الـ 30 يوماء الماضي،

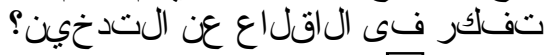

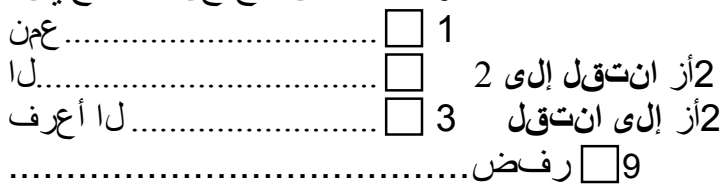

خلال الـ 30 يوماً الاضاض، مل لاحظت أية تحذيدات تتعلق بالصحة على أ:2

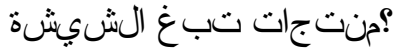

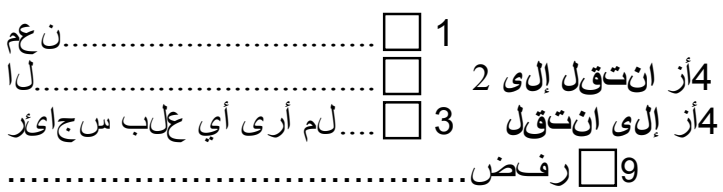

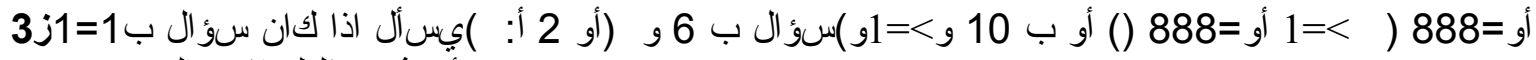

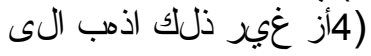

منتجات تبغ الشيشة على تيالصح تحذيرات مل الخلال الــ 30 يوماء الماضي، جعلتك تفكلكر في الفاقل القاع عن التدخين؟

if.

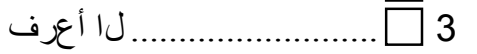

\section{2}

. $\square 9$

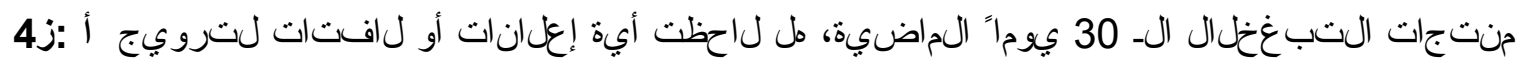

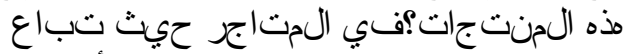

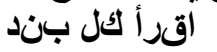




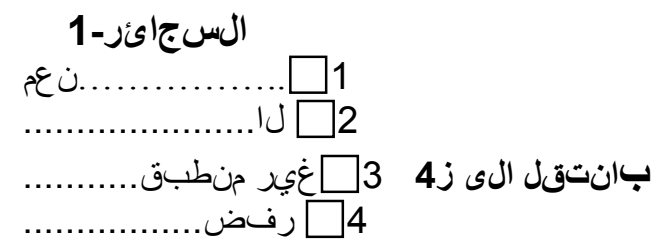

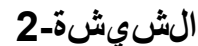

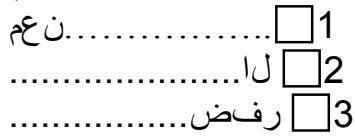

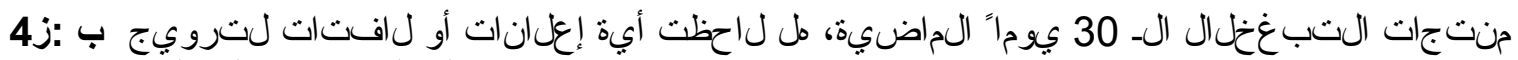

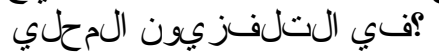
اقنرأ كل بند

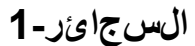

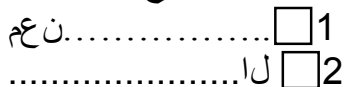

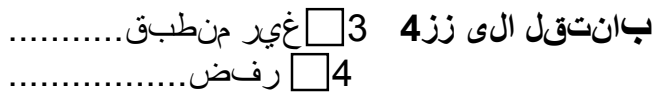

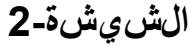 \\ קعن............... $\square 1$ \\ $1 \mathrm{\square}{ }_{2}$ \\ 3}

ز44: منتجات خلال الـ 30 يوماً الماضية، مل لاحظت أية إعلانات أو لافتات لترويج

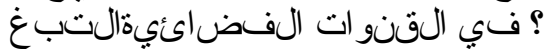

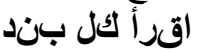

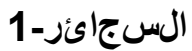

…...................... $\square 1$

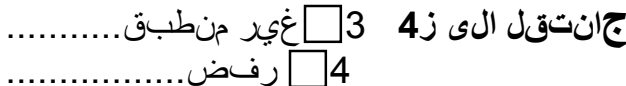

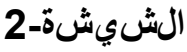 \\ קن................. 1 \\ .... $\square 2$}

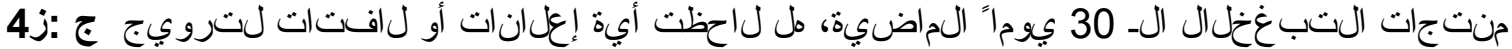

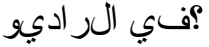

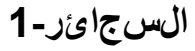

......................... $\square 1$

دانتقل الى ز4 3 إغير منطبق............... 


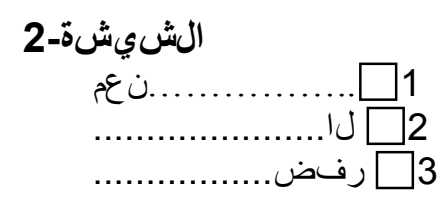

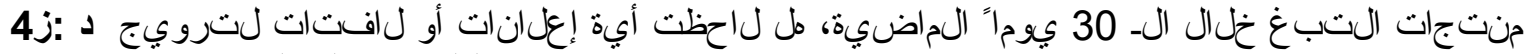
؟ اللو حات ال إعلانيثفى لت اقرأ كول بند

السجائر-1

ㄷ........................... $\square 1$

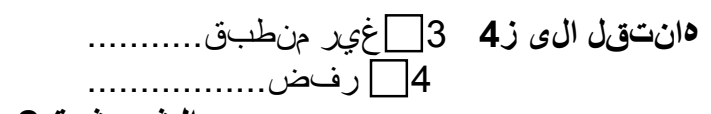

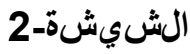

نं................ $\square 1$

4ز0 : منت جات التبغ خلال الـ 30 يوماً الماضية، مل لاحظت أية إعلانات أو لافتات لتروب ؟افتاتلات فت في

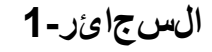

…....................... $\square 1$

وانتقل الى ز4

4

\section{اششيشة}

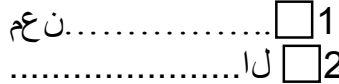

3

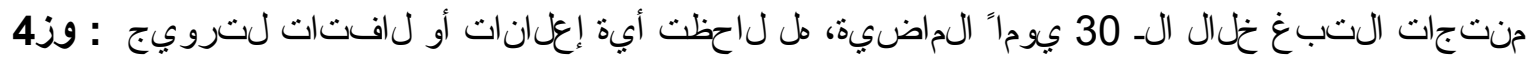

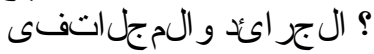

الس جائر-1

ז.......................... $\square 1$

زانتقل الى ز4

\section{الشيشة-2 \\ ن ن................ $\square 1$ \\ 3 $\square$ رفض.......................}

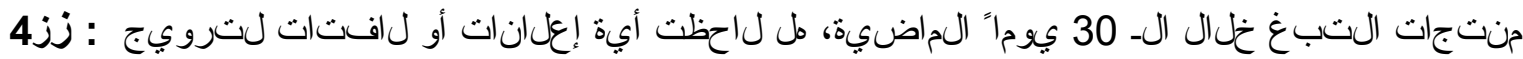
؟ دور السينمافى لَتروي

اقرأ كل بند

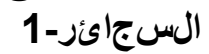



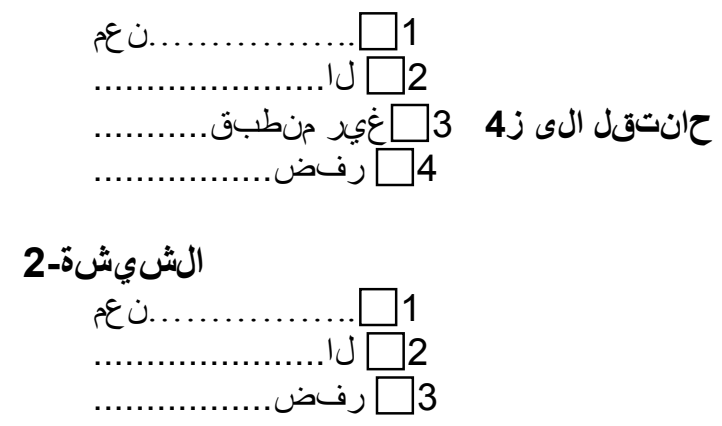

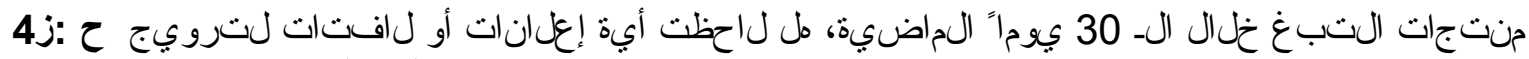

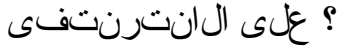

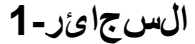

קن................ $\square 1$

....................... $\sqcup \square 2$

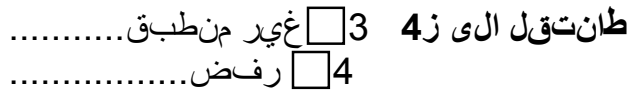

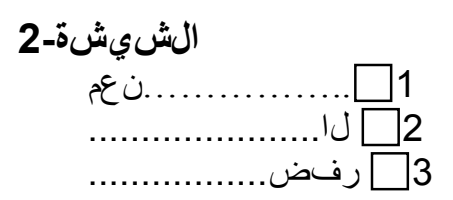

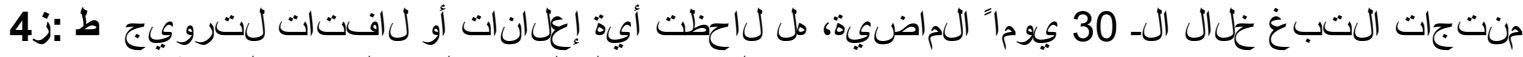

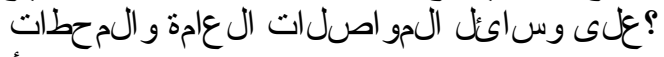

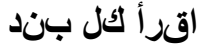

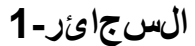
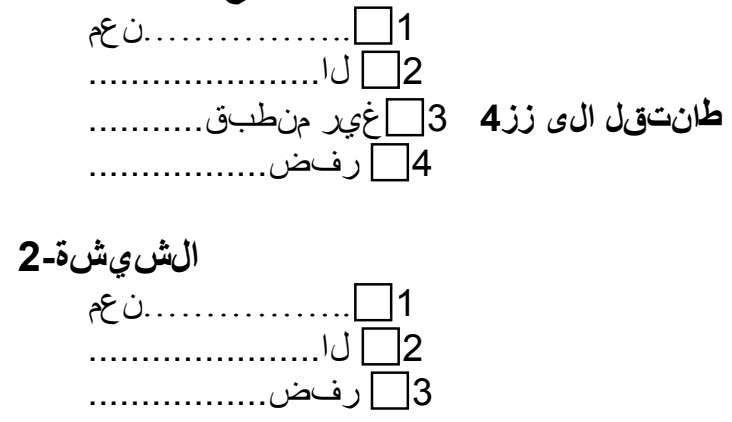

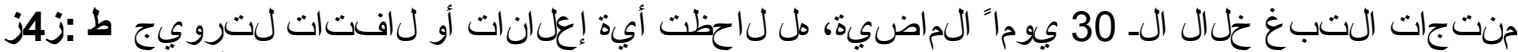

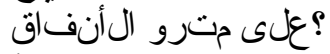

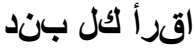

\section{السجائر-1}
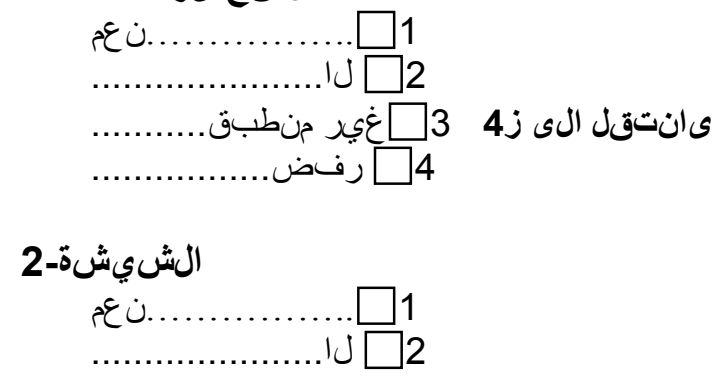
33

منتجات التبغ خلال الـ 30 يوماء الصاضية، لل لاحظت أية إعلانات أو لفتتات لترويج ى:4ز

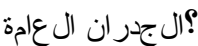

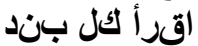

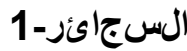

iعن................. $\square 1$

كانتقل الى ز4 4 كغيد منطبق................

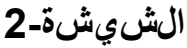

¿ن................ $\square 1$

....................... $\bigsqcup \square 2$

ـ $\square 3$

منتجات التبغخلال الـ 30 يوماء الماضية، مل لاحظت أبية إعلانات أو لفتتات لترويج ك:4ز

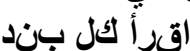

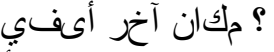

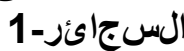

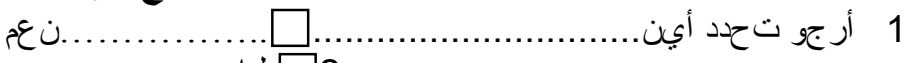

......1 $\square 2$

ص $\square 4$

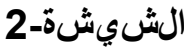

ن 1

….....................

اضية ترتبط : خلال الـ 30 يوماً العاضية، مل شاهت أي أحداث رياضية أو مناسبة ريز5

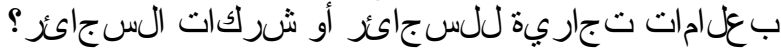

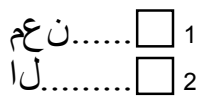

لا أعرف …................

الـ 30 يوماً الخيدة، مل لاحظت ايا من حجلت ترويج السجائز باستخدام الأتي: : خلال66

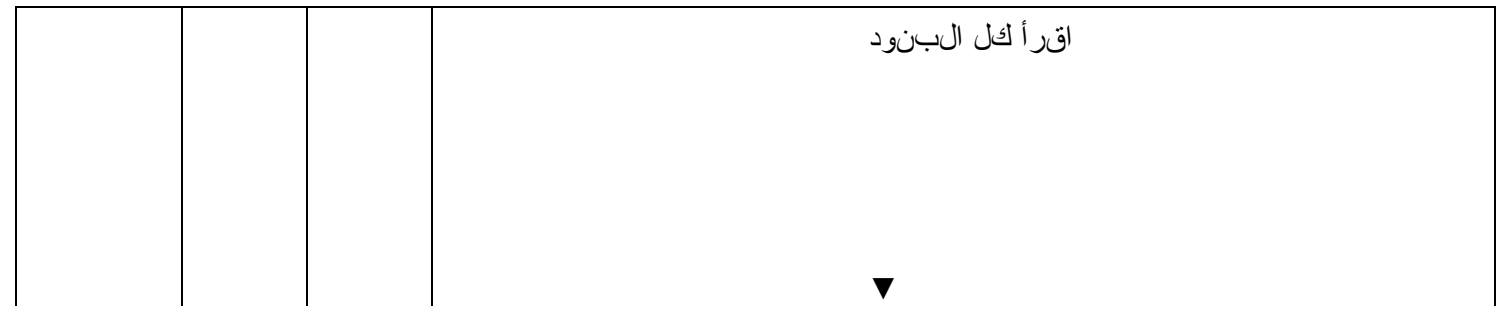

1- .

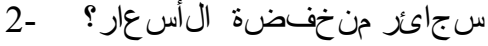

$\square 1 \ldots \ldots \square 2 \ldots \ldots . \square 7 \ldots \ldots . \square 9$ 


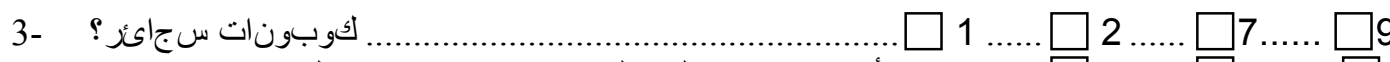

2

7...... $\square 9$

2 $7 \ldots . . . \square 9$

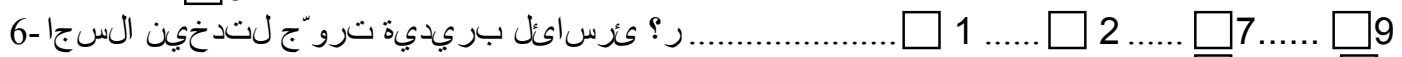

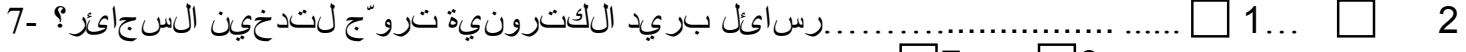

$8-$

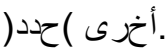

الـ 30 يوماً الماضية، مل شاهت أي بر امج تلفزيونية، مسلسلات أو خلال

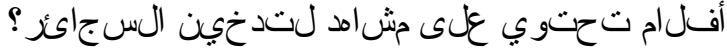

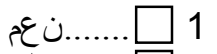

8انتقل الى زز 2

8انتقل الى زن الن

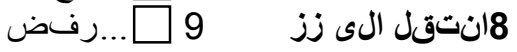

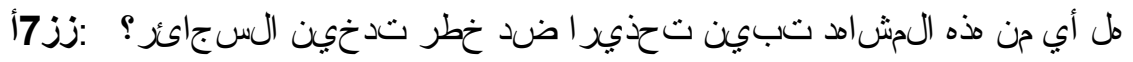

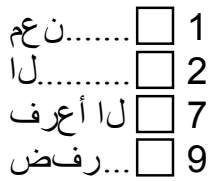

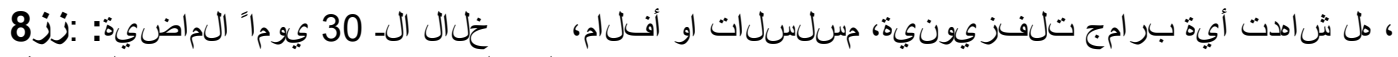

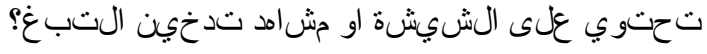

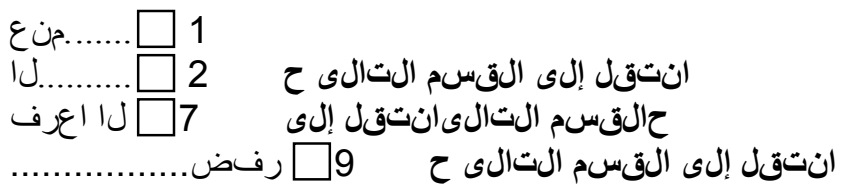

تببين تحذيد ا ضد مخاطر التدخين؟هذه المشاهد مل أي من أ:8زز

1
7

$\square 9$ 
القسم ح. المعرفة، الاتجاهات، و الإدر الك

التبغ.تدنخين يدور السؤال التالي عول ع1:

من خلال ما تعرفه أو تؤمن به، مل يتسبب التدخين في أمراض خطيرة؛

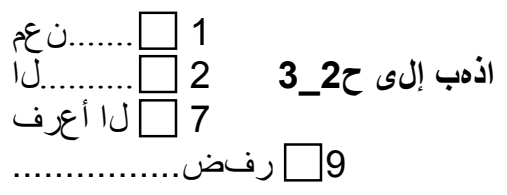

2ح على أساس ما تعرفه أو تؤمن به، مل يتسبب التدخين في المر اض التالية؟

\begin{tabular}{|l|l|c|}
\hline & & \\
& & \\
& &
\end{tabular}




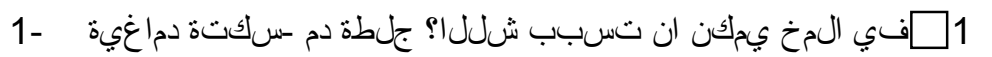
9.

$3-$

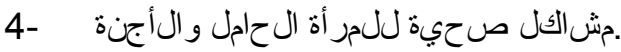

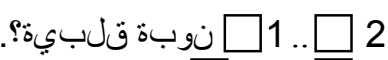
(1.... 22

$\square 7 \ldots \ldots \ldots \ldots . \square 9$.
$\square 7 \ldots \ldots \ldots \ldots .$.
$\square 7 \ldots \ldots \ldots \ldots .$.
$\square .9$

\section{1_2ح:}

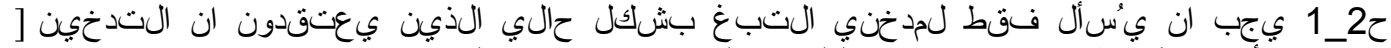

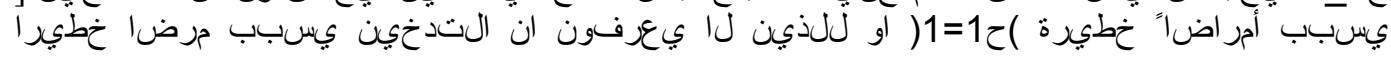
) $7=12($

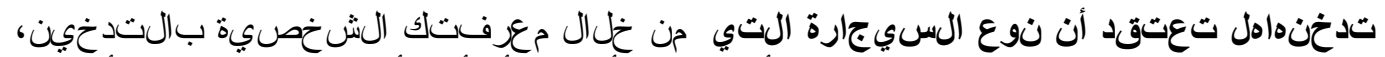

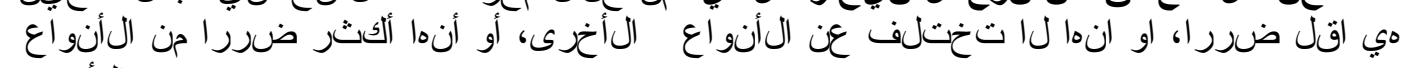

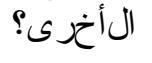

$$
\begin{aligned}
& \text { }
\end{aligned}
$$

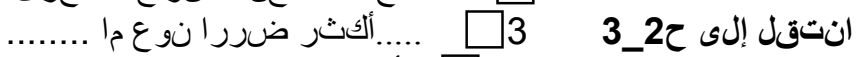

$$
\begin{aligned}
& \text {.................................................. } \\
& \text { 99 }
\end{aligned}
$$

ح1=2 و المتوقع أن تكون إجاباتم ما عـا مؤلاء الذين ينتمون ل- يُسال للجميع، [ ح2.2

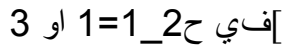

مل تعتقد ان بعض انواع السجائ قد تكون اقل ضرر ا من بعض الأنواع النَّى،

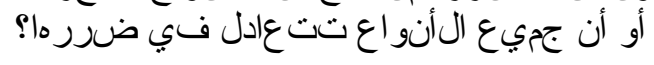

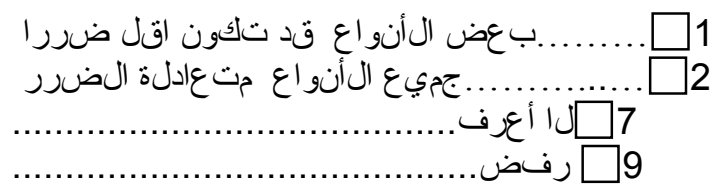

ادماناً على : من خلال معرفتك او اعتقادك، مل تعتقد ان تدخين الس جائر يسببح22 التب

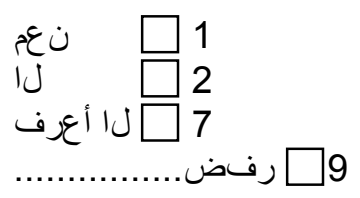

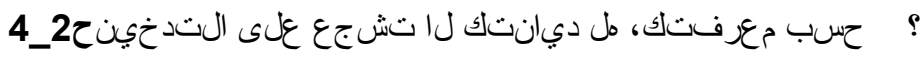

3 انتقل إلى ح ح 
رف ت

. $\square 9$

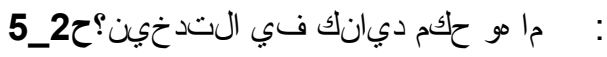

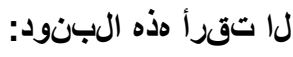

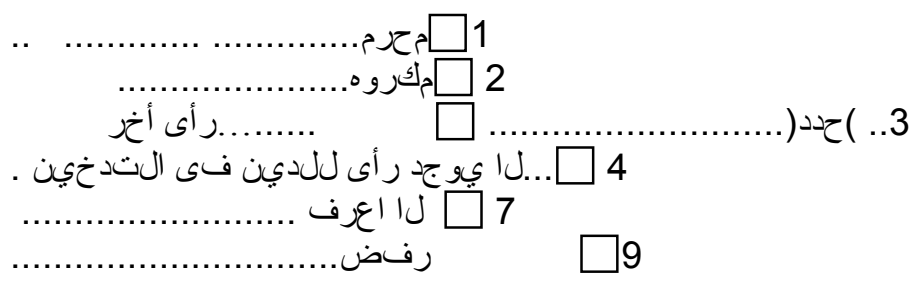

: من خلال معرفتك أو معتقداتك، مل تعتقد ان تدخين الشيشة يسبب أمراضا خطيرة؛ ح3 ح

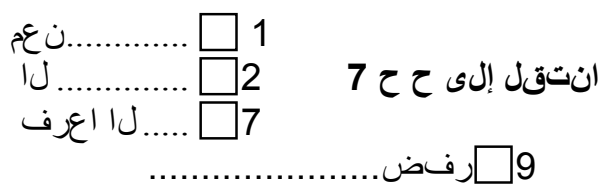

: ارتكاز اء على معرفتك أو معتقداتك، مل تعتقد ان تدخين الشيشة بيسب التالي:ح ح4

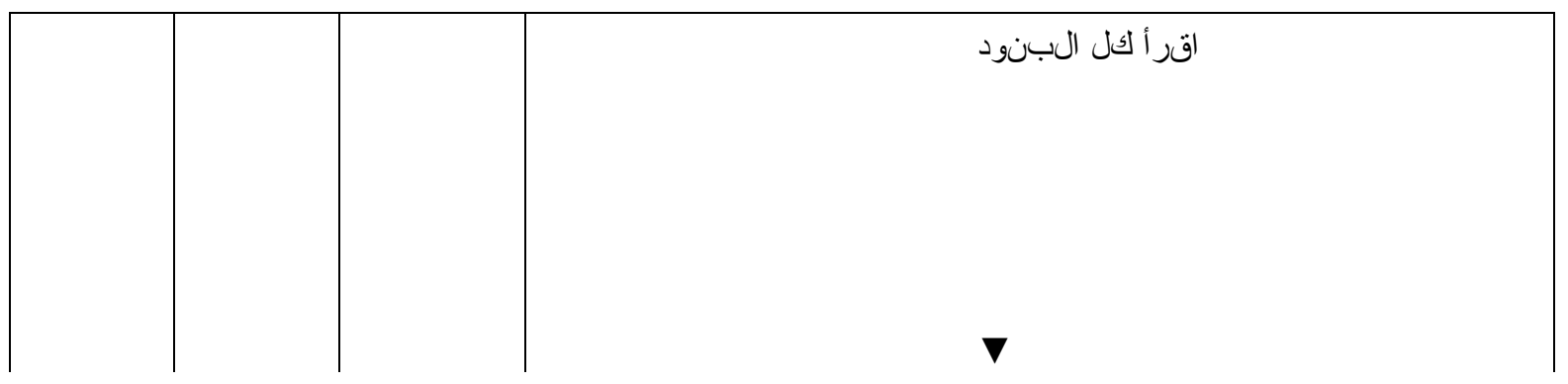

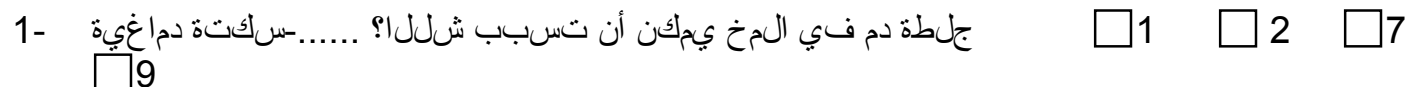

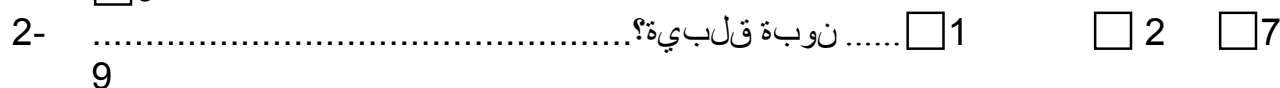

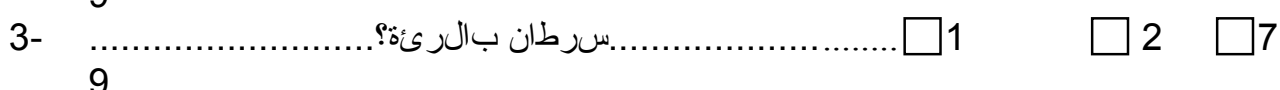

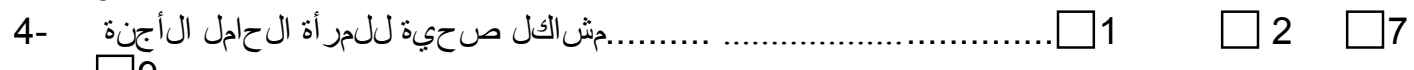
$\square 9$

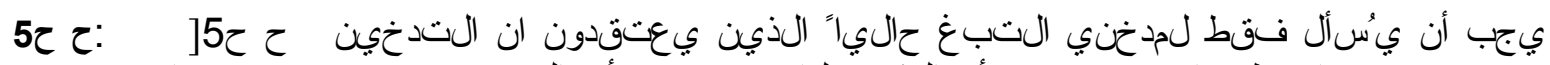

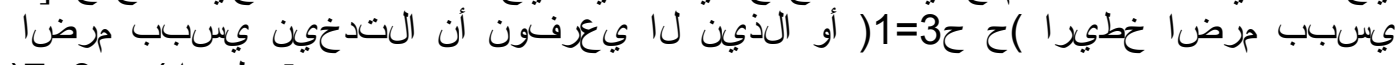
) 
تعتقد أن الشيشة أقل ضررا من من خلال خبرتك الشخصية في التدنين، لم

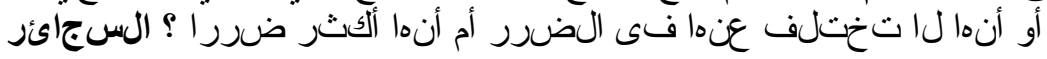

$$
\begin{aligned}
& \text { } 1 \\
& 2
\end{aligned}
$$

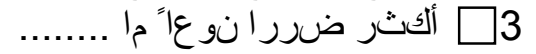

[يُسأل لل جميع، ما عـا هؤلاء الذين ينتمون لـ ح ح3=.2 :ح ح 6

$$
\begin{aligned}
& \text { مل تعتقد أن بعض أنواع تبغ الشيشة قد تكون اقل ضررا من بعض فض الأنواع }
\end{aligned}
$$

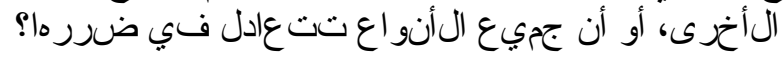

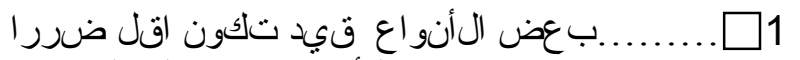

$$
\begin{aligned}
& \text { }
\end{aligned}
$$

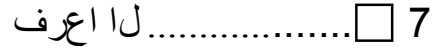

$$
\begin{aligned}
& \text {. } \square 9
\end{aligned}
$$

قد ان تدخين الشيشة يسبب :ارتكازاء على معرفتك او اعتقادلك، مل تعتح ح عل 7

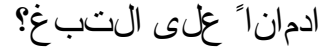

$$
\text { } 72
$$

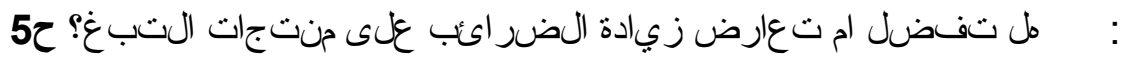

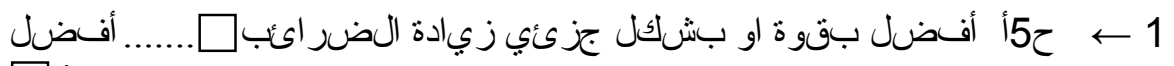

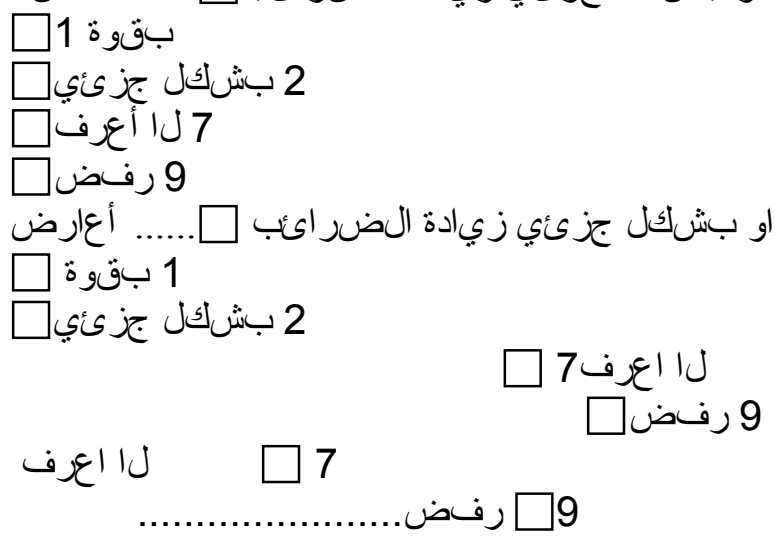

هل تفضل أم تعارض قانون ي حظر الدعاية لمنت جات التب غ؟ح6: 
حظر ال بقوة أو بشكل جزئي أفضل1 ٪ ع6أه....... أفضل 1

2 بشكل جزئي

$$
\begin{aligned}
& \text { لا العرف7 } \\
& 9 \text { رفض }
\end{aligned}
$$

حظر ال بقوة أو بشكل جزئي أعارض2 ـ ح6ب 口...... أعارض

1

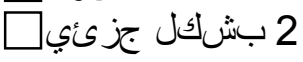

$$
\begin{aligned}
& \text { لا العرف7 } \\
& 9
\end{aligned}
$$

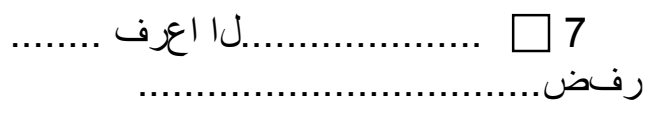

نهابية استببيان الفرد

ككانت هذه هي جميع أسئلتي. شكراً جزيلاً لكك على المشاركة في هذا الجسح الاحصائي المامام.

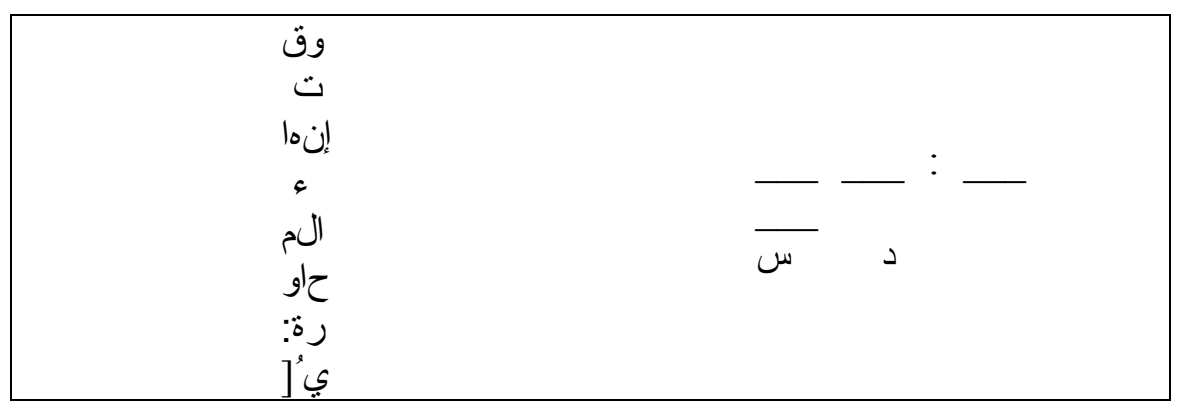




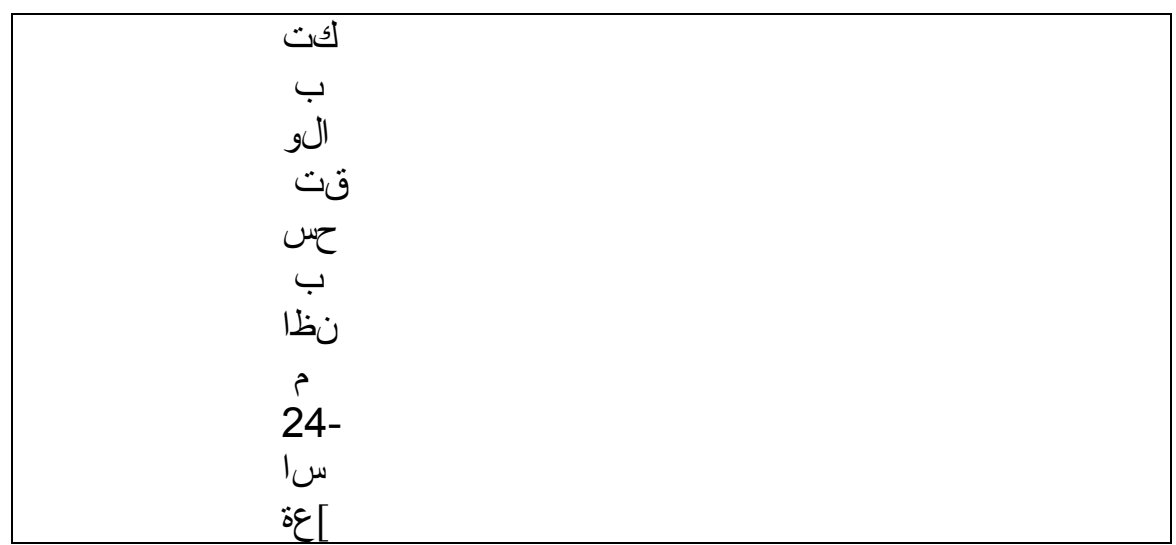

ل ملاحظاتك عن المحاورة: “ِّج 


\title{
Curriculum Vitae \\ December 2011
}

\section{Nadia Jalil Sweis}

\author{
ADDRESS \\ 10754 S. LockWood Ave. \\ Oak Lawn, IL, 60453 \\ Tel: (708) 425-4091 \\ E-Mail: nsweis1@uic.edu \\ Or_nadiasweis@yahoo.com
}

FIELDS OF INTEREST

Microeconomics, Macroeconomics, Mathematical Economics, Health Economics and International Trade.

\section{EDUCATION}

Ph.D. Economics(ABD), University of Illinois at Chicago, expected to graduate in 2011.

M.A. Economics, University of Illinois at Chicago, 2004

M.A. Economics, University of Jordan, 1999

B.Sc. Economics, University of Jordan, 1996

\section{EXPERIENCE}

2004,Jan-April, 2006: Part-time instructor at the department of Economics, School of Continuing Studies at Northwestern University, Chicago- Illinois.

2005,Jan-April, 2006: Part-time instructor at the department of Economics, Loyola University at Chicago, Chicago- Illinois

2004(Nov-present): Research Assistant, University of Chicago, Involved in mentoring pharmacy students in collecting data and establishing database for 3000 patients with arthritis to build a work instability model.

2004(June- Aug): Research elective at the University of Chicago, June- Aug 2004. (I structured a data base for patients with Rheumatoid Arthritis, and conducted a cost-effective analysis in an attempt to establish an economic model for arthritis).

1999-2002: Fulltime instructor in the Department of Economics, Al-Balqa' Applied University, AlSalt-Jordan.

2002(Jan-Nov): Member of the National Organization Committee charged with the preparation for conference on" Mathematics for Living" held in Amman, Amman-Jordan.

2002(Apr-Sep): Assistant to the Dean of Graduate Studies and Scientific Research in a UNDP project for" Enhancing Technical Training and Employment Opportunities for Jordanian Women", Apr-Sep, 2000.

1997-1998: Research and Teaching Assistant, University of Jordan, Amman-Jordan. 


\section{PUBLICATION}

Abstracts

1. Sweis, Nadia, et. al., Cost of Etanercept Versus Infliximab in the Treatment of Rheumatoid Arthritis, presented at the American College of Rheumatology Economic Conference, Oct 2004

\section{CERTIFICATE}

Teaching Certificate in Economics, University of Illinois at Chicago, 2004

\section{LANGUAGES}

Fluent in both English and Arabic, Fair in Turkish.

\section{COMPUTER KNOWLEDGE}

Knowledgeable in using different software packages, particularly:

SPSS, MATLAB, B34S, and STATA

VISA STATUS

American citizen

\section{REFERENCES}

Available upon request 